Cochrane Database of Systematic Reviews

\title{
Antifungal agents for preventing fungal infections in non- neutropenic critically ill patients (Review)
}

Cortegiani A, Russotto V, Maggiore A, Attanasio M, Naro AR, Raineri SM, Giarratano A

Cortegiani A, Russotto V, Maggiore A, Attanasio M, Naro AR, Raineri SM, Giarratano A.

Antifungal agents for preventing fungal infections in non-neutropenic critically ill patients.

Cochrane Database of Systematic Reviews 2016, Issue 1. Art. No.: CD004920.

DOI: 10.1002/14651858.CD004920.pub3.

www.cochranelibrary.com 
TABLE OF CONTENTS

HEADER

ABSTRACT

PLAIN LANGUAGE SUMMARY

SUMMARY OF FINDINGS

BACKGROUND

OBJECTIVES

METHODS

RESULTS

Figure 1.

Figure 2.

Figure 3.

Figure 4.

Figure 5.

Figure 6.

DISCUSSION

AUTHORS' CONCLUSIONS

ACKNOWLEDGEMENTS

REFERENCES

CHARACTERISTICS OF STUDIES

DATA AND ANALYSES

Analysis 1.1. Comparison 1 Primary analysis: untargeted antifungal treatment with any antifungal drug (systemic or nonabsorbable) compared to placebo/no antifungal/any other antifungal drug, Outcome 1 Mortality.

Analysis 1.2. Comparison 1 Primary analysis: untargeted antifungal treatment with any antifungal drug (systemic or nonabsorbable) compared to placebo/no antifungal/any other antifungal drug, Outcome 2 Proven invasive fungal infection. .

Analysis 1.3. Comparison 1 Primary analysis: untargeted antifungal treatment with any antifungal drug (systemic or nonabsorbable) compared to placebo/no antifungal/any other antifungal drug, Outcome 3 Proven or suspected invasive fungal infection.

Analysis 1.4. Comparison 1 Primary analysis: untargeted antifungal treatment with any antifungal drug (systemic or nonabsorbable) compared to placebo/no antifungal/any other antifungal drug, Outcome 4 Suspected invasive fungal infection.

Analysis 1.5. Comparison 1 Primary analysis: untargeted antifungal treatment with any antifungal drug (systemic or nonabsorbable) compared to placebo/no antifungal/any other antifungal drug, Outcome 5 Superficial fungal infection. .......

Analysis 1.6. Comparison 1 Primary analysis: untargeted antifungal treatment with any antifungal drug (systemic or nonabsorbable) compared to placebo/no antifungal/any other antifungal drug, Outcome 6 Fungal colonization.

Analysis 1.7. Comparison 1 Primary analysis: untargeted antifungal treatment with any antifungal drug (systemic or nonabsorbable) compared to placebo/no antifungal/any other antifungal drug, Outcome 7 Proven invasive fungal infection (azole-resistant Candida species).

Analysis 1.8. Comparison 1 Primary analysis: untargeted antifungal treatment with any antifungal drug (systemic or nonabsorbable) compared to placebo/no antifungal/any other antifungal drug, Outcome 8 Fungal colonization (azole-resistant Candida species).

Analysis 1.9. Comparison 1 Primary analysis: untargeted antifungal treatment with any antifungal drug (systemic or nonabsorbable) compared to placebo/no antifungal/any other antifungal drug, Outcome 9 Adverse events requiring cessation.

Analysis 2.1. Comparison 2 Subgroup analysis, Outcome 1 Mortality. Types of participants.

Analysis 2.2. Comparison 2 Subgroup analysis, Outcome 2 Mortality. Fluconazole dose.

Analysis 2.3. Comparison 2 Subgroup analysis, Outcome 3 Mortality. Systemic or non-absorbable antifungal drug. .................

Analysis 2.4. Comparison 2 Subgroup analysis, Outcome 4 Mortality. Drug class.

Analysis 2.5. Comparison 2 Subgroup analysis, Outcome 5 Mortality. Type of intervention.

Analysis 2.6. Comparison 2 Subgroup analysis, Outcome 6 Mortality. Type of control group.

Analysis 2.7. Comparison 2 Subgroup analysis, Outcome 7 Proven IFI. Type of participants.

Analysis 2.8. Comparison 2 Subgroup analysis, Outcome 8 Proven IFI. Fluconazole dose.

Analysis 2.9. Comparison 2 Subgroup analysis, Outcome 9 Proven IFI. Systemic or non-absorbable antifungal drug. ...............

Analysis 2.10. Comparison 2 Subgroup analysis, Outcome 10 Proven IFI. Drug class. 


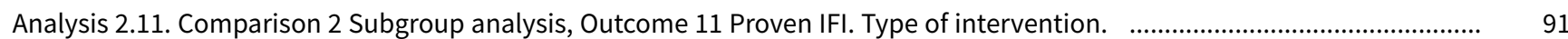

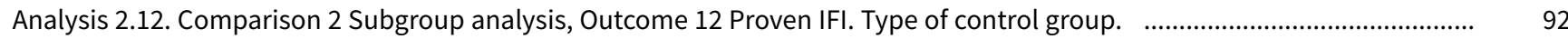

Analysis 3.1. Comparison 3 Sensitivity analysis, Outcome 1 Mortality. Fixed-effect model meta-analysis. .................................... 93

Analysis 3.2. Comparison 3 Sensitivity analysis, Outcome 2 Mortality. Risk of bias for key domains: all studies. ........................... 94

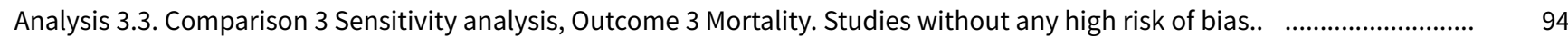

Analysis 3.4. Comparison 3 Sensitivity analysis, Outcome 4 Proven IFI. Fixed-effect model meta-analysis. .................................. 95

Analysis 3.5. Comparison 3 Sensitivity analysis, Outcome 5 Proven IFI. Risk of bias for key domains: all studies. ....................

Analysis 3.6. Comparison 3 Sensitivity analysis, Outcome 6 Proven IFI. Studies without any high risk of bias. ............................. 96

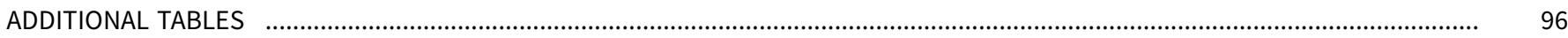

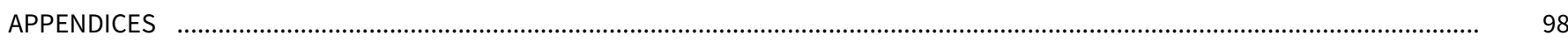

FEEDBACK

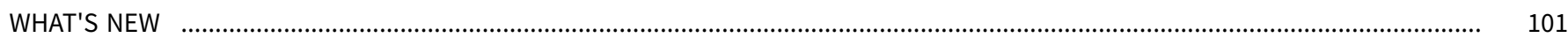

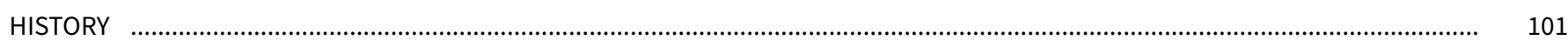

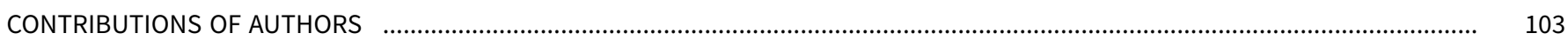

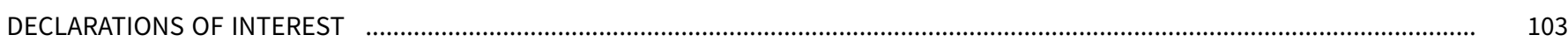

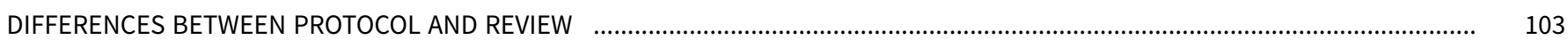

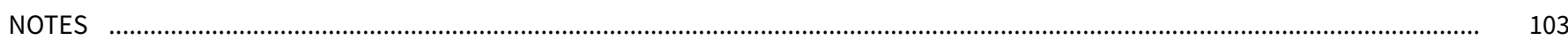

INDEX TERMS 
[Intervention Review]

\section{Antifungal agents for preventing fungal infections in non-neutropenic critically ill patients}

Andrea Cortegiani ${ }^{1}$, Vincenzo Russotto ${ }^{1}$, Alessandra Maggiore ${ }^{1}$, Massimo Attanasio², Alessandro R Naro², Santi Maurizio Raineri¹, Antonino Giarratano 1

1Department of Biopathology and Medical Biotechnologies (DIBIMED), Section of Anaesthesia, Analgesia, Intensive Care and Emergency, University Hospital P. Giaccone, University of Palermo, Palermo, Italy. ${ }^{2}$ Department of Statistics and Mathematical Sciences, University of Palermo, Palermo, Italy

Contact address: Andrea Cortegiani, Department of Biopathology and Medical Biotechnologies (DIBIMED), Section of Anaesthesia, Analgesia, Intensive Care and Emergency, University Hospital P. Giaccone, University of Palermo, Via del Vespro 129, Palermo, Italy. andreacortegiani85@gmail.com, andrea.cortegiani@unipa.it.

Editorial group: Cochrane Emergency and Critical Care Group

Publication status and date: Edited (no change to conclusions), published in Issue 12, 2018.

Citation: Cortegiani A, Russotto V, Maggiore A, Attanasio M, Naro AR, Raineri SM, Giarratano A. Antifungal agents for preventing fungal infections in non-neutropenic critically ill patients. Cochrane Database of Systematic Reviews 2016, Issue 1. Art. No.: CD004920. DOI: 10.1002/14651858.CD004920.pub3.

Copyright @ 2018 The Cochrane Collaboration. Published by John Wiley \& Sons, Ltd.

\section{A B S T R A C T}

\section{Background}

Invasive fungal infections are important causes of morbidity and mortality among critically ill patients. Early institution of antifungal therapy is pivotal for mortality reduction. Starting a targeted antifungal therapy after culture positivity and fungi identification requires a long time. Therefore, alternative strategies (globally defined as 'untargeted antifungal treatments') for antifungal therapy institution in patients without proven microbiological evidence of fungal infections have been discussed by international guidelines. This review was originally published in 2006 and updated in 2016. This updated review provides additional evidence for the clinician dealing with suspicion of fungal infection in critically ill, non-neutropenic patients, taking into account recent findings in this field.

\section{Objectives}

To assess the effects of untargeted treatment with any antifungal drug (either systemic or nonabsorbable) compared to placebo or no antifungal or any other antifungal drug (either systemic or nonabsorbable) in non-neutropenic, critically ill adults and children. We assessed effectiveness in terms of total (all-cause) mortality and incidence of proven invasive fungal infections as primary outcomes.

\section{Search methods}

We searched the following databases to February 2015: the Cochrane Central Register of Controlled Trials (CENTRAL), MEDLINE (OVID), and EMBASE (OVID). We also searched reference lists of identified studies and major reviews, abstracts of conference proceedings, scientific meetings and clinical trials registries. We contacted experts in the field, study authors and pharmaceutical companies as part of the search strategy.

\section{Selection criteria}

We included randomized controlled trials (RCTs) (irrespective of language or publication status) comparing the use of untargeted treatment with any antifungal drug (either systemic or nonabsorbable) to placebo, no antifungal, or another antifungal agent in non-neutropenic critically ill participants. 


\section{Data collection and analysis}

Three authors independently applied selection criteria, extracted data and assessed the risk of bias. We resolved any discrepancies by discussion. We synthesized data using the random-effects model and expressed the results as risk ratios (RR) with $95 \%$ confidence intervals. We assessed overall evidence quality using the GRADE approach.

\section{Main results}

We included 22 studies (total of 2761 participants). Of those 22 studies, 12 were included in the original published review and 10 were newly identified. Eleven trials compared the use of fluconazole to placebo or no antifungal treatment. Three trials compared ketoconazole versus placebo. One trial compared anidulafungin with placebo. One trial compared caspofungin to placebo. Two trials compared micafungin to placebo. One trial compared amphotericin B to placebo. Two trials compared nystatin to placebo and one trial compared the effect of clotrimazole, ketoconazole, nystatin and no treatment. We found two new ongoing studies and four new studies awaiting classification. The RCTs included participants of both genders with wide age range, severity of critical illness and clinical characteristics. Funding sources from pharmaceutical companies were reported in 11 trials and one trial reported funding from a government agency. Most of the studies had an overall unclear risk of bias for key domains of this review (random sequence generation, allocation concealment, incomplete outcome data). Two studies had a high risk of bias for key domains. Regarding the other domains (blinding of participants and personnel, outcome assessment, selective reporting, other bias), most of the studies had a low or unclear risk but four studies had a high risk of bias.

There was moderate grade evidence that untargeted antifungal treatment did not significantly reduce or increase total (all-cause) mortality (RR $0.93,95 \% \mathrm{Cl} 0.79$ to $1.09, \mathrm{P}$ value $=0.36$; participants $=2374$; studies $=19)$. With regard to the outcome of proven invasive fungal infection, there was low grade evidence that untargeted antifungal treatment significantly reduced the risk $(\mathrm{RR} 0.57,95 \% \mathrm{Cl} 0.39$ to 0.83 , $P$ value $=0.0001 ;$ participants $=2024$; studies $=17)$. The risk of fungal colonization was significantly reduced $(\mathrm{RR} 0.71,95 \% \mathrm{Cl} 0.52$ to 0.97 , $\mathrm{P}$ value $=0.03$; participants $=1030$; studies $=12$ ) but the quality of evidence was low. There was no difference in the risk of developing superficial fungal infection (RR $0.69,95 \% \mathrm{Cl} 0.37$ to 1.29 , $\mathrm{P}$ value $=0.24$; participants $=662$; studies $=5$; low grade of evidence) or in adverse events requiring cessation of treatment between the untargeted treatment group and the other group (RR $0.89,95 \% \mathrm{Cl} 0.62$ to $1.27, \mathrm{P}$ value $=0.51$; participants $=1691$; studies $=11$; low quality of evidence). The quality of evidence for the outcome of total (all-cause) mortality was moderate due to limitations in study design. The quality of evidence for the outcome of invasive fungal infection, superficial fungal infection, fungal colonization and adverse events requiring cessation of therapy was low due to limitations in study design, non-optimal total population size, risk of publication bias, and heterogeneity across studies.

\section{Authors' conclusions}

There is moderate quality evidence that the use of untargeted antifungal treatment is not associated with a significant reduction in total (allcause) mortality among critically ill, non-neutropenic adults and children compared to no antifungal treatment or placebo. The untargeted antifungal treatment may be associated with a reduction of invasive fungal infections but the quality of evidence is low, and both the heterogeneity and risk of publication bias is high.

Further high-quality RCTs are needed to improve the strength of the evidence, especially for more recent and less studied drugs (e.g. echinocandins). Future trials should adopt standardized definitions for microbiological outcomes (e.g. invasive fungal infection, colonization) to reduce heterogeneity. Emergence of resistance to antifungal drugs should be considered as outcome in studies investigating the effects of untargeted antifungal treatment to balance risks and benefit.

\section{PLAIN LANGUAGE SUMMARY}

\section{Antifungal agents for preventing fungal infections in critically ill adults and children with a normal number of neutrophils in the blood}

\section{Review question}

We reviewed the evidence about the effect of giving antifungal medications before a definitive diagnosis of fungal infections on mortality from all causes and development of severe infections due to fungi (invasive fungal infections) in adults and children who are critically ill but non-neutropenic, i.e. with a normal number of neutrophils in their blood.

\section{Background}

Critically ill adults and children may suffer from invasive fungal infections, such as those affecting the bloodstream and other organs. Once established, such infections are difficult to treat and frequently result in death. Antifungal medications are sometimes given to critically ill adults and children most prone to developing fungal infections and to those with signs of infections when it is still unclear if a fungus is the cause.

\section{Study characteristics}

We included 22 randomized controlled trials (RCTs) (total of 2761 participants). Eleven trials compared the use of fluconazole to placebo or no antifungal treatment. Three trials compared ketoconazole versus placebo. One trial compared anidulafungin with placebo. One 
trial compared caspofungin to placebo. Two trials compared micafungin to placebo. One trial compared amphotericin B to placebo. Two trials compared nystatin to placebo and one trial compared the effect of clotrimazole, ketoconazole, nystatin and no treatment. The RCTs included participants of both genders with a wide age range and severity of critical illness.

\section{Search date}

The evidence is current as of February 2015.

\section{Study funding sources}

Funding sources from drug manufacturers were reported in 11 out of 22 studies. Another study was funded by a government agency.

\section{Key results}

Results of 19 from 22 randomized trials involved 2374 participants and showed that antifungal medications given before definitive diagnosis of fungal infection did not reduce mortality from all causes. None of the studied drugs were associated with a significant reduction of mortality from all causes. However, results from 17 randomized studies involving 2024 participants showed that antifungal drugs significantly reduced the risk of developing invasive fungal infections.

We also reviewed the evidence from five trials (662 participants) about the effect of antifungal treatment on the development of superficial fungal infections but we did not find any significant difference. However, we found evidence from 12 trials ( 1020 participants) of a significant reduction of fungi in body sites (excluding blood) not causing an infection. Eleven trials (1691 participants) reported serious adverse events requiring cessation of therapy. We found no evidence of differences in serious adverse events requiring interruption of antifungal medications between people who received and those who did not receive them.

\section{Quality of the evidence}

The quality of evidence for the outcome of mortality (all-cause) was moderate due to limitations in study design. The quality of evidence for the outcome of invasive fungal infection, superficial fungal infection, fungal colonization and adverse events requiring cessation of therapy was low due to limitations in study design, non-optimal total number of patients studied and results inconsistent across studies.

\section{Conclusion}

There is moderate quality evidence that the use of antifungal treatment given before definitive diagnosis of fungal infection is not associated with a significant reduction in mortality from all causes among critically ill adults and children with a normal number of neutrophils in the blood. This type of antifungal treatment may be associated with a reduction of invasive fungal infections but the quality of evidence on this point is low.

Further studies with high-quality design are needed to improve the evidence. 


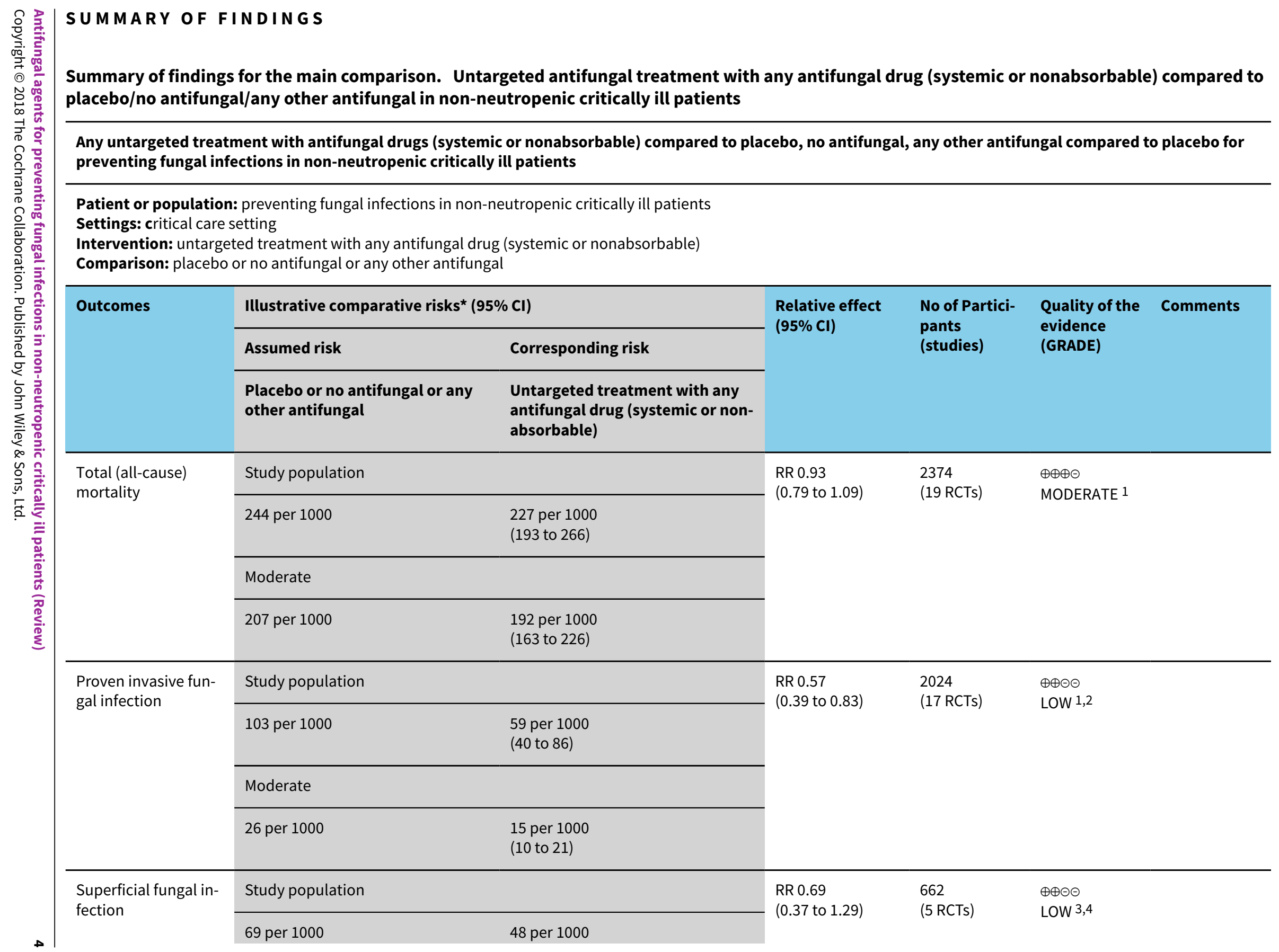




Moderate

31 per $1000 \quad 21$ per 1000

(11 to 40$)$

Fungal colonization

\section{Study population}

392 per 1000

(204 to 381)

Moderate

187 per $1000 \quad 132$ per 1000

(97 to 181)

Adverse events requiring cessation of study drug(s)

\section{Study population}

69 per 1000

62 per 1000

(43 to 88 )

Moderate

117 per 1000

104 per 1000

(72 to 148 )

*The basis for the assumed risk (e.g. the median control group risk across studies) is provided in footnotes. The corresponding risk (and its $95 \%$ confidence interval) is based on the assumed risk in the comparison group and the relative effect of the intervention (and its $95 \% \mathrm{Cl}$ ).

Cl: Confidence interval;

GRADE Working Group grades of evidence

High quality: Further research is very unlikely to change our confidence in the estimate of effect.

Moderate quality: Further research is likely to have an important impact on our confidence in the estimate of effect and may change the estimate.

Low quality: Further research is very likely to have an important impact on our confidence in the estimate of effect and is likely to change the estimate.

Very low quality: We are very uncertain about the estimate.

1 Most of studies that contributed to this result had an unclear risk of bias. Downgraded by one level.

${ }^{2}$ Asymmetry of the funnel plot detected by observation. Downgraded by one level.

${ }^{3}$ All the five studies that contributed to this result had an unclear risk of bias. Downgraded by one level.

${ }^{4}$ Total number of patients and events from studies that contributed to this result was less than the number of patients generated for the calculation of optimal information size.

Downgraded by one level.

5 All the studies that contributed to this result had an unclear risk of bias. Downgraded by one level. 
There was considerable statistical heterogeneity across studies. The use of different criteria for detection of fungal colonization in studies contributing to this result may have do clinical heterogeneity. Downgraded by one level.

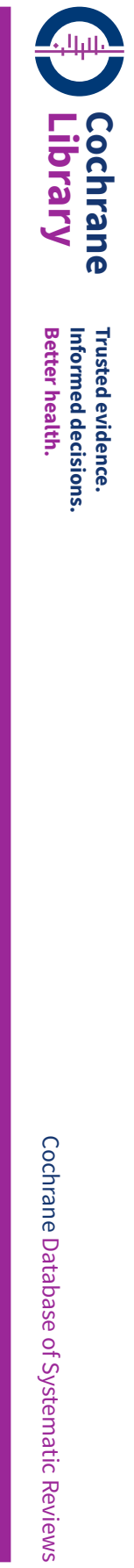




\section{B A C K G R O U N D}

\section{Description of the condition}

Invasive fungal infections (IFIs) are a well-documented complication of critically ill patients. Patients in an intensive care unit (ICU) have different risk factors for fungal infections development, including broad spectrum antibiotic therapy, disruption of natural barriers due to surgery or implantation of invasive devices (for treatment or monitoring), fungal colonization, impairment of immunological response (Hermsen 2011; OstroskyZeichner 2007). IFIs are a major cause of morbidity and mortality among critically ill patients. According to different studies, attributable mortality due to Candida spp. infections ranges from about 42\% to about 63\% (Kett 2011; Kollef 2012; Puig-Asensio 2014a). Moreover, IFls impose an important economic burden mainly due to prolonged ICU stay, cost of antifungal drugs and overall use of hospital resources (Dodds Ashley 2012; Hassan 2009; Rentz 1998). Bloodstream infection (BSI) due to Candida spp. (candidaemia) is considered the most common IFI in critically ill patients (Bassetti 2015; Kett 2011; Kullberg 2015; Vincent 2009). In specific subgroups of patients (e.g. abdominal surgical patients), other forms of IFIs are also frequent (e.g. intra-abdominal candidiasis), alone or in combination with candidaemia (Bassetti 2013; Bassetti 2015). Among fungal pathogens, Candida spp. are the most commonly isolated microorganisms, currently ranking the fourth most commonly identified pathogens in nosocomial BSIs and the third most common pathogens isolated in ICU patients (Vincent 2009; Wisplinghoff 2004). A prompt, effective antifungal treatment is one of the most important determinants for mortality reduction, especially in patients with septic shock attributed to Candida infections (Garey 2006; Kollef 2012; Morrell 2005; PuigAsensio 2014b).

\section{Description of the intervention}

The administration of an antifungal drug after the definitive microbiological proof of fungal infection constitutes what has been defined as targeted antifungal therapy. Due to the long turnaround time for culture results with late microbiological documentation in the course of infections (Bassetti 2013; Cuenca-Estrella 2012; Fernandez 2011), and the increasing mortality associated with a delay in therapy institution (Garey 2006; Kollef 2012, Morrell 2005; Puig-Asensio 2014b), different antifungal strategies have been studied for preventing IFI in non-neutropenic critically ill patients. The administration of any antifungal drug prior to the definitive microbiological evidence of fungal infection constitutes an untargeted antifungal treatment . Recently, the European Society of Clinical Microbiology and Infectious Diseases (ESCMID) provided the definitions of three different treatment strategies, classifying them into prophylactic, pre-emptive and empiric treatments (Cornely 2012). Prophylaxis has been defined as the administration of antifungal agents in patients without proven or suspected fungal infection (i.e. absence of microbiological or radiological evidence) but with risk factors for its development (e.g. patients treated with broad spectrum antibiotics, presence of a central venous catheter, under parenteral nutrition or who underwent major abdominal surgery). Pre-emptive treatment (diagnosisdriven approach) has been defined as treatment triggered by microbiological evidence of fungal infection, without definitive microbiological proof. Surrogate biomarkers for the presence of fungal infection (e.g. 1-3 ß-D-glucan, mannan/anti-mannan antibody) have been investigated for this purpose (Mikulska 2010;
Posteraro 2011). Empiric treatment (fever-driven approach) has been defined as the antifungal treatment triggered by signs and symptoms of infection in patients at risk for IFI, in the absence of microbiological evidence of infection at the moment of therapy institution.

\section{How the intervention might work}

A prompt effective antifungal treatment is one of the most important determinants for mortality reduction in patients with severe sepsis or septic shock due to fungal infections. Unfortunately, despite advances in microbiological techniques, the proven diagnosis of fungal infections requires several days and usually occurs late (Bassetti 2013; Cuenca-Estrella 2012; Fernandez 2011). The advantage of antifungal treatment given before definitive microbiological diagnosis has been established in high-risk patients such as cancer patients and solid organ transplant recipients (Cruciani 2006; Gøtzsche 2014; Marino 2010; Playford 2004a). In these populations, the use of antifungal agents has been proven to be effective for IFI reduction. However, in non-neutropenic critically ill patients, several antifungal strategies have been investigated among different selected populations (e.g. surgical or nonsurgical patients). In non-neutropenic critically ill patients, the definitive evidence for the effect on mortality and IFIs by untargeted treatment has not been established to date. Potential detrimental effects of the extensive use of antifungal agents are the emergence of Candida spp. with reduced susceptibility to drugs (Fekkar 2014; Pfaller 2012), drug-induced side effects and an increase of financial costs (Lortholary 2011).

\section{Why it is important to do this review}

Antifungal drugs given to critically ill patients before definitive microbiological proof of IFIs may have a positive impact on patients' outcome given the high morbidity and mortality, especially in case of inadequate and late antifungal treatment (Garey 2006; Kollef 2012; Morrell 2005; Puig-Asensio 2014b). The original review aimed to determine the benefits and harms of the prophylactic administration of antifungals in non-neutropenic, critically ill patients. That review incorporated the existing evidence up to 2005 (Playford 2006a). During these last 10 years, the administration of antifungal drugs for prevention of fungal infections has been further investigated, additional antifungal treatments have been introduced for this purpose and the role of colonization for subsequent development of fungal infection has been better clarified (Lau 2015; Pittet 1994; Vardakas 2009). This updated version was conducted to determine the current state of the evidence in this regard. Recently, different approaches for fungal infection prevention and treatment have been better defined and standardized by international guidelines (Cornely 2012). In the original review, authors used "antifungal prophylaxis" as a definition for the intervention encompassing the terms prophylaxis, pre-emptive and empiric treatments (Playford 2006a). In order to avoid confusion and considering the new definitions, in this updated version we decided to use the term "untargeted treatment" to identify the use of any antifungal agent given prior to the definitive microbiological diagnosis. "Un-targeted treatment" encompasses the terms prophylaxis, pre-emptive and empiric treatments. Recent evidence reconsidered the role of Candida spp. detection from respiratory tract specimens (Meerssemann 2009), leading to the suggestion by international guidelines of considering this event a colonization rather than invasive infection (Cornely 2012). Consequently, we modified the definition of a primary 
outcome (invasive fungal infection), excluding those events involving the respiratory tract. In older studies, azole antifungals (e.g. fluconazole, ketoconazole) were more commonly used for this purpose. Recently, another class of antifungal agents, namely echinocandins (e.g. anidulafungin, caspofungin, micafungin) have been introduced for both targeted and untargeted treatment use in a broad spectrum of clinical conditions including critically ill, non-neutropenic patients. Moreover, since Candida colonization has been identified as a risk factor for subsequent IFI (Lau 2015; Pittet 1994; Vardakas 2009), nonabsorbable antifungal drugs (e.g. nystatin) have been studied for its prevention. For this reason, we studied these types of antifungal drugs as part of the intervention of interest for this updated review.

\section{O B JE C T IVES}

To assess the effects of untargeted treatment with any antifungal drug (either systemic or nonabsorbable) compared to placebo or no antifungal or any other antifungal drug (either systemic or nonabsorbable) in non-neutropenic critically ill adults and children. We assessed effectiveness in terms of mortality and incidence of proven invasive fungal infections as primary outcomes.

\section{METHODS}

\section{Criteria for considering studies for this review}

\section{Types of studies}

We considered all randomized controlled trials (RCTs) that evaluated the effect of any antifungal agent given as untargeted treatment in non-neutropenic critically ill adults and children.

\section{Types of participants}

We considered trials involving adult participants (aged 18 years or over) and children (aged less than 18 years), classified as critically ill (such as those admitted to an ICU or having recently undergone an abdominal or other major surgical procedure).

We excluded trials involving neutropenic, neonatal or HIV-infected participants, participants predominantly with malignancies or solid organ transplant recipients, as systematic reviews have been published for these patient groups (Austin 2013a; Austin 2013b; Gøtzsche 2014).

We included trials including non-neutropenic critically ill participants along with other groups if the proportion of these was less than $25 \%$ or if data on non-neutropenic patients were separately provided.

\section{Types of interventions}

We considered trials if they involved the randomized comparison of any antifungal drug (either systemic or nonabsorbable) with placebo, no antifungal or any other antifungal drug (either systemic or nonabsorbable).

We included studies in which antifungal drugs were initiated before microbiological definitive evidence of infection (untargeted approach, encompassing the prophylactic, pre-emptive and empiric treatment).
We decided to consider an eligible intervention the administration of untargeted treatment with nonabsorbable antifungals since colonization has been described as a risk factor for subsequent development of IFIs (Lau 2015; Pittet 1994; Vardakas 2009) and the use of nonabsorbable antifungal has been recently studied as a measure for risk reduction (Giglio 2012). We defined nonabsorbable antifungal as a drug administered enterally (e.g. orally or through a nasogastric tube) with a topical antifungal effect and no systemic absorption.

The study groups were required to differ only for the antifungal regimen under investigation; other co-interventions and aspects of care, including the routine use of other antimicrobial agents, were required to be the same to avoid potentially confounded comparisons.

We excluded studies not reporting the molecule of the antifungal drug used and if this information was not obtained after contacting the authors of the studies.

\section{Types of outcome measures}

\section{Primary outcomes}

1. Total (all-cause) mortality.

2. Proven invasive fungal infection. The criteria for proven IFI included a clinical illness consistent with the diagnosis and either histopathological evidence of IFI or a positive fungal culture from one or more sterile site specimens (including blood). Positive culture of Candida spp. from the respiratory tract, even in presence of systemic or respiratory signs of infections, was classified as colonization instead of IFI. Funguria (as indicated by a positive urine fungal culture), in the absence of a complicated urinary tract infection, and fungal oesophagitis were classified as superficial fungal infections.

\section{Secondary outcomes}

1. Proven or suspected invasive fungal infection. This outcome measure incorporated both proven IFI cases (defined above) and suspected IFI cases (defined as the initiation of systemic antifungal therapy without the fulfilment of the criteria for a proven IFI) in trials that reported both outcomes.

2. Suspected invasive fungal infection. Suspected invasive fungal infections were defined as the initiation of systemic antifungal therapy without the fulfilment of the criteria for a proven IFI.

3. Superficial fungal infection. Superficial fungal infections were defined as superficial cutaneous, oropharyngeal, oesophageal or uncomplicated urinary tract fungal infections.

4. Fungal colonization. Fungal colonization was defined as a positive fungal culture from a single participant in at least one body site that either developed (if not present at baseline) or persisted (if present at baseline) during untargeted antifungal treatment.

5. Proven invasive fungal infection caused by an azole-resistant Candida species (defined as Candida glabrata, Candida krusei, or another species with documented azole resistance) or a filamentous fungus (such as Aspergillus species). Note: although newer azole antifungal agents (such as voriconazole and posaconazole) have activity against these fungal pathogens, we used the term azole-resistant Candida spp. to denote fluconazole/ketoconazole resistance. This outcome was already considered in the original review (Playford 2006a). We decided 
to analyse it from studies investigating the use of azoles as intervention drug.

6. Fungal colonization with azole-resistant Candida species. This outcome was already considered in the original review (Playford 2006a). We decided to analyse it from studies investigating the use of azoles as intervention drug.

7. Adverse events requiring cessation of study drug(s).

We analysed description of clinical and laboratory data provided in each study and we categorized the events according to the definitions above regardless of study authors' classification. Where insufficient information was available to classify events, we contacted study authors for clarification.

The time point of assessment of outcome measures was at the time of discharge from ICU or at the end of untargeted treatment, whichever was longer.

\section{Search methods for identification of studies}

\section{Electronic searches}

For the original review (Playford 2006a), the authors searched the Cochrane Central Register of Controlled Trials (CENTRAL, 2005, Issue 3), MEDLINE (OVID: 1966 to 2 September 2005), EMBASE (OVID: 1980 to week 36,2005$)$.

For this updated review we searched all the above mentioned databases from the previous starting date to February 2015. The search terms used in this updated review are listed in Appendix 1.

We searched the following databases of ongoing/completed trials using the same search terms included in the search strategy for the main databases:

1. ClinicalTrials.gov

2. European Clinical Trials Database (EudraCT)

3. International Clinical Trials Registry Platform (ICTRP)

4. ISRCTN registry

5. Australian New Zealand Clinical Trials Registry (ANZCTR)

6. German Clinical Trials Register (GermanCTR)

We conducted the last search of these databases on 10 April 2015.

We did not apply a language restriction.

\section{Searching other resources}

We searched the proceedings of major relevant conferences (including, but not limited to: Interscience Conference on Antimicrobial Agents and Chemotherapy; American Society for Microbiology; Infectious Diseases Society of America; European Society of Clinical Microbiology and Infectious Diseases; American Society of Anesthesiologists; European Society of Intensive Care Medicine; Society of Critical Care Medicine; International Symposium on Intensive Care and Emergency Medicine. We searched the reference lists of identified trials and major reviews. We contacted researchers active in the field and primary authors of identified relevant trials for additional published and unpublished trial data. We contacted manufacturers of the study drugs for additional published or unpublished trial data. We accepted letters, abstracts, and unpublished trials to reduce publication bias. If we suspected duplicate publications, we contacted the study authors for clarification and, if confirmed, we used the publication with the longest follow-up data for the review. We searched these resources until 18 April 2015.

\section{Data collection and analysis}

\section{Selection of studies}

For this updated review three authors (AC, VR, AM) independently retrieved the search report to identify potentially eligible studies, considering titles and abstracts. The same authors analysed the full texts of potentially eligible articles.

Two authors (AC, VR) were responsible for contacting the authors of studies if additional information were required for assessment of eligibility and study quality. When disagreement was encountered about eligibility of studies, it was resolved after discussion and consensus among the three authors who performed the scan (AC, VR, AM) and two additional authors (SMR, AG).

\section{Data extraction and management}

For this updated review, two authors (AC, VR) designed a data extraction form in order to extract data from studies. All items recommended in Section 7 of the Cochrane Handbook for Systematic Reviews of Interventions (Higgins 2011a) were addressed in the extraction process (Appendix 2). Three authors (AC, VR, AM) independently extracted data from studies. When discrepancies were encountered in the extraction process, it was resolved by consensus among the three authors who extracted the data (AC, VR, $A M)$ and two additional authors (SMR, AG).

\section{Assessment of risk of bias in included studies}

Three authors (AC, VR, AM) assessed the risk of bias of the included studies using the Cochrane tool for assessing risk of bias, as described in Section 8 of the Cochrane Handbook for Systematic Reviews of Interventions (Higgins 2011a). When discrepancies were met, the authors discussed with two additional authors (SMR, AG) to solve by consensus. The domains assessed in each included study were:

1. Random sequence generation (selection bias)

2. Allocation concealment (selection bias)

3. Blinding of participants and personnel (performance bias)

4. Blinding of outcome assessment (detection bias)

5. Incomplete outcome data (attrition bias)

6. Selective reporting (reporting bias)

7. Other bias

In accordance with the Cochrane Handbook for Systematic Reviews of Interventions (Higgins 2011b), all authors defined by consensus key domains among assessed bias for all outcomes (random sequence generation, allocation concealment, incomplete outcome data). We excluded for the primary analysis the studies presenting high risk of bias in one or more key domains (Higgins 2011b).

\section{Measures of treatment effect}

We analysed data using the risk ratio (RR) and 95\% confidence intervals $(\mathrm{Cl})$. No continuous or time-to-event outcome measures were addressed as part of this review. 


\section{Unit of analysis issues}

We analysed data using participants who were individually randomized to each group for each outcome addressed.

\section{Dealing with missing data}

We attempted to obtain missing data from trial authors. When possible, we extracted data to allow an intention-to-treat (ITT) analysis in which all randomly assigned participants were analysed in the groups to which they were originally randomized. We calculated the number of excluded participants and the proportion out of the initial number of randomized participants. When information was not available about an outcome, we did not use imputation and we performed an available case analysis (Higgins 2011c).

\section{Assessment of heterogeneity}

Clinical heterogeneity was addressed considering participants' and treatment characteristics (including drugs, dosage and type of antifungal treatment). Methodologic heterogeneity was assessed by comparing the risk of bias in the included studies. Statistical heterogeneity between trials was assessed by visually examining the funnel plot, using the $\mathrm{Chi}^{2}$ test and the $\mathrm{I}^{2}$ statistic to assess inconsistency (percentage of variability in effect estimates that is due to heterogeneity rather than to sampling error). A P value less than 0.10 and $\mathrm{I}^{2}$ statistic value in excess of $50 \%$ were taken as indicative of substantial heterogeneity (Higgins 2011d).

\section{Assessment of reporting biases}

To determine the presence or absence of reporting bias, we planned to examine funnel plots for meta-analysis of primary outcomes that included 10 or more studies to determine if they were symmetrical. We did a visual assessment of funnel plots for primary outcomes.

\section{Data synthesis}

Review Manager 5 was used to perform the update of this metaanalysis. For each outcome, all eligible studies that reported the outcome were included and participants who were treated with an untargeted antifungal treatment with any drug (systemic or nonabsorbable) were compared with those who received placebo, no antifungal or any other antifungal drug (with specified molecule). We pooled the results from different trials using a random-effects model and compared with a fixed-effect model in a sensitivity analysis.

\section{Subgroup analysis and investigation of heterogeneity}

Should we have identified adequate numbers of eligible studies (at least two for each subgroup), we planned to conduct the following subgroup analyses for this updated review:

- Types of participants (post-surgical participants $\geq 75 \%$ versus < $75 \%)$

- Fluconazole doses ( $\geq 400 \mathrm{mg} /$ day and $<400 \mathrm{mg} /$ day)

We performed the following additional subgroup analyses:

- Systemic versus non-absorbable antifungal drug

- Drugs class (azoles versus echinocandins)

- Type of treatment (empiric treatment versus prophylaxis)

- Type of control group (placebo or no intervention)

\section{Sensitivity analysis}

We updated the following sensitivity analyses from the original review:

- Random-effects versus fixed-effect model

- Random sequence generation (low risk versus unclear and high risk of bias)

- Allocation concealment (low risk versus unclear and high risk of bias)

- Blinding of outcome assessors (low risk versus unclear and high risk of bias)

We additionally performed the following sensitivity analyses:

- Risk of bias for key domains (all studies versus unclear and low risk)

- Incomplete data outcome (low risk versus unclear and high risk)

- Studies without any high risk of bias.

\section{Summary of findings}

We used the GRADE approach to interpret findings (Schünemann 2011). We used GRADEpro software (GRADEpro) to import data from Review Manager 5 to create 'Summary of findings' tables using information on quality of evidence, magnitude of effects of the interventions examined and sums of available data on all important outcomes from each study included in the comparison. The GRADE approach considers 'quality' to be a judgement of the extent to which we can be confident that the estimates of effect are correct (Schünemann 2011). Evidence from randomized controlled studies initially was graded as high and was downgraded by one for serious (or by two for very serious) limitations (risk of bias), indirectness of evidence, serious inconsistency, imprecision of effect estimates or potential publication bias. We selected the following outcomes for the 'Summary of findings' table:

1. Total (all-cause) mortality

2. Proven invasive fungal infection

3. Superficial fungal infection

4. Fungal colonization

5. Adverse events requiring cessation of study drug(s)

\section{RE S U L T S}

\section{Description of studies}

\section{Results of the search}

We identified a total of 3725 records from both databases and other sources ( 3687 through databases search and 38 from other sources). After we removed duplicates, 3281 records were screened from title and abstract. We excluded articles at the title and abstract stage (3230) included studies with a non-randomized design, with other than untargeted antifungal treatment or studies including an ineligible population. We examined 51 records further for eligibility from full-texts (Figure 1). Of these, we excluded a total of 18 articles (Characteristics of excluded studies). The reasons for exclusion were as follows: not randomized design (two studies), ineligible population (three studies), ineligible interventions (10 studies), outcomes not relevant (one study), results not available after contacting investigators and sponsors (two studies). We included 22 studies in the qualitative analysis (Characteristics of included 
studies). Among them, 12 studies were already included in the original review (Playford 2006a), and 10 were additionally included in this update. Eleven trials compared the use of fluconazole to placebo or no antifungal treatment. Three trials compared ketoconazole versus placebo. One trial compared anidulafungin with placebo. One trial compared caspofungin to placebo. Two trials compared micafungin to placebo. One trial compared amphotericin B to placebo. Two trials compared nystatin to placebo and one trial compared the effect of clotrimazole, ketoconazole, nystatin and no treatment. 
Figure 1. Flow diagram.

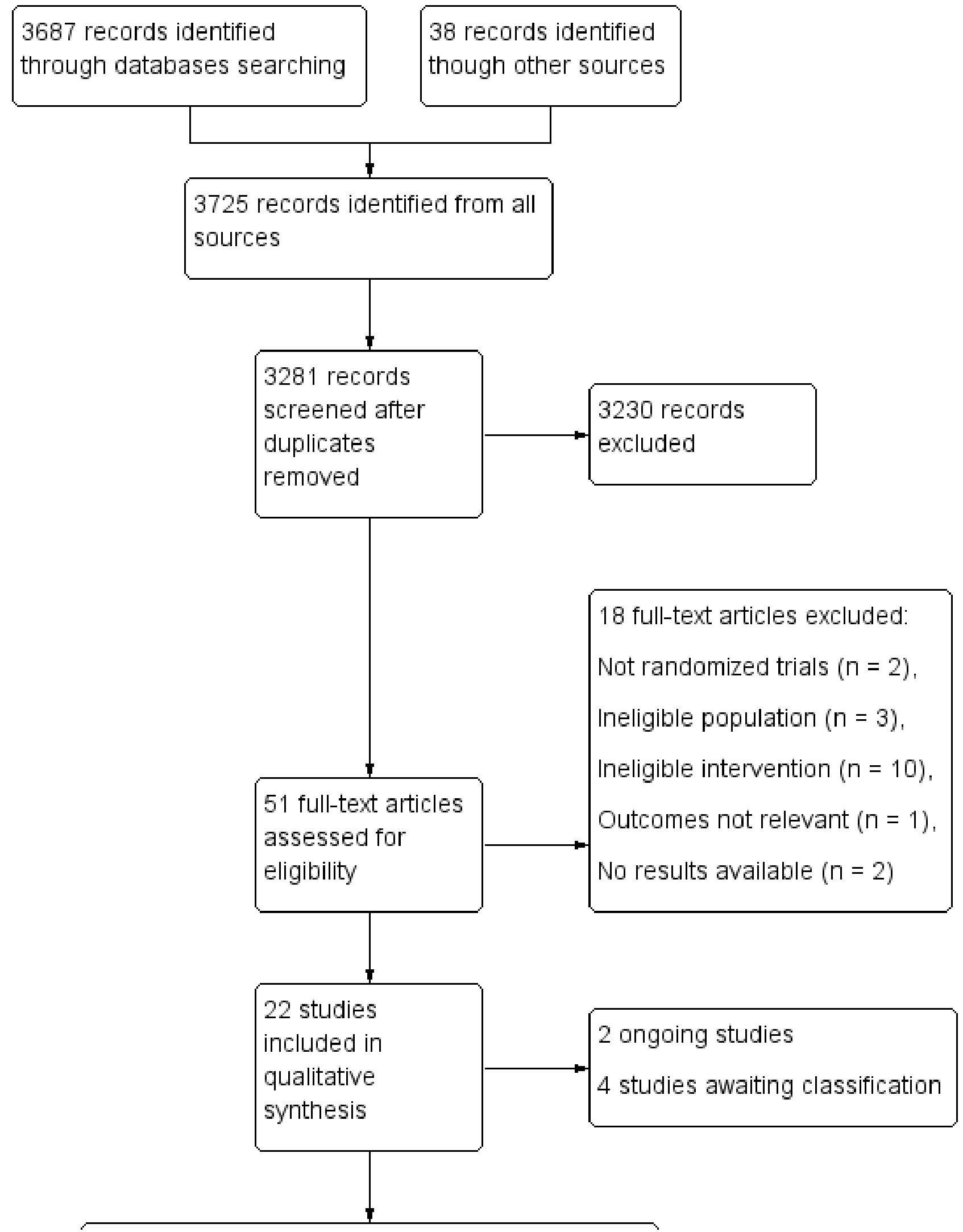


Figure 1. (Continued)

19 studies included in meta-analyses of all-cause
mortality. Reasons for exclusion: no data reported
$(n=1)$, high risk of bias for key domains $(n=1)$,
outcome not eligible and high risk of bias of key
domains ( $n=1)$.
17 studies included in meta-analyses of proven
invasive fungal infection. Reasons for exclusion:
no data reported ( $n=3)$, high risk of bias for key
domains $(n=2)$

We also identified two new ongoing studies (Characteristics of ongoing studies); and four studies awaiting classification (Characteristics of studies awaiting classification).

We included 19 studies in the quantitative analysis for mortality. We excluded one study due to no data about this outcome ( $\mathrm{He}$ 2003); and one study for high risk of bias for key domains (Savino 1994). Another study was excluded for the outcome of mortality due to both ineligible outcome data and for high risk of bias for key domains (Beshey 2014).

We included 17 studies in the quantitative analysis for proven IFI. Three studies were excluded because data were not available for this outcome (Albert 2014; ARDS Network 2000; Yu 1993); and two other studies because of high risk of bias for key domains (Beshey 2014; Savino 1994).

\section{Included studies}

We included 22 randomized studies in this updated review (See Characteristics of included studies). The total number of participants was 2761 .

Ables 2000 included 119 participants at least 14 years of age, admitted to a single ICU in the United States either with a diagnosis of trauma or who had undergone intra-abdominal or intrathoracic surgery. Furthermore, participants were required to have an anticipated length of ICU stay of more than 48 hours and at least one manifest risk factor within 48 hours of ICU admission (central venous catheter placement, administration of total parenteral nutrition, artificial ventilation for more than 24 hours, or treatment with broad-spectrum antibiotics). Baseline characteristics reported in the analysis included mean age (46 in the treatment group, 42 in the placebo group), sex ( 82 men and 37 women) and mean acute physiology and chronic health evaluation (APACHE) II score (18 in both groups). Participants were randomized to receive either fluconazole ( $800 \mathrm{mg}$ initially followed by $400 \mathrm{mg}$ daily intravenously, orally, or enterally) or placebo (given by same route of administration) for the duration of ICU stay. This study was supported by an investigator-initiated grant from Roerig/Pfizer.
Albert 2014 included 61 adult people admitted to five ICUs in Canada for at least 96 hours who developed a clinically suspected ventilator-associated pneumonia (VAP) after 48 hours of mechanical ventilation. Participants were included if a respiratory tract secretion culture was positive for Candida spp. Respiratory tract specimens were collected within 24 hours of suspicion of infection. Baseline characteristics reported in the analysis included mean age (57.6 in the intervention group, 63 years in the placebo group), sex (44 men and 16 women) mean APACHE II score (22.9 in the treatment group, 23 in the placebo group), mean sequential organ failure assessment score (SOFA) score (3.8 in both groups). Participants were randomized to receive either anidulafungin (200 mg intravenously, followed by $100 \mathrm{mg}$ daily for at least 72 hours) or matching placebo. When Candida spp. were sensitive to fluconazole, participants were de-escalated to fluconazole or matching placebo. Participants were treated for a total of 14 days. The study was halted prematurely because of difficulty in recruiting participants and diminishing study resources. Sources of support for this study came from Physicians' Services Incorporated Foundation and Pfizer.

The ARDS Network trial included 234 people aged at least 18 years admitted to 24 ICUs in the United States, who were ventilated and who developed acute lung injury (ALI) or acute respiratory distress syndrome (ARDS) from direct and indirect lung injury (ARDS Network 2000). Reported baseline characteristics included mean age (55 in the treatment group, 52 in the placebo group), sex (140 men and 94 women), mean APACHE III score (81.6 in the treatment group, 81 in the placebo group). Participants were randomized to receive either ketoconazole (400 mg daily enterally) or placebo for 21 days or until more than 48 hours of unassisted ventilation was achieved. This study tested the efficacy of ketoconazole in reducing mortality and morbidity in people with ARDS based on its anti-inflammatory activity. Thus, this study did not test the direct antifungal activity of ketoconazole. This study was supported by National Institute of Health/National Heart, Lung, and Blood Institute contracts (United States).

Beshey 2014 included 75 adult people admitted to a single ICU in Egypt who were mechanically ventilated for at least 48 hours and expected to remain so for at least an additional 
72 hours. Participants were randomized into three groups: group I, who did not receive any prophylactic medication; group II, who received selective digestive decontamination (SDD) consisting of oral decontamination by chlorhexidine, gastrointestinal tract decontamination by oral colistin, respiratory tract decontamination by cefotaxime; group III who received fluconazole $(200 \mathrm{mg}$ on the first day, then $100 \mathrm{mg}$ orally, once a day) in addition to SDD until initiation of systemic antifungals according to cultures results or ICU discharge. Reported baseline characteristics included mean age (50.9 in group I, 51.9 in group II, 48.5 in group III), sex (40 men and 35 women), and mean APACHE II score (26 in both group I and II, 27 in group III).

Eggimann 1999 included 49 people at least 16 years of age admitted to two ICUs in Switzerland, with recent abdominal surgery and who had recurrent gastrointestinal perforation or anastomotic leakages that were either suspected or confirmed by surgery. Reported baseline characteristics reported in the analysis included median age (63 years in the treatment group and 57 in the placebo group), sex ( 28 men and 15 women), median APACHE II score (13 in both treatment and placebo groups). Participants were randomized to receive either fluconazole (400 $\mathrm{mg}$ daily intravenously) or placebo until complete resolution of the intra-abdominal disease. The study was halted prematurely due to slow recruitment. This study was supported in part by a grant from Pfizer.

Garbino 2002 included 220 people over 18 years of age admitted to a single ICU in Switzerland for surgical or medical reasons or trauma. Participants were mechanically ventilated for at least 48 hours and expected to remain so for an additional 72 hours. All participants received selective decontamination of the digestive tract with oral polymyxin B, neomycin, and vancomycin. Baseline characteristics reported in the analysis included mean age (52.9 years in the treatment group, 55.9 years in the placebo group), sex (140 men and 64 women), mean APACHE II score (20.9 in the treatment group, 21.3 in the placebo group). Participants were randomized to receive fluconazole (100 mg daily intravenously) or placebo until withdrawal from mechanical ventilation. The study was supported by an unrestricted grant by Pfizer.

Giglio 2012 included 128 people over 18 years of age, admitted to a single ICU in Italy for surgical reasons or trauma, who were mechanically ventilated for more than 48 hours. Baseline characteristics reported in the analysis included mean age ( 54 years in the treatment group and 58 years in the control group), sex (61 men and 38 women), mean APACHE II score (19.5 in the treatment group, 19.3 in the control group), mean SOFA score (seven in both treatment and control groups). Participants were randomized to receive either nystatin prophylaxis $\left(2 \times 10^{6}\right.$ unit three times daily via the nasogastric tube) or no nystatin prophylaxis as control.

He 2003 included 70 people admitted to a single hospital in China with pancreatitis according to the Pancreas Surgery Group of the Chinese Medical Association 1997 diagnostic criteria (Pancreatic Group Chinese Medical Association 1997); and at least one predisposing factor for fungal infection (gerontism, diabetes, dysfunction of one or more organ, hyperglycaemia, central venous catheter, total parenteral nutrition, urinary catheterization, surgical operation, gastrointestinal fistula, ICU admission, mechanical ventilation for at least five days, broad-spectrum antibiotics for at least five days, or super broad-spectrum antibiotics at least three days). Participants were randomized to receive fluconazole (100 mg daily intravenously), garlicin (120 mg daily intravenously), or neither. Reported baseline characteristics included mean age (48.7 years in the antifungal group, 51.4 in the garlicin group, 50.5 years in the control group), sex (37 men and 33 women) and mean APACHE II score (13.2 in the antifungal group, 11.8 in the garlicin group, 11.6 in the control group). Participants were randomized to receive fluconazole (100 mg daily intravenously), garlicin (120 mg daily intravenously) or neither. Treatment was continued until relief of predisposing factors. We did not consider the garlicin group for the purpose of this current review.

Jacobs 2003 included 71 people admitted to a single ICU in Saudi Arabia with a diagnosis of septic shock according to criteria established in 1992 by the American College of Chest Physicians/Critical Care Society Consensus Conference within 24 hours of onset, from either intra-abdominal sepsis or nosocomial pneumonia (Bone 1992). Reported baseline characteristics included age distribution (17 participants in both groups were younger than 50 years of age, 16 participants in the treatment group were older than 50 years of age, and 21 participants in the placebo group were older than 50 years of age), sex (40 men and 31 women), mean APACHE II score (18.7 in the treatment group, 18.1 in the placebo group). Participants were randomized to receive either fluconazole $(200 \mathrm{mg}$ daily intravenously) or placebo for the duration of the septic shock.

Leon 1990 included 51 adult people admitted to a single ICU in France for surgical or medical reasons with at least one serious infection under broad spectrum antibiotic treatment. Reported baseline characteristics included mean age (62 years) and mean acute severity index on admission (14.3 in the intervention group and 13.4 in the control group). Participants were randomized to receive either amphotericin $\mathrm{B}$ ( $2 \mathrm{~g} /$ day via nasogastric tube) or placebo.

Namikawa 2013 included 81 adult people aged at least 70 years who underwent gastric cancer surgery in a single hospital in Japan. Participants had a plasma concentration of B-D-glucan equal or higher than $11 \mathrm{pg} / \mathrm{ml}$. Reported baseline characteristics included median age ( 78 years for both groups), sex ( 13 men and 13 women), and the International Union Against Cancer tumor-node-metastasis (TNM) classification (Sobin 2009). Participants were randomized to receive either fluconazole $(800 \mathrm{mg}$ daily for the first two days intravenously, followed by $400 \mathrm{mg}$ daily intravenously for the following five days) or no fluconazole.

NCT00048750. In this phase three unpublished trial, investigators included 103 people at least 16 years of age. Twenty-one ICUs in the United States and Canada participated in this study. Participants were included if they had a predicted ICU stay of at least 72 hours and were judged to be at a high risk of developing IFIs based on risk factors (usage of systemic antibiotics, use of total parenteral nutrition, renal failure, fungal colonization). Participants' reported baseline characteristics included mean age (52.8 years in the treatment group and 59.9 in the placebo group), sex (61 men and 41 women), mean APACHE II score (16.4 in treatment group and 19.1 in the placebo group), and mean Marshall score (5.7 in the treatment group and 6.3 in the placebo group) (Marshall 1995). Participants were randomized to receive either micafungin $(100 \mathrm{mg}$ daily intravenously) or placebo until ICU discharge. The study was discontinued because the sponsor (Astellas Pharma) concluded that many truly high risk participants were receiving antifungal prophylaxis off-study and consequently they were not enrolled into 
the study. It was judged that a reversal of this trend was unlikely and that a low incidence of fungal events would continue.

NCT01122368. In this phase two unpublished study, investigators included 252 people aged at least 18 years of age, admitted to 53 ICUs in Europe with localized/generalized intra-abdominal infection either community acquired or of nosocomial origin requiring surgery. Participants' baseline characteristics were not available because although they were initially reported in the unpublished document reporting results, they were subsequently removed. Participants were randomized to receive either micafungin (100 mg daily intravenously) or placebo until recovery of gastrointestinal tract function, confirmation of IFI, administration of an alternative antifungal drug or death. This study was sponsored by Astellas Pharma.

Normand 2005 included 116 people at least 18 years of age, admitted to a single ICU in France for surgical or medical reasons or trauma, who were expected to require mechanical ventilation for more than 48 hours. Baseline characteristics reported in the analysis included mean age (59 years in the treatment group and 57 in the control group), sex (65 men and 33 women), mean simplified acute physiology score (SAPS) II score (40 in the treatment group, 39 in the control group). Participants were randomized to receive either nystatin prophylaxis ( $3 \times 10^{6}$ unit daily orally) or no oral nystatin prophylaxis.

Ostrosky-Zeichner 2014 included 222 people aged at least 18 years, admitted to $15 \mathrm{ICUs}$ in the United States for at least three days, who were mechanically ventilated, received any broad spectrum antibiotic, had a central venous catheter and presented at least one additional risk factor among parenteral nutrition, dialysis, major surgery, pancreatitis, systemic steroids or other immunosuppressive agents. Reported baseline characteristics for participants receiving the intervention of interest included mean age (57.7 in the treatment group and 55.4 in the placebo group), sex (114 men and 72 women), mean APACHE II score (25.0 in the treatment group and 24.9 in the control group). Participants were randomized to receive either caspofungin ( $70 \mathrm{mg}$ loading dose, followed by $50 \mathrm{mg}$ daily intravenously) or placebo throughout the ICU stay. In this study, there was a second phase characterized by pre-emptive therapy for subjects who developed proven or probable IFI. We considered only the prophylactic phase of the trial for the purpose of this review. This study was supported and sponsored by Merck.

Parizkova 2000 included 38 people aged at least 18 years of age admitted to a single ICU in the Czech Republic for surgical or medical reasons. Participants were included within five days of admission. They should have received at least 24 hours of antibiotic therapy and at least 48 hours of mechanical ventilation. Reported baseline characteristics included mean age (46 years in the treatment group and 43 in the control group), mean APACHE II score (23.6 in the treatment group and 22.5 in the control group), mean SOFA score (10.8 in the treatment group and 8.6 in the control group). Participants were randomized to receive either fluconazole (100 mg daily intravenously) or no fluconazole until ICU discharge.

Pelz 2001 included 260 people admitted to a single surgical ICU in the United States for surgical reasons with an expected length of stay of at least three days. Reported baseline characteristics included median age ( 63 years in the treatment group and 66 years in the placebo group), sex (130 men and 130 women), median
APACHE III score (63 in the treatment group, 65 in the control group). Participants were randomized to receive either fluconazole $(800 \mathrm{mg}$ loading then $400 \mathrm{mg}$ daily enterally) or placebo until ICU discharge or initiation of an empiric antifungal treatment.

Sandven 2002 included 110 adult people with intra-abdominal perforation or anastomotic leakage from 13 hospitals in Norway. Baseline characteristics reported in the analysis included median age (68 years in the treatment group, 60 years in the placebo group) and sex (52 men and 57 women). Participants were randomized to receive either fluconazole ( $400 \mathrm{mg}$ intravenously) or placebo as a single dose given in the operating room. The study was terminated prematurely due to slow recruitment. The study was supported by Pfizer which provided bottles containing either 400 $\mathrm{mg}$ of fluconazole or placebo.

Savino 1994 included 292 people admitted to a single ICU in the United States for more than 48 hours with an expected ICU length of stay of at least 48 hours. Reasons for admission were surgery or trauma. Participants were randomized to receive ketoconazole (200 $\mathrm{mg}$ daily enterally), clotrimazole (10 mg three times daily enterally), nystatin ( 2 million units four times daily enterally), or no antifungal until ICU discharge. Reported baseline characteristics included mean age (54 in the clotrimazole group, 57 in the ketoconazole group, 53 in the nystatin group, 54 in the control group), sex (166 men and 126 women), median APACHE II score (12 in the clotrimazole group, 10 in the ketoconazole group, 12 in the nystatin group, 11 in the control group).

Schuster 2008 included 270 febrile people aged 18 years or older, admitted to 26 ICUs in United States with a predicted ICU stay of at least 96 consecutive hours and an APACHE II score of at least 16 within 24 hours from admission. All participants had a central venous catheter for at least 24 hours and received broad spectrum antibiotics for at least four days. Baseline characteristics reported in the analysis included mean age (53 in the treatment group and 51 in the placebo group), sex (192 men and 57 women), median APACHE II score (22 in the treated group and 20 in the placebo group). Participants were randomized to receive either fluconazole (800 mg daily intravenously) or placebo for 14 days. The sponsor (Pfizer) monitored the trial, assisted the investigators in protocol development and creation of a case report form, provided the study drug, maintained the database and assisted in analysis.

Slotman 1987 included 74 people admitted to a single surgical ICU in the United States without fungal colonization and with at least three of the following risk factors: age greater than 40 years, second- and third-degree burns covering greater than $30 \%$ of body surface area, antibiotics for more than seven days, three or more antibiotics, severe sepsis unresponsive to antibiotics, diabetes, steroids for more than seven days, acute renal failure, immunosuppressive therapy or chemotherapy, advanced malignancy, total parenteral nutrition, multi trauma, serum glucose greater than $11.1 \mathrm{mmol} / \mathrm{L}$, intra-abdominal abscess, peritonitis, or severe head injury. Median age was 65 in the treatment group and 59 in the placebo group. Participants colonized with Candida at baseline were excluded from the analysis by the authors. Participants were randomized to receive either ketoconazole (200 mg daily enterally) or placebo for 21 days or until ICU discharge. This study was supported by Janssen Pharmaceutica.

Yu 1993 included 54 people with surgical sepsis aged at least 16 years admitted to a single surgical ICU in United States. 
Reported baseline characteristics included mean age (48 years in the treatment group, 58 in the placebo group), sex (38 men, 16 women), mean APACHE II score (12 in the treatment group, 14 in the placebo group). Participants were randomized to receive either ketoconazole (400 mg daily enterally) or placebo for 21 days or until ICU discharge. The investigators began with a $200 \mathrm{mg}$ daily dose of ketoconazole, also administered enterally, but the dose was doubled after the first five participants were treated because of low serum concentrations of the drug. This study investigated the effect of ketoconazole for preventing ARDS in surgical septic participants basing on its anti-inflammatory activity. Thus, the antifungal activity of ketoconazole was not tested directly. This study was supported by Janssen Pharmaceutica.

In all the studies included in the quantitative analysis, the intervention (any antifungal drug for untargeted treatment, either systemic or nonabsorbable) was compared to placebo or no antifungal. We did not find any study eligible for inclusion in the quantitative analysis comparing the effect of two or more different antifungal drugs or regimens.

\section{Excluded studies}

We excluded a total of 18 studies after the review of full records. (See Characteristics of excluded studies). Two studies were not randomized trials (Azoulay 2011; NCT00689338). Three studies were excluded because the population was ineligible (Daeem 2012; Latif 2012; Restrepo 2010). We excluded 10 studies because the interventions studied were not eligible (Aerdts 1991; Blair 1991; De Jonge 2003; Hanson 2011; Milanov 2010; Milanov 2013; NCT00163111; NCT01524081; Sorkine 1996; Wang 2009). One study was excluded since it did not include relevant outcomes (NCT01045798). Two studies were excluded because the results were not available after contacting both study investigators and sponsors (NCT00095316; NCT00099775).

\section{Ongoing studies}

We identified two ongoing studies (see Characteristics of ongoing studies). In one of the ongoing studies, febrile participants aged 18 years or older and suspected of suffering from an IFI are randomized to receive either a step-down therapy consisting on micafungin followed by fluconazole or fluconazole (or other azoles) monotherapy (Lass-Flörl 2013). The primary endpoint is the breakthrough of fungal infections. The expected sample size is 190 participants.

In another study, adult people admitted to 23 ICUs in France, mechanically ventilated for more than four days with sepsis of unknown origin and with at least one extra-digestive fungal colonization site and multiple organ failure, are eligible for randomization (Timsit 2012). Participants are randomized to receive either micafungin (100 mg daily for 14 days intravenously) or placebo. The primary outcome is survival at 28 days without proven invasive infection and breakthrough fungal infection occurring at least 48 hours after initiation of treatment. The expected sample size is 260 participants.

\section{Studies awaiting classification}

We classified four studies as awaiting classification (see Characteristics of studies awaiting classification). Two studies were identified through searching trial registries (Milesi 2002; Whitby 2005). In these cases, we could not know if the results were available. We identified two other studies in which it was not possible to evaluate the eligibility of the population (Chen 2013; Havlicek 2008). In all cases, we contacted the study authors and searched for other sources to get the necessary information without success.

\section{Risk of bias in included studies}

Full description of judgements regarding risk of bias can be found in the 'Risk of bias' tables following each study in Characteristics of included studies and in Figure 2 and Figure 3.

Figure 2. Risk of bias graph: review authors' judgements about each risk of bias item presented as percentages across all included studies.

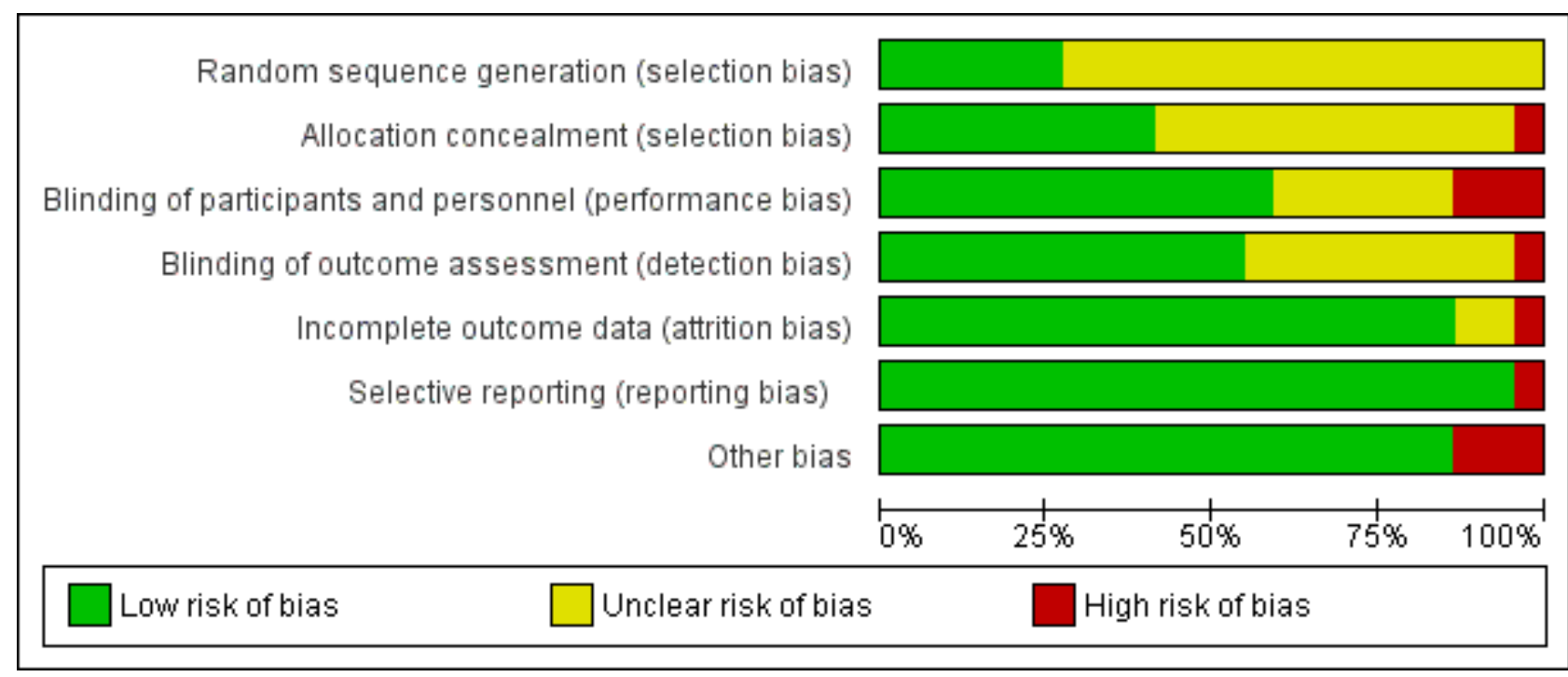


Figure 3. Risk of bias summary: review authors' judgements about each risk of bias item for each included study.

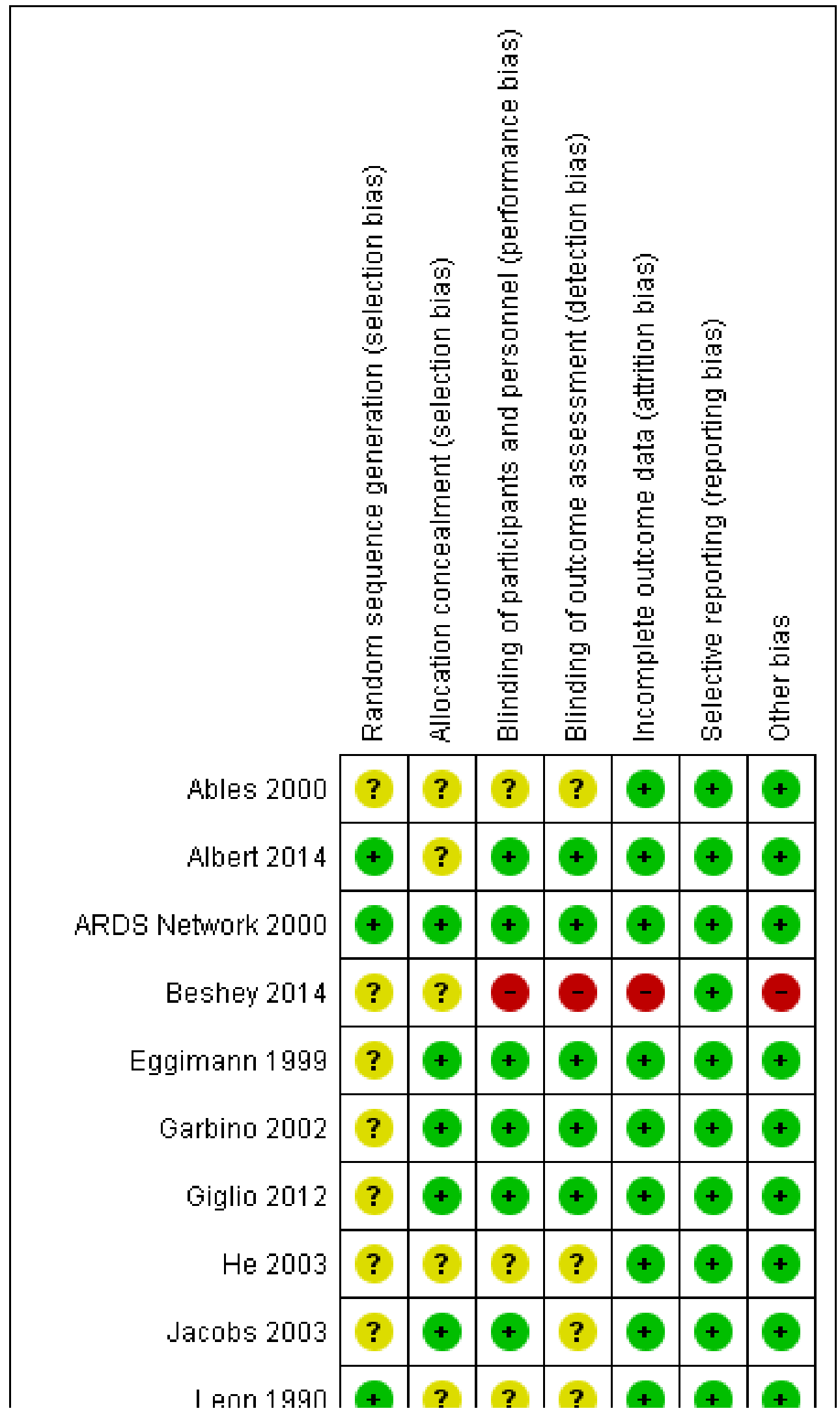


Figure 3. (Continued)

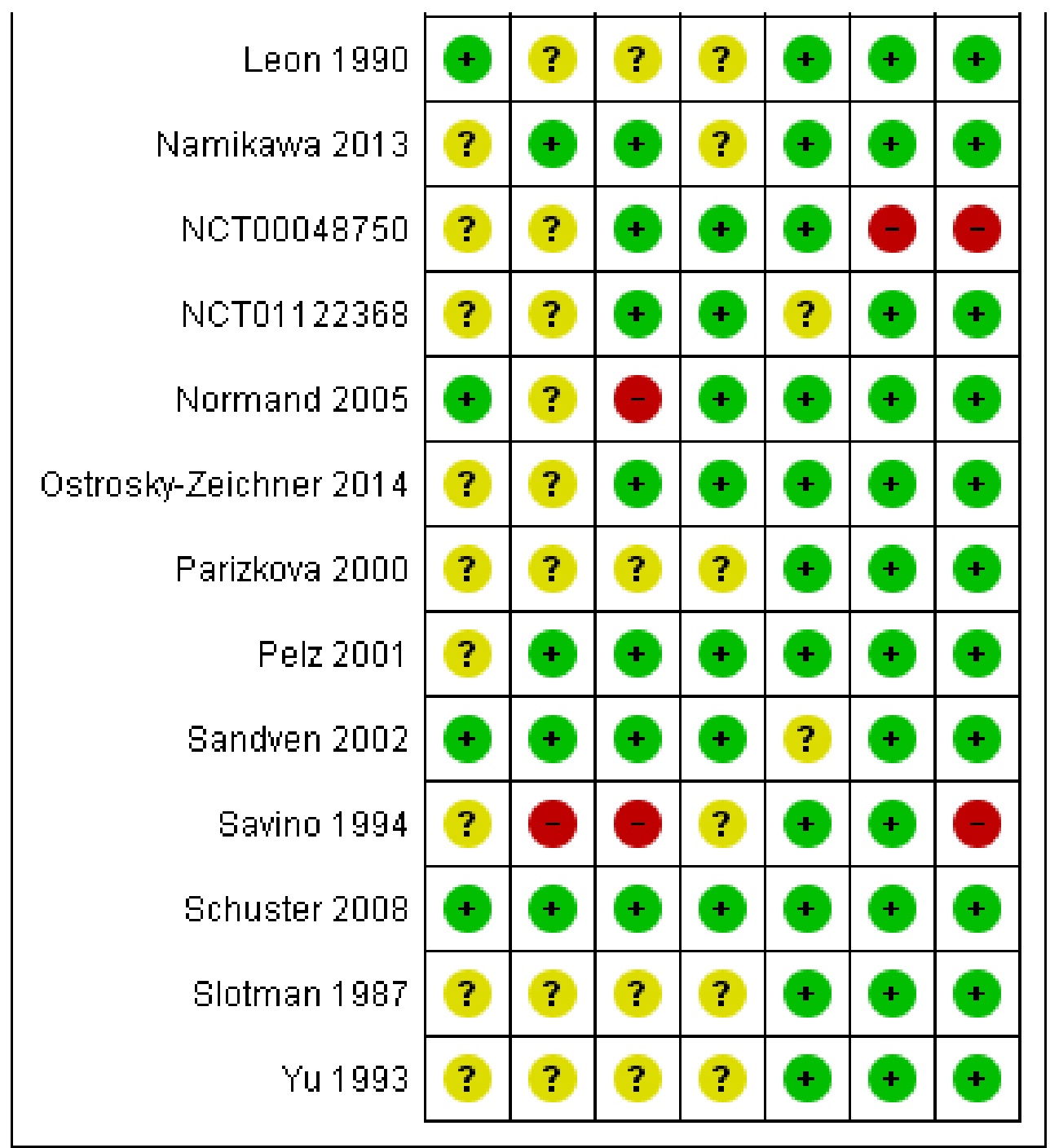

\section{Allocation}

Adequate random sequence generation was reported in details in six studies (Albert 2014; ARDS Network 2000; Leon 1990; Normand 2005; Sandven 2002; Schuster 2008). In four studies a computergenerated randomization sequence was adopted (Albert 2014; ARDS Network 2000; Normand 2005; Schuster 2008). In one study, a randomization table was used (Leon 1990); and in another study a random number generator was adopted (Sandven 2002). According to the information provided, these trials were judged to have a low risk of bias due to inadequate randomization. In eight studies a description of both method and type of the randomization was partially missing (Eggimann 1999; Garbino 2002; Giglio 2012; Jacobs 2003; NCT00048750; Namikawa 2013; Ostrosky-Zeichner 2014; Pelz 2001). Moreover, in seven studies it was almost completely lacking (Ables 2000; Beshey 2014; He 2003; NCT01122368; Parizkova 2000; Slotman 1987; Yu 1993). In another study, the description of the randomization process provided by the study authors was not clear enough to permit a judgement (Savino 1994). These 16 studies were judged to be at unclear risk of selection bias due to inadequate randomization.
Regarding allocation concealment, nine studies described robust and appropriate methods (central allocation or randomization done by pharmacy or just after the enrolment of the participant) leading to a low risk of selection bias (ARDS Network 2000; Eggimann 1999; Garbino 2002; Giglio 2012; Jacobs 2003; Namikawa 2013; Pelz 2001; Sandven 2002; Schuster 2008). In twelve studies, the information provided was not sufficient to enable us to make a judgement leading to the assignment of an unclear risk of selection bias due to inadequate allocation concealment (Ables 2000; Albert 2014; Beshey 2014; NCT00048750; He 2003; Leon 1990; NCT01122368; Normand 2005; Ostrosky-Zeichner 2014; Parizkova 2000; Slotman 1987; Yu 1993). In one study, there was a high risk of inadequate allocation concealment due to a reallocation of already randomized participants presenting specific clinical criteria to the other treatment groups (Savino 1994).

\section{Blinding}

Eleven studies provided appropriate detail concerning blinding of personnel and outcome assessors and were judged to be at low risk of bias in these domains (Albert 2014; ARDS Network 2000; Eggimann 1999; Garbino 2002; Giglio 2012; NCT00048750; 
NCT01122368; Ostrosky-Zeichner 2014; Pelz 2001; Sandven 2002; Schuster 2008). In two studies blinding of personnel was adequate but it was not clear if the outcome assessors were blinded (Jacobs 2003; Namikawa 2013). Six studies did not report enough information about blinding; they were also judged at unclear risk of both performance and detection bias (Ables 2000; He 2003; Leon 1990; Parizkova 2000; Slotman 1987; Yu 1993). In one study there was a high risk of inadequate blinding of personnel and a low risk of detection bias due to blinding of outcome assessors (Normand 2005). In the study by Savino 1994 there was a high risk of inadequate blinding of personnel and it was also unclear if the outcome assessors were blinded to treatment assignment. In the study by Beshey 2014 blinding of personnel and outcome assessors was lacking, leading to a high risk of both performance and detection bias.

\section{Incomplete outcome data}

In 10 studies no missing outcome data were observed leading to a low risk of bias (Albert 2014; ARDS Network 2000; He 2003; Jacobs 2003; Leon 1990; Namikawa 2013; Pelz 2001; Parizkova 2000; Savino 1994; Yu 1993). In seven studies missing data were balanced in numbers across groups and a low risk of bias was then attributed (Ables 2000; Eggimann 1999; Garbino 2002; Giglio 2012; Normand 2005; Ostrosky-Zeichner 2014; Schuster 2008). In one study there was no description of data about participants who had been initially randomized but died or were discharged before the end of the study period (Beshey 2014). Even though the authors pre-specified the exclusion of participants who would have not completed the study period, we believe this could have biased the results due to a high risk of incomplete outcome data.

In one study missing data were unlikely to be related to true outcome, leading to a low risk of bias (NCT00048750). In one study reasons for exclusion of participants were pre-specified and they were excluded retrospectively; for this reason we attributed a low risk of attrition bias (Slotman 1987). In one study insufficient information to establish the potential risk of incomplete outcome data were provided, leading to an unclear risk of bias (NCT01122368). In another study authors did not provide sufficient information on whether the exclusion of eight participants happened before or after the randomization and we assigned an unclear risk of bias for this reason (Sandven 2002).

\section{Selective reporting}

In four studies the protocol was available and all pre-specified outcomes were reported (Albert 2014; Giglio 2012; NCT01122368; Ostrosky-Zeichner 2014). In 17 studies a protocol was not available but the published reports included all the expected outcomes (Ables 2000; ARDS Network 2000; Beshey 2014; Eggimann 1999; Garbino 2002; He 2003; Jacobs 2003; Leon 1990; Namikawa 2013; Normand 2005; Parizkova 2000; Pelz 2001; Sandven 2002; Savino 1994; Schuster 2008; Slotman 1987; Yu 1993). In one study an outcome described in the protocol was not reported in the results and we assigned a high risk of reporting bias for this reason (NCT00048750).

\section{Other potential sources of bias}

In 19 studies no other potential sources of bias were detected leading to a low risk of other bias (Ables 2000; Albert 2014; ARDS Network 2000; Eggimann 1999; Garbino 2002; Giglio 2012; He 2003; Jacobs 2003; Leon 1990; Namikawa 2013; NCT01122368; Normand 2005; Ostrosky-Zeichner 2014; Parizkova 2000; Pelz 2001; Sandven 2002; Schuster 2008; Slotman 1987; Yu 1993). In one study, participants received the intervention on admission to ICU although the inclusion criteria stated the need for at least 48 hours of mechanical ventilation for inclusion; thus, there seems to be unclear relationships between inclusion, randomization, allocation concealment and timing of treatment (Beshey 2014). In one study a sample size of 600 participants was originally planned; however, after a data review, a low incidence of fungal endpoints was observed due to a low recruitment rate (NCT00048750). This was attributed to the off-study administration of antifungals to truly high risk participants in the participating centres and the study was terminated. After consensus, we decided to consider this study at high risk of other bias for this reason. In another study, participants with altered liver function were not allocated in one treatment group (ketoconazole) leading to a potential unbalanced allocation of most critically ill people (Savino 1994).

\section{Effects of interventions}

See: Summary of findings for the main comparison Untargeted antifungal treatment with any antifungal drug (systemic or nonabsorbable) compared to placebo/no antifungal/any other antifungal in non-neutropenic critically ill patients

\section{Primary outcomes}

\section{Total (all-cause) mortality}

\section{(See Analysis 1.1)}

The mortality analysis involved 2374 participants from 19 studies (Ables 2000; Albert 2014; ARDS Network 2000; Eggimann 1999; Garbino 2002; Giglio 2012; Jacobs 2003; Leon 1990; Namikawa 2013; NCT00048750; NCT01122368; Normand 2005; OstroskyZeichner 2014; Parizkova 2000; Pelz 2001; Sandven 2002; Schuster 2008; Slotman 1987; Yu 1993). Of these participants 1186 were allocated to the untargeted antifungal treatment group and 1188 to the placebo/no antifungal/any other antifungal group. Overall, $564 / 2374(23.8 \%)$ died during the study period, $274 / 1186(23.1 \%)$ in the treatment group and $290 / 1188(24.4 \%)$ in the other group. This difference was not statistically significant. The risk ratio (RR) of dying if allocated to the untargeted antifungal treatment group compared to the other group was $0.93(95 \% \mathrm{Cl} 0.79$ to $1.09, \mathrm{P}$ value $=$ $0.36, I^{2}$ statistic $\left.=16 \%\right)$. There is no statistically significant difference in the treatment effect on mortality according to the drug used in the treatment group (Figure 4). The funnel plot for this outcome was symmetrical. The quality of evidence was moderate because most of the studies contributing to this outcome had an overall unclear risk of bias. 
Figure 4. Forest plot of comparison: 1 Untargeted treatment with any antifungal drug (systemic or nonabsorbable) compared to placebo/no antifungal/any other antifungal, outcome: 1.1 Mortality.

\begin{tabular}{|c|c|c|c|c|c|c|c|}
\hline Study or Subgroup & \multicolumn{2}{|c|}{ Antifungal } & Control & ol & Weight & $\begin{array}{c}\text { Risk Ratio } \\
\text { M-H, Random, 95\% Cl }\end{array}$ & $\begin{array}{c}\text { Risk Ratio } \\
\text { M-H, Random, } 95 \% \mathrm{Cl}\end{array}$ \\
\hline \multicolumn{7}{|l|}{ 1.1.1 Fluconazole } & \\
\hline Ables 2000 & 12 & 60 & 12 & 60 & $4.5 \%$ & $1.00[0.49,2.05]$ & \\
\hline Eggimann 1999 & 7 & 23 & 10 & 20 & $4.1 \%$ & $0.61[0.29,1.30]$ & \\
\hline Garbino 2002 & 41 & 105 & 43 & 103 & $14.7 \%$ & $0.94[0.67,1.30]$ & \\
\hline Jacobs 2003 & 7 & 32 & 21 & 39 & $4.5 \%$ & $0.41[0.20,0.83]$ & $\longrightarrow$ \\
\hline Namikawa 2013 & 0 & 13 & 0 & 13 & & Not estimable & \\
\hline Parizkova 2000 & 4 & 18 & 0 & 20 & $0.3 \%$ & $9.95[0.57,172.84]$ & \\
\hline Pelz 2001 & 14 & 130 & 16 & 130 & $5.0 \%$ & $0.88[0.45,1.72]$ & \\
\hline Sandven 2002 & 4 & 53 & 8 & 56 & $1.9 \%$ & $0.53[0.17,1.65]$ & \\
\hline $\begin{array}{l}\text { Schuster } 2008 \\
\text { Subtotal (95\% Cl) }\end{array}$ & 29 & $\begin{array}{l}124 \\
558\end{array}$ & 22 & $\begin{array}{l}131 \\
572\end{array}$ & $\begin{array}{r}8.3 \% \\
43.5 \%\end{array}$ & $\begin{array}{l}1.39[0.85,2.29] \\
\mathbf{0 . 8 6}[\mathbf{0 . 6 2}, \mathbf{1 . 1 8}]\end{array}$ & \\
\hline \multicolumn{8}{|c|}{$\begin{array}{l}\text { Heterogeneity: } \text { Tau }^{2}=0.09 ; \mathrm{Chi}^{2}=12.46, \mathrm{df}=7(P=0.09) ; I^{2}=44 \% \\
\text { Test for overall effect: } Z=0.95(P=0.34)\end{array}$} \\
\hline \multicolumn{8}{|l|}{ 1.1.2 Ketoconazole } \\
\hline ARDS Network 2000 & 41 & 117 & 40 & 117 & $13.6 \%$ & $1.02[0.72,1.46]$ & \\
\hline Slotman 1987 & 11 & 35 & 15 & 36 & $5.8 \%$ & $0.75[0.40,1.41]$ & \\
\hline $\begin{array}{l}\text { Yu } 1993 \\
\text { Subtotal (95\% Cl) }\end{array}$ & 4 & $\begin{array}{r}26 \\
178\end{array}$ & 11 & $\begin{array}{r}28 \\
181\end{array}$ & $\begin{array}{r}2.4 \% \\
21.8 \%\end{array}$ & $\begin{array}{l}0.39[0.14,1.08] \\
\mathbf{0 . 8 0}[0.51,1.26]\end{array}$ & \\
\hline $\begin{array}{l}\text { Total events } \\
\text { Heterogeneity: } \operatorname{Tau}^{2}=0.0 \\
\text { Test for overall effect: } Z=\end{array}$ & $\begin{array}{c}56 \\
\mathrm{Chi}^{2}=3 \\
97(\mathrm{P}=0\end{array}$ & $\begin{array}{l}44, d f= \\
.33)\end{array}$ & $\begin{array}{c}66 \\
2(P=0\end{array}$ & $18) ;\left.\right|^{2}=$ & $=42 \%$ & & \\
\hline \multicolumn{8}{|l|}{ 1.1.3 Caspofungin } \\
\hline $\begin{array}{l}\text { Ostrosky-Zeichner } 2014 \\
\text { Subtotal }(95 \% \mathrm{Cl})\end{array}$ & 24 & $\begin{array}{l}117 \\
117\end{array}$ & 16 & $\begin{array}{l}102 \\
102\end{array}$ & $\begin{array}{l}6.6 \% \\
6.6 \%\end{array}$ & $\begin{array}{r}1.31[0.74,2.32] \\
1.31[0.74,2.32]\end{array}$ & \\
\hline $\begin{array}{l}\text { Total events } \\
\text { Heterogeneity: Not applic } \\
\text { Test for overall effect: } Z=\end{array}$ & $\begin{array}{l}24 \\
\text { ble } \\
92(P=0\end{array}$ & .36) & 16 & & & & \\
\hline \multicolumn{8}{|l|}{ 1.1.4 Micafungin } \\
\hline NCT00048750 & 5 & 51 & 8 & 51 & $2.3 \%$ & $0.63[0.22,1.78]$ & \\
\hline $\begin{array}{l}\text { NCT01122368 } \\
\text { Subtotal (95\% Cl) }\end{array}$ & 31 & $\begin{array}{l}122 \\
173\end{array}$ & 28 & $\begin{array}{l}126 \\
177\end{array}$ & $\begin{array}{r}9.8 \% \\
12.1 \%\end{array}$ & $\begin{array}{l}1.14[0.73,1.79] \\
1.03[0.65,1.62]\end{array}$ & \\
\hline $\begin{array}{l}\text { Total events } \\
\text { Heterogeneity: } \operatorname{Tau}^{2}=0.0 \\
\text { Test for overall effect: } Z=\end{array}$ & $\begin{array}{c}36 \\
\mathrm{Chi}^{2}=1 \\
11(\mathrm{P}=0\end{array}$ & $\begin{array}{l}09, \mathrm{df}= \\
.92)\end{array}$ & $\begin{array}{c}36 \\
=1(P=0\end{array}$ & $.30) ;\left.\right|^{2}=$ & $=8 \%$ & & \\
\hline \multicolumn{8}{|l|}{ 1.1.5 Amphotericin B } \\
\hline $\begin{array}{l}\text { Leon } 1990 \\
\text { Subtotal }(\mathbf{9 5} \% \mathrm{Cl})\end{array}$ & 6 & $\begin{array}{l}24 \\
24\end{array}$ & 4 & $\begin{array}{l}27 \\
27\end{array}$ & $\begin{array}{l}1.9 \% \\
1.9 \%\end{array}$ & $\begin{array}{c}1.69[0.54,5.27] \\
1.69[0.54,5.27]\end{array}$ & \\
\hline $\begin{array}{l}\text { Total events } \\
\text { Heterogeneity: Not applic } \\
\text { Test for overall effect: } Z=\end{array}$ & $\begin{array}{l}\quad 6 \\
\text { ble } \\
90(P=0\end{array}$ & & 4 & & & & \\
\hline \multicolumn{8}{|l|}{ 1.1.6 Nystatin } \\
\hline Giglio 2012 & 14 & 54 & 15 & 53 & $5.8 \%$ & $0.92[0.49,1.71]$ & \\
\hline $\begin{array}{l}\text { Normand } 2005 \\
\text { Subtotal }(95 \% \mathrm{Cl})\end{array}$ & 13 & $\begin{array}{r}51 \\
105\end{array}$ & 15 & $\begin{array}{r}47 \\
100\end{array}$ & $\begin{array}{r}5.7 \% \\
11.5 \%\end{array}$ & $\begin{array}{l}0.80[0.43,1.50] \\
\mathbf{0 . 8 6}[0.55, \mathbf{1 . 3 3}]\end{array}$ & \\
\hline $\begin{array}{l}\text { Total events } \\
\text { Heterogeneity: } \operatorname{Tau}^{2}=0.0 \\
\text { Test for overall effect: } Z=\end{array}$ & $\begin{array}{c}27 \\
\mathrm{Chi}^{2}=0 \\
69(\mathrm{P}=0\end{array}$ & $\begin{array}{l}09, \mathrm{df}= \\
.49)\end{array}$ & $\begin{array}{c}30 \\
=1(P=0\end{array}$ & $.76) ; 1^{2}=$ & $=0 \%$ & & \\
\hline 1.1.7 Anidulafungin & & & & & & & \\
\hline $\begin{array}{l}\text { Albert } 2014 \\
\text { Subtotal }(95 \% \mathrm{Cl})\end{array}$ & 7 & $\begin{array}{l}31 \\
31\end{array}$ & 6 & $\begin{array}{l}29 \\
29\end{array}$ & $\begin{array}{l}2.6 \% \\
2.6 \%\end{array}$ & $\begin{array}{l}1.09[0.42,2.87] \\
1.09[0.42,2.87]\end{array}$ & \\
\hline $\begin{array}{l}\text { Total events } \\
\text { Heterogeneity: Not applic } \\
\text { Test for overall effect: } Z=\end{array}$ & $\begin{array}{l}\quad 7 \\
\text { ble } \\
18(P=0\end{array}$ & $.86)$ & 6 & & & & \\
\hline Total $(95 \% \mathrm{Cl})$ & & 1186 & & 1188 & $100.0 \%$ & $0.93[0.79,1.09]$ & \\
\hline
\end{tabular}




\section{Figure 4. (Continued)}

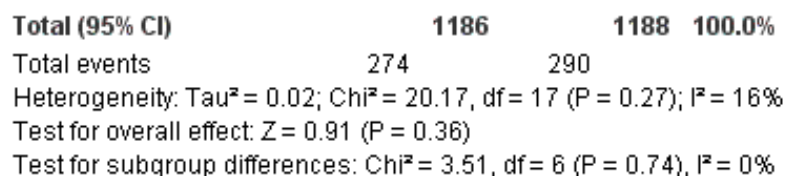

\section{Proven invasive fungal infection}

(See Analysis 1.2)

This outcome involved 2024 participants from 17 studies, 1009 allocated to the untargeted antifungal group and 1015 in the other group (Ables 2000; Eggimann 1999; Garbino 2002; Giglio 2012; He 2003; Jacobs 2003; Leon 1990; Namikawa 2013; NCT00048750; NCT01122368; Normand 2005; Ostrosky-Zeichner 2014; Parizkova 2000; Pelz 2001; Sandven 2002; Schuster 2008; Slotman 1987). In total, 162 proven IFI were reported, $57(35.2 \%)$ in the treatment group and $105(64.8 \%)$ in the other group. The risk of developing a
$0.93[0.79,1.09]$

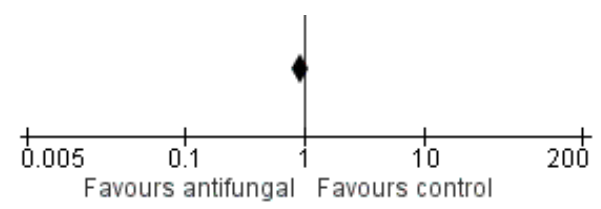

proven IFI if allocated to the untargeted antifungal treatment group compared to other group was statistically significantly reduced, with a RR of $0.57\left(95 \% \mathrm{Cl} 0.39\right.$ to $0.83, \mathrm{P}$ value $=0.003, \mathrm{I}^{2}$ statistic $=$ $27 \%)$.

According to the drug used for the untargeted treatment, a statistically significant effect was observed for fluconazole (RR 0.45 , $95 \% \mathrm{Cl} 0.30$ to 0.68 ; studies $=10, \mathrm{P}$ value $=0.0001, \mathrm{I}^{2}$ statistic $\left.=0 \%\right)$ and for caspofungin in the only study included investigating its use (RR 0.12, 95\% Cl 0.02 to 0.97 ; $\mathrm{P}$ value $=0.05$ ) (Figure 5). For this outcome, the test for subgroup difference, according to the drug used, was significant $\left(\mathrm{P}\right.$ value $=0.04, \mathrm{I}^{2}$ statistic $\left.=60.1 \%\right)$. 
Figure 5. Forest plot of comparison: 1 Untargeted antifungal treatment with any antifungal drug (systemic or nonabsorbable) compared to placebo/no antifungal/any other antifungal, outcome: 1.2 Proven invasive fungal infection

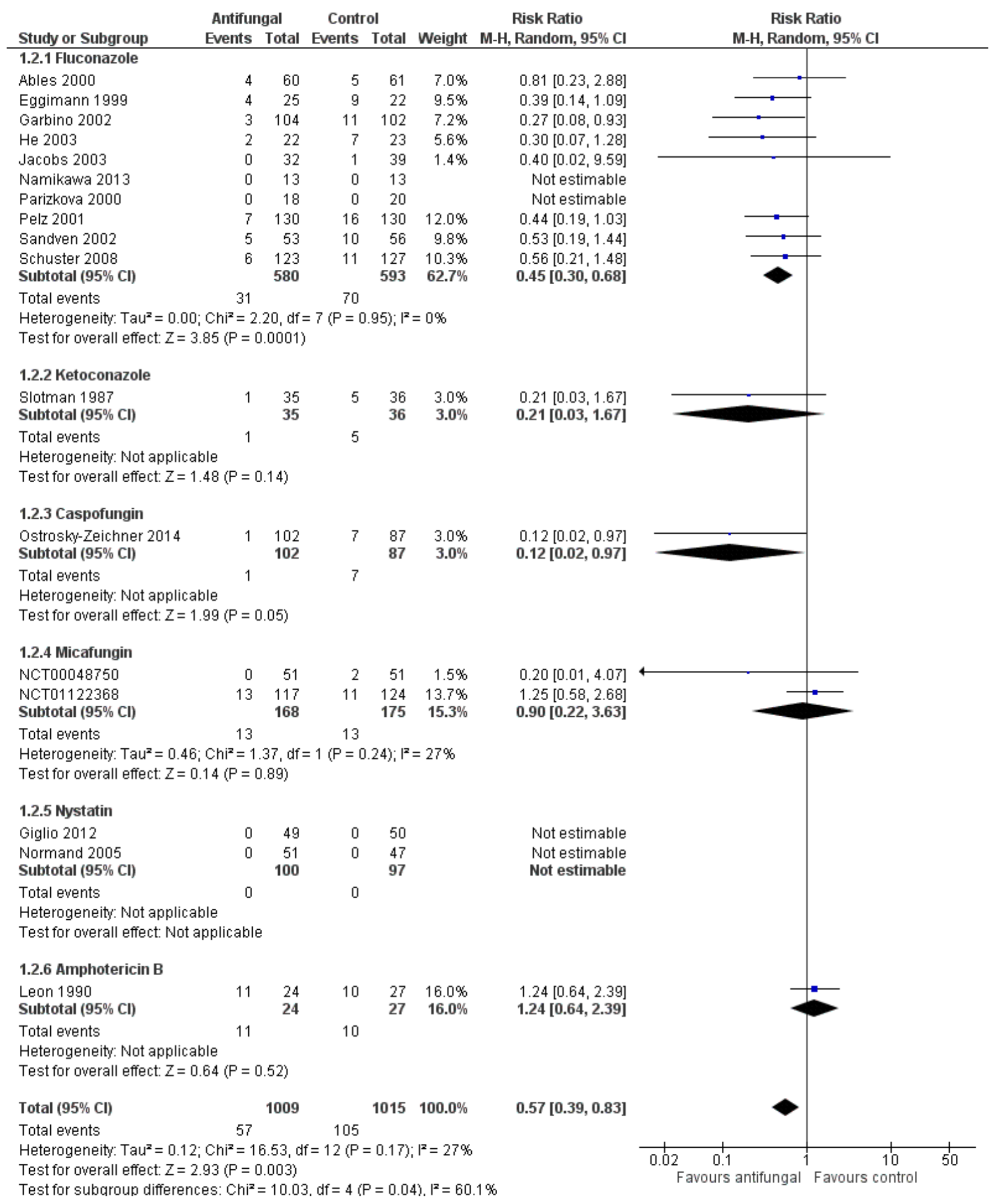


The quality of evidence was low due to the unclear risk of bias of the contributing studies and the potential for publication bias detected through the observation of asymmetry of the funnel plot (Figure 6).

Figure 6. Funnel plot of comparison: 1 Untargeted antifungal treatment with any antifungal drug (systemic or nonabsorbable) compared to placebo/no antifungal/any other antifungal, outcome: 1.2 Proven invasive fungal infection.

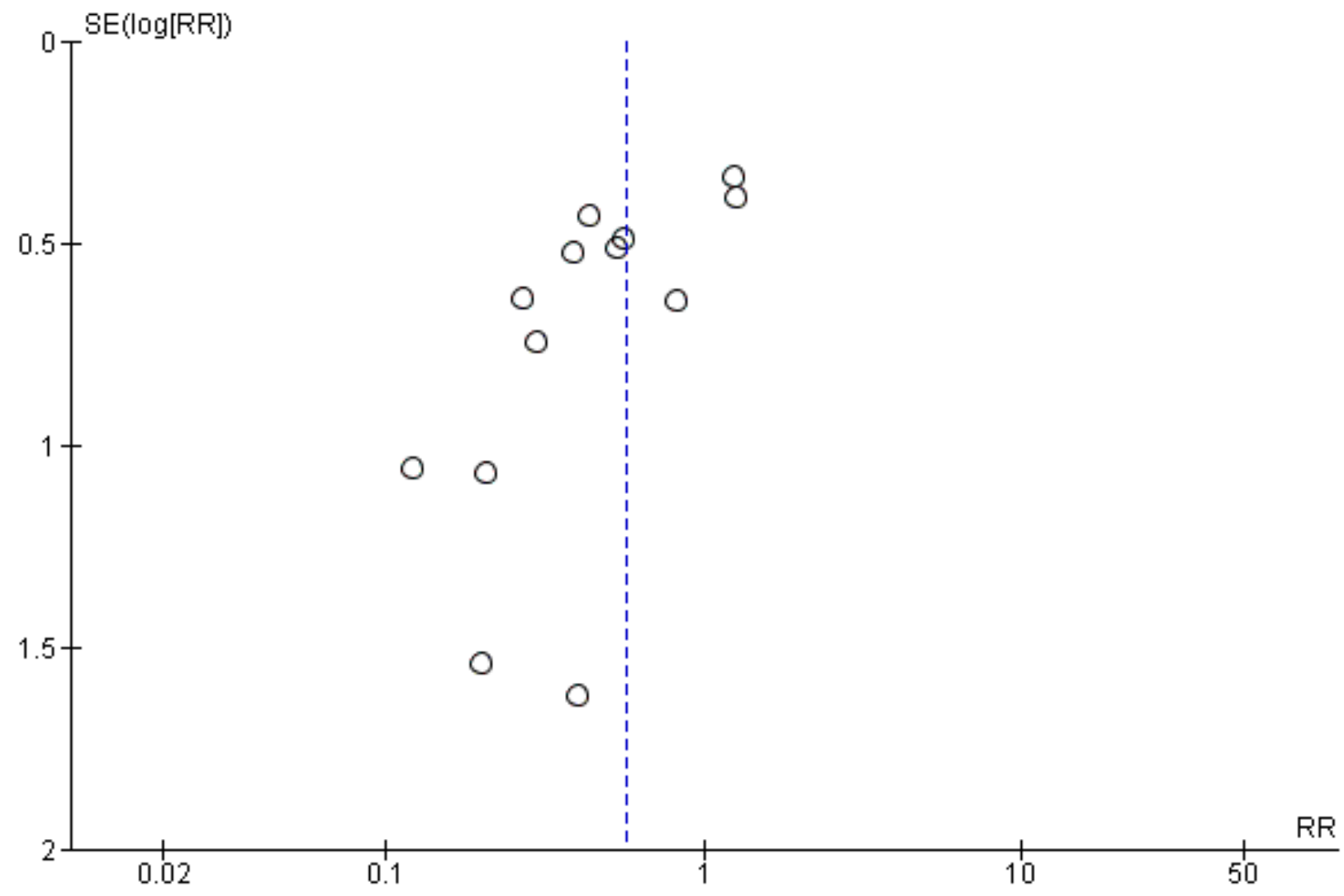

\section{Secondary outcomes}

\section{Proven or suspected invasive fungal infection}

\section{(See Analysis 1.3)}

Five studies reported this outcome with a total of 911 participants (Ables 2000; Garbino 2002; Pelz 2001; Sandven 2002; Schuster 2008). Fifty-three proven or suspected IFI were reported in the untargeted antifungal treatment group and 84 in the other group. The RR of developing proven or suspected IFI in the treatment group compared to the other group was $0.63(95 \% \mathrm{Cl} 0.39$ to $1.00 ; \mathrm{P}$ value $=0.05, I^{2}$ statistic $=45 \%$ ).

\section{Suspected fungal infection}

\section{(See Analysis 1.4)}

Five studies reported this outcome including 911 participants, 462 in the treatment group and 449 in the control group (Ables 2000; Garbino 2002; Ostrosky-Zeichner 2014; Pelz 2001; Sandven 2002). A total of 68 suspected fungal infections were observed, 33 in the untargeted antifungal treatment group and 35 in the other group. The risk of developing a suspected fungal infection was not statistically significant with a RR of 0.94 (95\% Cl 0.38 to 2.32; P value $=0.89$ ). There was a significant statistical heterogeneity across studies reporting this outcome $\left(I^{2}\right.$ statistic $\left.=43 \%\right)$. The quality of evidence for this outcome was low. All the five studies contributing to this result had an unclear risk of bias leading to a downgrade. Moreover, the total number of participants and events from studies contributing to this result were less than the number which would be generated for the calculation of the optimal information size. We applied a further downgrading for this reason.

\section{Superficial fungal infection}

\section{(See Analysis 1.5)}

Five studies reported this outcome with a total of 38 events from 662 participants (Ables 2000; Garbino 2002; Leon 1990; Namikawa 2013; Pelz 2001). Fifteen superficial fungal infections occurred in the 331 participants treated with the untargeted antifungal treatment and 23 occurred in the other group including 331 participants. The risk of developing a superficial fungal infection was not statistically significantly different between the two groups (RR 0.69, 95\% Cl 0.37 to $1.29 ; \mathrm{P}$ value $=0.24, \mathrm{I}^{2}$ statistic $=0 \%$ ). 


\section{Fungal colonization}

\section{(See Analysis 1.6)}

Twelve studies reported this outcome involving 1030 participants, 510 in the untargeted antifungal treatment group and 520 in the other group (Ables 2000; Albert 2014; Eggimann 1999; Garbino 2002; Giglio 2012; Jacobs 2003; Namikawa 2013; NCT00048750; NCT01122368; Parizkova 2000; Slotman 1987; Yu 1993). In the intervention group, 145 participants developed a fungal colonization in comparison to 204 participants in the other group. The RR of developing fungal colonization if allocated to the untargeted treatment group was $0.71(95 \% \mathrm{Cl} 0.52$ to 0.97 ; P value $=0.03$ ). The quality of evidence was rated as low as all studies that contributed to this result had an unclear risk of bias and a downgrading was applied. Moreover, we observed a significant statistical heterogeneity across studies $\left(I^{2}\right.$ statistic $\left.=78 \%\right)$ possibly linked to a clinical heterogeneity that could be explained by the adoption of different criteria for detection of colonization (e.g. different numbers of sites or different locations of sites (or both) analysed for fungal cultures). We applied a further downgrading for this reason.

\section{Proven invasive fungal infection (Azole-resistant Candida species)}

(See Analysis 1.7)

Eight studies reported this outcome including 1058 participants globally (524 in the treatment group and 534 in the other group) (Ables 2000; Eggimann 1999; Garbino 2002; Jacobs 2003; Parizkova 2000; Pelz 2001; Schuster 2008; Slotman 1987). Five proven IFIs by azole-resistant Candida species were described in the treatment group in comparison to 12 in the other group. The risk of developing a proven IFI due to azole-resistant Candida species for participants allocated in the untargeted antifungal treatment group was not statistically significant with a RR of $0.53(95 \% \mathrm{Cl} 0.20$ to 1.40 ; P value $=0.20, \mathrm{I}^{2}$ statistic $=0 \%$ )

\section{Fungal colonization (azole-resistant Candida species)}

(See Analysis 1.8)

Five studies reported this outcome including 409 participants, 203 in the untargeted antifungal treatment group and 206 in the other group (Ables 2000; Eggimann 1999; Garbino 2002; Parizkova 2000; Slotman 1987). Twenty-one participants colonized by azoleresistant Candida species were reported, nine in the treatment group and 12 in the control group. The RR of developing a fungal colonization by azole-resistant Candida species was $1.03(95 \% \mathrm{Cl}$ 0.34 to $3.12 ; \mathrm{P}$ value $=0.95, \mathrm{I}^{2}$ statistic $=21 \%$ ) .

\section{Adverse events requiring cessation of study drug(s)}

(See Analysis 1.9)

Eleven studies reported adverse events requiring cessation of the treatment, enrolling globally 1691 participants (853 in the untargeted antifungal treatment group and 838 in the other group) (Ables 2000; ARDS Network 2000; Eggimann 1999; Garbino 2002; Giglio 2012; NCT00048750; NCT01122368; Normand 2005; OstroskyZeichner 2014; Schuster 2008; Yu 1993). A total of 109 events were reported, 51 in the treatment group and 58 in the other group. The RR of developing an adverse event requiring cessation of treatment if receiving an untargeted antifungal treatment was $0.89\left(95 \% \mathrm{Cl} 0.62\right.$ to $1.27, \mathrm{P}$ value $=0.51, \mathrm{I}^{2}$ statistic $\left.=0 \%\right)$. We did not identify a statistically significant difference among the different drugs studied. The overall quality of evidence was low. We downgraded by one level for the unclear risk of bias of most studies contributing to this outcome. We further downgraded by another level due to the low number of total participants and events compared to the optimal information size.

\section{Subgroup analysis}

We conducted subgroup analysis assessing mortality and proven invasive fungal infection.

In subgroup analyses based on type of participants, the effect of untargeted treatment in studies with $75 \%$ or more of post-surgical participants was not statistically significantly different between the two groups for mortality (RR 0.81, 95\% Cl 0.60 to 1.08; Analysis 2.1.1; studies = seven, Eggimann 1999; Namikawa 2013; NCT01122368; Pelz 2001; Sandven 2002; Slotman 1987; Yu 1993), but significantly different for proven IFI (RR 0.57, 95\% Cl 0.33 to 0.99; Analysis 2.7.1; studies = six, Eggimann 1999; Namikawa 2013; NCT01122368; Pelz 2001; Sandven 2002; Slotman 1987). Concerning studies with fewer than $75 \%$ of post-surgical participants, the risk was not statistically significantly different between groups for both mortality (RR 1.00, $95 \% \mathrm{Cl} 0.78$ to 1.28; Analysis 2.1.2; studies = 10, Ables 2000; Albert 2014; Garbino 2002; Giglio 2012; Jacobs 2003; Leon 1990; Normand 2005; Ostrosky-Zeichner 2014; Parizkova 2000; Schuster 2008) and proven IFI (RR 0.57, 95\% Cl 0.29 to 1.15; Analysis 2.7.2; studies = nine, Ables 2000; Garbino 2002; Giglio 2012; Jacobs 2003; Leon 1990; Normand 2005; Ostrosky-Zeichner 2014; Parizkova 2000; Schuster 2008).

In the subgroup analysis for total fluconazole daily dose of $400 \mathrm{mg}$ or more used as untargeted treatment, the mortality risk was not statistically significantly different between groups (RR $0.95,95 \% \mathrm{Cl}$ 0.68 to 1.33; Analysis 2.2.1; studies = six, Ables 2000; Eggimann 1999; Namikawa 2013; Pelz 2001; Sandven 2002; Schuster 2008); whereas the risk of developing proven IFI was statistically significantly different (RR 0.51, 95\% Cl 0.32 to 0.79; Analysis 2.8.1; studies = six, Ables 2000; Eggimann 1999; Namikawa 2013; Pelz 2001; Sandven 2002; Schuster 2008). Concerning studies investigating a total daily dose of fluconazole of less than $400 \mathrm{mg}$, the risk for mortality was not statistically significantly different between groups (RR 0.82 , $95 \% \mathrm{Cl} 0.33$ to 2.03; Analysis 2.2.2; studies = three, Garbino 2002; Jacobs 2003; Parizkova 2000); whereas a statistically significant difference was noticed for proven IFI (RR $0.29,95 \% \mathrm{Cl} 0.12$ to 0.72 ; Analysis 2.8.2; studies = four, Garbino 2002; He 2003; Jacobs 2003; Parizkova 2000).

In the subgroup analysis for studies using systemic drugs, there was a statistically insignificant difference between the two groups for mortality (RR $0.91,95 \% \mathrm{Cl} 0.76$ to 1.11 ; Analysis 2.3.1; studies = 16, Ables 2000; Albert 2014; ARDS Network 2000; Eggimann 1999; Garbino 2002; Jacobs 2003; Namikawa 2013; NCT00048750; NCT01122368; Ostrosky-Zeichner 2014; Parizkova 2000; Pelz 2001; Sandven 2002; Schuster 2008; Slotman 1987; Yu 1993); but a significant difference for the risk of proven IFI (RR 0.52, 95\% Cl 0.37 to 0.73; Analysis 2.9.1; studies $=14$, Ables 2000; Eggimann 1999; Garbino 2002; He 2003; Jacobs 2003; Namikawa 2013; NCT00048750; NCT01122368; Ostrosky-Zeichner 2014; Parizkova 2000; Pelz 2001; Sandven 2002; Schuster 2008; Slotman 1987). Concerning the use of nonabsorbable drugs (nystatin and enteral amphotericin B) as antifungal for untargeted treatment, there was 
a statistically insignificant difference e between the two groups both for mortality risk (RR 0.94, 95\% Cl 0.62 to 1.41; Analysis 2.3.2; studies = three, Giglio 2012; Leon 1990; Normand 2005) and for proven IFI risk (RR 1.24, 95\% $\mathrm{Cl} 0.64$ to 2.39; Analysis 2.9.2; studies = three, Giglio 2012; Leon 1990; Normand 2005). Comparing the effect of systemic and nonabsorbable drugs, we obtained a statistically significant test for subgroup difference for proven IFI ( $P$ value $=0.02$; $1^{2}$ statistic $=80.9 \%$; Analysis 2.9).

In the subgroup analysis based on drug class, the effect of azole (fluconazole and ketoconazole) as untargeted treatment was not statistically significantly different between two groups for mortality (RR 0.84, 95\% Cl 0.67 to 1.07; Analysis 2.4.1; studies = 12, Ables 2000; ARDS Network 2000; Eggimann 1999; Garbino 2002; Jacobs 2003; Namikawa 2013; Parizkova 2000; Pelz 2001; Sandven 2002; Schuster 2008; Slotman 1987; Yu 1993) but statistically significantly different for proven IFI (RR $0.44,95 \% \mathrm{Cl} 0.30$ to 0.66 ; Analysis 2.10.1; studies = 11, Ables 2000; Eggimann 1999; Garbino 2002; He 2003; Jacobs 2003; Namikawa 2013; Parizkova 2000; Pelz 2001; Sandven 2002; Schuster 2008; Slotman 1987). The effect of echinocandins (caspofungin, micafungin, anidulafungin) was not statistically significantly different between groups for both mortality (RR 1.12, 95\% Cl 0.82 to 1.54; Analysis 2.4.2; studies = four, Albert 2014; NCT00048750; NCT01122368; Ostrosky-Zeichner 2014) and proven IFI (RR $0.42,95 \% \mathrm{Cl} 0.07$ to 2.46; Analysis 2.10.2; studies = three, NCT00048750; NCT01122368; Ostrosky-Zeichner 2014).

In the subgroup analysis for type of intervention, we evaluated the effect of prophylaxis and empiric treatment. Concerning the use of antifungal prophylaxis, there was no difference between the two groups for mortality (RR $0.92,95 \% \mathrm{Cl} 0.78$ to 1.09 ; Analysis 2.5.1; studies = 12, Ables 2000; ARDS Network 2000; Eggimann 1999; Garbino 2002; Giglio 2012; NCT00048750; Normand 2005 OstroskyZeichner 2014; Parizkova 2000; Pelz 2001; Sandven 2002; Slotman 1987); but a statistically significant difference for proven IFI (RR $0.39,95 \% \mathrm{Cl} 0.26$ to 0.60 ; Analysis 2.11.1; studies = 12, Ables 2000; Eggimann 1999; Garbino 2002; Giglio 2012; He 2003; NCT00048750; Normand 2005; Ostrosky-Zeichner 2014; Parizkova 2000; Pelz 2001; Sandven 2002; Slotman 1987). The effect of the empiric treatment was not statistically significantly different between groups for both mortality (RR 0.90, 95\% Cl 0.57 to 1.44; Analysis 2.5.2; studies = 6, Albert 2014; Jacobs 2003; Leon 1990; NCT01122368; Schuster 2008; Yu 1993) and proven IFI (RR 1.03, 95\% Cl 0.67 to 1.60; Analysis 2.11.2; studies = 4, Jacobs 2003; Leon 1990; NCT01122368; Schuster 2008). Comparing the effect of prophylaxis and empiric treatment, we calculated a statistically significant test for subgroup difference for proven IFI ( $\mathrm{P}$ value $=0.002 ; I^{2}$ statistic $=89.6 \%$; Analysis 2.11$)$.

In the subgroup analysis for type of control group, we assessed the effect of the intervention in studies having either placebo or no intervention as control group. Concerning studies having placebo as control group, there was no statistically significant difference between the two groups for mortality (RR 0.93, 95\% $\mathrm{Cl} 0.78$ to 1.11; Analysis 2.6.1; studies = 15, Ables 2000; Albert 2014; ARDS Network 2000; Eggimann 1999; Garbino 2002; Jacobs 2003; Leon 1990; NCT00048750; NCT01122368; Ostrosky-Zeichner 2014; Pelz 2001; Sandven 2002; Schuster 2008; Slotman 1987; Yu 1993), but a statistically significant difference for proven IFI (RR $0.59,95 \% \mathrm{Cl} 0.39$ to 0.87 ; Analysis 2.12.1; studies $=12$; Ables 2000; Eggimann 1999; Garbino 2002; Jacobs 2003; Leon 1990; NCT00048750; NCT01122368; Ostrosky-Zeichner 2014; Pelz 2001; Sandven 2002; Schuster 2008; Slotman 1987). Concerning studies having no intervention as control group, we found a statistically insignificant difference among the two groups for both mortality (RR 0.95, 95\% Cl 0.52 to 1.74; Analysis 2.6.2; studies = 4, Giglio 2012; Namikawa 2013; Normand 2005; Parizkova 2000) and proven IFI (RR $0.30,95 \% \mathrm{Cl} 0.07$ to 1.28; Analysis 2.12.2; studies = 5, Giglio 2012; He 2003; Namikawa 2013; Normand 2005; Parizkova 2000).

\section{Sensitivity analysis}

We evaluated mortality and proven IFI in studies using a fixedeffect model meta-analysis. Using this model, the risk for mortality remained not statistically significantly different between groups (RR 0.95, 95\% Cl 0.82 to 1.09; Analysis 3.1; studies = 19, Ables 2000; Albert 2014; ARDS Network 2000; Eggimann 1999; Garbino 2002; Giglio 2012; Jacobs 2003; Leon 1990; Namikawa 2013; NCT00048750; NCT01122368; Normand 2005; Ostrosky-Zeichner 2014; Parizkova 2000; Pelz 2001; Sandven 2002; Schuster 2008; Savino 1994; Yu 1993); and the risk of developing proven IFI remained statistically significantly different (RR $0.56,95 \% \mathrm{Cl} 0.42$ to 0.75; Analysis 3.4; studies = 17, Ables 2000; Eggimann 1999; Garbino 2002; Giglio 2012; He 2003; Jacobs 2003; Leon 1990; Namikawa 2013; NCT00048750; NCT01122368; Normand 2005; Ostrosky-Zeichner 2014; Parizkova 2000; Pelz 2001; Sandven 2002; Schuster 2008; Slotman 1987).

We also assessed the risk for both outcomes considering all studies whatever the risk of bias in key domains (random sequence generation, allocation concealment, incomplete data outcome). We obtained a statistically insignificant difference for mortality between groups (RR $0.93,95 \% \mathrm{Cl} 0.80$ to 1.08 ; Analysis 3.2; studies = 20, Ables 2000; Albert 2014; ARDS Network 2000; Eggimann 1999; Garbino 2002; Giglio 2012; Jacobs 2003; Leon 1990; Namikawa 2013; NCT00048750; NCT01122368; Normand 2005; OstroskyZeichner 2014; Parizkova 2000; Pelz 2001; Sandven 2002; Savino 1994; Schuster 2008; Slotman 1987; Yu 1993); and a statistically significant difference in risk of developing proven IFI (RR 0.55, $95 \% \mathrm{Cl} 0.38$ to 0.81 ; Analysis 3.5; studies $=19$, Ables 2000; Beshey 2014; Eggimann 1999; Garbino 2002; Giglio 2012; He 2003; Jacobs 2003; Leon 1990; Namikawa 2013; NCT00048750; NCT01122368; Normand 2005; Ostrosky-Zeichner 2014; Parizkova 2000; Pelz 2001; Sandven 2002; Savino 1994; Schuster 2008; Slotman 1987).

We analysed the risk for both outcomes considering only studies without any high risk of bias for key domains. The risk of mortality remained not statistically different (RR $0.94,95 \% \mathrm{Cl}$ 0.79 to 1.12; Analysis 3.3; studies = 17, Ables 2000; Albert 2014; ARDS Network 2000; Eggimann 1999; Garbino 2002; Giglio 2012; Jacobs 2003; Leon 1990; Namikawa 2013; NCT01122368; OstroskyZeichner 2014; Parizkova 2000; Pelz 2001; Sandven 2002; Schuster 2008; Slotman 1987; Yu 1993), whereas the risk of developing a proven IFI remained statistically different between groups (RR 0.59, $95 \% \mathrm{Cl} 0.40$ to 0.88; Analysis 3.6; studies = 14, Ables 2000; Eggimann 1999; Garbino 2002; Giglio 2012; He 2003; Jacobs 2003; Leon 1990; Namikawa 2013; NCT01122368; Ostrosky-Zeichner 2014; Parizkova 2000; Pelz 2001; Sandven 2002; Schuster 2008).

We also assessed the risk for mortality and proven IFI between groups considering studies with low versus unclear and high risk of bias in random sequence generation, allocation concealment, incomplete data outcome, blinding of outcome assessment. We reported the results in an additional table (see Table 1 ). 


\section{DISCUSSION}

\section{Summary of main results}

The effect estimates for main outcomes are detailed in Summary of findings for the main comparison.

We found moderate quality evidence from 19 studies (2374 participants) that the use of untargeted antifungal treatment in non-neutropenic critically ill patients was not associated with significant survival benefits since it did not significantly reduce or increase total (all-cause) mortality. Evidence from 17 studies in 2014 people showed that untargeted antifungal treatment may significantly reduce the incidence of invasive fungal infections (IFIs). The quality of evidence for this outcome was low. We found low-quality evidence that untargeted antifungal treatment may significantly reduce fungal colonization whereas it did not significantly reduce the incidence of superficial fungal infections. Moreover, we found low quality evidence, from 11 studies, supporting that there is no increase in the risk of adverse events requiring cessation of antifungal treatment. Evidence from included studies showed that the use of untargeted antifungal treatment did not significantly reduce or increase the incidence of IFIs by azole-resistant Candida species, fungal colonization by azole-resistant Candida species and suspected IFIs. The use of untargeted antifungal treatment did not significantly reduce the incidence of proven or suspected IFIs.

\section{Overall completeness and applicability of evidence}

The findings of this review need to be interpreted in light of the following considerations. Firstly, there is a lack of eligible high-quality randomized controlled trials addressing our outcomes of interest. Only two trials were judged to have an overall low risk of bias (ARDS Network 2000; Schuster 2008). Secondly, the overall effect of untargeted antifungal treatment came from studies investigating the use of different antifungal drugs covering a wide period of research. The effect of an untargeted antifungal treatment may be influenced by the type of drug used, due to fungal microbiological epidemiology and patterns of resistance to antimicrobials in different ICUs and hospitals (Kett 2011; Pfaller 2011). There was a predominence of studies investigating the use of fluconazole (and azoles in general). Other drugs were tested in few studies. The subgroup analyses, investigating the effects of azoles, echinocandins, systemic and nonabsorbable drugs separately, aimed to deal with this issue (see Analysis 2.3; Analysis 2.4; Analysis 2.9; Analysis 2.10). On the other hand, the participants included in this review seem to be representative of the general population of non-neutropenic critically ill people, due to the relatively high number of participants for both primary outcomes, different clinical characteristics and severity of illness, and the wide range of geographic locations of enrolling centres.

\section{Quality of the evidence}

The quality of the evidence contributing to the main outcomes is described in the Summary of findings for the main comparison. The overall quality of evidence contributing to the effect estimate for mortality was considered of moderate grade since most studies that contributed to this outcome had an unclear risk of bias and the quality of evidence was downgraded for this reason. For the outcome of proven IFI, the quality of evidence was rated low due to the unclear risk of bias of the contributing studies and the potential for publication bias detected through the observation of asymmetry of the funnel plot (Figure 6). A low quality of evidence was also attributed to the outcome of superficial fungal infection, since all five studies contributing to this result had an unclear risk of bias and downgrading was applied (Ables 2000; Garbino 2002; Leon 1990; Namikawa 2013; Pelz 2001). Moreover, the total number of participants and events from studies contributing to the outcome of superficial fungal infection was less than the number which would be generated for the calculation of the optimal information size: a further downgrading was applied for this reason. For the outcome of fungal colonization, the quality of evidence was rated as low as all studies that contributed to this result had an unclear risk of bias: a downgrading was applied. Moreover, a significant statistical heterogeneity across studies was observed. A clinical heterogeneity across studies investigating the outcome of fungal colonization may be explained by the adoption of different criteria for detection of colonization (e.g. different numbers of sites or different locations of sites (or both) analysed for fungal cultures); we applied a further downgrading for this reason. Regarding the outcome of adverse events requiring cessation of study drug, the overall quality of evidence was low. We downgraded by one level for the unclear risk of bias of most studies contributing to this outcome. We further downgraded by another level due to the low number of total participants and events compared to the optimal information size.

\section{Potential biases in the review process}

An unrestricted comprehensive literature search was conducted for both the original and the updated review aiming to minimize reporting and selection bias. We searched clinical trial registries from which we retrieved eligible studies with partial missing data (e.g. part of results and participants characteristics) (NCT00048750; NCT01122368). A reconsideration of these studies should be taken into account in light of their possible future peer-reviewed publication. As part of our search strategy, we contacted study authors, sponsors and pharmaceutical companies of studies reported as ongoing, or completed, but without published results. Moreover, we tried to obtain further information from authors of already published studies in cases of doubt about data. However, on some occasions we had incomplete correspondence. We also had incomplete correspondence regarding the studies awaiting classification (Chen 2013; Havlicek 2008; Milesi 2002; Whitby 2005). In two studies we could not ascertain the proportion of included patients with neutropenia even though results were available (Chen 2013; Havlicek 2008). We decided not to include these studies in order to avoid potential bias in the review process. In the other two studies we could not obtain necessary further information and results (Milesi 2002; Whitby 2005).

In some studies reporting fungal colonization, the outcome did not fit our definition (e.g. studies reporting number of colonized sites by fungi per participants or colonization index). Where possible, we obtained data suitable for our analysis from study authors upon request. However, when the number of participants with at least one colonized site was not available (see Types of outcome measures), this outcome was not considered for the quantitative analysis.

For each included study, we provided a definition for the type of untargeted antifungal treatment used (i.e. prophylactic, preemptive, empiric treatment) according to international guidelines (Cornely 2012). However, due to incomplete description of participants' characteristics and settings, this definition attribution 
was not always straightforward. It may be argued that the intervention studied in this review (untargeted antifungal treatment) encompassed three different treatment strategies possibly leading to heterogeneity. However, it should be considered that all three different antifungal strategies are used before the definitive proof of fungal infections and that is the reason why they are studied as a single intervention in both the original and updated review (Playford 2006a). These aspects should be considered by the reader when considering the results of the subgroup analysis according to the type of treatment.

\section{Agreements and disagreements with other studies or reviews}

Several systematic reviews studied the use of antifungal treatment for prevention of IFIs (Cruciani 2005; Ho 2005; Shorr 2005; Vardakas 2006). They all included critically ill surgical participants and most of their evidence was based on the use of azoles for prophylaxis. They showed a significant reduction of IFIs rate with an associated reduction of mortality risk observed only in one meta-analysis (Cruciani 2005). Of note, the results for IFIs were similar to that observed in subgroup analysis for azoles (see Analysis 2.10). However, our update encompasses a wider range of participants' characteristics (e.g. both medical and surgical critically ill participants) and this should be considered when these results are compared with those from our review. To our knowledge, there are no more recent systematic reviews investigating the use of azoles, echinocandins, nonabsorbable antifungal drugs as untargeted antifungal treatment in non-neutropenic adult critically ill patients. Systematic reviews on antifungal agents for prevention of fungal infections were conducted in many other settings including: low-birth weight infants (Austin 2013a; Austin 2013b), children (Blyth 2010), people affected by cancer (Robenshtok 2007; Gøtzsche 2014), solid organ transplant recipients (Cruciani 2006; Marino 2010; Playford 2004a). In low-birth weight infants and children the use of antifungal prophylaxis was not associated with a mortality reduction (Austin 2013a; Austin 2013b; Blyth 2010), whereas a reduction of IFIs was described (Austin 2013a; Austin 2013b). In people with cancer or who underwent hematopoietic stem-cell transplantation, a mortality reduction was observed with antifungal prophylaxis or empiric treatment (Gøtzsche 2014; Robenshtok 2007). A reduction of IFIs in people with cancer was observed after the use of amphotericin B, fluconazole and itraconazole but not with the use of ketoconazole or miconazole (Gøtzsche 2014). In people who underwent liver transplantation, a reduction of IFI, but not of mortality was reported after antifungal prophylaxis (Cruciani 2006). Due to the different settings and people's characteristics, a comparison of these results with those from this update is not feasible.

\section{AUTHORS' CONCLUSIONS}

\section{Implications for practice}

At present, in critically ill, non-neutropenic patients, there is moderate-quality evidence that un-targeted treatment with any antifungal drug does not significantly increase or reduce total (all-cause) mortality. There is low-grade evidence supporting the use of untargeted antifungal treatment for prevention of invasive fungal infection. The reduction of invasive fungal infections is observed when fluconazole and caspofungin are used as antifungal medication. Low-quality evidence supports the efficacy of the intervention for fungal colonization reduction. The use of untargeted antifungal drugs does not seem to be associated with an increase of superficial fungal infections and adverse events requiring cessation of treatment with low quality of evidence for both outcomes. The clinical decision of starting an untargeted antifungal treatment in non-neutropenic critically ill patients should consider patients' characteristics, type of drugs available and feasible type of antifungal strategy (i.e. prophylactic, preemptive and empiric).

\section{Implications for research}

The evidence provided by this updated review on the effect of untargeted antifungal treatment is not conclusive. Further research may be justified focusing on which specific untargeted antifungal treatment among prophylactic, pre-emptive and empiric is most beneficial in non-neutropenic, critically ill patients. Further highquality randomized controlled trials should be done to investigate the use of drugs less studied in this setting to date. Two ongoing trials are addressing some of these issues, giving more evidence in the next future (Lass-Flörl 2013; Timsit 2012).

Future trials should adopt standardized definitions of microbiological outcomes (e.g. invasive fungal infection, fungal colonization) to reduce heterogeneity. Moreover, they should consider the emergence of resistance to antifungal drugs, especially with the use of recently introduced compounds (e.g. echinocandins), to balance risks and benefit of untargeted antifungal treatment .

\section{ACK N O WLEDGEMENTS}

We wish to acknowledge EG Playford, AC Webster, TC Sorrell, JC Craig, the authors of the original review on this topic (Playford 2006a). Although they did not directly participate in this updated version, they made a significant contribution to this review, building the foundation upon which the updated version was created.

We report the acknowledgements of the authors of the original review to Dr Harald Herkner, Dr Sibel Ascioglu, Dr Peter C Gøtzsche, Dr Ann Møller, Amy Godfrey Arkle, Janet Wale, Iveta Simera, Dr Mical Paul, Prof Nathan Pace and Cochrane Gynaecological Cancer Group, in particular Jill Porthouse and Dr Chris Williams, for their help during the preparation of the original review (Playford 2006a).

We would like to thank Jane Cracknell of the Cochrane Anaesthesia, Critical and Emergency Care Group (ACE) and Karen Hovhannisyan Trials Search Co-ordinator for their kind assistance during the preparation of this updated review (Cortegiani 2016). We would like to acknowledge also Prof. G. Tamburello from the University of Palermo for her kind assistance in translating articles from Chinese.

Finally, we would like to thank Harald Herkner (content and statistical editor), Philippe Eggimann, Jean-Louis Vincent, Andre C Kalil (peer reviewers), Robert Wyllie (consumer referee) for their help and editorial advice during the preparation of this systematic review. 


\section{R E F E R E N C E S}

\section{References to studies included in this review}

Ables $\mathbf{2 0 0 0}$ \{published data only\}

Ables AZ, Blumer NA, Valainis GT, Godenick MT, Kajdasz DK, Palesch YY. Fluconazole prophylaxis of severe candida infection in trauma and postsurgical patients: A prospective, doubleblind, randomized, placebo-controlled trial. Infectious Diseases in Clinical Practice 2000;9(4):169-75. [EMBASE: 2000158943]

\section{Albert 2014 \{published data only\}}

Albert M, Williamson D, Muscedere J, Lauzier F, Rotstein C, Kanji S, et al. Candida in the respiratory tract secretions of critically ill patients and the impact of antifungal treatment: a randomized placebo controlled pilot trial (CANTREAT study). Intensive Care Medicine 2014;40(9):1313-22. [PUBMED: 24981955]

\section{ARDS Network 2000 \{published data only\}}

ARDS Network Authors. Ketoconazole for early treatment of acute lung injury and acute respiratory distress syndrome: a randomized controlled trial. JAMA 2000;283(15):1995-2002. [PUBMED: 10789668]

\section{Beshey 2014 \{published data only\}}

Beshey BN, Okasha AS, Eldin MEN. Fluconazole and selective digestive decontamination for prevention of Candida infection in high risk critically ill patients. Alexandria Journal of Medicine 2014;50(1):93-8. [Science Direct S2090506813000572]

\section{Eggimann 1999 \{published data only\}}

Eggimann P, Francioli P, Bille J, Schneider R, Wu MM, Chapuis G, et al. Fluconazole prophylaxis prevents intra-abdominal candidiasis in high-risk surgical patients. Critical Care Medicine 1999;27(6):1066-72. [PUBMED: 10397206]

Garbino 2002 \{published data only (unpublished sought but not used)\}

Garbino J, Lew D, Romand JA, Auckenthaler P, Suter P, Pittet D. Fluconazole prevents severe Candida spp infections in highrisk critically ill patients. A randomized, double-blind, placebocontrolled study. 37th Interscience Conference of Antimicrobial Agents and Chemotherapy, Toronto, Canada, 28 September1 October. Washington: American Society for Microbiology, 1997:Abstract LM-23b.

* Garbino J, Lew DP, Romand JA, Hugonenet S, Auckenthaler R, Pittet D. Prevention of severe Candida infections in nonneutropenic, high-risk, critically ill patients: a randomized, double-blind, placebo-controlled trial in patients treated by selective digestive decontamination. Intensive Care Medicine 2002;28(12):1708-17. [PUBMED: 12447512]

\section{Giglio 2012 \{published data only\}}

Giglio M, Caggiano G, Dalfino L, Brienza N, Alicino I, Sgobio A, et al. Oral nystatin prophylaxis in surgical/trauma ICU patients: a randomized clinical trial. Critical Care 2012;16(2):R57. [PUBMED: 22490643]
He 2003 \{published data only\}

He YM, Lv XS, Ai ZL, Liu ZS, Qian Q, Sun Q, et al. Prevention and therapy of fungal infection in severe acute pancreatitis: $A$ prospective clinical study. World Journal of Gastroenterology 2003;9(11):2619-21. [PUBMED: 14606111]

\section{Jacobs 2003 \{published data only\}}

Jacobs S, Price Evans DA, Tariq M, Al Omar NF. Fluconazole improves survival in septic shock: a randomized double-blind prospective study. Critical Care Medicine 2003;31(7):1938-46. [MEDLINE: 12847386]

\section{Leon 1990 \{published data only\}}

Leon A, Toubas D, Renard P, Suinat JL, Raclot P, Cousson J, et al. Diagnosis and prevention of candidosis in the intensive care unit [Diagnostic et prévention des candidoses en réanimation]. Agressologie 1990;31(8):514-8. [PUBMED: 2089973]

\section{Namikawa 2013 \{published data only\}}

Namikawa T, Kitagawa H, Yamatsuji T, Naomoto Y, Kobayashi M, Hanazaki K. Pre-emptive treatment of fungal infection based on plasma $\beta$-D-glucan levels after gastric surgery for gastric cancer in elderly patients. Journal of Gastroenterology and Hepatology 2013;28(9):1457-61. [PUBMED: 23574148]

\section{NCT00048750 \{unpublished data only\}}

NCT00048750. A phase 3, randomized, double-blind comparative study of micafungin (FK 463) versus placebo as preemptive prophylactic antifungal therapy in patients in the intensive care unit. clinicaltrials.gov/ct2/show/NCT00048750 2002.

NCT01122368 \{unpublished data only\}

NCT01122368. A Study to evaluate preemptive treatment of Invasive Candidiasis in high risk surgical subjects (INTENSE). clinicaltrials.gov/ct2/show/NCT01122368 2010.

\section{Normand 2005 \{published data only\}}

Normand S, Francois B, Dardé ML, Bouteille B, Bonnivard M, Preux PM, et al. Oral nystatin prophylaxis of Candida spp. colonization in ventilated critically ill patients. Intensive Care Medicine 2005;31(11):1508-13. [PUBMED: 16195905]

\section{Ostrosky-Zeichner 2014 \{published data only\}}

Ostrosky-Zeichner L, Shoham S, Vazquez J, Reboli A, Betts R, Barron MA, et al. MSG-01: A Multicenter, Randomized, Double-Blind, Placebo Controlled Trial of Caspofungin (CAS) Prophylaxis vs Placebo Followed by Pre-Emptive Therapy for Invasive Candidiasis (IC) in High-Risk Adults in the Critical Care Setting. Preliminary Results. Proceedings of the Annual meeting of the Society for Healthcare epidemiology of America; 2011 Apr 1-4; Dallas, Texas. 2011.

* Ostrosky-Zeichner L, Shoham S, Vazquez J, Reboli A, Betts R, Barron MA, et al. MSG01: A randomized, double-blind, placebocontrolled trial of caspofungin prophylaxis followed by preemptive therapy for invasive candidiasis in high-risk adults in the critical care setting. Clinical Infectious Diseases 2014;58(9):1219-26. [PUBMED: 24550378] 
Parizkova 2000 \{published data only\}

* Parizkova R, Cerny V, Dostal P, Truhlar A. The effect of prophylactic fluconazole administration on fungal infection in critically ill patients. Anesteziologie a neodkladna pece 2000;11(6):271-5. [EMBASE: 2001046296]

Parizkova R, Dostal P, Cerny V. Fluconazole prophylaxis of systemic candida infection in non-neutropenic critically ill patients: a prospective randomized study. Critical Care 1999;3(Suppl 1):P061. [PUBMED: PMC3301764]

Pelz 2001 \{published data only\}

Pelz RK, Hendrix CW, Swoboda SM, Diener-West M, Merz WG, Hammond J, et al. Double-blind placebo-controlled trial of fluconazole to prevent candidal infections in critically ill surgical patients. Annals of Surgery 2001;233(4):542-8. [PUBMED: 11303137]

\section{Sandven 2002 \{published data only\}}

Sandven P, Qvist H, Skovlund E, Giercksky KE, NORGAS Group and the Norwegian Yeast Study. Significance of Candida recovered from intraoperative specimens in patients with intraabdominal perforations. Critical Care Medicine 2002;30(3):541-7. [PUBMED: 11990912]

\section{Savino 1994 \{published data only\}}

Savino JA, Agarwal N, Wry P, Policastro A, Cerabona T, Austria L. Routine prophylactic antifungal agents (clotrimazole, ketoconazole, and nystatin) in nontransplant/nonburned critically ill surgical and trauma patients. Journal of TraumaInjury Infection \& Critical Care 1994;36(1):20-5. [PUBMED: 8295245]

\section{Schuster 2008 \{published data only\}}

Schuster MG, Edwards JE Jr, Sobel JD, Darouiche RO, Karchmer AW, Hadley S, et al. Empirical Fluconazole versus Placebo for Intensive Care Unit PatientsA Randomized Trial. Annals of Internal Medicine 2008;149(2):83-90. [PUBMED: 18626047]

\section{Slotman 1987 \{published data only\}}

* Slotman GJ, Burchard KW. Ketoconazole prevents Candida sepsis in critically ill surgical patients. Archives of Surgery 1987;122(2):147-51. [MEDLINE: 3545141]

Slotman GJ, Burchard KW, D'Arezzo A, Gann DS. Ketoconazole prevents acute respiratory failure in critically ill surgical patients. The Journal of Trauma 1988;28(5):648-54. [MEDLINE: 3285017]

\section{Yu 1993 \{published data only\}}

Yu M, Tomasa G. A double-blind, prospective, randomized trial of ketoconazole, a thromboxane synthetase inhibitor, in the prophylaxis of the adult respiratory distress syndrome. Critical Care Medicine 1993;21(11):1635-42. [PUBMED: 8222677]

\section{References to studies excluded from this review}

Aerdts 1991 \{published data only\}

Aerdts SJ, van Dalen R, Clasener HA, Festen J, van Lier HJ, Vollaard EJ. Antibiotic prophylaxis of respiratory tract infection in mechanically ventilated patients. A prospective, blinded, randomized trial of the effect of a novel regimen. Chest 1991;100(3):783-91. [PUBMED: 1889273]

\section{Azoulay 2011 \{published data only\}}

Azoulay E, Timsit JF, Souweine B, Legriel S, Max A, Misset B, et al. Weekly high dose liposomal amphotericin B (L-AMB) in septic shock patients with multiple candida colonization: AMBIDEX study. Intensive Care Medicine. 22nd Annual Congress of the European Society of Intensive Care Medicine (ESICM). Vienna, Austria., 2011; Vol. 37, issue Suppl 1:S6-314. [PUBMED: 21905295]

\section{Blair 1991 \{published data only\}}

Blair P, Rowlands BJ, Lowry K, Webb H, Armstrong P, Smilie J. Selective decontamination of the digestive tract: a stratified, randomized, prospective study in a mixed intensive care unit. Surgery 1991;110(2):303-10. [PUBMED: 1650036 ]

\section{Daeem 2012 \{published data only\}}

Daeem DA. Efficacy of prophylactic fluconazole in reducing candidemia in high risk nicu and picu patients. Archives of Disease in Childhood. 4th Congress of the European Academy of Paediatric Societies Istanbul Turkey., 2012; Vol. 97, issue Suppl 2:A380. [EMBASE: 71063264]

\section{De Jonge 2003 \{published data only\}}

De Jonge E, Schultz MJ, Spanjaard I, Bossuyt PM Vroom MB, Dankert J, et al. Effects of selective decontamination of digestive tract on mortality and acquisition of resistant bacteria in intensive care: a randomised controlled trial. Lancet 2003;362(9389):1011-6. [PUBMED: 14522530]

\section{Hanson 2011 \{published data only\}}

Hanson KE, Pfeiffer CD, Lease ED, Balch AH, Zaas AK, Perfect JR, et al. $\beta$-D-glucan surveillance with preemptive anidulafungin for invasive candidiasis in intensive care unit patients: a randomized pilot study. PLoS One 2012;7(8):e42282. [PUBMED: 22879929]

\section{Latif 2012 \{published data only\}}

Latif ADA, Abdel Sultan MH, Mohamed HE. Efficacy of Prophylactic Fluconazole in Reducing Candidemia in High Risk NICU and PICU Patients. Life Science Journal 2012;9(1):817-24. [Web of Science: 000306398400118]

\section{Milanov 2010 \{published data only\}}

Milanov SG, Georgiev G, Todorova V, Kozarov L, Milanov M. Efficacy and utility of a protocol for pre-emptive antimycotic therapy. Critical Care. 30rd International Symposium on Intensive Care and Emergency Medicine, Brussels, Belgium., 2010; Vol. 14, issue Suppl 1:70. [PubMed Central 2934516]

\section{Milanov 2013 \{published data only\}}

Milanov S, Todorova VT, Georgiev G, Milanov M. Empirical versus preemptive antimycotic therapy in terms of outcome benefit. Critical Care. 33rd International Symposium on Intensive Care and Emergency Medicine, Brussels, Belgium, 2013; Vol. 17, issue Suppl 2:84. [PubMed Cantral 3643104] 
NCT00095316 \{unpublished data only\}

NCT00095316. Caspofungin Study for Fungal Infections in Adults in Critical Care Settings. clinicaltrials.gov/ct2/show/ NCT00095316 2004.

\section{NCT00099775 \{unpublished data only\}}

NCT00099775. Caspofungin to Prevent Candidiasis in Adults in Hospital Intensive Care Units. clinicaltrials.gov/ct2/show/ NCT00099775 2004.

\section{NCT00163111 \{unpublished data only\}}

NCT00163111. A Clinical Study Intended To Compare Treatment With Voriconazole To Treatment With Amphotericin Followed By Fluconazole In Patients With Candidemia, A Serious Fungus Infection Of The Blood. clinicaltrials.gov/ct2/show/ NCT001631112005.

\section{NCT00689338 \{unpublished data only\}}

NCT00689338. Anidulafungin Candidemia/Invasive Candidiasis Intensive Care Study (ICE). clinicaltrials.gov/ct2/show/ NCT00689338 2008.

\section{NCT01045798 \{unpublished data only\}}

* NCT01045798. Pilot Feasibility Study With Patients Who Are at High Risk For Developing Invasive Candidiasis in a Critical Care Setting (MK-0991-067). clinicaltrials.gov/ct2/show/study/ NCT01045798?sect=X73401562010.

\section{NCT01524081 \{unpublished data only\}}

NCT01524081. Antibiotic Prophylaxis in the Prevention of Surgical Site Infections After Selected Urgent Abdominal Surgical Procedures. clinicaltrials.gov/ct2/show/NCT01524081 2012.

\section{Restrepo 2010 \{published data only\}}

Restrepo C, Chacon J, Manjarres G. Fungal peritonitis in peritoneal dialysis patients: successful prophylaxis with fluconazole, as demonstrated by prospective randomized control trial. Peritoneal Dialysis International 2010;30(6):619-25. [PUBMED: 20634438]

\section{Sorkine 1996 \{published data only\}}

Sorkine P, Nagar H, Weinbroum A, Setton A, Israitel E, Scarlatt A, et al. Administration of amphotericin $B$ in lipid emulsion decreases nephrotoxicity: results of a prospective, randomized, controlled study in critically ill patients. Critical Care Medicine 1996;24(8):1311-5. [PUBMED: 8706484]

\section{Wang 2009 \{published data only\}}

Wang DH, Gao XJ, Wei LQ, Xia R, Li Q, Peng M, et al. The preemptive treatment of invasive Candida infection with reference of corrected colonization index in critically ill patients: a multicentre, prospective, randomized controlled clinical study. Zhongguo Wei Zhong Bing Ji Jiu Yi Xue 2009;21(9):525-8. [PUBMED: 19751559]

\section{References to studies awaiting assessment}

Chen 2013 \{published data only\}

Chen Z, Yang CL, He HW, Zeng J. The clinical research of nystatin in prevention of invasive fungal infections in patients on mechanical ventilation in intensive care unit. Zhonghua Wei Zhong Bing Ji Jiu Yi Xue 2013;25(8):475-8. [PUBMED: 24021043]

Havlicek 2008 \{published data only\}

* Havlicek K, Cervinka V, Sakra L, Motycka V, Mencl K. Preemptive antimycotic treatment in critically ill patients in the Czech Republic. International Surgery 2008;93(4):244-6. [PUBMED: 19731862]

Havlícek K, Motycka V, Sákra L, Mencl K, Ninger V, Safusová L. Preemptive antimycotic therapy in critically ill patients. Rozhledy v chirurgii : měsičník Československé chirurgické společnosti 2003;82(2):67-71. [PUBMED: 12712902]

\section{Milesi 2002 \{unpublished data only\}}

ISRCTN40372159. Effects of digestive decontamination by amphotericine $B$ on Candida colonisation and on the risk of invasive candidiasis in a surgical intensive care unit: a prospective randomised study. www.isrctn.com/ ISRCTN40372159 2002.

\section{Whitby 2005 \{unpublished data only\}} ACTRN12605000596606. Safety and efficacy of ambisome versus conventional amphotericin B in the treatment of patients with suspected or confirmed mycosis. www.anzctr.org.au/Trial/ Registration/TrialReview.aspx?ACTRN=12605000596606 2005.

\section{References to ongoing studies}

\section{Lass-Flörl 2013 \{published data only\}}

EudraCT number: 2012-003172-39. Micafungin-Deescalation study: Evalutating the rate of breakthrough infections of micafungin followed by fluconazole versus fluconazole (or other azoles) in febrile patients. www.clinicaltrialsregister.eu/ctrsearch/trial/2012-003172-39/AT 2013.

Timsit 2012 \{published data only\}

NCT01773876. Empirical Antifungal Treatment in ICUS (EMPIRICUS). clinicaltrials.gov/ct2/show/NCT01773876 2012.

Timsit JF, Azoulay E, Cornet M, Gangneux JP, Jullien V, Vésin A, et al. EMPIRICUS micafungin versus placebo during nosocomial sepsis in Candida multi-colonized ICU patients with multiple organ failures: study protocol for a randomized controlled trial. Trials 2013;14:399. [PUBMED: 24261608]

\section{Additional references}

\section{Austin 2013a}

Austin N, McGuide W. Prophylactic systemic antifungal agents to prevent mortality and morbidity in very low birth weight infants. Cochrane Database of Systematic Reviews 2013, Issue 4. [DOI: 10.1002/14651858.CD003850.pub4] 


\section{Austin 2013b}

Austin N, Darlow BA, McGuire W. Prophylactic oral/topical non-absorbed antifungal agents to prevent invasive fungal infection in very low birth weight infants. Cochrane Database of Systematic Reviews 2013, Issue 3. [DOI: 10.1002/14651858.CD003478.pub4]

\section{Bassetti 2013}

Bassetti M, Marchetti M, Chakrabarti A, Colizza S, GarnachoMontero J, Kett DH, et al. A research agenda on the management of intra-abdominal candidiasis: results from a consensus of multinational experts. Intensive Care Medicine 2013;39(12):2092-106. [PUBMED: 24105327]

\section{Bassetti 2015}

Bassetti M, Righi E, Ansaldi F, Merelli M, Scarpato C, Antonelli M, et al. A multicenter multinational study of abdominal candidiasis: epidemiology, outcomes and predictors of mortality. Intensive Care Medicine 2015;41(9):1601-10. [PUBMED: 26077063]

\section{Blyth 2010}

Blyth CC, Hale K, Palasanthiran P, O'Brien T, Bennett MH. Antifungal therapy in infants and children with proven, probable or suspected invasive fungal infections. Cochrane Database of Systematic Reviews 2010, Issue 2. [DOI: 10.1002/14651858.CD006343.pub2; PUBMED: 20166083]

\section{Bone 1992}

Bone RC, Balk RA, Cerra FB, Dellinger RP, Fein AM, Knaus WA, et al. Definitions for sepsis and organ failure and guidelines for the use of innovative therapies in sepsis. The ACCP/SCCM Consensus Conference Committee. American College of Chest Physicians/Society of Critical Care Medicine. Chest 1992;101(6):1644-55. [PUBMED: 1303622]

\section{Cornely 2012}

Cornely OA, Bassetti M, Calandra T, Garbino J, Kullberg BJ, Lortholary O. ESCMID guideline for the diagnosis and management of Candida diseases 2012: non-neutropenic adult patients. Clinical Microbiology and Infection 2012;18 Suppl 7:19-37. [PUBMED: 23137135]

\section{Cruciani 2005}

Cruciani M, de Lalla F, Mengoli C. Prophylaxis of Candida infections in adult trauma and surgical intensive care patients: a systematic review and meta-analysis. Intensive Care Medicine 2005;31(11):1479-87. [PUBMED: 16172847]

\section{Cruciani 2006}

Cruciani M, Mengoli C, Malena M, Bosco O, Serpelloni G, Grossi P. Antifungal prophylaxis in liver transplant patients: a systematic review and meta-analysis. Liver Transplantation 2006;12(5):850-8. [PUBMED: 16628697]

\section{Cuenca-Estrella 2012}

Cuenca-Estrella M, Verweij PE, Arendrup MC, Arikan-Akdagli S, Bille J, Donnelly JP, et al. ESCMID guideline for the diagnosis and management of Candida diseases 2012: diagnostic procedures. Clinical Microbiology and Infection 2012;18(Suppl 7):9-18. [PUBMED: 23137134]

\section{D'Amico 2009}

D'Amico R, Pifferi S, Torri V, Brazzi L, Parmelli E, Liberati A. Antibiotic prophylaxis to reduce respiratory tract infections and mortality in adults receiving intensive care. Cochrane Database of Systematic Reviews 2009, Issue 4. [DOI: 10.1002/14651858.CD000022.pub3]

\section{Dodds Ashley 2012}

Dodds Ashley E, Drew R, Johnson M, Danna R, Dabrowski D, Walker $V$, et al. Cost of invasive fungal infections in the era of new diagnostics and expanded treatment options. Pharmacotherapy 2012;32(10):890-901. [PUBMED: 23033228]

\section{Fekkar 2014}

Fekkar A, Dannaoui E, Meyer I, Imbert S, Brossas JY, Uzunov M, et al. Emergence of echinocandin-resistant Candida spp. in a hospital setting: a consequence of 10 years of increasing use of antifungal therapy?. European Journal of Clinical Microbiology \& Infectious Diseases 2014;33(9):1489-96. [PUBMED: 24715154]

\section{Fernandez 2011}

Fernandez J, Erstad BL, Petty W, Nix DE. Time to positive culture and identification for Candida blood stream infections. Diagnostic Microbiology and Infectious Disease 2009;64(4):402-7. [PUBMED: 19446982]

\section{Garey 2006}

Garey KW, Rege M, Pai MP, Mingo DE, Suda KJ, Turpin RS, et al. Time to initiation of fluconazole therapy impacts mortality in patients with candidemia: a multi-institutional study. Clinical Infectious Diseases 2006;43(1):25-31.

\section{GRADEpro [Computer program]}

McMaster University. GRADEpro GDT. www.gradepro.org. McMaster University, 2015.

\section{Gøtzsche 2014}

Gøtzsche PC, Johansen HK. Routine versus selective antifungal administration for control of fungal infections in patients with cancer. Cochrane Database of Systematic Reviews 2014, Issue 9. [DOI: 10.1002/14651858.CD000026.pub2]

\section{Hassan 2009}

Hassan I, Powell G, Sidhu M, Hart WM, Denning DW. Excess mortality, length of stay and cost attributable to candidaemia. Journal of Infection 2009;59(5):360-5. [PUBMED: 19744519 ]

\section{Hermsen 2011}

Hermsen ED, Zapapas MK, Maiefski M, Rupp ME, Freifeld AG, Kalil AC. Validation and comparison of clinical prediction rules for invasive candidiasis in intensive care unit patients: a matched case-control study. Critical Care 2011;15:R198. [PUBMED: 21846332]

\section{Higgins 2011a}

Higgins JPT, Green S (editors). Cochrane Handbook for Systematic Reviews of Interventions 5.1.0 [updated March 2011]. The Cochrane Collaboration, 2011. Available from www.cochrane-handbook.org. 


\section{Higgins 2011b}

Higgins JPT, Altman DG, Sterne JAC (editors). Chapter 8: Assessing risk of bias in included studies. In: Higgins JPT, Green S (editors). Cochrane Handbook for Systematic Reviews of Interventions Version 5.1.0 (updated March 2011). The Cochrane Collaboration, 2011.. Available from www.cochranehandbook.org.

\section{Higgins 2011c}

Higgins JPT, Deeks JJ, Altman DG (editors). Chapter 16: Special topics in statistics. In: Higgins JPT, Green S (editors), Cochrane Handbook for Systematic Reviews of Interventions Version 5.1.0 (updated March 2011). The Cochrane Collaboration, 2011.. Available from www.cochrane-handbook.org.

\section{Higgins 2011d}

Deeks JJ, Higgins JPT, Altman DG (editors). Chapter 9: Analysing data and undertaking meta-analyses. In: Higgins JPT, Green $S$ (editors). Cochrane Handbook for Systematic Reviews of Interventions Version 5.1.0 (updated March 2011). The Cochrane Collaboration, 2011. Available from www.cochranehandbook.org.

\section{Ho 2005}

Ho KM, Lipman J, Dobb GJ, Webb SA. The use of prophylactic fluconazole in immunocompetent high-risk surgical patients: a meta-analysis. Critical Care 2005;9:R710-7. [PUBMED: 16280069]

\section{Kett 2011}

Kett DH, Azoulay E, Echeverria PM, Vincent JL, EPIC II Group of Investigators. Candida bloodstream infections in intensive care units: analysis of the extended prevalence of infection in intensive care unit study. Critical Care Medicine 2011;39(4):665-70. [PUBMED: 21169817]

\section{Kollef 2012}

Kollef M, Micek S, Hampton N, Doherty JA, Kumar A. Septic shock attributed to Candida infection: importance of empiric therapy and source control. Clinical Infectious Diseases 2012;54(12):1740-6. [PUBMED: 22423135]

\section{Kullberg 2015}

Kullberg BJ, Arendrup MC. Invasive Candidiasis. New England Journal of Medicine 2015;373(15):1445-56. [PUBMED: 26444731]

\section{Lau 2015}

Lau AF, Kabir M, Chen SC, Playford EG, Marriot DJ, et al. Candida colonization as a risk marker for invasive candidiasis in mixed medical-surgical intensive care units: development and evaluation of a simple, standard protocol. Journal of Clinical Microbiology 2015;54(4):1324-30. [PUBMED: 25673797]

\section{Lortholary 2011}

Lortholary O, Desnos-Ollivier M, Sitbon K, Fontanet A, Bretagne S, Dromer F, et al. Recent exposure to caspofungin or fluconazole influences the epidemiology of candidemia: a prospective multicenter study involving 2,441 patients. Antimicrobial Agents and Chemotherapy 2011;55(2):532-8. [PUBMED: 21078946]

\section{Marino 2010}

Marino E, Gallagher JC. Prophylactic antifungal agents used after lung transplantation. The Annals of Pharmacotherapy 2010;44(3):546-56. [PUBMED: 20179260]

\section{Marshall 1995}

Marshall JC, Cook DJ, Christou NV, Bernard GR, Sprung CL, Sibbald WJ. Multiple organ dysfunction score: a reliable descriptor of a complex clinical outcome. Critical Care Medicine 1995;23(10):1638-52. [PUBMED: 7587228]

\section{Meerssemann 2009}

Meersseman W, Lagrou K, Spriet I, Maertens J, Verbeken E, Peetermans WE, et al. Significance of the isolation of Candida species from airway samples in critically ill patients: a prospective, autopsy study. Intensive Care Medicine 2009;35(9):1526-31. [PUBMED: 19357832]

\section{Mikulska 2010}

Mikulska M, Calandra T, Sanguinetti M, Poulain D, Viscoli C, the Third European Conference on Infections in Leukemia Group. The use of mannan antigen and anti-mannan antibodies in the diagnosis of invasive candidiasis: recommendations from the Third European Conference on Infections in Leukemia. Critical Care 2010;14:R222. [PUBMED: 21143834]

\section{Morrell 2005}

Matthew M, Fraser VJ, Kollef MH. Delaying the empiric treatment of Candida bloodstream infection until positive blood culture results are obtained: a potential risk factor for hospital mortality. Antimicrobial Agents and Chemotherapy 2005;49(9):3640-5. [PUBMED: 16127033]

\section{Ostrosky-Zeichner 2007}

Ostrosky-Zeichner L, Sable C, Sobel J, Alexander BD, Donowitz G, Kan V, et al. Multicenter retrospective development and validation of a clinical prediction rule for nosocomial invasive candidiasis in the intensive care setting. European Journal of Clinical Microbiology and Infectious Diseases 2007;26(4):271-6. [PUBMED: 17333081]

\section{Pancreatic Group Chinese Medical Association 1997}

Pancreatic Group, Chinese Medical Association. Clinical diagnosis and classification standard of acute pancreatitis. Zhonghua Waike Zazhi 1997;35:773-5.

\section{Pfaller 2012}

Pfaller MA. Antifungal drug resistance: mechanisms, epidemiology, and consequences for treatment. The American Journal of Medicine 2012;125(1):S2-S13. [PUBMED: 22196207]

\section{Pfaller 2011}

Pfaller MA, Moet GJ, Messer SA, Jones RN, Castanheira M. Geographic Variations in Species Distribution and Echinocandin and Azole Antifungal Resistance Rates among Candida Bloodstream Infection Isolates: Report from the SENTRY Antimicrobial Surveillance Program (2008 to 2009). Journal of Clinical Microbiology 2011;49(1):396-9. [PUBMED: 21068282] 


\section{Pittet 1994}

Pittet D, Monod M, Suter PM, Frenk E, Auckenthaler R. Candida colonisation and subsequent infections in critically ill surgical patients. Annals of Surgery 1994;220(6):751-8. [MEDLINE: 7986142]

\section{Playford 2004a}

Playford EG, Webster AC, Sorrell TC, Craig JC. Antifungal agents for preventing fungal infections in solid organ transplant recipients. Cochrane Database of Systematic Reviews 2004, Issue 3. [DOI: 10.1002/14651858.CD004291.pub2]

\section{Posteraro 2011}

Posteraro B, De Pascale G, Tumbarello M, Torelli R, Pennisi MA, Bello $G$, et al. Early diagnosis of candidemia in intensive care unit patients with sepsis: a prospective comparison of (1-3)-bD-glucan assay, Candida score, and colonization index. Critical Care 2011;15:R249. [PUBMED: 22018278]

\section{Puig-Asensio 2014a}

Puig-Asensio M, Padilla B, Garnacho-Montero J, Zaragoza O, Aguado JM, Zaragoza R, et al. Epidemiology and predictive factors for early and late mortality in Candida bloodstream infections: a population-based surveillance in Spain. Clinical Microbiology and Infection 2014;20(4):O245-54. [PUBMED: 24125548]

\section{Puig-Asensio 2014b}

Puig-Asensio M, Pemán J, Zaragoza R, Garnacho-Montero J, Martín-Mazuelos E, Cuenca-Estrella M, et al. Impact of therapeutic strategies on the prognosis of candidemia in the ICU. Critical Care Medicine 2014;42(6):1423-32. [PUBMED: 24557426]

\section{Rentz 1998}

Rentz AM, Halpern MT, Bowden R. The impact of candidemia on length of hospital stay, outcome, and overall cost of illness. Clinical Infectious Diseases 1998;27(4):781-8. [MEDLINE: 9798034]

\section{Review Manager 5 [Computer program]}

The Nordic Cochrane Centre, The Cochrane Collaboration. Review Manager (RevMan). Version 5.3. Copenhagen: The Nordic Cochrane Centre, The Cochrane Collaboration, 2014.

\section{Robenshtok 2007}

Robenshtok E, Gafter-Gvili A, Goldberg E, Weinberger M, Yeshurun M, Leibovici L, et al. Antifungal prophylaxis in cancer patients after chemotherapy or hematopoietic stem-cell transplantation: systematic review and meta-analysis. Journal of Clinical Oncology 2007;25(34):5471-89. [MEDLINE: 17909198]

\section{Schünemann 2011}

Schünemann HJ, Oxman AD, Vist GE, Higgins JPT, Deeks JJ, Glasziou P, et al. Chapter 12: Interpreting results and drawing conclusions. In: Higgins JPT, Green S (editors), Cochrane Handbook for Systematic Reviews of Interventions. Version 5.1.0 [updated March 2011]. The Cochrane Collaboration, 2011. Available from www.cochrane-handbook.org.

\section{Shorr 2005}

Schorr AF, Chung K, Jackson WL, Waterman PE, Kollef MH. Fluconazole prophylaxis in critically-ill surgical patients: a metaanalysis. Critical Care Medicine 2005;33(9):1928-35. [PUBMED: 16148461]

\section{Sobin 2009}

Sobin LH, Gospodarowicz MK, Wittekind C. TNM Classification of Malignant Tumours. 7th Edition. Chichester, West Sussex, UK: Wiley, 2009.

\section{Vardakas 2006}

Vardakas KZ, Samonis G, Michalopoulos A, Soteriades ES, Falagas ME. Antifungal prophylaxis with azoles in high-risk surgical intensive care unit patients: a meta-analysis of randomized, placebo controlled trials. Critical Care Medicine 2006;34(4):1216-24. [MEDLINE: 16484923]

\section{Vardakas 2009}

Vardakas KZ, Michalopoulos A, Kiriakidou KG, Siampli EP, Samonis G, Falagas ME. Candidaemia: incidence, risk factors, characteristics and outcomes in immunocompetent critically ill patients. Clinical Microbiology and Infection 2009;15(3):289-92. [PUBMED: 19154488]

\section{Vincent 2009}

Vincent JL, Rello J, Marshall J, Silva E, Anzueto A, Martin CD, et al. International Study of the Prevalence and Outcomes of Infection in Intensive Care Units. JAMA 2009;302(21):2323-9. [PUBMED: 19952319]

\section{Wisplinghoff 2004}

Wisplinghoff H, Bischoff T, Tallent SM, Seifert H, Wenzel RP, Edmond MB. Nosocomial bloodstream infections in US hospitals: analysis of 24,179 cases from a prospective nationwide surveillance study. Clinical Infectious Diseases 2004;39(3):309-17. [PUBMED: 15306996]

\section{References to other published versions of this review \\ Cortegiani 2016}

Cortegiani A, Russotto V, Maggiore A, Attanasio M, Naro AR, Raineri SM, et al. Antifungal agents for preventing fungal infections in non-neutropenic critically ill patients. Cochrane Database of Systematic Reviews 2016, Issue 1. [DOI: 10.1002/14651858.CD004920.pub3]

\section{Cortegiani 2017}

Cortegiani A, Russotto V, Giarratano A. Associations of antifungal treatments with prevention of fungal infection in critically ill patients without neutropenia. JAMA 2017;317(3):311-2. [DOI: 10.1001/jama.2016.16535]

\section{Playford 2004b}

Playford EG, Webster AC, Sorrell TC, Craig JC. Antifungal agents for preventing fungal infections in non-neutropenic critically-ill patients. Cochrane Database of Systematic Reviews 2004, Issue 3. [DOI: 10.1002/14651858.CD004920] 


\section{Playford 2006a}

Playford EG, Webster AC, Sorrell TC, Craig JC. Antifungal agents for preventing fungal infections in non-neutropenic critically ill patients. Cochrane Database of Systematic Reviews 2006, Issue 1. [DOI: 10.1002/14651858.CD004920.pub2]

\section{Playford 2006b}

Playford EG, Webster AC, Sorrell TC, Craig JC. Antifungal agents for preventing fungal infections in non-neutropenic critically ill and surgical patients: systematic review and metaanalysis of randomized clinical trials. Journal of Antimicrobial Chemotherapy 2006;25(9):549-61.

* Indicates the major publication for the study

\section{CHARACTERISTICS OF STUDIES}

Characteristics of included studies [ordered by study ID]

\section{Ables 2000}

\begin{tabular}{ll}
\hline Methods & Multicentre, randomized, parallel-group study \\
& Duration of the study: October 1994 to December 1996 \\
Patients excluded/patients randomized: $6 / 125(5 \%)$ \\
Sample size calculation/method description: No/No
\end{tabular}

\section{Participants}

Patients randomized: 125

Age (mean): 46 years (treatment group), 42 years (placebo group)

Sex: 82 men, 37 women

Inclusion criteria: trauma or surgical patients, expected length of stay $>48$ hours, $>1$ risk factors (e.g. central venous line, total parenteral nutrition, mechanical ventilation, antibiotics administration, etc.)

Exclusion criteria: unexpected serious adverse reaction to azole drugs, thrombocytopenia (<5000/ $\mathrm{mm} 3$ ), leucopenia $(<4000 / \mathrm{mm} 3$ ), increasing liver function tests greater than five times the upper limits of normal, pregnancy, anticipated life expectancy of less than three months, severe liver disease, current treatment with a systemic antifungal agent

Percentage post-surgical: $>30 \%$

Percentage colonized with Candida at baseline: $24 \%$

Interventions 1. Fluconazole $800 \mathrm{mg} /$ day IV initially then $400 \mathrm{mg} /$ day IV or orally $(n=63)$

2. Placebo $(n=62)$

Duration of the intervention: until ICU discharge

\begin{tabular}{ll}
\hline Outcomes & Mortality \\
Proven IFI & Suspected IFI \\
& Proven or suspected IFI \\
& Proven IFI with azole-resistant species \\
& Superficial FI \\
& Fungal colonization \\
& Fungal colonization with azole-resistant species \\
& Adverse events requiring cessation
\end{tabular}

Follow-up duration: until hospital discharge

Type of antifungal treat- $\quad$ Prophylaxis
ment
ment 
Ables 2000 (Continued)
Declaration of interest
Not reported among the primary researchers

\begin{tabular}{|c|c|c|}
\hline Notes & \multicolumn{2}{|c|}{$\begin{array}{l}\text { Country: USA } \\
\text { Setting: single hospital, adult ICU }\end{array}$} \\
\hline \multicolumn{3}{|l|}{ Risk of bias } \\
\hline Bias & Authors' judgement & Support for judgement \\
\hline $\begin{array}{l}\text { Random sequence genera- } \\
\text { tion (selection bias) }\end{array}$ & Unclear risk & $\begin{array}{l}\text { Quote: "Patients meeting the eligibility criteria were randomly assigned to re- } \\
\text { ceive one of the following two prophylaxis regimen..." }\end{array}$ \\
\hline & & Comment: insufficient information to make a judgement \\
\hline $\begin{array}{l}\text { Allocation concealment } \\
\text { (selection bias) }\end{array}$ & Unclear risk & Comment: insufficient information to make a judgement \\
\hline $\begin{array}{l}\text { Blinding of participants } \\
\text { and personnel (perfor- } \\
\text { mance bias) } \\
\text { All outcomes }\end{array}$ & Unclear risk & Comment: insufficient information to make a judgement \\
\hline $\begin{array}{l}\text { Blinding of outcome as- } \\
\text { sessment (detection bias) } \\
\text { All outcomes }\end{array}$ & Unclear risk & Comment: insufficient information to make a judgement \\
\hline $\begin{array}{l}\text { Incomplete outcome data } \\
\text { (attrition bias) } \\
\text { All outcomes }\end{array}$ & Low risk & $\begin{array}{l}\text { Comment: missing outcome data balanced in numbers across groups, and rea- } \\
\text { sons for missing outcome data unlikely to be related to true outcome }\end{array}$ \\
\hline $\begin{array}{l}\text { Selective reporting (re- } \\
\text { porting bias) }\end{array}$ & Low risk & $\begin{array}{l}\text { Comment: the study protocol was not available, but it was clear that the pub- } \\
\text { lished report included all expected outcomes }\end{array}$ \\
\hline Other bias & Low risk & The study appeared free of other sources of bias \\
\hline
\end{tabular}

\section{Albert 2014}

$\begin{array}{ll}\text { Methods } & \text { Multicentre pilot randomized trial of antifungal therapy in critically ill patients with a clinical suspicion } \\ \text { of ventilator-associated pneumonia with positive airway secretion specimens for Candida spp. An ob- } \\ \text { servational group with patients without Candida spp. in their airway secretions was also included }\end{array}$

Duration of the study: August 2010 to July 2012

Patients excluded/patients randomized: $1 / 61$ (1.6\%)

Sample size calculation/method description: Yes/Yes

Age (mean): 57.6 years (treatment group), 63 years (placebo group)

Sex: 44 men, 16 women

Inclusion criteria: Non-immunocompromised adult patients admitted to ICU for at least 96 hours who developed a clinically suspected ventilator-associated pneumonia after 48 hours of mechanical ven- 
Albert 2014 (Continued)

tilation and who had grown Candida spp. from respiratory tract secretion cultures collected within 24 hours of suspicion of infection

Exclusion criteria: patients with Candida spp. in any other site

\section{Percentage post-surgical: $44 \%$}

Percentage colonized with Candida at baseline: $98 \%$

1. Anidulafungin $200 \mathrm{mg}$ IV followed by $100 \mathrm{mg}$ daily for at least 72 hours (study medication was de-es-
calated in a blinded manner by the local research pharmacist to fluconazole or matching placebo when
Candida spp. were sensitive to fluconazole; $77.4 \%$ of the patients in the intervention arm were sequen-
tially transferred to fluconazole) $(n=32)$

2. Placebo $(n=29)$

Duration of the intervention: 14 days

\begin{tabular}{ll}
\hline Outcomes & Mortality \\
& Fungal colonization \\
& Follow-up duration: for the ICU stay or until 28 days after enrolment \\
\hline $\begin{array}{l}\text { Type of antifungal treat- } \\
\text { ment }\end{array}$ & Empiric \\
\hline $\begin{array}{l}\text { Funding sources } \\
\text { Declaration of interest } \\
\text { among the primary re- } \\
\text { searchers }\end{array}$ & Quote: "Sources of support: Physicians' Services Incorporated Foundation and Pfizer Inc." \\
\hline $\begin{array}{l}\text { Notes } \\
\text { The authors declare no potential conflict of interest }\end{array}$ \\
$\begin{array}{l}\text { Country: Canada } \\
\text { Setting: multicentre study, ICU } \\
\text { Other: One patient was moved from the interventional arm to observational group (before starting the } \\
\text { treatment) because he did not have all inclusion criteria. We did not consider the observational group } \\
\text { for the analysis. }\end{array}$ \\
$\begin{array}{l}\text { The study was halted prematurely because of difficulty in recruiting patients and diminishing study re- } \\
\text { sources }\end{array}$
\end{tabular}

\section{Risk of bias}

\begin{tabular}{|c|c|c|}
\hline Bias & Authors' judgement & Support for judgement \\
\hline $\begin{array}{l}\text { Random sequence genera- } \\
\text { tion (selection bias) }\end{array}$ & Low risk & $\begin{array}{l}\text { Quote: "Study patients were randomized using a web-based system to receive } \\
\text { antifungals or matching placebo" }\end{array}$ \\
\hline $\begin{array}{l}\text { Allocation concealment } \\
\text { (selection bias) }\end{array}$ & Unclear risk & $\begin{array}{l}\text { Comment: insufficient information to make a judgement about allocation con- } \\
\text { cealment }\end{array}$ \\
\hline $\begin{array}{l}\text { Blinding of participants } \\
\text { and personnel (perfor- } \\
\text { mance bias) } \\
\text { All outcomes }\end{array}$ & Low risk & $\begin{array}{l}\text { Quote: "Masking: double blind (subject, caregiver, investigator, outcomes as- } \\
\text { sessor)" (quoted from the study protocol) }\end{array}$ \\
\hline
\end{tabular}


Albert 2014 (Continued)

$\begin{array}{ll}\begin{array}{l}\text { Blinding of outcome as- } \\ \text { sessment (detection bias) }\end{array} \quad \text { Low risk } & \begin{array}{l}\text { Quote: "masking: double blind (subject, caregiver, investigator, outcomes, as- } \\ \text { sessor)" (quoted from study protocol) }\end{array}\end{array}$

All outcomes sessor)" (quoted from study protocol)

\begin{tabular}{lll}
\hline $\begin{array}{l}\text { Incomplete outcome data } \\
\text { (attrition bias) } \\
\text { All outcomes }\end{array}$ & Low risk & Comment: no missing outcome data \\
\hline $\begin{array}{l}\text { Selective reporting (re- } \\
\text { porting bias) }\end{array}$ & Low risk & $\begin{array}{l}\text { Comment: the study protocol was available and all of the study pre-specified } \\
\text { outcomes that were of interest in the review were reported }\end{array}$ \\
\hline Other bias & Low risk & Comment: the study appeared be free from others bias \\
\hline
\end{tabular}

\begin{tabular}{ll}
\hline Methods & Multicentre, randomized, parallel-group study \\
Duration of the study: March 1996 to January 1997 \\
Patients excluded/patients randomized: $0 / 234(0 \%)$ \\
Sample size calculation/method description: Yes/Yes
\end{tabular}

\section{Participants}

Patients randomized: 234

Age (mean): 55 years (treatment group), 52 years (placebo group)

Sex: 140 men, 94 women

Inclusion criteria: acute lung injury (ALI) or acute respiratory distress syndrome (ARDS) for direct or indirect lung injury

Exclusion criteria: age younger than 18 years, participation in other interventional trials within previous 30 days, pregnancy, increased intracranial pressure, neurologic conditions that could impair weaning from ventilator support, sickle cell disease, severe chronic respiratory disease, morbid obesity, burns covering at least $30 \%$ or a history of bone marrow or lung transplantation

Patients were also excluded if the clinicians caring for them were not agreeable to using volume-cycled assist/control ventilation for at least 12 hours or were not committed to providing aggressive life support at the time of enrolment. Finally, patients were excluded if they received any imidazole within seven days or terfenadine, astemizole, or cisapride within the preceding three days; had an allergy to imidazoles or their derivatives; had severe chronic liver disease (defined as a Child-Pugh score of $\geq 10$ ); or had evidence of acute viral, ischemic, or toxic hepatitis with moderate or severe acute hepatocellular or cholestatic injury

Percentage post-surgical: not reported

Percentage colonized with Candida at baseline: not reported

Interventions 1. Ketoconazole $400 \mathrm{mg} /$ day orally $(\mathrm{n}=117)$

2. Placebo $(n=117)$

Duration of the intervention: until 48 hours post-extubation

\begin{tabular}{ll}
\hline Outcomes & Mortality \\
& Adverse events requiring cessation
\end{tabular}

Follow-up duration: not stated 
ARDS Network 2000 (Continued)

Type of antifungal treat- Prophylactic ment

Funding sources

Quote: "This work was supported by National Institute of Health/National Heart, Lung, and Blood Institute Contracts N01-HR46054-64"

\section{Declaration of interest Not reported}

among the primary re-

searchers

Country: USA
Setting: 24 centres, adult ICU
Other: This study tested the efficacy of ketoconazole in reducing mortality and morbidity in patients
with ARDS basing on its anti-inflammatory activity. Thus, the study did not investigate the antifungal
effect of ketoconazole directly

\section{Risk of bias}

\begin{tabular}{lll}
\hline Bias & Authors' judgement & Support for judgement \\
\hline $\begin{array}{l}\text { Random sequence genera- } \\
\text { tion (selection bias) }\end{array}$ & Low risk & $\begin{array}{l}\text { Quote: "The data coordinating center provided assignment using a comput- } \\
\text { er-generated randomization" }\end{array}$ \\
\hline $\begin{array}{l}\text { Allocation concealment } \\
\text { (selection bias) }\end{array}$ & Low risk & $\begin{array}{l}\text { Quote: "After informed consent was obtained, the data coordinating center } \\
\text { provided assignment using a computer-generated randomization" } \\
\text { Comment: central allocation of participants }\end{array}$ \\
\hline
\end{tabular}

$\begin{array}{ll}\begin{array}{l}\text { Blinding of participants } \\ \text { and personnel (perfor- }\end{array} & \begin{array}{l}\text { Quote: "The local research pharmacist was unblinded to the treatment assign- } \\ \text { ment and prepared the study drug for administration while the patients, inves- } \\ \text { mance bias) }\end{array} \\ \begin{array}{l}\text { tigators, study coordinator, and all clinical personnel remained blinded to the } \\ \text { All outcomes }\end{array} & \text { randomization" }\end{array}$

\begin{tabular}{|c|c|c|}
\hline $\begin{array}{l}\text { Blinding of outcome as- } \\
\text { sessment (detection bias) } \\
\text { All outcomes }\end{array}$ & Low risk & $\begin{array}{l}\text { Quote: "The local research pharmacist was unblinded to the treatment assign- } \\
\text { ment and prepared the study drug for administration while the patients, inves- } \\
\text { tigators, study coordinator, and all clinical personnel remained blinded to the } \\
\text { randomization" }\end{array}$ \\
\hline
\end{tabular}

\begin{tabular}{|c|c|c|}
\hline $\begin{array}{l}\text { Incomplete outcome data } \\
\text { (attrition bias) }\end{array}$ & Low risk & $\begin{array}{l}\text { Comment: no missing outcome data. All patients who were randomized were } \\
\text { included in the final analysis }\end{array}$ \\
\hline
\end{tabular}

All outcomes

\begin{tabular}{|c|c|c|}
\hline $\begin{array}{l}\text { Selective reporting (re- } \\
\text { porting bias) }\end{array}$ & Low risk & $\begin{array}{l}\text { Comment: the study protocol was not available but it was clear that the pub } \\
\text { lished report included all expected outcomes }\end{array}$ \\
\hline
\end{tabular}

\begin{tabular}{|c|c|c|}
\hline porting bias) & & lished report included all expected outcomes \\
\hline Other bias & Low risk & Comment: the study appeared free of other biases \\
\hline
\end{tabular}

\section{Beshey 2014}

Methods Monocentre, randomized, parallel-group (three groups) study

Duration of the study: not reported

Patients excluded/patients randomized: $0 / 75(0 \%)$

Sample size calculation/method description: Yes/Yes 
Beshey 2014 (Continued)

Participants
Patients randomized: 75

Age (mean): 51.9 years (SDD), 48.9 years (SDD + fluconazole), 50.9 years (no intervention)

Sex: 40 men, 35 women

Inclusion criteria: mechanical ventilation $>48$ hours and expected further 72 hours.

Exclusion criteria: pregnancy, receipt of antifungal agents within seven days before ICU admission, age younger than 18 years, an expectation that the patient would not survive more than 24 hours, and patients who did not complete the 15 day period of the study either due to discharge from ICU or death

Percentage post-surgical: not reported

Percentage colonized with Candida at baseline: not reported

Interventions

1. SDD: oral decontamination with chlorhexidine to the mouth and gums every six hours for the whole period of the study; gut decontamination with colistin, polymyxin $E 1,500,000$ units enterally every eight hours for the whole period of the study; respiratory tract decontamination with cefotaxime 1 gram IV every eight hours for four days $(n=25)$

2. SDD + fluconazole: $200 \mathrm{mg}$ fluconazole enterally on the first day, then $100 \mathrm{mg}$ every day $(n=25)$

3. No intervention $(n=25)$

Duration of the intervention: until initiation of systemic antifungal drug according to cultures results or ICU discharge

\begin{tabular}{|c|c|c|}
\hline \multirow[t]{3}{*}{ Outcomes } & \multicolumn{2}{|l|}{ Proven IFI } \\
\hline & \multicolumn{2}{|l|}{ Fungal colonization } \\
\hline & \multicolumn{2}{|c|}{$\begin{array}{l}\text { Follow-up duration: two weeks from admission or the institution of systemic antifungal drug accord- } \\
\text { ing to the cultures results }\end{array}$} \\
\hline $\begin{array}{l}\text { Type of antifungal treat- } \\
\text { ment }\end{array}$ & \multicolumn{2}{|l|}{ Prophylactic } \\
\hline Funding sources & \multicolumn{2}{|c|}{ Quote: "Open access funded by Alexandria University Faculty of Medicine" } \\
\hline $\begin{array}{l}\text { Declaration of interest } \\
\text { among the primary re- } \\
\text { searchers }\end{array}$ & \multicolumn{2}{|l|}{ Quote: "None declared" } \\
\hline \multirow[t]{3}{*}{ Notes } & \multicolumn{2}{|l|}{ Country: Egypt } \\
\hline & \multicolumn{2}{|c|}{ Setting: single hospital, adult ICU } \\
\hline & \multicolumn{2}{|c|}{$\begin{array}{l}\text { Other: we did not include this study in the quantitative analysis due to high risk of bias in the key do- } \\
\text { mains }\end{array}$} \\
\hline \multicolumn{3}{|l|}{ Risk of bias } \\
\hline Bias & Authors' judgement & Support for judgement \\
\hline $\begin{array}{l}\text { Random sequence genera- } \\
\text { tion (selection bias) }\end{array}$ & Unclear risk & $\begin{array}{l}\text { Quote: "patients were randomly categorized into three equals groups ( } 25 \text { pa- } \\
\text { tients each)" }\end{array}$ \\
\hline & & Comment: insufficient information to make a judgement \\
\hline
\end{tabular}


Beshey 2014 (Continued)

$\begin{aligned} & \text { Allocation concealment } \\ & \text { (selection bias) }\end{aligned} \quad$ Unclear risk Comment: insufficient information to make a judgement

\begin{tabular}{|c|c|c|}
\hline $\begin{array}{l}\text { Blinding of participants } \\
\text { and personnel (perfor- }\end{array}$ & High risk & $\begin{array}{l}\text { Comment: no placebo and no masking of the drugs. No blinding of partici- } \\
\text { pants and personnel }\end{array}$ \\
\hline
\end{tabular}

mance bias)

All outcomes

Blinding of outcome as-
sessment (detection bias) $\quad$ High risk Comment: no blinding of outcome assessment

ent (detection bias)

All outcomes

Incomplete outcome data High risk

(attrition bias)

All outcomes

\begin{abstract}
Quote: "the study period was 15 days from admission...patients were excluded...if they did not complete the 15 day period of the study either due to discharge from ICU or death".

Comment: The authors excluded patients who died or were discharged within the 15-day period of intervention. The study did not report the number of these patients and the events that possibly occurred to them. Even though the primary outcome of this study is the effect of treatment in terms of reduction of severity score, colonization and infections during the study period, the missing data from patients excluded for this reason could be a potential source of bias. According to the study protocol, it was clear that these patients had been excluded retrospectively (after randomization and either discharge or death within 15 days)
\end{abstract}

\begin{tabular}{lll}
\hline $\begin{array}{l}\text { Selective reporting (re- } \\
\text { porting bias) }\end{array}$ & Low risk & $\begin{array}{l}\text { Comment: the study protocol was not available but it was clear that the pub- } \\
\text { lished report included all expected outcomes, including those that were pre- } \\
\text { specified }\end{array}$ \\
\hline Other bias & High risk & $\begin{array}{l}\text { Comment: the study had a potential source of bias related to the specific study } \\
\text { design used (patients were considered eligible if they were mechanically venti- } \\
\text { lated during the previous 48 hours. However, study intervention (SDD) was giv- } \\
\text { en from the first day of ICU admission) }\end{array}$
\end{tabular}

Eggimann 1999

Two-centre, randomized, parallel group study
Duration of the study: the period was 30-month long but the date were not reported
Patients excluded/patients randomized: $6 / 49(12 \%)$

Sample size calculation/method description: Yes/Yes

Participants

Patients randomized: 49

Age (median): 63 years (treatment group), 57 years (placebo group)

Sex: 28 male, 15 women

Inclusion criteria: recent abdominal surgery, recurrent gastrointestinal tract perforation, or anastomotic leakage

Exclusion criteria: documented or probable fungal infection requiring antifungal therapy, treatment with any investigational drug or with systemic antifungal drugs within 2 weeks of study entry, liver function tests that were at least five times the upper limit of normal, hepatic coma, renal failure requiring haemodialysis or peritoneal dialysis, or a high probability of death within 72 hours of study entry

Percentage post-surgical: $100 \%$ 
Eggimann 1999 (Continued)

Percentage colonized with Candida at baseline: $40 \%$

Interventions 1. Fluconazole $400 \mathrm{mg} /$ day IV $(\mathrm{n}=25)$

2. Placebo $(n=24)$

Duration of the intervention: until complete resolution of intra-abdominal disease

$\begin{array}{ll}\text { Outcomes } & \text { Mortality } \\ & \text { Proven IFI } \\ & \text { Proven IFI with azole-resistant species } \\ & \text { Fungal colonization } \\ & \text { Fungal colonization with azole-resistant species } \\ & \text { Adverse events requiring cessation }\end{array}$

Follow-up duration: until one week post-prophylaxis

\begin{tabular}{ll}
$\begin{array}{l}\text { Type of antifungal treat- } \\
\text { ment }\end{array}$ & Prophylaxis \\
\hline Funding sources & $\begin{array}{l}\text { Quote: "Supported, in part, by a grant from Pfizer AG, Zurich, Switzerland. The funding agency did not } \\
\text { participate in the collection or in the analysis of the data" }\end{array}$ \\
\hline
\end{tabular}

Declaration of interest Not reported among the primary researchers

\begin{tabular}{|c|c|c|}
\hline Notes & \multicolumn{2}{|c|}{$\begin{array}{l}\text { Country: Switzerland } \\
\text { Setting: two hospitals, adult surgical/medical ICU } \\
\text { Other: the study was halted prematurely due to slow recruitment }\end{array}$} \\
\hline \multicolumn{3}{|l|}{ Risk of bias } \\
\hline Bias & Authors' judgement & Support for judgement \\
\hline $\begin{array}{l}\text { Random sequence genera- } \\
\text { tion (selection bias) }\end{array}$ & Unclear risk & Comment: insufficient information to make a judgement \\
\hline $\begin{array}{l}\text { Allocation concealment } \\
\text { (selection bias) }\end{array}$ & Low risk & $\begin{array}{l}\text { Quote: "Each hospital pharmacy was provided with a randomization list estab- } \\
\text { lished using randomly permuted blocks of ten, so as to allocate five patients to } \\
\text { each regimen for every ten patients entered into the study" }\end{array}$ \\
\hline $\begin{array}{l}\text { Blinding of participants } \\
\text { and personnel (perfor- } \\
\text { mance bias) } \\
\text { All outcomes }\end{array}$ & Low risk & $\begin{array}{l}\text { Quote: "Patients were randomized to receive fluconazole ( } 400 \mathrm{mg} \text { once a day) } \\
\text { or an identical-appearing placebo ( } 5 \% \text { dextrose) administered intravenously } \\
\text { for } 30 \text { minutes" } \\
\text { Comment: probably patients and personnel were blinded }\end{array}$ \\
\hline $\begin{array}{l}\text { Blinding of outcome as- } \\
\text { sessment (detection bias) } \\
\text { All outcomes }\end{array}$ & Low risk & $\begin{array}{l}\text { Quote: "To ensure the uniform recording of data, they were collected by a sin- } \\
\text { gle person (P.E.) who was blinded as to study drug assignments. A five-person } \\
\text { monitoring committee, composed of three infectious disease specialists, a } \\
\text { general surgeon, and a clinical microbiologist, performed blinded evaluation } \\
\text { of each patient's eligibility, medical and surgical treatments, result of prophy- } \\
\text { laxis, cause of any infection, and cause of death" }\end{array}$ \\
\hline $\begin{array}{l}\text { Incomplete outcome data } \\
\text { (attrition bias) } \\
\text { All outcomes }\end{array}$ & Low risk & $\begin{array}{l}\text { Comment: missing data outcome balanced across groups, with similar reasons } \\
\text { for missing data across groups }\end{array}$ \\
\hline
\end{tabular}


Eggimann 1999 (Continued)

Selective reporting (re- Low risk Comment: the study protocol was not available but it was clear that the pubporting bias) lished report included all expected outcomes, including those that were prespecified

Other bias Low risk Comment: The study appeared free of other sources of bias

Garbino 2002

Methods
Duration of the study: the period was 30 months but the dates were not reported
Patients excluded/patients randomized: $16 / 220(7 \%)$

Sample size calculation/method description: Yes/Yes

\begin{abstract}
Participants
Patients randomized: 220

Age (mean): 52.9 years (treatment group), 55.9 years (placebo group)

Sex: 140 men, 64 women

Inclusion criteria: mechanical ventilation $>48$ hours and expected further 72 hours and receiving selective digestive decontamination

Exclusion criteria: life expectancy less than 7 days after randomization, history of systemic fungal infection, allergy to azoles, treatment with an antifungal agent seven days before randomization, blood culture positive for Candida spp. at study entry, acquired immunodeficiency syndrome, persistence of a prothrombin time less than $50 \%$ after 24 hours of administration of vitamin $\mathrm{K}(20 \mathrm{mg})$, neutropenia, pregnancy, anticipated duration of mechanical ventilation less than 72 hours at study entry, and refusal to give informed consent.

Percentage post-surgical: $60 \%$

Percentage colonized with Candida at baseline: $48 \%$
\end{abstract}

Interventions $\quad$ 1. Fluconazole $100 \mathrm{mg} /$ day IV $(\mathrm{n}=110)$

2. Placebo $(n=110)$

Duration of the intervention: until withdrawal from mechanical ventilation

\begin{tabular}{ll}
\hline Outcomes & Mortality \\
& Proven IFI \\
& Suspected IFI \\
& Proven IFI with azole-resistant species \\
& Superficial FI \\
& Fungal colonization \\
& Fungal colonization with azole-resistant species \\
& Adverse events requiring cessation
\end{tabular}

Follow-up duration: at least 30 days

\begin{tabular}{ll}
\hline $\begin{array}{l}\text { Type of antifungal treat- } \\
\text { ment }\end{array}$ & Prophylaxis \\
\hline Funding sources & Quote: "The study was supported by an unrestricted grant by Pfizer Inc. Zurich, Switzerland" \\
\hline $\begin{array}{l}\text { Declaration of interest } \\
\text { among the primary re- }\end{array}$ & Not reported \\
searchers &
\end{tabular}


Garbino 2002 (Continued)

$\begin{array}{ll}\text { Notes } & \text { Country: Switzerland } \\ \text { Setting: single hospital, adult surgical/medical ICU }\end{array}$

\section{Risk of bias}

\begin{tabular}{lll} 
Bias & Authors' judgement & Support for judgement \\
\hline $\begin{array}{l}\text { Random sequence genera- } \\
\text { tion (selection bias) }\end{array}$ & Unclear risk & $\begin{array}{l}\text { Quote: "Patients were randomly assigned... according to a list blinded to the } \\
\text { study investigators and physicians in charge" }\end{array}$ \\
& $\begin{array}{l}\text { Comment: insufficient information to make a judgement about random se- } \\
\text { quence generation }\end{array}$
\end{tabular}

\begin{tabular}{ll}
\hline $\begin{array}{l}\text { Allocation concealment } \\
\text { (selection bias) }\end{array}$ & Low risk \\
suote: "Patients were randomly assigned... according to a list blinded to the \\
studyestigators and physicians in charge"
\end{tabular}

\begin{tabular}{|c|c|c|}
\hline $\begin{array}{l}\text { Blinding of participants } \\
\text { and personnel (perfor- } \\
\text { mance bias) } \\
\text { All outcomes }\end{array}$ & Low risk & $\begin{array}{l}\text { Quote: "Patients were randomly assigned to receive PNV (polymyxin B ( } 150 \\
\mathrm{mg} \text { ), neomycin ( } 1000 \mathrm{mg} \text { ), and vancomycin ( } 1000 \mathrm{mg} \text { ), in a } 60 \mathrm{ml} \text { solution) } \\
\text { plus intravenous fluconazole }(100 \mathrm{mg} \text { in } 50 \mathrm{ml} \mathrm{NaCl} 0.9 \% ; \mathrm{n}=103 \text { ) or PNV plus } \\
\text { placebo ( } 50 \mathrm{ml} \mathrm{NaCl} 0.9 \% ; \mathrm{n}=101) \text { according to a list blinded to the study in- } \\
\text { vestigators and physicians in charge" }\end{array}$ \\
\hline
\end{tabular}

\begin{tabular}{|c|c|c|}
\hline $\begin{array}{l}\text { Blinding of outcome as- } \\
\text { sessment (detection bias) }\end{array}$ & Low risk & $\begin{array}{l}\text { Quote: "Patients were randomly assigned... according to a list blinded to the } \\
\text { study investigators and physicians in charge" }\end{array}$ \\
\hline
\end{tabular}

\begin{tabular}{lll}
\hline $\begin{array}{l}\text { Incomplete outcome data } \\
\text { (attrition bias) } \\
\text { All outcomes }\end{array}$ & Low risk & $\begin{array}{l}\text { Comment: missing outcome data balanced in numbers across intervention } \\
\text { groups, with similar reasons for missing data across groups }\end{array}$ \\
\hline $\begin{array}{l}\text { Selective reporting (re- } \\
\text { porting bias) }\end{array}$ & Low risk & $\begin{array}{l}\text { Comment: the study protocol was not available but it was clear that the pub- } \\
\text { lished reports included all expected outcomes }\end{array}$ \\
\hline Other bias & Low risk & Comment: the study appeared to be free of other sources of bias \\
\hline
\end{tabular}

Giglio 2012

Monocentre, randomized, parallel-group study
Duration of the study: November 2008 to August 2009
Patients excluded/patients randomized: $29 / 128(23 \%)$
Sample size calculation/method description: Yes/Yes

Participants

Patients randomized: 128

Age (mean): 54 years (treatment group), 38 years (no intervention group)

Sex: 61 men, 38 women

Inclusion criteria: surgical patients admitted to ICU, $>18$ years of age and expected to require invasive mechanical ventilation for more than 48 hours

Exclusion criteria: pregnancy, proven Candida infections, prophylactic or curative antifungal treatment within last 2 months, contraindication to oral drug administration, known allergy to nystatin or its derivatives, and prior inclusion in the study 
Giglio 2012 (Continued)

Percentage post-surgical: $61 \%$

Percentage colonized with Candida at baseline: $70 \%$

Interventions

1. Nystatin $2 \times 10^{6}$ unit administered three times daily via nasogastric tube $(n=75)$

2. No intervention $(n=53)$

Duration of the intervention: not reported

\begin{tabular}{|c|c|c|}
\hline \multirow[t]{5}{*}{ Outcomes } & \multicolumn{2}{|l|}{ Mortality } \\
\hline & \multicolumn{2}{|l|}{ Proven IFI } \\
\hline & \multicolumn{2}{|l|}{ Fungal colonization } \\
\hline & \multicolumn{2}{|c|}{ Adverse events requiring cessation } \\
\hline & \multicolumn{2}{|c|}{ Follow-up duration: throughout the ICU stay } \\
\hline $\begin{array}{l}\text { Type of antifungal treat- } \\
\text { ment }\end{array}$ & \multicolumn{2}{|l|}{ Prophylaxis } \\
\hline Funding sources & \multicolumn{2}{|c|}{ Quote: "Support was provided solely from departmental sources" } \\
\hline $\begin{array}{l}\text { Declaration of interest } \\
\text { among the primary re- } \\
\text { searchers }\end{array}$ & \multicolumn{2}{|c|}{ Quote: "The authors declare that they have no competing interests" } \\
\hline Notes & \multirow{2}{*}{\multicolumn{2}{|c|}{$\begin{array}{l}\text { Country: Italy } \\
\text { Setting: single hospital, adult ICU }\end{array}$}} \\
\hline & & \\
\hline \multicolumn{3}{|l|}{ Risk of bias } \\
\hline Bias & Authors' judgement & Support for judgement \\
\hline Random sequence genera- & Unclear risk & Quote: "Patients were randomized to one of the two study groups" \\
\hline 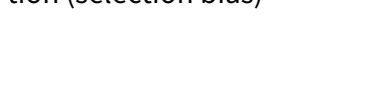 & & $\begin{array}{l}\text { Comment: insufficient information to make a judgement about random se- } \\
\text { quence generation }\end{array}$ \\
\hline $\begin{array}{l}\text { Allocation concealment } \\
\text { (selection bias) }\end{array}$ & Low risk & $\begin{array}{l}\text { Quote: "Patients were randomized to one of the two study groups, according } \\
\text { to a randomization sealed envelope opened on admission to the ICU" }\end{array}$ \\
\hline $\begin{array}{l}\text { Blinding of participants } \\
\text { and personnel (perfor- } \\
\text { mance bias) } \\
\text { All outcomes }\end{array}$ & Low risk & $\begin{array}{l}\text { Quote: "The attending physicians were not aware of the results of the coloniza- } \\
\text { tion samples, and therefore no empirical or pre-emptive antifungal therapy } \\
\text { was in place in enrolled patients" }\end{array}$ \\
\hline $\begin{array}{l}\text { Blinding of outcome as- } \\
\text { sessment (detection bias) } \\
\text { All outcomes }\end{array}$ & Low risk & $\begin{array}{l}\text { Quote: "Group assignment was not indicated on the specimens, so the mycol- } \\
\text { ogists were therefore blinded to treatment allocation" }\end{array}$ \\
\hline $\begin{array}{l}\text { Incomplete outcome data } \\
\text { (attrition bias) } \\
\text { All outcomes }\end{array}$ & Low risk & Comment: missing data outcome balanced across groups \\
\hline
\end{tabular}


Giglio 2012 (Continued)

$\begin{array}{ll}\begin{array}{l}\text { Selective reporting (re- } \quad \text { Low risk } \\ \text { porting bias) }\end{array} & \begin{array}{l}\text { Comment: the study protocol was available and all of the study's pre-specified } \\ \text { (primary and secondary) outcomes of interest for review were reported in the } \\ \text { prespecified way }\end{array}\end{array}$

\begin{tabular}{ll}
\hline Other bias $\quad$ Low risk $\quad$ Comment: The study appeared free of other sources of bias \\
\hline
\end{tabular}

He 2003

Methods Monocentre randomized trial with three parallel groups: 1) fluconazole; 2) garlicin; 3) no intervention.
We did not consider the garlicin group for this review

Duration of the study: January 1998 to December 2002

Patients excluded/patients randomized: 0/70 (0\%)

Sample size calculation/method description: No/No

Patients randomized: 70
Age (mean): 48.7 years (fluconazole group), 51.4 years (garlicin group) years, 50.5 years (no interven-
tion group)
Sex: $37 \mathrm{men}, 33$ women
Inclusion criteria: clinical diagnosis criteria for acute pancreatitis proposed by the Pancreas Surgery
Group of the Chinese Medical Association in 1997 and complicated with one of the following predispos-
ing factors of deep fungal infections such as gerontism, history of diabetes, dysfunction of one or more
organs, non-iatrogenic fasting hyperglycaemia (9 mmol/L), central venous catheter, total parenteral
nutrition, retaining urethral catheterization, operation, gastrointestinal fistula, ICU, breathing machine
supported $\geq$ five days, user of glucocorticoid $\geq$ five days, administration of broad spectrum antibiotics $\geq$
five days or super broad spectrum antibiotics $\geq$ five days

Exclusion criteria: not stated

Percentage post-surgical: not stated

Percentage colonized with Candida at baseline: not stated

I. Fluconazole $100 \mathrm{mg} /$ day IV $(n=22)$
2. Garlicin $120 \mathrm{mg} /$ day IV $(n=25)$
3. No intervention $(n=23)$
Duration of the intervention: until relief of predisposing condition

Outcomes Proven IFI

Follow-up duration: not stated

Type of antifungal treat- Prophylaxis
ment

\begin{tabular}{ll}
\hline Funding sources & Not reported \\
\hline $\begin{array}{l}\text { Declaration of interest } \\
\text { among the primary re- } \\
\text { searchers }\end{array}$ & Not reported \\
\hline Notes & $\begin{array}{l}\text { Country: China } \\
\text { Setting: single hospital, ward and ICU }\end{array}$ \\
\hline
\end{tabular}

\section{Risk of bias}

Antifungal agents for preventing fungal infections in non-neutropenic critically ill patients (Review)

Copyright $\odot 2018$ The Cochrane Collaboration. Published by John Wiley \& Sons, Ltd. 
He 2003 (Continued)

\begin{tabular}{lll} 
Bias & Authors' judgement & Support for judgement \\
\hline $\begin{array}{l}\text { Random sequence genera- } \\
\text { tion (selection bias) }\end{array}$ & Unclear risk & Comment: insufficient information to permit a judgement \\
\hline
\end{tabular}

Allocation concealment Unclear risk Comment: insufficient information to permit a judgement

(selection bias)

Blinding of participants Unclear risk Comment: insufficient information to permit a judgement
and personnel (perfor-
mance bias)
All outcomes

\begin{tabular}{|c|c|c|}
\hline $\begin{array}{l}\text { Blinding of outcome as- } \\
\text { sessment (detection bias) } \\
\text { All outcomes }\end{array}$ & Unclear risk & Comment: insufficient information about blinding of outcome assessment \\
\hline $\begin{array}{l}\text { Incomplete outcome data } \\
\text { (attrition bias) } \\
\text { All outcomes }\end{array}$ & Low risk & Comment: no missing data outcome. All randomized patients were analysed \\
\hline $\begin{array}{l}\text { Selective reporting (re- } \\
\text { porting bias) }\end{array}$ & Low risk & $\begin{array}{l}\text { Comment: the protocol was not available but it was clear that published re- } \\
\text { port included all expected outcomes }\end{array}$ \\
\hline Other bias & Low risk & Comment: no apparent risk for other bias \\
\hline
\end{tabular}

Jacobs 2003

$\begin{array}{ll}\text { Methods } & \text { Monocentre, randomized, parallel-group study } \\ & \text { Duration of the study: December } 1998 \text { to June } 2001 \\ \text { Patients excluded/patients randomized: } 0 / 71(0 \%)\end{array}$

Sample size calculation/method description: No/No

Patients randomized: 71
Pge (mean): 17 patients in both group had < 50 years of age, 16 patients in the treatment group had >
50 years of age, 21 patients in the placebo group had > 50 years of age
Sex: 40 men, 31 women
Inclusion criteria: early septic shock (within 24 hours of onset) from gastrointestinal tract perforation
or nosocomial pneumonia
Exclusion criteria: pregnant women, patients aged $>16$ yrs; patients with cirrhosis of the liver, under-
lying malignancy, or neurologic failure (Glasgow Coma Scale score < six) or any patients considered as
having a hopeless prognosis, (i.e. any patient unlikely to survive 30 days)
Percentage post-surgical: $65 \%$
Percentage colonized with Candida at baseline: $6 \%$

Interventions Fluconazole $200 \mathrm{mg}$ daily IV $(\mathrm{n}=32)$

2. Placebo $(n=39)$

Duration of the intervention: for duration of septic shock

\begin{tabular}{ll}
\hline Outcomes & Mortality \\
& Proven IFI
\end{tabular}


Jacobs 2003 (Continued)

Proven IFI with azole-resistant species

Fungal colonization

Follow-up duration: 30 days

Type of antifungal treat- Empiric
ment

ment

\begin{tabular}{ll}
\hline Funding sources & Not reported \\
\hline $\begin{array}{l}\text { Declaration of interest } \\
\text { among the primary re- } \\
\text { searchers }\end{array}$ & Not reported \\
\hline
\end{tabular}

\begin{tabular}{ll}
\hline Notes & Country: Saudi Arabia \\
Setting: single hospital, adult surgical/medical ICU
\end{tabular}

\section{Risk of bias}

\begin{tabular}{lll}
\hline Bias & Authors' judgement & Support for judgement \\
\hline $\begin{array}{l}\text { Random sequence genera- } \\
\text { tion (selection bias) }\end{array}$ & Unclear risk & $\begin{array}{l}\text { Quote: "all patients...were randomized by a closed envelope system in our } \\
\text { pharmacy..." }\end{array}$ \\
& $\begin{array}{l}\text { Comment: insufficient information to make a judgement about random se- } \\
\text { quence generation }\end{array}$ \\
\hline
\end{tabular}

\begin{tabular}{ll}
\hline $\begin{array}{l}\text { Allocation concealment } \\
\text { (selection bias) }\end{array}$ & $\begin{array}{l}\text { Quote: "all patients...were randomized by a closed envelope system in our } \\
\text { pharmacy to receive } 200 \mathrm{mg} \text { of fluconazole daily in } 100 \mathrm{~mL} \text { of isotonic saline } \\
\text { over } 1 \mathrm{hr} \text { by intravenous infusion (test group), or } 100 \mathrm{~mL} \text { of isotonic saline } \\
\text { alone by intravenous infusion over } 1 \mathrm{hr} \text { (placebo group) for the duration of } \\
\text { their septic shock" } \\
\text { Comment: central allocation (pharmacy-controlled randomization) }\end{array}$
\end{tabular}

\begin{tabular}{|c|c|c|}
\hline $\begin{array}{l}\text { Blinding of participants } \\
\text { and personnel (perfor- } \\
\text { mance bias) } \\
\text { All outcomes }\end{array}$ & Low risk & $\begin{array}{l}\text { Quote: "all patients...were randomized by a closed envelope system in our } \\
\text { pharmacy to receive } 200 \mathrm{mg} \text { of fluconazole daily in } 100 \mathrm{~mL} \text { of isotonic saline } \\
\text { over } 1 \mathrm{hr} \text { by intravenous infusion (test group), or } 100 \mathrm{~mL} \text { of isotonic saline } \\
\text { alone by intravenous infusion over } 1 \mathrm{hr} \text { (placebo group) for the duration of } \\
\text { their septic shock" }\end{array}$ \\
\hline & & Quote: "Doctors and nurses were unaware of treatment randomization" \\
\hline
\end{tabular}

\begin{tabular}{ll}
\hline Blinding of outcome as- & Unclear risk $\quad$ Comment: insufficient information about blinding of outcome assessment \\
sessment (detection bias) &
\end{tabular}

All outcomes

\begin{tabular}{lll}
\hline $\begin{array}{l}\text { Incomplete outcome data } \\
\text { (attrition bias) } \\
\text { All outcomes }\end{array}$ & Low risk & Comment: no missing data outcome \\
\hline $\begin{array}{l}\text { Selective reporting (re- } \\
\text { porting bias) }\end{array}$ & Low risk & $\begin{array}{l}\text { Comment: the study protocol was not available but it was clear that published } \\
\text { report included all expected outcomes }\end{array}$ \\
\hline Other bias & Low risk & Comment: the study appeared free of other sources of bias \\
\hline
\end{tabular}


Leon 1990

\begin{tabular}{ll}
\hline Methods & Duration of the intervention: 1 July 1987 to 1 August 1989 \\
Patients excluded/patients randomized: $0 / 51(0 \%)$ \\
Sample size calculation/method description: No/No \\
\hline Participants \\
Age (mean): 62 years \\
Sex: not reported \\
Inclusion criteria: patients with severe infections treated with broad spectrum antibiotic therapy \\
Exclusion criteria: not stated
\end{tabular}

Exclusion criteria: not stated

Percentage post-surgical: $18 \%$

Percentage colonized with Candida at baseline: $50 \%$

\begin{tabular}{ll}
\hline Interventions & 1. Amphotericin B orally 2 g daily $(\mathrm{n}=24)$ \\
& 2. Placebo $(\mathrm{n}=27)$ \\
& Duration of the intervention: not reported \\
\hline Outcomes & Mortality \\
& Proven IFI \\
& Superficial fungal infection \\
& Follow-up duration: until ICU discharge \\
\hline $\begin{array}{l}\text { Type of antifungal treat- } \\
\text { ment }\end{array}$ & Empiric \\
\hline $\begin{array}{l}\text { Funding sources } \\
\begin{array}{l}\text { Declaration of interest } \\
\text { among the primary re- } \\
\text { searchers }\end{array}\end{array}$ \\
\hline
\end{tabular}

\begin{tabular}{ll}
\hline Notes & Country: France \\
& Setting: single hospital, adult ICU \\
\hline
\end{tabular}

\section{Risk of bias}

\begin{tabular}{lll}
\hline Bias & Authors' judgement & Support for judgement \\
\hline $\begin{array}{l}\text { Random sequence genera- } \\
\text { tion (selection bias) }\end{array}$ & Low risk & Comment: patients randomized according to a randomization table \\
\hline $\begin{array}{l}\text { Allocation concealment } \\
\text { (selection bias) }\end{array}$ & Unclear risk & Comment: insufficient information to permit a judgement \\
\hline $\begin{array}{l}\text { Blinding of participants } \\
\text { and personnel (perfor- } \\
\text { mance bias) }\end{array}$ & Unclear risk & Comment: insufficient information to permit a judgement \\
\hline
\end{tabular}


Leon 1990 (Continued)

All outcomes

Blinding of outcome as-
sessment (detection bias) $\quad$ Unclear risk Comment: insufficient information about blinding of outcome assessment

All outcomes

\begin{tabular}{lll}
\hline $\begin{array}{l}\text { Incomplete outcome data } \\
\text { (attrition bias) } \\
\text { All outcomes }\end{array}$ & Low risk & Comment: no missing data outcome \\
\hline $\begin{array}{l}\text { Selective reporting (re- } \\
\text { porting bias) }\end{array}$ & Low risk & $\begin{array}{l}\text { Comment: the study protocol was not available but it is clear that the pub- } \\
\text { lished report included all expected outcomes }\end{array}$ \\
\hline Other bias & Low risk & Comment: the study appeared free of other sources of bias \\
\hline
\end{tabular}

Namikawa 2013

\begin{tabular}{l} 
Monocentre, randomized, parallel-group study \\
Duration of the study: 2009 to 2011 \\
Number excluded/number randomized: $0 / 26(0 \%)$ \\
Sample size calculation/method description: No/No \\
\hline
\end{tabular}

\section{Participants}

\section{Patients randomized: 26}

Age (median): 78 years (both groups)

Sex: 13 men, 13 women

Inclusion criteria: patients aged $\geq 70$ years who underwent elective gastrectomy for gastric cancer and $1,3-\beta$-D-glucan $\geq 11 \mathrm{pg} / \mathrm{mL}$

\section{Exclusion criteria: not stated}

\section{Percentage post-surgical: $100 \%$}

Percentage colonized with Candida at baseline: not stated

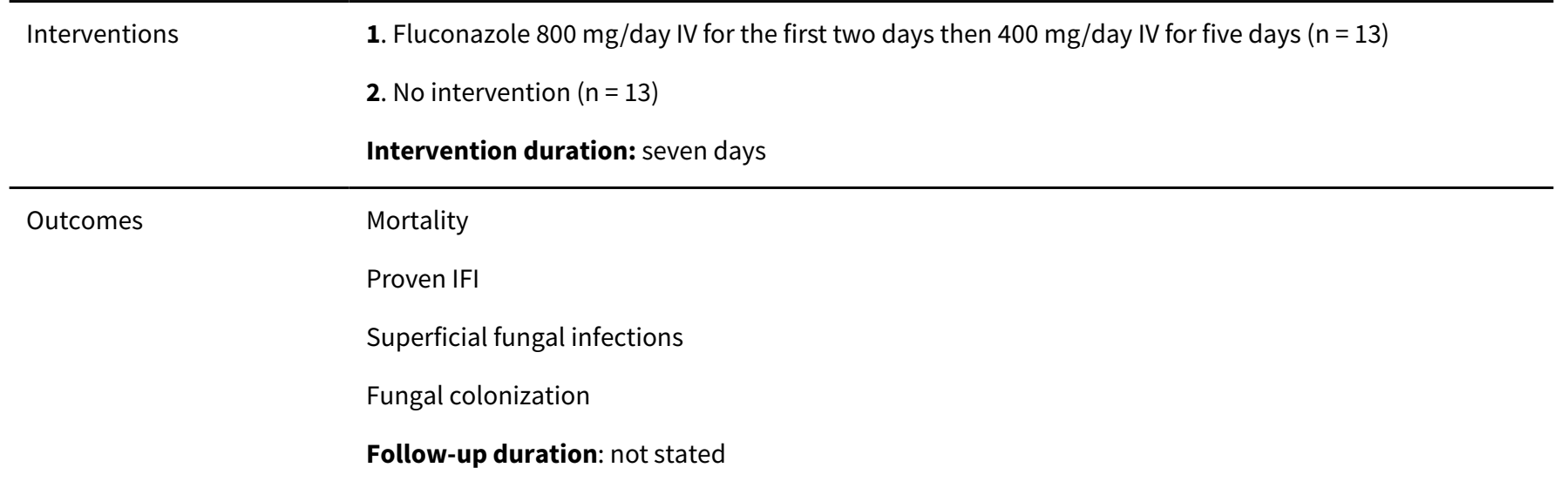

\footnotetext{
Type of antifungal treat- Pre-emptive ment
} 
Namikawa 2013 (Continued)
Funding sources
Quote: "None"

Declaration of interest among the primary re-

Quote: "None of the authors received funding or have any competing interests to disclose" searchers

\begin{tabular}{|c|c|c|}
\hline Notes & \multicolumn{2}{|l|}{$\begin{array}{l}\text { Country: Japan } \\
\text { Setting: single hospital }\end{array}$} \\
\hline \multicolumn{3}{|l|}{ Risk of bias } \\
\hline Bias & Authors' judgement & Support for judgement \\
\hline $\begin{array}{l}\text { Random sequence genera- } \\
\text { tion (selection bias) }\end{array}$ & Unclear risk & $\begin{array}{l}\text { Quote: "Patients were randomized using blinded envelope to rule out any se- } \\
\text { lection bias" }\end{array}$ \\
\hline & & $\begin{array}{l}\text { Comment: insufficient information to make a judgement about random se- } \\
\text { quence generation }\end{array}$ \\
\hline $\begin{array}{l}\text { Allocation concealment } \\
\text { (selection bias) }\end{array}$ & Low risk & $\begin{array}{l}\text { Quote: "Patients were randomized using blinded envelope to rule out any se- } \\
\text { lection bias" }\end{array}$ \\
\hline $\begin{array}{l}\text { Blinding of participants } \\
\text { and personnel (perfor- } \\
\text { mance bias) } \\
\text { All outcomes }\end{array}$ & Low risk & $\begin{array}{l}\text { Comment: no blinding, but we judged that outcome was not influenced by } \\
\text { lack of blinding }\end{array}$ \\
\hline $\begin{array}{l}\text { Blinding of outcome as- } \\
\text { sessment (detection bias) } \\
\text { All outcomes }\end{array}$ & Unclear risk & Comment: insufficient information about blinding of outcome assessment \\
\hline $\begin{array}{l}\text { Incomplete outcome data } \\
\text { (attrition bias) } \\
\text { All outcomes }\end{array}$ & Low risk & Comment: no missing outcome data \\
\hline $\begin{array}{l}\text { Selective reporting (re- } \\
\text { porting bias) }\end{array}$ & Low risk & $\begin{array}{l}\text { Comment: the study protocol was not available but it was clear that the pub- } \\
\text { lished report included all expected outcomes }\end{array}$ \\
\hline Other bias & Low risk & Comment: the study appears to be free of other bias \\
\hline
\end{tabular}

NCT00048750

Methods Phase three multicentre, randomized, parallel-group study

Duration of the study: 15 January 2003 to 25 June 2003

Patients excluded/patients randomized: $1 / 103$ (0.97\%)

Sample size calculation/method description: Yes/No

Patients randomized: 103
Age (mean): 52.8 years (treatment group), 59.9 years (placebo group)
Sex: 61 men, 41 women
Inclusion criteria: patients $\geq 16$ years with a predicted ICU stay of at least 72 hours


Exclusion criteria: pregnancy or nursing, evidence of active invasive fungal infection, patients that had received more than one dose of a systemic antifungal agent within 72 hours prior the first dose of study drug, HIV positive, ventilator assisted device, Injury Severity Score $>50$, history of anaphylaxis attributed to echinocandin class of antifungals, concomitant medical condition that could create an unacceptable addition risk for the patient, life expectancy of less than 72 hours

Patients randomized: 103

Percentage post-surgical: not reported

Percentage colonized with Candida at baseline: $23 / 102$ (22.5\%)

\begin{tabular}{|c|c|}
\hline \multirow[t]{3}{*}{ Interventions } & 1. Micafungin $100 \mathrm{mg}$ daily IV $(\mathrm{n}=52)$ \\
\hline & 1. Placebo $(n=51)$ \\
\hline & Duration of the intervention: for duration of ICU stay \\
\hline \multirow[t]{5}{*}{ Outcomes } & Mortality \\
\hline & Proven IFI \\
\hline & Fungal colonization \\
\hline & Adverse events requiring cessation \\
\hline & Follow-up duration: one week following discontinuation of study drug \\
\hline $\begin{array}{l}\text { Type of antifungal treat- } \\
\text { ment }\end{array}$ & Prophylaxis \\
\hline
\end{tabular}

\begin{tabular}{ll}
\hline Funding sources & Sponsor: Astellas Pharma Inc. \\
\hline $\begin{array}{l}\text { Declaration of interest } \\
\text { among the primary re- } \\
\text { searchers }\end{array}$ & Not reported \\
\hline
\end{tabular}

Country: Canada and USA
Setting: multicentre study (21 centres)
Other: the study was discontinued because the sponsor concluded that many truly high risk patients
were receiving anti-fungal prophylaxis off-study and consequently not being enrolled into the study

\section{Risk of bias}

\begin{tabular}{|c|c|c|}
\hline Bias & Authors' judgement & Support for judgement \\
\hline $\begin{array}{l}\text { Random sequence genera- } \\
\text { tion (selection bias) }\end{array}$ & Unclear risk & $\begin{array}{l}\text { Quote: "This was a phase } 3 \text {, multicentre, randomized ( } 1: 1) \text {, double-blind, par- } \\
\text { allel-group study" "After providing the required informed consent documenta- } \\
\text { tion, eligible patients were stratified by study center and length of stay in the } \\
\text { ICU (<7 days and } \geq 7 \text { days) and randomized (1:1) to receive micafungin ( } 100 \\
\text { mg/day) or placebo ( } 0.9 \% \text { sodium chloride)" }\end{array}$ \\
\hline
\end{tabular}

\begin{tabular}{lll}
$\begin{array}{l}\text { Allocation concealment } \\
\text { (selection bias) }\end{array}$ & Unclear risk & Comment: insufficient information to make a judgement \\
\hline $\begin{array}{l}\text { Blinding of participants } \\
\begin{array}{l}\text { and personnel (perfor- } \\
\text { mance bias) }\end{array}\end{array}$ & Low risk & Quote: "Double Blind (Subject, Caregiver, Investigator, Outcomes Assessor)". \\
\end{tabular}


NCT00048750 (Continued)

All outcomes

\begin{tabular}{|c|c|c|}
\hline $\begin{array}{l}\text { Blinding of outcome as- } \\
\text { sessment (detection bias) }\end{array}$ & Low risk & Quote: "Double Blind (Subject, Caregiver, Investigator, Outcomes Assessor)" \\
\hline All outcomes & & Comment: Information obtained from the study protocol \\
\hline
\end{tabular}

Incomplete outcome data Low risk (attrition bias)

Comment: reasons for missing outcome data unlikely to be related to true out-

All outcomes come Selective reporting (re- High risk
porting bias)
Comment: the study protocol was available and the previously reported outcome of probable invasive infection was reported in the results

Other bias High risk

\begin{abstract}
Quote: "Six hundred male and female patients were planned to be enrolled in the study. Due to the low incidence of fungal endpoints observed at the time of an initial blinded data review, a survey on patient entry was conducted and an investigators' meeting was held. At that time the sponsor concluded that many truly high risk patients were receiving anti-fungal prophylaxis off study and consequently not being enrolled into the study. It was judged that a reversal of this trend was unlikely and that a low incidence of fungal events would continue. Therefore, the study was discontinued"

Comment: This trend altered greatly the enrolment so we judged the study to be at high risk for other bias
\end{abstract}

\title{
NCT01122368
}

Methods

Phase two multicentre, randomized, parallel-group study

Duration of the study: 13 July 2010 to 15 December 2011

Patients excluded/patients randomized: 4/252 (1.6\%) for mortality; 11/252 (4.4\%) for IFI

Sample size calculation/method description: Yes/No

\section{Patients randomized: 252}

Age: not reported (patients' characteristics originally reported in a summary table removed from the unpublished document on 25 April 2013)

\author{
Sex: not reported \\ Inclusion criteria: localized or generalized intra-abdominal infection that required surgery and ICU \\ stay
}

Exclusion criteria: acute pancreatitis; neutropenia $\left(<1,000 / \mathrm{mm}^{3}\right)$ at the time of randomization; infected intra-peritoneal dialysis; patients undergoing solid organ transplantation, documented invasive candidiasis at the time of randomization, expected survival < 48 hours; any systemically active anti-fungal within 14 days prior to administration of the study drug; allergy, hypersensitivity, or any serious reaction to an echinocandin anti-fungal or any of the study drug excipients; received and/or had taken an investigational drug within 28 days prior to randomization; pregnant woman or breast-feeding mother; 'Do Not Resuscitate' order, severe liver insufficiency, advanced liver fibrosis, cirrhosis or hepatitis.

\section{Percentage post-surgical: $100 \%$}

Percentage colonized with Candida at baseline: $27 \%$ (65/241) patients included in the Full analysis set 
NCT01122368 (Continued)
Interventions
1. Micafungin $100 \mathrm{mg} /$ day $(\mathrm{n}=122)$
2. Placebo $(n=126)$
Duration of the intervention: Sufficient improvement of surgical condition as indicated by the recov- ery of GI function allowing introduction of enteral feeding of at least $50 \%$ of daily calorie requirement, confirmation of IFI, administration of alternative anti-fungal therapy or death

\begin{tabular}{ll} 
Outcomes & Mortality \\
& Proven IFI \\
& $\begin{array}{l}\text { Fungal colonization } \\
\text { Follow-up duration: until end of treatment }\end{array}$ \\
& Empiric \\
\hline $\begin{array}{l}\text { Type of antifungal treat- } \\
\text { ment }\end{array}$ & Astellas Pharma Inc. \\
\hline $\begin{array}{l}\text { Funding sources } \\
\text { Declaration of interest } \\
\text { among the primary re- } \\
\text { searchers }\end{array}$ & Not reported \\
\hline Notes & Country: Europe (17 countries) \\
& Setting: multicentre study (53 centres) ICU \\
\hline
\end{tabular}

\section{Risk of bias}

\begin{tabular}{|c|c|c|}
\hline Bias & Authors' judgement & Support for judgement \\
\hline $\begin{array}{l}\text { Random sequence genera- } \\
\text { tion (selection bias) }\end{array}$ & Unclear risk & $\begin{array}{l}\text { Comment: insufficient information to make a judgement about the randomiza- } \\
\text { tion sequence generation }\end{array}$ \\
\hline $\begin{array}{l}\text { Allocation concealment } \\
\text { (selection bias) }\end{array}$ & Unclear risk & $\begin{array}{l}\text { Quote: "Allocation: Randomized" (quoted from study protocol) } \\
\text { Comment: insufficient information to make a judgement about concealment }\end{array}$ \\
\hline $\begin{array}{l}\text { Blinding of participants } \\
\text { and personnel (perfor- } \\
\text { mance bias) } \\
\text { All outcomes }\end{array}$ & Low risk & $\begin{array}{l}\text { Quote: "Masking: double blind (subject, caregiver, investigator, outcomes as- } \\
\text { sessor)" (Quoted from study protocol) }\end{array}$ \\
\hline $\begin{array}{l}\text { Blinding of outcome as- } \\
\text { sessment (detection bias) } \\
\text { All outcomes }\end{array}$ & Low risk & $\begin{array}{l}\text { Quote: "Masking: double blind (subject, caregiver, investigator, outcomes as- } \\
\text { sessor)" (Quoted from study protocol) }\end{array}$ \\
\hline $\begin{array}{l}\text { Incomplete outcome data } \\
\text { (attrition bias) } \\
\text { All outcomes }\end{array}$ & Unclear risk & $\begin{array}{l}\text { Comment: no clear reasons to exclude patients from "enrolled" group. No } \\
\text { clear reasons related to the lack of reporting primary outcome for patients ex- } \\
\text { cluded from the safety analysis. Maybe the reasons were described in tables } \\
\text { that had been removed from the reporting document on } 25 / 04 / 2013\end{array}$ \\
\hline $\begin{array}{l}\text { Selective reporting (re- } \\
\text { porting bias) }\end{array}$ & Low risk & $\begin{array}{l}\text { Comment: the study protocol was available and all of the study prespecified } \\
\text { (primary and secondary) outcomes were reported in the prespecified way }\end{array}$ \\
\hline Other bias & Low risk & Comment: the study appeared free of other sources of bias \\
\hline
\end{tabular}


Normand 2005

Methods Monocentre, randomized, parallel-group study

Duration of the study: February 2002 to July 2002

Patients excluded/patients randomized: 18/116 (15\%)

Sample size calculation/method described: Yes/Yes

Patients randomized: 116
Age (mean): 59 years (treatment group), 57 years (no intervention group)
Sex: 65 male, 33 women
Inclusion criteria: patients admitted to ICU and expected to require invasive mechanical ventilation
for more than 48 hours
Exclusion criteria: pregnancy, prophylactic or curative antifungal treatment within the last two
months, contraindication to oral drug administration, known allergy to nystatin or its derivatives, and
prior inclusion in the study, patients who exhibited at baseline a Candida spp. colonization or infection

Percentage post-surgical: $19 \%$ (19/98)

Percentage colonized with Candida at baseline: $0 \%$

\begin{tabular}{ll}
\hline Interventions & $\begin{array}{l}\text { 1. Nystatin }(\mathrm{n}=60) 10^{6} \text { Unit orally three times daily } \\
\text { 2. No intervention }(\mathrm{n}=56) \\
\text { Duration of the intervention: not reported }\end{array}$ \\
\hline Outcomes & Mortality \\
Proven IFI & Fungal colonization \\
Fungal colonization with azole-resistant Candida species \\
Follow-up duration: until ICU discharge
\end{tabular}

Type of antifungal treat- Prophylaxis
ment

\begin{tabular}{|c|c|c|}
\hline Funding sources & \multicolumn{2}{|l|}{ Not reported } \\
\hline $\begin{array}{l}\text { Declaration of interest } \\
\text { among the primary re- } \\
\text { searchers }\end{array}$ & \multicolumn{2}{|l|}{ Not reported } \\
\hline \multirow[t]{2}{*}{ Notes } & \multicolumn{2}{|l|}{ Country: France } \\
\hline & \multicolumn{2}{|c|}{ Setting: single centre, ICU } \\
\hline \multicolumn{3}{|l|}{ Risk of bias } \\
\hline Bias & Authors' judgement & Support for judgement \\
\hline $\begin{array}{l}\text { Random sequence genera- } \\
\text { tion (selection bias) }\end{array}$ & Low risk & $\begin{array}{l}\text { Quote: "A computer-generated randomization list in balanced blocks of un- } \\
\text { equal sizes was used and patients..." }\end{array}$ \\
\hline
\end{tabular}


Normand 2005 (Continued)

Allocation concealment Unclear risk Comment: insufficient information to make a judgement (selection bias)

Blinding of participant

High risk

Comment: no blinding of participants and personnel

and personnel (perfor-

mance bias)

All outcomes

\begin{tabular}{|c|c|c|}
\hline $\begin{array}{l}\text { Blinding of outcome as- } \\
\text { sessment (detection bias) } \\
\text { All outcomes }\end{array}$ & Low risk & $\begin{array}{l}\text { Quote: "...blinded assessment of the objective primary evaluation criterion"; } \\
\text { "Group assignment was not indicated on specimens, the mycologists were } \\
\text { therefore blinded to treatment allocation" }\end{array}$ \\
\hline
\end{tabular}

Incomplete outcome data Low risk

(attrition bias)

All outcomes

Comment: missing outcome data balanced in numbers across groups, with similar reasons for missing data across groups

\begin{tabular}{ll}
\hline $\begin{array}{l}\text { Selective reporting (re- } \\
\text { porting bias) }\end{array}$ & Low risk \\
\end{tabular}

\begin{tabular}{ll}
\hline Other bias Low risk The study appeared free of other bias \\
\hline
\end{tabular}

\section{Ostrosky-Zeichner 2014}

$\begin{array}{ll}\text { Methods } & \text { Phase four multicentre, randomized, double-blind, placebo-controlled study with two arms (caspofun- } \\ \text { gin prophylaxis versus placebo), followed by pre-emptive therapy for subjects who develop proven or } \\ \text { probable IFI. We considered only the prophylactic phase of the trial for the purpose of this review }\end{array}$

Duration of the study: August 2007 to March 2010

Patients excluded/patients randomized: $36 / 222$ (15\%)

Sample size calculation/method description: Yes/Yes

Age (mean): 57.7 years (treatment group), 55.4 years (placebo group)

Sex: 114 men, 72 women

Inclusion criteria: patients admitted to the ICU during the preceding three days (minimum of 48 hours in ICU) and expected to stay in the ICU for at least another 48 hours, ventilated, received antibiotics, had a central line, and had one additional risk factor (parenteral nutrition, dialysis, surgery, pancreatitis, systemic steroids, or other immunosuppressants)

Exclusion criteria: allergy or intolerance to echinocandins, absolute neutrophil count $<500 \mathrm{cell} / \mu \mathrm{L}$, AIDS, aplastic anaemia or chronic granulomatous disease, moderate or severe hepatic insufficiency, pregnancy or lactation, subjects likely to die within 24 hours of enrolment, antifungal therapy within 10 days prior to study, documentation of any active invasive fungal infection upon enrolment, previous enrolment in this study, and investigational agent within the 10 days prior entry

\section{Percentage post-surgical: $25 \%$}

Percentage colonized with Candida at baseline: not reported

Interventions

1. Caspofungin $70 \mathrm{mg} /$ day IV loading dose followed by $50 \mathrm{mg} /$ day IV $(\mathrm{n}=117$ )

2. Placebo $(n=102)$ 
Ostrosky-Zeichner 2014 (Continued)

Intervention duration: throughout the ICU stay. When subjects met the primary endpoint (proven or probable IC), investigators were allowed to break the blind and subjects receiving placebo were started on therapy with caspofungin. Subjects receiving caspofungin were allowed to continue or to switch to other agents

$\begin{array}{ll}\text { Outcomes } & \text { Mortality } \\ & \text { Proven IFI } \\ \text { Suspected IFI } \\ \text { Proven or suspected IFI } \\ \text { Adverse events requiring cessation } \\ \text { Follow-up duration: until hospital discharge }\end{array}$

Type of antifungal treat- Prophylaxis

ment

Funding sources $\quad$ Quote: "This study was supported and sponsored by Merck \& Co, Inc."

Declaration of interest among the primary researchers

Quote: "L. O. Z. has received research grants from Merck, Astellas, Pfizer, and Associates of Cape Cod, and is a consultant and speaker for and has received honoraria from Merck, Astellas, and Pfizer. S. S. receives research funding from Astellas, Merck, and Pfizer, and is a member of the Merck Scientific Advisory Board. J. V. has received honoraria from Astellas and Forest; has received grants from Merck, Astellas, and Pfizer; and is a consultant for Astellas and Forest. R. Bed. has received research grants from Merck and Janssen Pharmaceuticals and has participated in ad hoc scientific advisory boards for Serono, ViiV, and Gilead Sciences. J. E. M. has received a research grant from Medline Industries and sits on an advisory board for Cepheid. S. G. R. has received research funding from Merck, Astellas, and Pfizer. C. W. is a full-time employee of and own stocks in Merck. M. H. N. has received research support from Merck, Pfizer, and Astellas. C. A. K. has participated in other clinical trials from Merck. P. G. P has received grants and research support from Merck, Astellas, Gilead, and T2 Biosystems and is an ad hoc advisor for Merck, Astellas, Gilead, Scynexis, Viamet, and T2 Biosystems. All other authors report no potential conflicts"

$\begin{array}{ll}\text { Notes } & \text { Country: USA } \\ & \text { Setting: multicentre (15 centres), ICU }\end{array}$

\section{Risk of bias}

\begin{tabular}{lll}
\hline Bias & Authors' judgement & Support for judgement \\
\hline $\begin{array}{l}\text { Random sequence genera- } \\
\text { tion (selection bias) }\end{array}$ & Unclear risk & Quote: "Block randomization was stratified by APACHE II score ( $\leq 20$ or $>20)$ " \\
& & $\begin{array}{l}\text { Comment: insufficient information to make a judgement about randomization } \\
\text { sequence generation }\end{array}$ \\
\hline
\end{tabular}

Allocation concealment $\quad$ Unclear risk Comment: insufficient information to make a judgement
(selection bias)

\begin{tabular}{|c|c|c|}
\hline $\begin{array}{l}\text { Blinding of participants } \\
\text { and personnel (perfor- } \\
\text { mance bias) } \\
\text { All outcomes }\end{array}$ & Low risk & $\begin{array}{l}\text { Quote: "Masking: Double Blind (Subject, Caregiver, Investigator, Outcomes As- } \\
\text { sessor)" (Quoted from protocol) }\end{array}$ \\
\hline $\begin{array}{l}\text { Blinding of outcome as- } \\
\text { sessment (detection bias) } \\
\text { All outcomes }\end{array}$ & Low risk & $\begin{array}{l}\text { Quote: "Masking: Double Blind (Subject, Caregiver, Investigator, Outcomes As- } \\
\text { sessor)" (Quoted from protocol). }\end{array}$ \\
\hline
\end{tabular}


Comment: the blinding has been declared in the study and specified for trial registration. $A E$ and severe $A E$ managed by a data and safety monitoring board (DSMB) on treatment blinded fashion

\begin{tabular}{lll}
\hline $\begin{array}{l}\text { Incomplete outcome data } \\
\text { (attrition bias) } \\
\text { All outcomes }\end{array}$ & Low risk & $\begin{array}{l}\text { Comment: missing outcome data balanced in numbers across intervention } \\
\text { groups, with similar reasons for missing data across groups }\end{array}$ \\
\hline $\begin{array}{l}\text { Selective reporting (re- } \\
\text { porting bias) }\end{array}$ & Low risk & $\begin{array}{l}\text { Comment: the study protocol was available and all of the study prespecified } \\
\text { (primary and secondary) outcomes that were of interest for review were re- } \\
\text { ported in the prespecified way }\end{array}$ \\
\hline Other bias & Low risk & The study appeared free of other sources of bias \\
\hline
\end{tabular}

\section{Parizkova 2000}

\begin{tabular}{ll}
\hline Methods & Monocentre, randomized, parallel-group study \\
Duration of the study: 1997 to 1998 \\
Number excluded /number randomized: $0 / 38(0 \%)$ \\
Sample size calculation/method description: No/No \\
Patients randomized: 38 \\
Age (mean): 46 years (treatment group), 43 years (no intervention group) \\
Sex: not reported \\
Inclusion criteria: admitted to ICU < five days, receipt of antibiotics $>24$ hours, mechanical ventilation \\
$>48$ hours \\
Exclusion criteria: immunocompromised patients, autoimmune disease, cancer patients with metas- \\
tasis, mycotic infection, patients treated with antifungal drugs \\
Percentage post-surgical: $>37 \%$ \\
Percentage colonized with Candida at baseline: not stated
\end{tabular}

\begin{tabular}{ll}
\hline Interventions & $\begin{array}{l}\text { 1. Fluconazole } 100 \mathrm{mg} / \text { day IV }(\mathrm{n}=18) \\
\text { 2. No intervention }(\mathrm{n}=20) \\
\text { Duration of the intervention: throughout the ICU stay }\end{array}$ \\
\hline Outcomes & Mortality \\
Proven IFI \\
Proven IFI with azole-resistant Candida species \\
Fungal colonization \\
Fungal colonization with azole-resistant Candida species \\
Follow-up duration: not stated
\end{tabular}

Type of antifungal treat- Prophylaxis ment

\begin{tabular}{ll}
\hline Funding sources & Not reported \\
\hline $\begin{array}{l}\text { Declaration of interest } \\
\text { among the primary re- } \\
\text { searchers }\end{array}$ & Not reported \\
\hline
\end{tabular}


Parizkova 2000 (Continued)

$\begin{array}{ll}\text { Notes } & \text { Country: Czech Republic } \\ & \text { Setting: single centre, adult ICU }\end{array}$

\section{Risk of bias}

\begin{tabular}{|c|c|c|}
\hline Bias & Authors' judgement & Support for judgement \\
\hline $\begin{array}{l}\text { Random sequence genera- } \\
\text { tion (selection bias) }\end{array}$ & Unclear risk & Comment: insufficient information to make a judgement \\
\hline $\begin{array}{l}\text { Allocation concealment } \\
\text { (selection bias) }\end{array}$ & Unclear risk & Comment: insufficient information to make a judgement \\
\hline $\begin{array}{l}\text { Blinding of participants } \\
\text { and personnel (perfor- } \\
\text { mance bias) } \\
\text { All outcomes }\end{array}$ & Unclear risk & Comment: insufficient information to make a judgement \\
\hline $\begin{array}{l}\text { Blinding of outcome as- } \\
\text { sessment (detection bias) } \\
\text { All outcomes }\end{array}$ & Unclear risk & Comment: insufficient information about blinding of outcome assessment \\
\hline $\begin{array}{l}\text { Incomplete outcome data } \\
\text { (attrition bias) } \\
\text { All outcomes }\end{array}$ & Low risk & Comment: no missing outcome data \\
\hline $\begin{array}{l}\text { Selective reporting (re- } \\
\text { porting bias) }\end{array}$ & Low risk & $\begin{array}{l}\text { Comment: the study protocol was not available but it was clear that the pub- } \\
\text { lished reports included all expected outcomes }\end{array}$ \\
\hline Other bias & Low risk & Comment: no apparent risk for other bias \\
\hline
\end{tabular}

\section{Pelz 2001}

\begin{tabular}{ll}
\hline Methods & Monocentre, randomized, parallel-group study \\
Duration of the study: 7 January 1998 to 13 January 1999 \\
Patients excluded/patients randomized: $0 / 260(0 \%)$ \\
Sample size calculation/method description: Yes/Yes
\end{tabular}

\section{Participants}

\section{Patients randomized: 260}

Age (median): 63 years (treatment group), 60 years (placebo group)

Sex: 130 men, 130 women

Inclusion criteria: expected length of ICU stay $>3$ days

Exclusion criteria: pregnancy, receipt of antifungal agents within the seven days before ICU admission, age younger than 18 , or an expectation that the patient would not survive more than 24 hours

Percentage post-surgical: $91 \%$

Percentage colonized with Candida at baseline: $75 \%$

$\begin{array}{ll}\text { Interventions } & \text { 2. Fluconazole } 800 \mathrm{mg} \text { orally then } 400 \mathrm{mg} / \text { day orally }(\mathrm{n}=130)\end{array}$

2. Placebo $(n=130)$ 
Pelz 2001 (Continued)

Duration of the intervention: until initiation of empiric antifungal treatment or ICU discharge. Decision to initiate empiric antifungal treatment were made by nonstudy clinicians unaware of the study treatment and were based on clinical assessment and cultures

\begin{tabular}{|c|c|}
\hline \multirow[t]{5}{*}{ Outcomes } & $\begin{array}{l}\text { Mortality } \\
\text { Proven IFI } \\
\text { Suspected IFI }\end{array}$ \\
\hline & Superficial IFI \\
\hline & Proven or suspected IFI \\
\hline & Proven IFI with azole-resistant Candida species \\
\hline & Follow-up duration: until 3 days post-ICU discharge \\
\hline $\begin{array}{l}\text { Type of antifungal treat- } \\
\text { ment }\end{array}$ & Prophylaxis \\
\hline Funding sources & Not reported \\
\hline $\begin{array}{l}\text { Declaration of interest } \\
\text { among the primary re- } \\
\text { searchers }\end{array}$ & Not reported \\
\hline Notes & $\begin{array}{l}\text { Country: USA } \\
\text { Setting: single centre, adult surgical ICU }\end{array}$ \\
\hline
\end{tabular}

\section{Risk of bias}

Bias Authors' judgement Support for judgement

Random sequence genera- Unclear risk tion (selection bias)

Quote: "After enrollment, individual patients were randomly assigned by block design by the hospital pharmacy to receive, that day, a single, daily, enteral dose of fluconazole suspension or identical placebo"

Comment: insufficient information to make a judgement about random sequence generation

Allocation concealment Low risk
(selection bias)

Quote: "After enrollment, individual patients were randomly assigned by block design by the hospital pharmacy to receive, that day, a single, daily, enteral dose of fluconazole suspension or identical placebo"

Comment: central allocation, pharmacy controlled randomization

$\begin{array}{ll}\text { Blinding of participants } \quad \text { Low risk } & \text { Quote: "All patients and investigators were masked to the treatment assign- } \\ \text { and personnel (perfor- } & \text { ments" }\end{array}$

mance bias)

All outcomes

\begin{tabular}{lll}
\hline $\begin{array}{l}\text { Blinding of outcome as- } \\
\text { sessment (detection bias) } \\
\text { All outcomes }\end{array}$ & Low risk & $\begin{array}{l}\text { Quote: "All patients and investigators were masked to the treatment assign- } \\
\text { ments"; "Events were classified using predetermined criteria by a masked ad- } \\
\text { judication panel" }\end{array}$ \\
\hline $\begin{array}{l}\text { Incomplete outcome data } \\
\text { (attrition bias) } \\
\text { All outcomes }\end{array}$ & Low risk & $\begin{array}{l}\text { Comment: no missing outcome data. All patients who were randomized were } \\
\text { included in the final analysis }\end{array}$ \\
\hline $\begin{array}{l}\text { Selective reporting (re- } \\
\text { porting bias) }\end{array}$ & Low risk & $\begin{array}{l}\text { Comment: the study protocol was not available but it was clear that the pub- } \\
\text { lished report included all expected outcomes }\end{array}$
\end{tabular}


Pelz 2001 (Continued)

Other bias Low risk Comment: the study appears to be free of other sources of bias

Sandven 2002

Methods Duration of the intervention: March 1994 to June 1995

Number excluded/number randomized: unclear (insufficient information to make a judgement about the real number of randomized patients)

Sample size calculation/method description: No/No

Participants

Patients randomized: unclear (insufficient information to make a judgement about the real number of randomized patients)

Age (median): 68 years (treatment group), 60 years (placebo group)

Sex: 52 men, 57 women

Inclusion criteria: confirmed intra-abdominal perforation. A specimen obtained for microbiological culture from the abdominal cavity intraoperatively was needed

Exclusion criteria: antifungal treatment at the time of perforation

Percentage post-surgical: $100 \%$

Percentage colonized with Candida at baseline: not stated

Interventions

1. Fluconazole $400 \mathrm{mg}$ IV single dose intraoperatively $(n=53)$

2. Placebo $(n=56)$

Duration of the intervention: single dose in the operating room

\begin{tabular}{|c|c|}
\hline Outcomes & $\begin{array}{l}\text { Mortality } \\
\text { Proven IFI } \\
\text { Suspected IFI } \\
\text { Proven or suspected IFI } \\
\text { Follow-up duration: not stated }\end{array}$ \\
\hline $\begin{array}{l}\text { Type of antifungal treat- } \\
\text { ment }\end{array}$ & Prophylaxis \\
\hline Funding sources & $\begin{array}{l}\text { Quote: "Bottles containing either } 400 \text { mg of fluconazole or placebo were a generous gift from Pfizer In- } \\
\text { ternational" }\end{array}$ \\
\hline $\begin{array}{l}\text { Declaration of interest } \\
\text { among the primary re- } \\
\text { searchers }\end{array}$ & Not reported \\
\hline Notes & $\begin{array}{l}\text { Country: Norway } \\
\text { Setting: } 13 \text { centres, Operating room, ICU } \\
\text { Other: the study was designed to include } 120 \text { patients for an interim analysis to decide the total num- } \\
\text { ber of patients to be included in the study. Because of slow recruitment of patients, it was, however, } \\
\text { decided to terminate the study when } 109 \text { patients had been enrolled }\end{array}$ \\
\hline Risk of bias & \\
\hline Bias & Support for judgement \\
\hline
\end{tabular}


Sandven 2002 (Continued)

Random sequence genera- Low risk Quote: "Randomization was done using a random number generator" tion (selection bias)

$\begin{array}{ll}\begin{array}{l}\text { Allocation concealment } \\ \text { (selection bias) }\end{array} & \text { Quote: "Randomization was done using a random number generator and } \\ & \text { sealed envelopes containing the number and treatment allocation...A com- } \\ & \text { plete package containing transport media for microbial specimens and a 200- } \\ & \text { mL infusion bottle containing either } 400 \text { mg of fluconazole or placebo were al- } \\ \text { located to each patient according to the inclusion number" }\end{array}$

$\begin{array}{ll}\begin{array}{l}\text { Blinding of participants } \\ \text { and personnel (perfor- }\end{array} & \text { Luote: "A complete package containing transport media for microbial speci- } \\ \begin{array}{l}\text { mance bias) } \\ \text { All outcomes }\end{array} & \begin{array}{l}\text { mens and a 200-mL infusion bottle containing either } 400 \text { mg of fluconazole or } \\ \text { placebo were allocated to each patient according to the inclusion number" }\end{array} \\ & \text { Comment: patients and key study personnel were probably blinded }\end{array}$

\begin{tabular}{|c|c|c|}
\hline $\begin{array}{l}\text { Blinding of outcome as- } \\
\text { sessment (detection bias) }\end{array}$ & Low risk & $\begin{array}{l}\text { Comment: no description of outcome assessment, but the outcome measure- } \\
\text { ment is not likely to be influenced by lack of blinding }\end{array}$ \\
\hline
\end{tabular}

\begin{tabular}{lll}
\hline $\begin{array}{l}\text { Incomplete outcome data } \\
\text { (attrition bias) } \\
\text { All outcomes }\end{array}$ & Unclear risk & $\begin{array}{l}\text { Comment: no sufficient information to understand if the exclusion of eight pa- } \\
\text { tients occurred before or after randomization }\end{array}$ \\
\hline $\begin{array}{l}\text { Selective reporting (re- } \\
\text { porting bias) }\end{array}$ & Low risk & $\begin{array}{l}\text { Comment: the study protocol is not available but it is clear that the published } \\
\text { reports include all expected outcomes }\end{array}$ \\
\hline Other bias & Low risk & Comment: the study appears to have been free of other bias \\
\hline
\end{tabular}

Savino 1994

\begin{tabular}{l} 
Monocentre, randomized study with four groups of allocation \\
Duration of the study: July 1990 to December 1991 \\
Patients excluded/patients randomized: $0 / 292(0 \%)$ \\
Sample size calculation/method description: No/No \\
\hline
\end{tabular}

Participants

\section{Patients randomized: 292}

Age (mean): 54 years (clotrimazole group), 57 years (ketoconazole group), 53 years (nystatin group), 54 years (no intervention)

Sex: 166 men, 126 women

Inclusion criteria: expected length of stay $>48$ hours

Exclusion criteria: patients suffered from burn injury, underwent transplant, had received systemic antifungal agents within two weeks of the study, had evidence of a pre-existing systemic fungal infection or yeast colonization, pregnant women

Percentage post-surgical: $79 \%$

Percentage colonized with Candida at baseline: not stated
Interventions
1. Clotrimazole $30 \mathrm{mg} /$ day orally $(n=80)$.
2. Ketoconazole $200 \mathrm{mg} /$ day orally $(n=65)$
3. Nystatin 2 million units every six hours $(n=75)$
4. No intervention $(n=72)$ 
Savino 1994 (Continued)

Duration of the intervention: until ICU discharge

\begin{tabular}{|c|c|}
\hline Outcomes & $\begin{array}{l}\text { Mortality } \\
\text { Proven IFI } \\
\text { Fungal colonization } \\
\text { Follow-up duration: not stated }\end{array}$ \\
\hline $\begin{array}{l}\text { Type of antifungal treat- } \\
\text { ment }\end{array}$ & Prophylaxis \\
\hline Funding sources & Not reported \\
\hline $\begin{array}{l}\text { Declaration of interest } \\
\text { among the primary re- } \\
\text { searchers }\end{array}$ & Not reported \\
\hline
\end{tabular}

$\begin{array}{ll}\text { Notes } & \text { Country: USA } \\ & \text { Setting: single centre, adult surgical ICU }\end{array}$

Other: Study not included in the quantitative analysis due to high risk of bias in key domains

\section{Risk of bias}

\begin{tabular}{lll}
\hline Bias & Authors' judgement & Support for judgement \\
\hline $\begin{array}{l}\text { Random sequence genera- } \\
\text { tion (selection bias) }\end{array}$ & Unclear risk & $\begin{array}{l}\text { Quote: "Random assignment of patients to one of the four group was accom- } \\
\text { plished by drawing a sealed envelope sequentially from a box" }\end{array}$ \\
& $\begin{array}{l}\text { Comment: it was not clear to us what authors meant describing the random- } \\
\text { ization process }\end{array}$ \\
\hline
\end{tabular}

Allocation concealment High risk

Quote: "Patients assigned to group III, or ketoconazole, were not given ketoconazole if they had known sensitivity to ketoconazole, a current history of hepatitis or hepatic cirrhosis, or evidence of hepatic dysfunctions... Assignment of these patients to one of the three remaining groups was made by drawing the next envelope"

Comment: if the patient presented the conditions described by the authors and he/she was assigned to ketoconazole group, a selection bias could occur because the patient would be assigned to another group

\begin{tabular}{lll}
\hline $\begin{array}{l}\text { Blinding of participants } \\
\text { and personnel (perfor- } \\
\text { mance bias) } \\
\text { All outcomes }\end{array}$ & High risk & \\
\hline $\begin{array}{l}\text { Blinding of outcome as- } \\
\text { sessment (detection bias) } \\
\text { All outcomes }\end{array}$ & Unclear risk & Comment: insufficient information about blinding of outcome assessment \\
\hline $\begin{array}{l}\text { Incomplete outcome data } \\
\text { (attrition bias) } \\
\text { All outcomes }\end{array}$ & Low risk & $\begin{array}{l}\text { Comment: no missing data outcome. All patients who were randomized were } \\
\text { included in the final analysis }\end{array}$ \\
\hline $\begin{array}{l}\text { Selective reporting (re- } \\
\text { porting bias) }\end{array}$ & Low risk & $\begin{array}{l}\text { Comment: the study protocol was not available but it was clear that the pub- } \\
\text { lished report include all expected outcomes }\end{array}$ \\
\hline
\end{tabular}


Savino 1994 (Continued)

Other bias High risk
Comment: the study had a potential source of bias due to the specific study design (patients with altered liver function were allocated only in groups I, II and III, leading to a potential unbalanced allocation of critically ill patients

\section{Schuster 2008}

$\begin{array}{ll}\text { Methods } & \text { Multicentre, randomized, parallel-group study } \\ \text { Duration of the study: } 1995 \text { to } 2000 \\ \text { Patients excluded/patients randomized: } 21 / 270(8 \%)\end{array}$

Sample size calculation/method described: Yes/Yes

\section{Participants}

\section{Patients randomized: 270}

Age (mean): 53 years (treatment group), 51 years (placebo group)

Sex: 192 men, 57 women

Inclusion criteria: age 18 years or older, ICU stay of at least 96 consecutive hours, APACHE II score within 24 hours of randomization of 16 or more, four days of fever (defined as temperature $>38.3^{\circ} \mathrm{C}$ on three separate occasions at least 12 hours apart within 72 hours before study entry, with at least one temperature spike within 12 hours of study entry), broad-spectrum antibiotics (both gram-positive and gram-negative coverage) for at least 4 of the preceding six days, and the presence of a central venous catheter for at least 24 hours before study entry

Exclusion criteria: serum aspartate aminotransferase, alanine aminotransferase, or total bilirubin levels greater than 5 times the upper limit of normal; neutropenia (absolute neutrophil count $<1.0 \times 10^{9}$ cells/L); AIDS or HIV with CD4 count less than $0.5 \times 10^{9}$ cells/L; immunosuppressive treatment for organ or bone marrow transplantation; and ICU admission due to burn injury. Further exclusion criteria were receipt of terfenadine, cisapride, or any investigational drug within 14 days before study enrolment; evidence of an invasive fungal infection within seven days before study entry; life expectancy of 48 hours or less; or previous enrolment in the study

Percentage post-surgical: $52 \%$

Percentage colonized with Candida at baseline: $21 \%$

Interventions

1. Fluconazole $800 \mathrm{mg} /$ day IV $(\mathrm{n}=133)$

2. Placebo $(n=137)$

Duration of the intervention: 14 days

\begin{tabular}{ll}
\hline Outcomes & Mortality \\
& Proven IFI \\
& Proven IFI azole-resistant Candida species \\
& Fungal colonization \\
& Adverse events requiring cessation \\
& Follow-up duration: 30 days after the study drug was discontinued \\
\hline $\begin{array}{l}\text { Type of antifungal treat- } \\
\text { ment }\end{array}$ & Empiric \\
\hline \hline
\end{tabular}


Schuster 2008 (Continued)

Funding sources

Quote: "Grant Support: By Pfizer, New York, New York.

Our study was initiated and designed by investigators. Pfizer (New York, New York) sponsored and monitored the trial, assisted in protocol development and creation of the case report form, provided the study drug, and maintained the database. The sponsor assisted in analysis but not in interpretation of the data. The sponsor was not involved in the decision to publish the results"

Declaration of interest among the primary researchers
Quote: "Employment: H. Panzer (Pfizer), P. Biswas (Pfizer). Consultancies: J.E. Edwards (Merck \& Co. Pfizer, Cerexa, Eisai, Enzon), J.D. Sobel (Merck \& Co., Pfizer, Ther- Rx/KV Pharmaceutical), S. Hadley (Pfizer, Schering-Plough). Honoraria: J.D. Sobel (Merck \& Co., Pfizer, Astellas). Stock ownership or options (other than mutual funds): H. Panzer (Pfizer). Grants received: M.G.

Schuster (Pfizer), J.E. Edwards (Merck \& Co., Pfizer, Astellas), J.D. Sobel (Merck, Pfizer), S. Hadley (Pfizer, Astellas). Grants pending: J.E. Edwards (Pfizer). Other: R.O. Darouiche (Pfizer Speakers' Bureau)"

\begin{tabular}{ll}
\hline Notes & Country: USA \\
& Setting: 26 centres, ICU
\end{tabular}

\section{Risk of bias}

\begin{tabular}{|c|c|c|}
\hline Bias & Authors' judgement & Support for judgement \\
\hline $\begin{array}{l}\text { Random sequence genera- } \\
\text { tion (selection bias) }\end{array}$ & Low risk & $\begin{array}{l}\text { Quote: "Randomization was stratified by site and generated centrally by com- } \\
\text { puter" }\end{array}$ \\
\hline $\begin{array}{l}\text { Allocation concealment } \\
\text { (selection bias) }\end{array}$ & Low risk & $\begin{array}{l}\text { Quote: "Study drugs were assigned through a telephone call from the pharma- } \\
\text { cist to a central interactive voice-response system" }\end{array}$ \\
\hline $\begin{array}{l}\text { Blinding of participants } \\
\text { and personnel (perfor- } \\
\text { mance bias) } \\
\text { All outcomes }\end{array}$ & Low risk & $\begin{array}{l}\text { Quote: "Participants and all members of the study and health care team, ex- } \\
\text { cept the investigational pharmacist, were blinded to study drug assignment" }\end{array}$ \\
\hline $\begin{array}{l}\text { Blinding of outcome as- } \\
\text { sessment (detection bias) } \\
\text { All outcomes }\end{array}$ & Low risk & $\begin{array}{l}\text { Quote: "Participants and all members of the study and health care team, ex- } \\
\text { cept the investigational pharmacist, were blinded to study drug assignment" }\end{array}$ \\
\hline $\begin{array}{l}\text { Incomplete outcome data } \\
\text { (attrition bias) } \\
\text { All outcomes }\end{array}$ & Low risk & $\begin{array}{l}\text { Comment: missing outcome data balanced in numbers across groups, with } \\
\text { similar reasons for missing data across groups }\end{array}$ \\
\hline $\begin{array}{l}\text { Selective reporting (re- } \\
\text { porting bias) }\end{array}$ & Low risk & $\begin{array}{l}\text { Comment: the study protocol was not available but it was clear that the pub- } \\
\text { lished report included all expected outcomes }\end{array}$ \\
\hline Other bias & Low risk & The study appears to have been free of other sources of bias \\
\hline
\end{tabular}

Slotman 1987

$\begin{array}{ll}\text { Methods } & \text { Monocentre, randomized, parallel-group study } \\ \text { Duration of the study: not reported } \\ \text { Patients excluded/patients randomized: } 17 / 74(23 \%)\end{array}$

Sample size calculation/method description: No/No

Participants Patients randomized: 74


Sex: not reported

Inclusion criteria: adult patients without fungal colonization and with three or more risk factors for fungal infection (age greater than 40 years, second- and third-degree burns covering greater than $30 \%$ of body surface area, antibiotics greater than seven days, three or more antibiotics, severe sepsis unresponsive to antibiotics, diabetes, steroids greater than seven days, acute renal failure, immunosuppressive therapy or chemotherapy, advanced malignancy, total parenteral nutrition, multi trauma, serum glucose greater than $11.1 \mathrm{mmol} / \mathrm{L}$, intra-abdominal abscess, peritonitis, or severe head injury)

Exclusion criteria: pregnant patients, patients with sensitivity to ketoconazole, or any of the imidazole derivatives, patients with a previous or current history of hepatic cirrhosis, or acute hepatic failure

Percentage post-surgical: $97 \%$

Percentage colonized with Candida at baseline: $20 \%$

Interventions $\quad$ 1. Ketoconazole $200 \mathrm{mg} /$ day orally $(\mathrm{n}=27)$

2. Placebo $(n=30)$

Duration of the intervention: until ICU discharge

\begin{tabular}{ll}
\hline Outcomes & Mortality \\
& Proven IFI \\
& Proven IFI with azole-resistant Candida species \\
& Fungal colonization \\
& Fungal colonization with azole-resistant Candida species \\
& Follow-up duration: until ICU discharge
\end{tabular}

Type of antifungal treat- Prophylaxis

ment

Funding sources $\quad$ Quote: "Grant Support by Janssen Pharmaceutica, New Brunswick, NJ."

Declaration of interest Not reported

among the primary re-

searchers

$\begin{array}{ll}\text { Notes } & \text { Country: USA } \\ \text { Setting: single hospital, adult surgical ICU } \\ \text { Other: Patients colonized with Candida at baseline excluded from the analysis }\end{array}$

\section{Risk of bias}

\begin{tabular}{lll}
\hline Bias & Authors' judgement & Support for judgement \\
\hline $\begin{array}{l}\text { Random sequence genera- } \\
\text { tion (selection bias) }\end{array}$ & Unclear risk & Comment: insufficient information to make a judgement \\
\hline $\begin{array}{l}\text { Allocation concealment } \\
\text { (selection bias) }\end{array}$ & Unclear risk & Comment: insufficient information to make a judgement \\
\hline $\begin{array}{l}\text { Blinding of participants } \\
\text { and personnel (perfor- } \\
\text { mance bias) }\end{array}$ & Unclear risk & Comment: insufficient information to make a judgement \\
$\begin{array}{l}\text { All outcomes } \\
\begin{array}{l}\text { Blinding of outcome as- } \\
\text { sessment (detection bias) }\end{array}\end{array}$ & Unclear risk & Comment: insufficient information to make a judgement \\
\end{tabular}


Slotman 1987 (Continued)

All outcomes

\section{Incomplete outcome data Low risk} (attrition bias)

All outcomes
Quote: "Randomized patients who were found subsequently to have been colonized with fungi within 24 hours of entry into the study were considered precolonized and were excluded retrospectively"

Comment: prespecified reason for excluding patients from the analysis

\begin{tabular}{lll}
\hline $\begin{array}{l}\text { Selective reporting (re- } \\
\text { porting bias) }\end{array}$ & Low risk & $\begin{array}{l}\text { The study protocol was not available but it was clear that published report in- } \\
\text { cluded all expected outcomes }\end{array}$ \\
\hline Other bias & Low risk & Comment: the study appears to be free of other sources of bias \\
\hline
\end{tabular}

\section{Yu 1993}

\begin{tabular}{ll}
\hline Methods & Monocentre, randomized, parallel-group study \\
& Duration of the study: not reported \\
Patients excluded/patients randomized: $0 / 54(0 \%)$ \\
Sample size calculation/method description: Yes/No
\end{tabular}

\section{Patients randomized: 54}

Age (mean): 48 years (treatment group), 58 years (placebo group)

Sex: 38 men, 16 women

Inclusion criteria: sepsis

Exclusion criteria: patients aged $<16$ years old, pregnant, history of cirrhosis, liver function test showed concentrations to be more than two times increased for bilirubin, transaminases.

Percentage post-surgical: $100 \%$

Percentage colonized with Candida at baseline: not reported

$\begin{array}{ll}\text { Interventions } & \text { 1. Ketoconazole } 400 \mathrm{mg} / \text { day orally }(\mathrm{n}=26) \\ \text { 2. Placebo }(\mathrm{n}=28)\end{array}$

2. Placebo $(n=28)$

Duration of the intervention: until ICU discharge

\begin{tabular}{ll}
\hline Outcomes & Mortality \\
& Fungal colonization \\
& Adverse events requiring cessation \\
& Follow-up duration: not reported \\
\hline
\end{tabular}

Type of antifungal treat- Empiric ment

Funding sources $\quad$ Quote: "Grant support by The Queens Medical Center, Honolulu, HI, and Janssen Company"

Declaration of interest Not reported
among the primary researchers

\begin{tabular}{ll}
\hline Notes & Country: USA \\
& Setting: single hospital, adult surgical ICU
\end{tabular}


Yu 1993 (Continued)

Other: This study investigated the effect of ketoconazole for preventing ARDS in septic patients based on its anti-inflammatory activity. Thus, the antifungal activity of ketoconazole was not tested directly

\section{Risk of bias}

\begin{tabular}{|c|c|c|}
\hline Bias & Authors' judgement & Support for judgement \\
\hline $\begin{array}{l}\text { Random sequence genera- } \\
\text { tion (selection bias) }\end{array}$ & Unclear risk & Comment: insufficient information to make a judgement \\
\hline $\begin{array}{l}\text { Allocation concealment } \\
\text { (selection bias) }\end{array}$ & Unclear risk & Comment: insufficient information to make a judgement \\
\hline $\begin{array}{l}\text { Blinding of participants } \\
\text { and personnel (perfor- } \\
\text { mance bias) } \\
\text { All outcomes }\end{array}$ & Unclear risk & Comment: insufficient information to make a judgement \\
\hline $\begin{array}{l}\text { Blinding of outcome as- } \\
\text { sessment (detection bias) } \\
\text { All outcomes }\end{array}$ & Unclear risk & Comment: insufficient information to make a judgement \\
\hline $\begin{array}{l}\text { Incomplete outcome data } \\
\text { (attrition bias) } \\
\text { All outcomes }\end{array}$ & Low risk & Comment: no missing outcome data \\
\hline $\begin{array}{l}\text { Selective reporting (re- } \\
\text { porting bias) }\end{array}$ & Low risk & $\begin{array}{l}\text { Comment: the study protocol was not available but it was clear that published } \\
\text { reports included all expected outcomes }\end{array}$ \\
\hline Other bias & Low risk & Comment: the study appears to be free of other sources of bias \\
\hline
\end{tabular}

In the outcomes section, we reported the outcomes of interest for this review extracted from each study.

$\mathrm{AE}=$ adverse events

AIDS = acquired immune deficiency syndrome

$A L I=$ acute lung injury

APACHE = acute physiology and chronic health evaluation

ARDS = acute respiratory distress syndrome

CD4 = cluster of differentiation 4

$\mathrm{DSMB}=$ data and safety monitoring board

HIV = human immunodeficiency virus

$\mathrm{ICU}=$ intensive care unit

$\mathrm{IFI}=$ invasive fungal infection

IV = intravenously

$\mathrm{N}=$ number (simple size)

$\mathrm{PNV}=$ polymyxin $\mathrm{B}$, neomycin, vancomycin

$\mathrm{SDD}=$ selective digestive decontamination

Characteristics of excluded studies [ordered by study ID]

\begin{tabular}{ll}
\hline Study & Reason for exclusion \\
\hline Aerdts 1991 & $\begin{array}{l}\text { Ineligible intervention (treatment among randomized patients differed in other co-interventions } \\
\text { rather than in antifungal treatment only) }\end{array}$ \\
\hline Azoulay 2011 & Non-randomized design \\
\hline
\end{tabular}




\begin{tabular}{|c|c|}
\hline Study & Reason for exclusion \\
\hline Blair 1991 & $\begin{array}{l}\text { Ineligible intervention (treatment among randomized patients differed in other cointerventions } \\
\text { rather than in antifungal treatment only) }\end{array}$ \\
\hline Daeem 2012 & Ineligible population (neonates and paediatric patients) \\
\hline De Jonge 2003 & $\begin{array}{l}\text { Ineligible intervention (selective digestive decontamination). The antifungal drug was part of a de- } \\
\text { contamination regimen. Groups received treatments that differed also in other co-interventions } \\
\text { rather than in antifungal treatment only }\end{array}$ \\
\hline Hanson 2011 & $\begin{array}{l}\text { Ineligible intervention (pre-emptive therapy with anidulafungin according to beta-D-glucan level } \\
\text { versus empiric therapy according to opinion of physician in charge) }\end{array}$ \\
\hline Latif 2012 & Ineligible population (neonates and paediatric patients) \\
\hline Milanov 2010 & Ineligible intervention (antifungal agents used not described) \\
\hline Milanov 2013 & $\begin{array}{l}\text { Ineligible intervention (empiric versus pre-emptive antifungal therapy; antifungal agents used not } \\
\text { described) }\end{array}$ \\
\hline NCT00095316 & No results available (information obtained from the sponsor) \\
\hline NCT00099775 & No results available (information obtained from the sponsor) \\
\hline NCT00163111 & Ineligible interventions (comparing two regimens for targeted antifungal treatment) \\
\hline NCT00689338 & Non-randomized design \\
\hline NCT01045798 & $\begin{array}{l}\text { Outcomes not relevant (feasibility study investigating the proportion of patients discontinued from } \\
\text { study therapy to be treated with empirical antifungal therapy outside of the context of the study) }\end{array}$ \\
\hline NCT01524081 & $\begin{array}{l}\text { Ineligible intervention (groups differing not only for antifungal treatment but also for co-interven- } \\
\text { tions) }\end{array}$ \\
\hline Restrepo 2010 & Ineligible population (not critically ill participants) \\
\hline Sorkine 1996 & Ineligible intervention (targeted antifungal therapy) \\
\hline Wang 2009 & $\begin{array}{l}\text { Ineligible intervention (antifungal drugs given according to corrected colonization index or opinion } \\
\text { of physician in charge; antifungal agents used not specified) }\end{array}$ \\
\hline
\end{tabular}

\section{Characteristics of studies awaiting assessment [ordered by study ID]}

\section{Chen 2013}

\begin{tabular}{|c|c|}
\hline Methods & Two-arm single centre randomized study \\
\hline \multirow[t]{2}{*}{ Participants } & $\begin{array}{l}124 \text { critically ill patients admitted to Department of Critical Care Medicine of Jiangxi Provincial Peo- } \\
\text { ple's Hospital from } 1 \text { May } 2012 \text { to } 30 \text { April } 2013 \text { needing mechanical ventilation. More Inclusion cri- } \\
\text { teria: APACHE II > 15, at risk for IFI }\end{array}$ \\
\hline & $\begin{array}{l}\text { Exclusion criteria: patients with IFI, length of stay in ICU }<3 \text { days, patients receiving antifungal } \\
\text { drugs, allergy to antifungal drugs }\end{array}$ \\
\hline
\end{tabular}


Chen 2013 (Continued)

Another group received nystatin $1000 \mathrm{kU}$ three times a day via the gastric tube

\begin{tabular}{ll}
\hline Outcomes & Candida colonization (Corrected colonization index) \\
Incidence of candidaemia \\
ICU stay \\
Mortality \\
\hline We could not know the percentage of included neutropenic patients or treated with immunosup- \\
pressive therapy (information was recorded by the investigators but not reported) \\
PubMed: 24021043 \\
Contact: Zeng Jun, Department of Critical Care Medicine, People's Hospital of Jiangxi Province, \\
Nanchang 330006, Jiangxi, China. Corresponding author: Zeng Jun, Email: Katherine-cjl@163.com \\
\hline
\end{tabular}

Havlicek 2008

\begin{tabular}{ll}
\hline Methods & Two-arm single centre randomized trial \\
\hline Participants & 147 critically ill cancer, burned and trauma patients who had reached a RSS $\geq 10$ \\
& Exclusion criteria: RSS $\leq 10$ \\
\hline
\end{tabular}

Interventions Group 1: Itraconazole $200 \mathrm{mg}$ orally two times a day

Group 2: no antifungal treatment

\begin{tabular}{ll}
\hline Outcomes & Fungal colonization \\
& Fungal infection \\
& Mortality \\
\hline Notes & $\begin{array}{l}\text { One of the criteria for evaluating RSS used by the investigator was the presence of neutropenia. We } \\
\text { could not know the percentage of included neutropenic patients. } \\
\text { Contact: Havlicek K, Department of Surgery, Institute of Medical Studies, Pardubice General Hospi- } \\
\text { tal, Pardubice, Czech Republic } \\
\text { PubMed: } 19731862\end{array}$ \\
\hline
\end{tabular}

Milesi 2002

\begin{tabular}{ll}
\hline Methods & Two-arm single centre randomized controlled trial \\
\hline Participants & $\begin{array}{l}\text { 1. Both males and females, no age limits } \\
\text { 2. Patients hospitalized in a surgical intensive care unit with severe head trauma (Glasgow Coma } \\
\text { Scale }<8 \text { ), heavy abdominal surgery or traumatic post-operative abdomen }\end{array}$ \\
3. Patients who have recently started a prolonged antibiotic therapy \\
4. Long lasting hospitalisation in a intensive care unit
\end{tabular}


Milesi 2002 (Continued)

5. Screening candiduria above $10^{4}$ colony forming units (cfu)/ml

\begin{tabular}{ll}
\hline Interventions & Patients in group 1 received, from inclusion in the study, a measuring-spoonful of amphotericin B \\
& $10 \%(1$ measuring spoonful $=15 \mathrm{ml})$, drinkable solution, three times a day along with a mouthwash \\
with the same solution. Patients in group 2 received the placebo, dispensed in the same manner as \\
amphotericin B, at the same moment and frequency.
\end{tabular}

\begin{tabular}{ll}
\hline Outcomes & $\begin{array}{l}\text { Primary outcome: Percentage of patients with Candida colonization index }(\mathrm{Cl})>0.5, \text { assessed } \\
\text { weekly for } 4 \text { weeks }\end{array}$
\end{tabular}
weekly for 4 weeks

Secondary outcome: Evaluation of fungal flora and candidaemia, assessed weekly for 4 weeks.

\begin{tabular}{ll}
\hline Notes & Target sample size: 40 patients \\
& Overall declared trial end date: $01 / 08 / 2003$ \\
& Contact: Nadine Milesi, University Hospital of Dijon, Dijon 21033 Cedex, France \\
\hline
\end{tabular}

Whitby 2005

\begin{tabular}{ll}
\hline Methods & Two-arm single centre randomized controlled study \\
\hline Participants & $\begin{array}{l}\text { Males and females with highly suspected or confirmed invasive fungal infection. Patients' clinical } \\
\text { characteristics not stated }\end{array}$ \\
\hline Interventions & $\begin{array}{l}\text { Liposomal amphotericin B or conventional amphotericin B for a minimum of } 14 \text { days. Salvage ther- } \\
\text { apy (AmBisome } 5 \mathrm{mg} / \mathrm{kg} / \text { day). Total duration of therapy depends on the infection and the patient's } \\
\text { condition }\end{array}$ \\
\hline Outcomes & $\begin{array}{l}\text { Primary outcome: rate of treatment-related adverse events } \\
\text { and rescue period }\end{array}$ \\
\hline Notes & $\begin{array}{l}\text { Target sample size: } 104 . \text { Recruitment status: completed. } \\
\text { Contact: Michael Whitby, Infectious Diseases Department, Princess Alexandra Hospital, Ipswich Rd, } \\
\text { Woolloongabba, QLD, Australia }\end{array}$
\end{tabular}

APACHE $=$ acute physiology and chronic health evaluation

$\mathrm{Cfu}=$ colony forming units

$\mathrm{Cl}=$ colonization index

$I C U=$ intensive care unit

$\mathrm{IFI}=$ invasive fungal infection

$\mathrm{kU}=$ kilounits

$\mathrm{RSS}=$ risk severity score

Characteristics of ongoing studies [ordered by study ID]

\section{Lass-Flörl 2013}

\begin{tabular}{ll}
\hline Trial name or title & Micafungin-De-escalation study: Evalutating the rate of breakthrough infections of micafungin fol- \\
lowed by fluconazole versus fluconazole (or other azoles) in febrile patients
\end{tabular}

Methods Two-arm multicentre randomized controlled trial


Lass-Flörl 2013 (Continued)

Participants Adult patients who are suspicious of suffering from invasive fungal infections

\begin{tabular}{ll}
\hline Interventions & $\begin{array}{l}\text { 1) Micafungin followed by fluconazole } \\
\text { 2) Fluconazole (or other azoles) }\end{array}$ \\
\hline Outcomes & $\begin{array}{l}\text { Rate of breakthrough fungal infections, length of ICU stay, length of in-hospital stay, fungal colo- } \\
\text { nization index, total days of antifungal treatment, change from baseline values of the SOFA score, } \\
\text { incidence of drug-related unexpected serious adverse events, survival rate }\end{array}$
\end{tabular}

\begin{tabular}{ll}
\hline Starting date & May 2013 \\
\hline Contact information & $\begin{array}{l}\text { Cornelia Lass-Flörl, Medizinische Universität Innsbruck, Abteilung für Hygiene und Medizinische } \\
\text { Mikrobiologie, Innsbruck, Austria }\end{array}$ \\
\hline Notes & Target Sample size: 190 patients \\
\hline
\end{tabular}

\section{Timsit 2012}

\begin{tabular}{|c|c|}
\hline Trial name or title & $\begin{array}{l}\text { Micafungin Versus Placebo in the Nosocomial Sepsis in Patients Multi-colonized With Candida, Ran- } \\
\text { domized Controlled Trial (EMPIRICUS) }\end{array}$ \\
\hline Methods & Two-arm multicentre randomized controlled trial \\
\hline Participants & $\begin{array}{l}\text { Adult patients, mechanically ventilated for more than four days with sepsis of unknown origin and } \\
\text { with at least one extra-digestive fungal colonization site and multiple organ failure }\end{array}$ \\
\hline \multirow[t]{2}{*}{ Interventions } & 1) Micafungin $100 \mathrm{mg}$ intravenously once a day for 14 days (empiric therapy) \\
\hline & 2) placebo for 14 days \\
\hline \multirow[t]{2}{*}{ Outcomes } & $\begin{array}{l}\text { Primary outcomes: survival to } 28 \text { days without proven invasive infection; breakthrough infections } \\
\text { occurring at least } 48 \text { hours after initiation of treatment }\end{array}$ \\
\hline & $\begin{array}{l}\text { Secondary outcomes: All-cause mortality at } 28 \text { day and } 90 \text { days, antifungal-free survival at } 28 \text {-days, } \\
\text { organ failure, mechanical ventilation use, colonization index, serum biomarkers (1-3)- } \beta \text {-D-glucan } \\
\text { level, mannan antigenaemia, anti-mannan antibodies, blood Candida PCR), incidence of ventila- } \\
\text { tor-associated bacterial pneumonia, pharmacokinetic/pharmacodynamic (PK/PD) profile of mica- } \\
\text { fungin, tolerance of micafungin }\end{array}$ \\
\hline Starting date & July 2012 \\
\hline Contact information & $\begin{array}{l}\text { Jean-François Timsit, University Grenoble 1, Intensive Care Unit, Albert Michallon Hospital, BP 217, } \\
38043 \text { Grenoble, Cedex 9, France }\end{array}$ \\
\hline Notes & Target sample size: 260 patients \\
\hline
\end{tabular}

In the outcome section, we described the outcomes reported by the investigators.

$I C U=$ intensive care unit

SOFA = sequential organ failure assessment score

\section{DATA AND ANALYSES}


Comparison 1. Primary analysis: untargeted antifungal treatment with any antifungal drug (systemic or nonabsorbable) compared to placebo/no antifungal/any other antifungal drug

\begin{tabular}{|c|c|c|c|c|}
\hline Outcome or subgroup title & $\begin{array}{l}\text { No. of } \\
\text { studies }\end{array}$ & $\begin{array}{l}\text { No. of } \\
\text { partici- } \\
\text { pants }\end{array}$ & Statistical method & Effect size \\
\hline 1 Mortality & 19 & 2374 & Risk Ratio (M-H, Random, 95\% Cl) & $0.93[0.79,1.09]$ \\
\hline 1.1 Fluconazole & 9 & 1130 & Risk Ratio (M-H, Random, 95\% Cl) & $0.86[0.62,1.18]$ \\
\hline 1.2 Ketoconazole & 3 & 359 & Risk Ratio (M-H, Random, 95\% Cl) & $0.80[0.51,1.26]$ \\
\hline 1.3 Caspofungin & 1 & 219 & Risk Ratio (M-H, Random, 95\% Cl) & $1.31[0.74,2.32]$ \\
\hline 1.4 Micafungin & 2 & 350 & Risk Ratio (M-H, Random, 95\% Cl) & $1.03[0.65,1.62]$ \\
\hline 1.5 Amphotericin B & 1 & 51 & Risk Ratio (M-H, Random, 95\% Cl) & $1.69[0.54,5.27]$ \\
\hline 1.6 Nystatin & 2 & 205 & Risk Ratio (M-H, Random, 95\% Cl) & $0.86[0.55,1.33]$ \\
\hline 1.7 Anidulafungin & 1 & 60 & Risk Ratio (M-H, Random, 95\% Cl) & $1.09[0.42,2.87]$ \\
\hline 2 Proven invasive fungal infection & 17 & 2024 & Risk Ratio (M-H, Random, 95\% Cl) & $0.57[0.39,0.83]$ \\
\hline 2.1 Fluconazole & 10 & 1173 & Risk Ratio (M-H, Random, 95\% Cl) & $0.45[0.30,0.68]$ \\
\hline 2.2 Ketoconazole & 1 & 71 & Risk Ratio (M-H, Random, 95\% Cl) & $0.21[0.03,1.67]$ \\
\hline 2.3 Caspofungin & 1 & 189 & Risk Ratio (M-H, Random, 95\% Cl) & $0.12[0.02,0.97]$ \\
\hline 2.4 Micafungin & 2 & 343 & Risk Ratio (M-H, Random, 95\% Cl) & $0.90[0.22,3.63]$ \\
\hline 2.5 Nystatin & 2 & 197 & Risk Ratio (M-H, Random, 95\% Cl) & $0.0[0.0,0.0]$ \\
\hline 2.6 Amphotericin B & 1 & 51 & Risk Ratio (M-H, Random, 95\% Cl) & $1.24[0.64,2.39]$ \\
\hline $\begin{array}{l}3 \text { Proven or suspected invasive } \\
\text { fungal infection }\end{array}$ & 5 & 911 & Risk Ratio (M-H, Random, 95\% Cl) & $0.63[0.39,1.00]$ \\
\hline 3.1 Fluconazole & 4 & 696 & Risk Ratio (M-H, Random, 95\% Cl) & $0.63[0.32,1.25]$ \\
\hline 3.2 Caspofungin & 1 & 215 & Risk Ratio (M-H, Random, 95\% Cl) & $0.63[0.39,1.01]$ \\
\hline $\begin{array}{l}4 \text { Suspected invasive fungal in- } \\
\text { fection }\end{array}$ & 5 & 911 & Risk Ratio (M-H, Random, 95\% Cl) & $0.94[0.38,2.32]$ \\
\hline 4.1 Fluconazole & 4 & 696 & Risk Ratio (M-H, Random, 95\% Cl) & $1.14[0.25,5.13]$ \\
\hline 4.2 Caspofungin & 1 & 215 & Risk Ratio (M-H, Random, 95\% Cl) & $0.78[0.46,1.31]$ \\
\hline 5 Superficial fungal infection & 5 & 662 & Risk Ratio (M-H, Random, 95\% Cl) & $0.69[0.37,1.29]$ \\
\hline 5.1 Fluconazole & 4 & 611 & Risk Ratio (M-H, Random, 95\% Cl) & $0.62[0.29,1.30]$ \\
\hline 5.2 Amphotericin B & 1 & 51 & Risk Ratio (M-H, Random, 95\% Cl) & $0.9[0.27,2.97]$ \\
\hline 6 Fungal colonization & 12 & 1030 & Risk Ratio (M-H, Random, 95\% Cl) & $0.71[0.52,0.97]$ \\
\hline
\end{tabular}




\begin{tabular}{|c|c|c|c|c|}
\hline Outcome or subgroup title & $\begin{array}{l}\text { No. of } \\
\text { studies }\end{array}$ & $\begin{array}{l}\text { No. of } \\
\text { partici- } \\
\text { pants }\end{array}$ & Statistical method & Effect size \\
\hline 6.1 Fluconazole & 6 & 403 & Risk Ratio (M-H, Random, 95\% Cl) & $0.60[0.30,1.20]$ \\
\hline 6.2 Ketoconazole & 2 & 125 & Risk Ratio (M-H, Random, 95\% Cl) & $0.68[0.45,1.03]$ \\
\hline 6.3 Micafungin & 2 & 343 & Risk Ratio (M-H, Random, 95\% Cl) & $0.74[0.58,0.94]$ \\
\hline 6.4 Nystatin & 1 & 99 & Risk Ratio (M-H, Random, 95\% Cl) & $1.17[0.46,2.97]$ \\
\hline 6.5 Anidalafungin & 1 & 60 & Risk Ratio (M-H, Random, 95\% Cl) & $1.87[0.18,19.55]$ \\
\hline $\begin{array}{l}7 \text { Proven invasive fungal infection } \\
\text { (azole-resistant Candida species) }\end{array}$ & 8 & 1058 & Risk Ratio (M-H, Random, 95\% Cl) & $0.53[0.20,1.40]$ \\
\hline 7.1 Fluconazole & 7 & 987 & Risk Ratio (M-H, Random, 95\% Cl) & $0.56[0.20,1.54]$ \\
\hline 7.2 Ketoconazole & 1 & 71 & Risk Ratio (M-H, Random, 95\% Cl) & $0.34[0.01,8.14]$ \\
\hline $\begin{array}{l}8 \text { Fungal colonization (azole-re- } \\
\text { sistant Candida species) }\end{array}$ & 5 & 311 & Risk Ratio (M-H, Random, 95\% Cl) & $1.03[0.34,3.12]$ \\
\hline 8.1 Fluconazole & 4 & 254 & Risk Ratio (M-H, Random, 95\% Cl) & $1.74[0.58,5.17]$ \\
\hline 8.2 Ketoconazole & 1 & 57 & Risk Ratio (M-H, Random, 95\% Cl) & $0.19[0.02,1.44]$ \\
\hline $\begin{array}{l}9 \text { Adverse events requiring cessa- } \\
\text { tion }\end{array}$ & 11 & 1691 & Risk Ratio (M-H, Random, 95\% Cl) & $0.89[0.62,1.27]$ \\
\hline 9.1 Fluconazole & 4 & 637 & Risk Ratio (M-H, Random, 95\% Cl) & $0.72[0.38,1.35]$ \\
\hline 9.2 Ketoconazole & 2 & 288 & Risk Ratio (M-H, Random, 95\% Cl) & $1.24[0.20,7.59]$ \\
\hline 9.3 Caspofungin & 1 & 219 & Risk Ratio (M-H, Random, 95\% Cl) & $0.87[0.13,6.08]$ \\
\hline 9.4 Micafungin & 2 & 350 & Risk Ratio (M-H, Random, 95\% Cl) & $1.02[0.60,1.74]$ \\
\hline 9.5 Nystatin & 2 & 197 & Risk Ratio (M-H, Random, 95\% Cl) & $0.0[0.0,0.0]$ \\
\hline
\end{tabular}

Analysis 1.1. Comparison 1 Primary analysis: untargeted antifungal treatment with any antifungal drug (systemic or nonabsorbable) compared to placebo/no antifungal/any other antifungal drug, Outcome 1 Mortality.

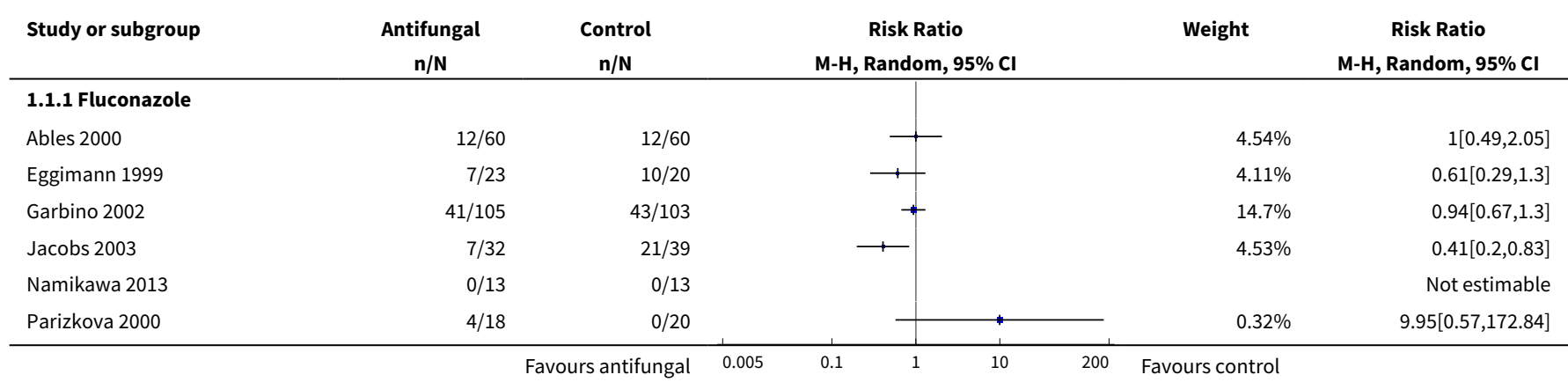




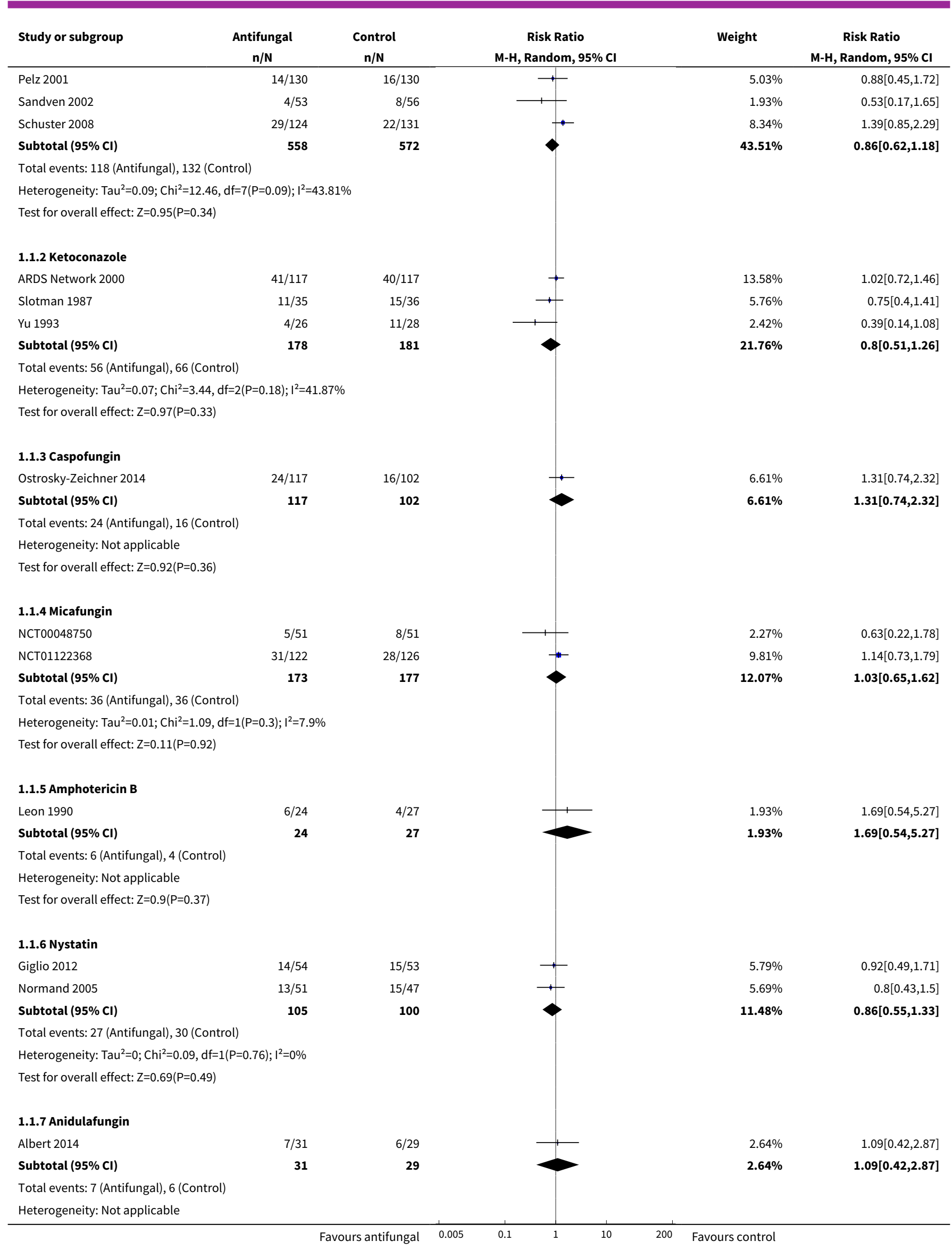

Antifungal agents for preventing fungal infections in non-neutropenic critically ill patients (Review) 


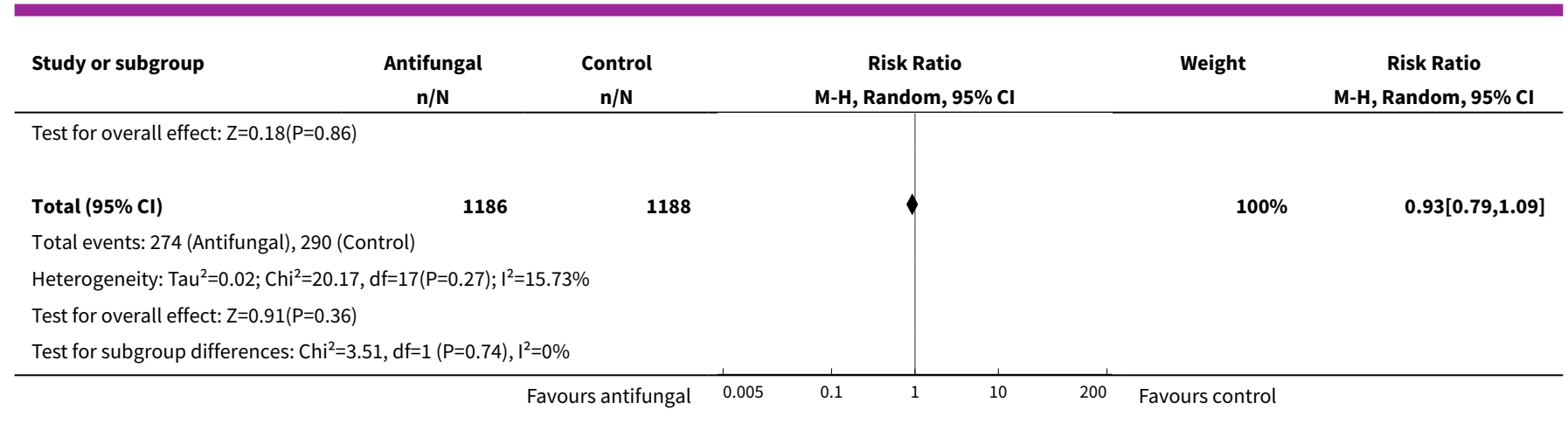

Analysis 1.2. Comparison 1 Primary analysis: untargeted antifungal treatment
with any antifungal drug (systemic or nonabsorbable) compared to placebo/no
antifungal/any other antifungal drug, Outcome 2 Proven invasive fungal infection.

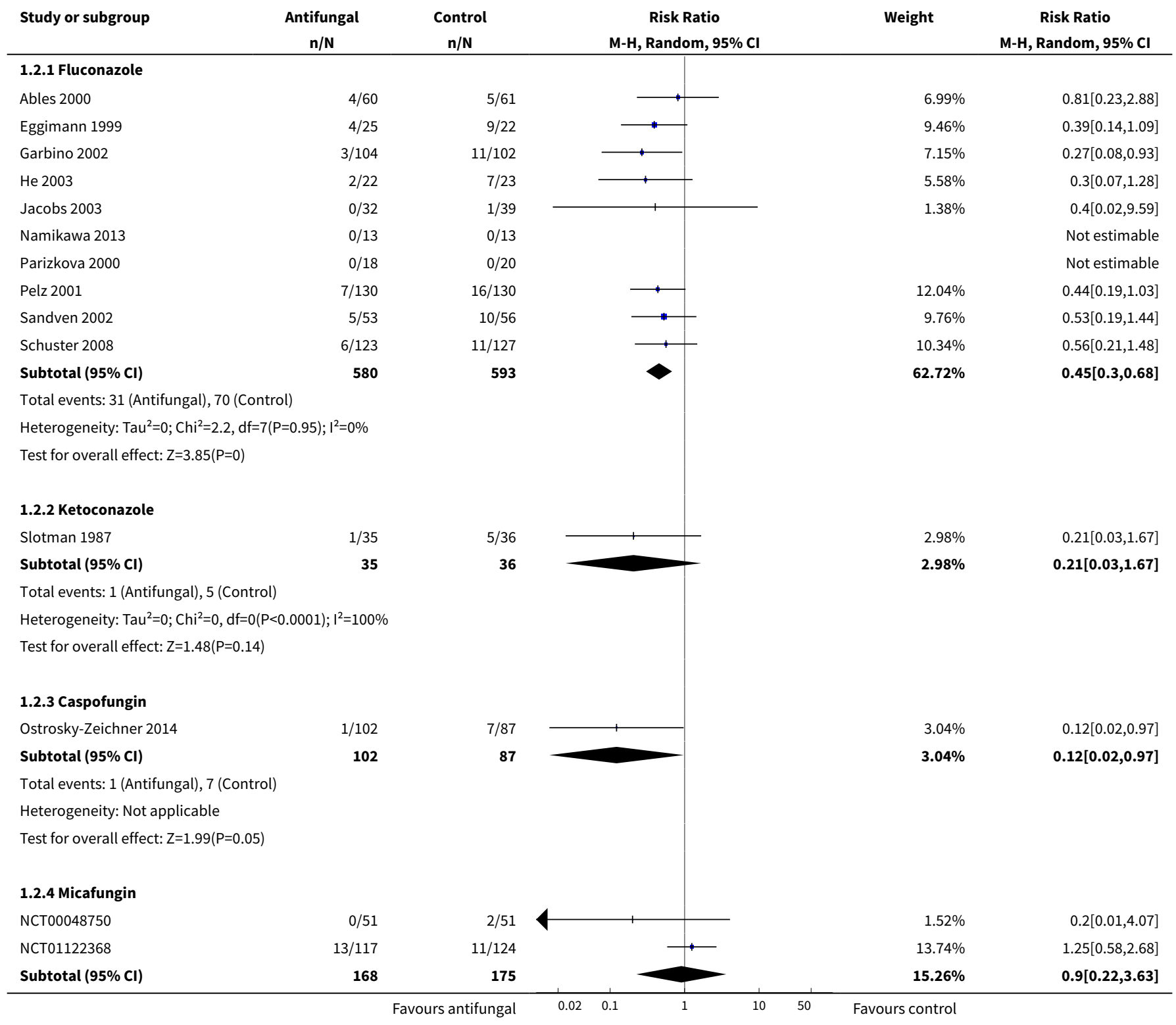




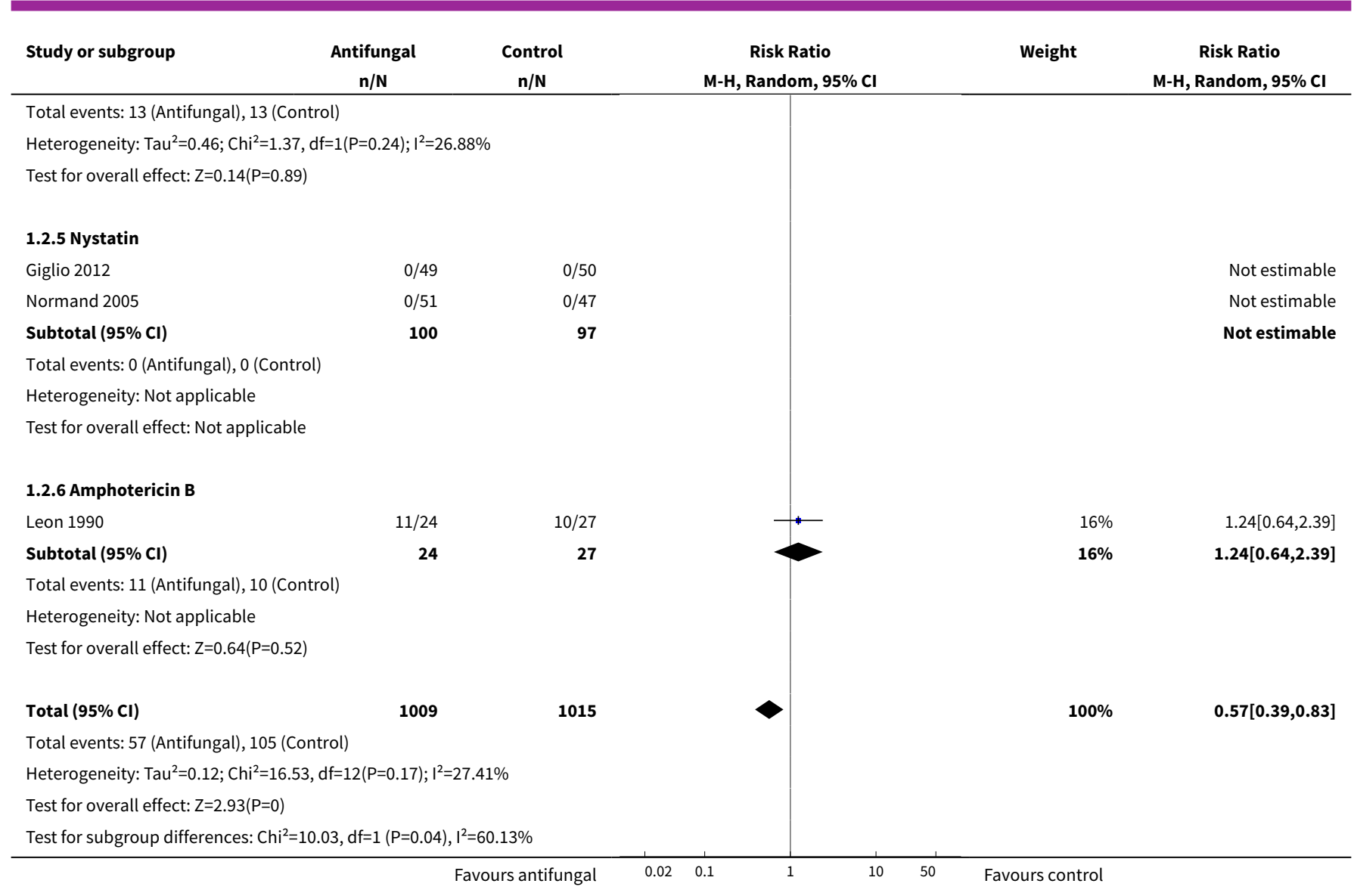

Analysis 1.3. Comparison 1 Primary analysis: untargeted antifungal treatment with any antifungal drug (systemic or nonabsorbable) compared to placebo/no antifungal/ any other antifungal drug, Outcome 3 Proven or suspected invasive fungal infection.

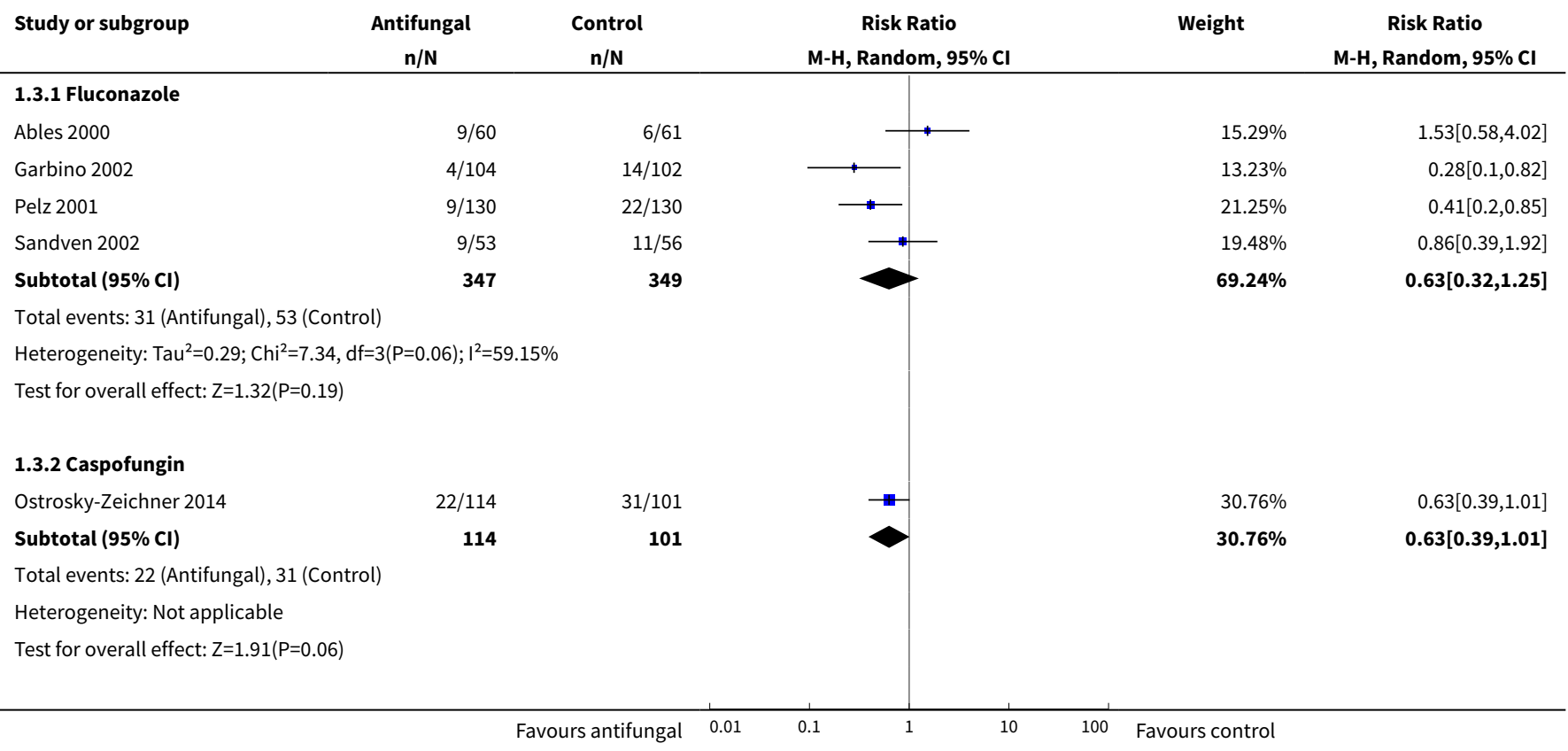




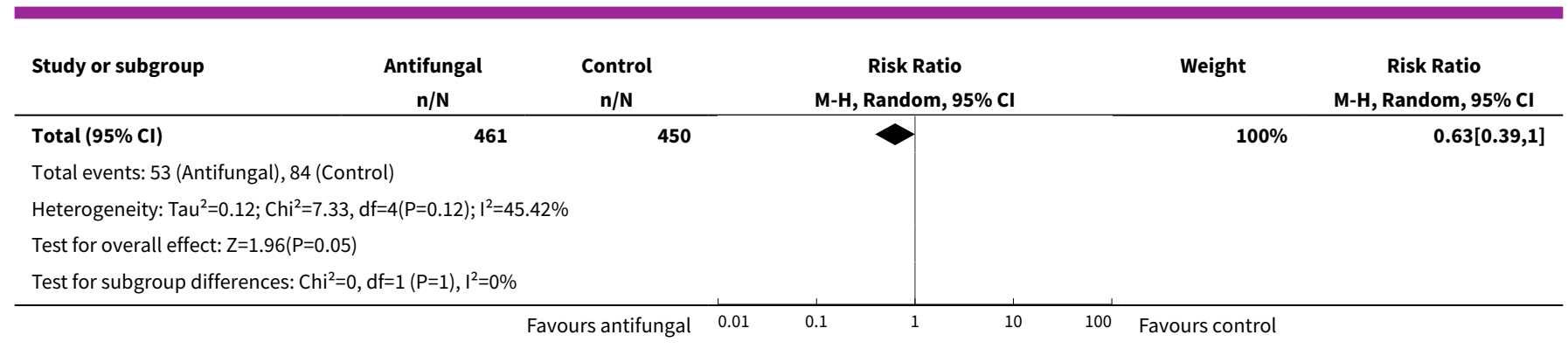

Analysis 1.4. Comparison 1 Primary analysis: untargeted antifungal treatment with any antifungal drug (systemic or nonabsorbable) compared to placebo/no antifungal/any other antifungal drug, Outcome 4 Suspected invasive fungal infection.

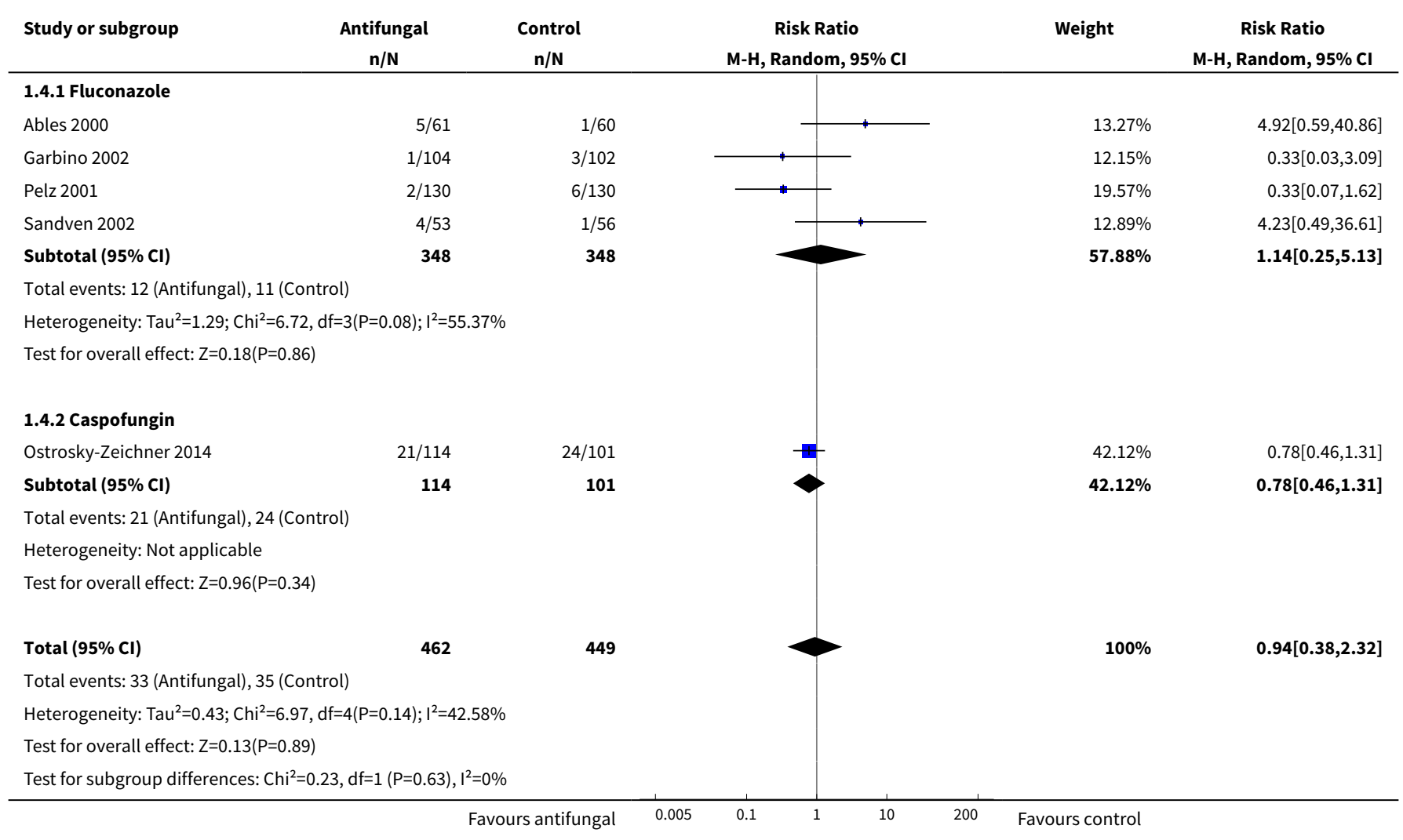

Analysis 1.5. Comparison 1 Primary analysis: untargeted antifungal treatment with any antifungal drug (systemic or nonabsorbable) compared to placebo/ no antifungal/any other antifungal drug, Outcome 5 Superficial fungal infection.

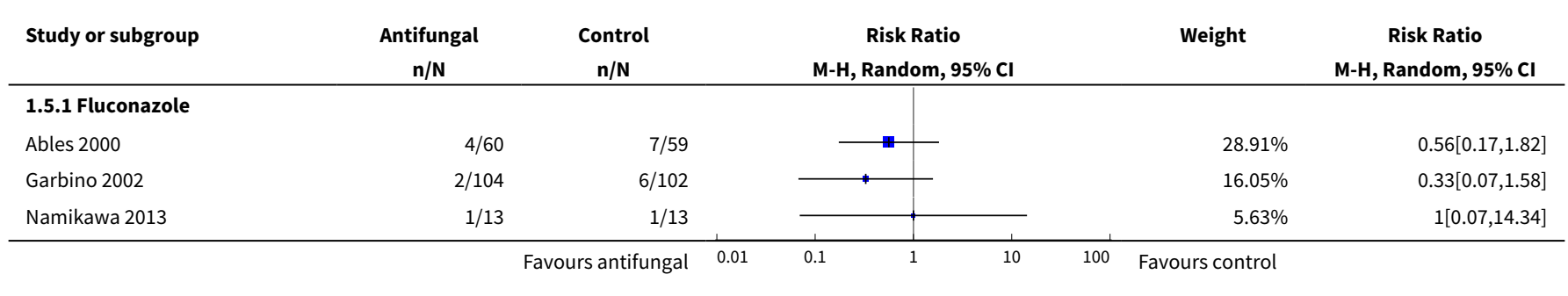




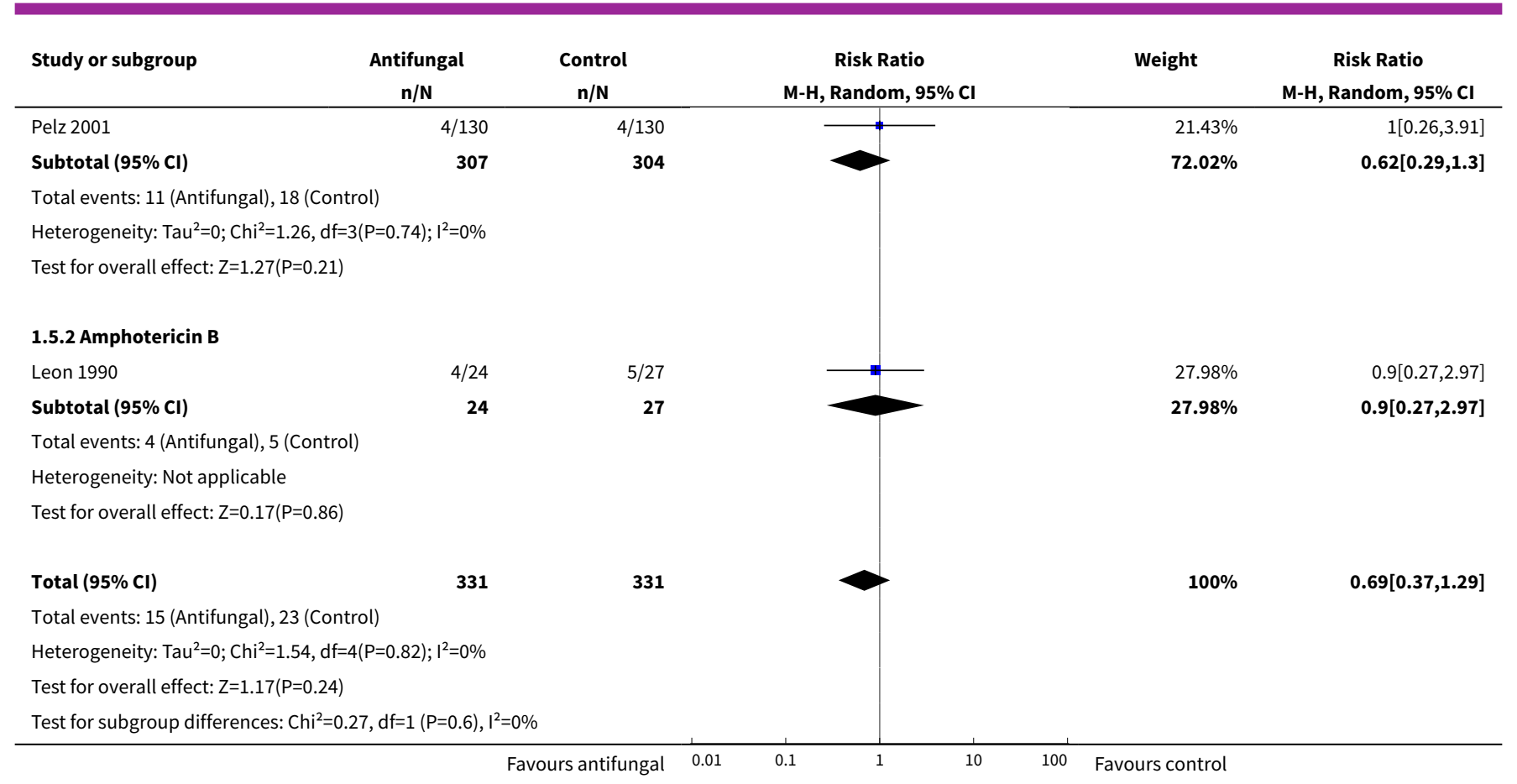

Analysis 1.6. Comparison 1 Primary analysis: untargeted antifungal treatment with any antifungal drug (systemic or nonabsorbable) compared to placebo/no antifungal/any other antifungal drug, Outcome 6 Fungal colonization.

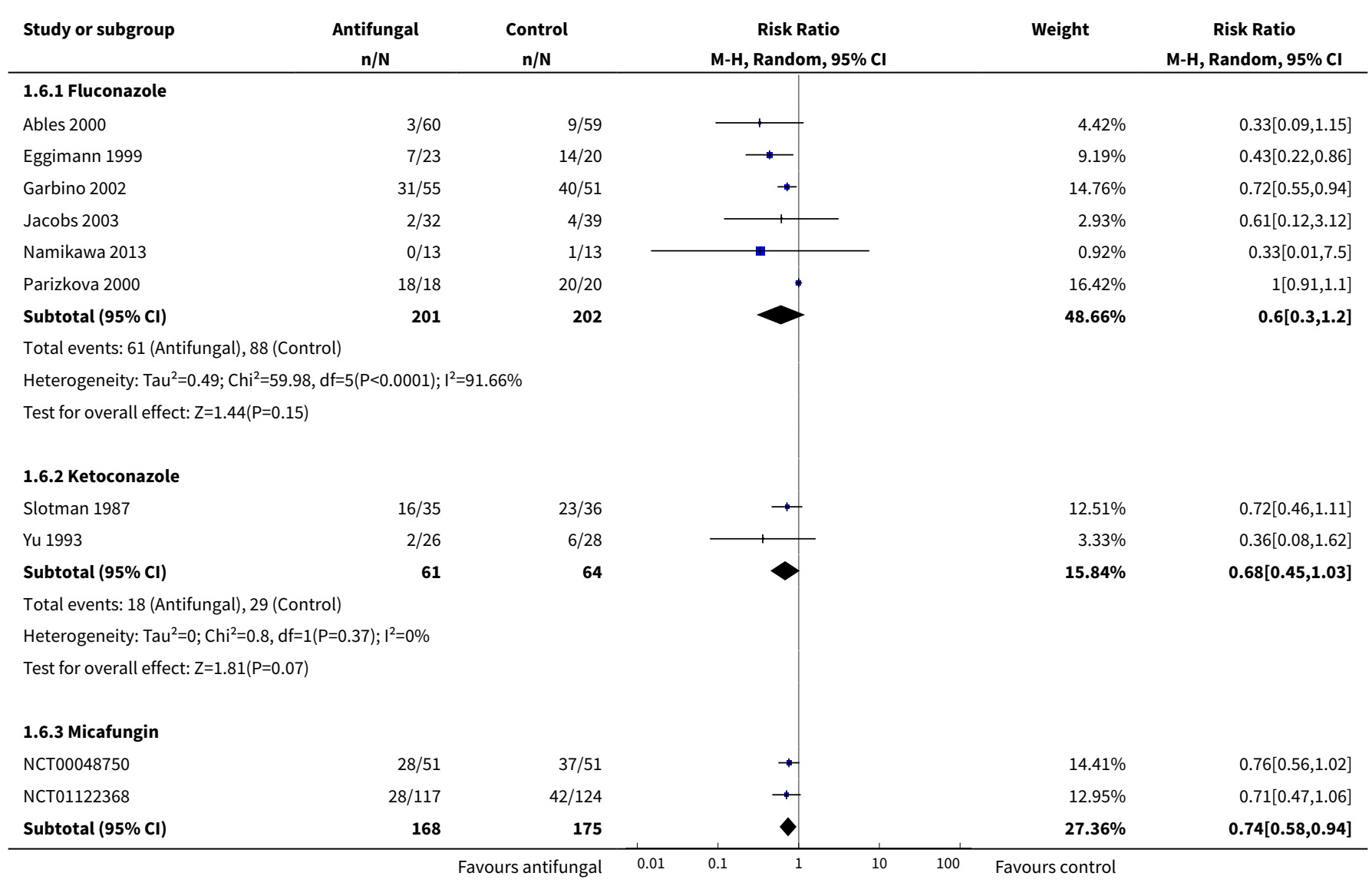




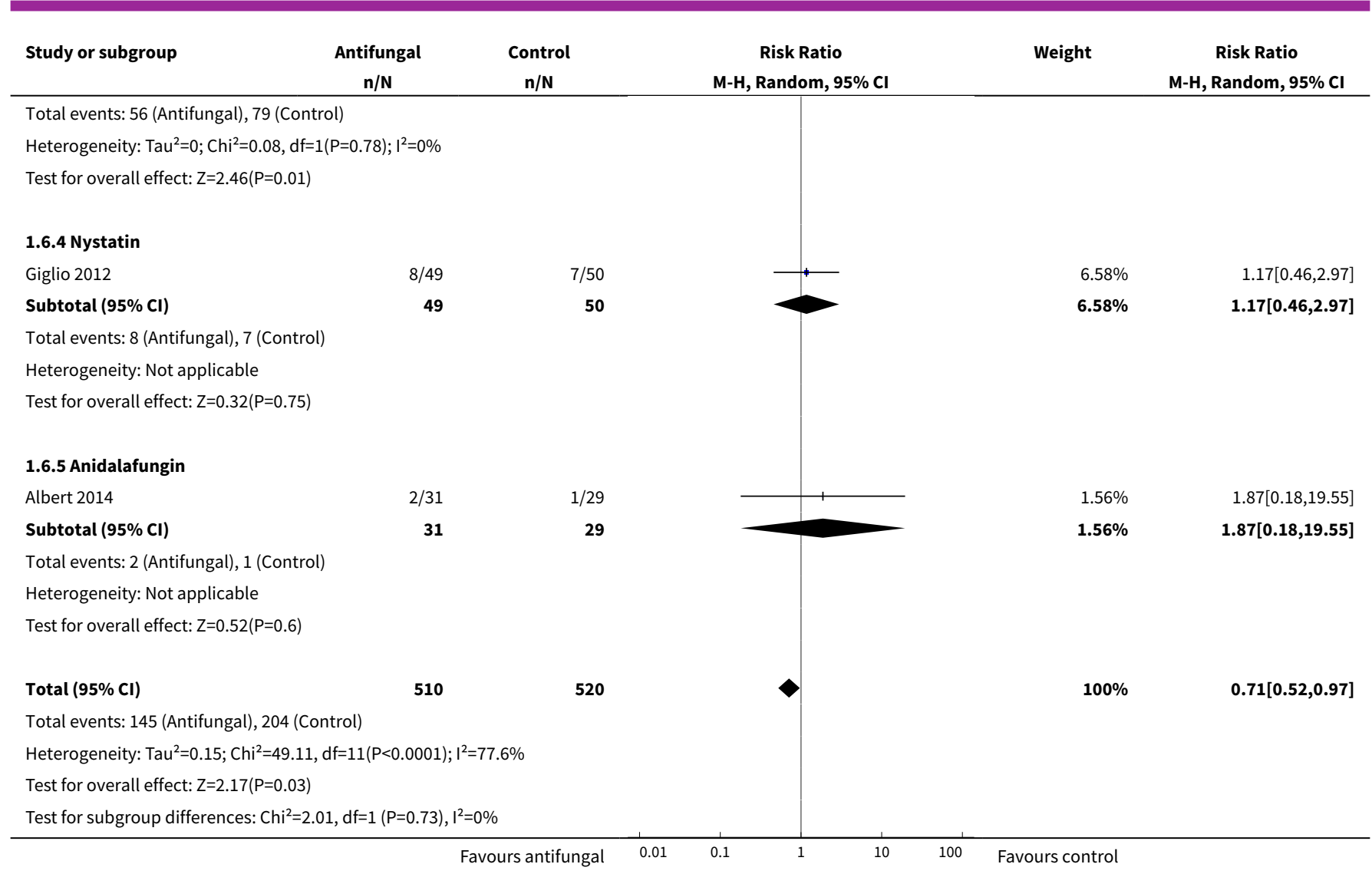

\begin{abstract}
Analysis 1.7. Comparison 1 Primary analysis: untargeted antifungal treatment with any antifungal drug (systemic or nonabsorbable) compared to placebo/no antifungal/any other antifungal drug, Outcome 7 Proven invasive fungal infection (azole-resistant Candida species).
\end{abstract}

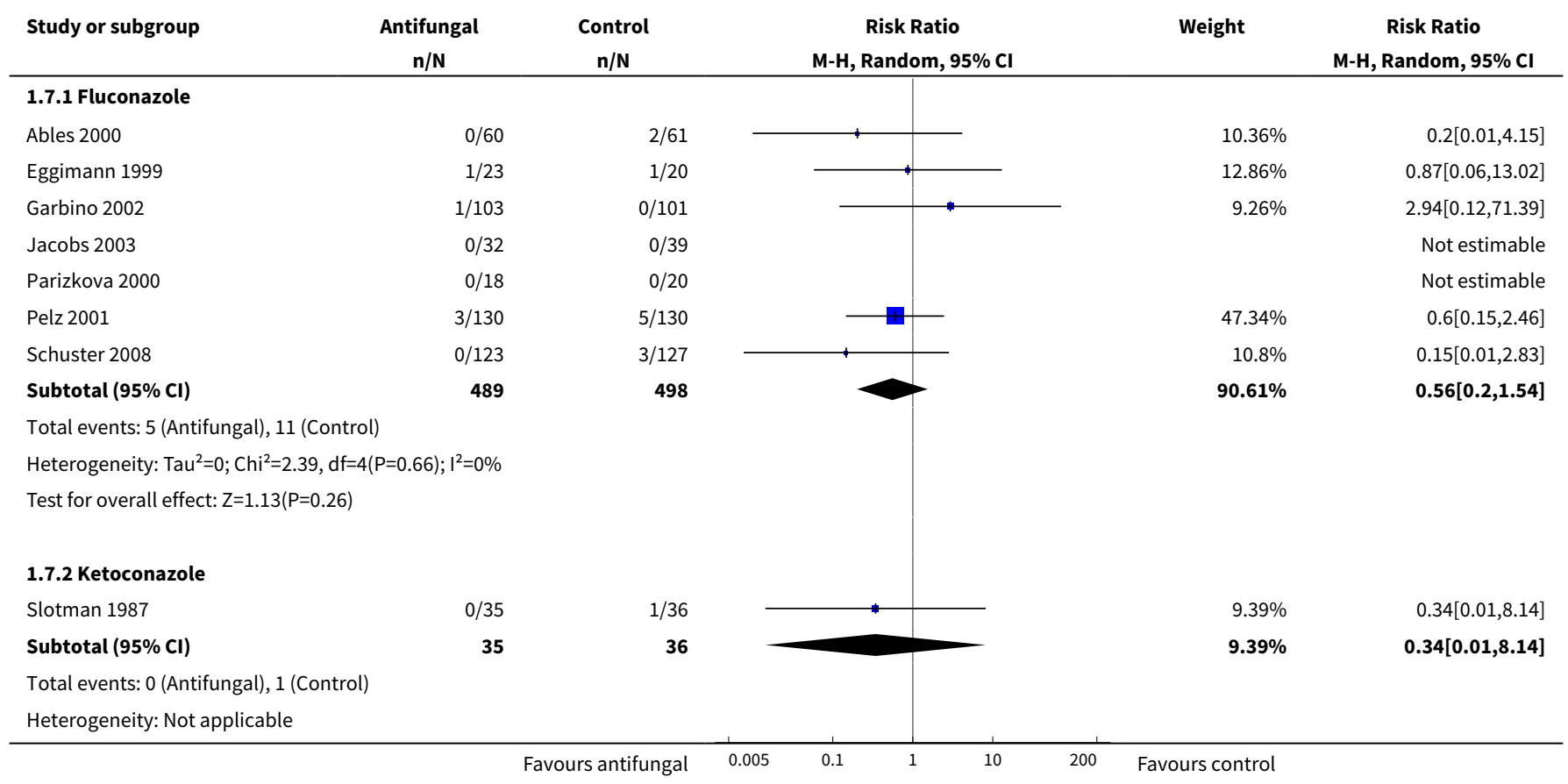




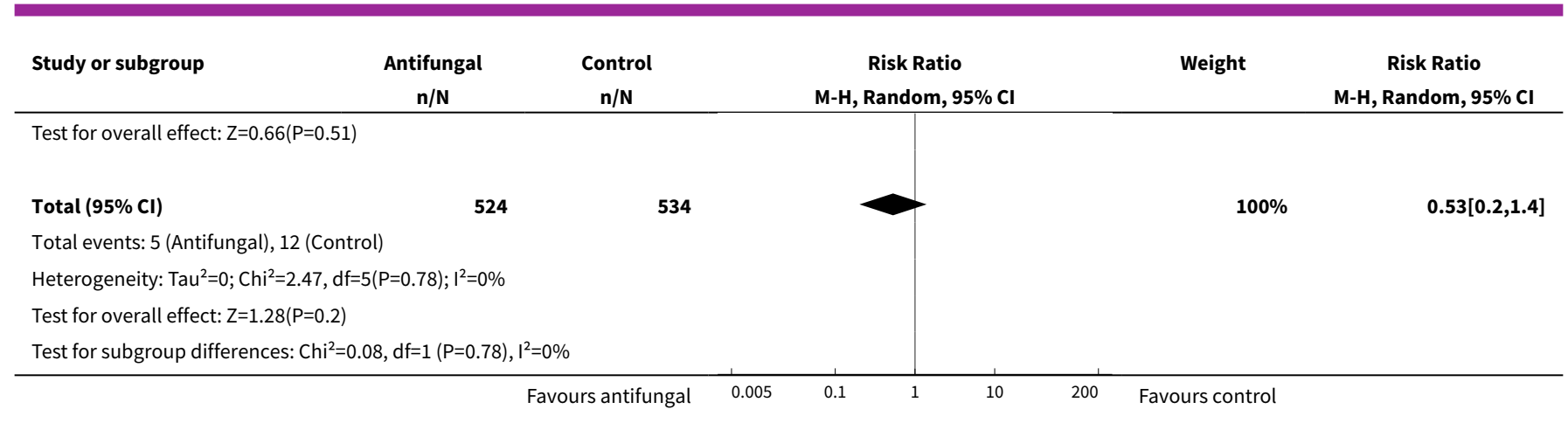

Analysis 1.8. Comparison 1 Primary analysis: untargeted antifungal treatment with any antifungal drug (systemic or nonabsorbable) compared to placebo/no antifungal/any other antifungal drug, Outcome 8 Fungal colonization (azole-resistant Candida species).

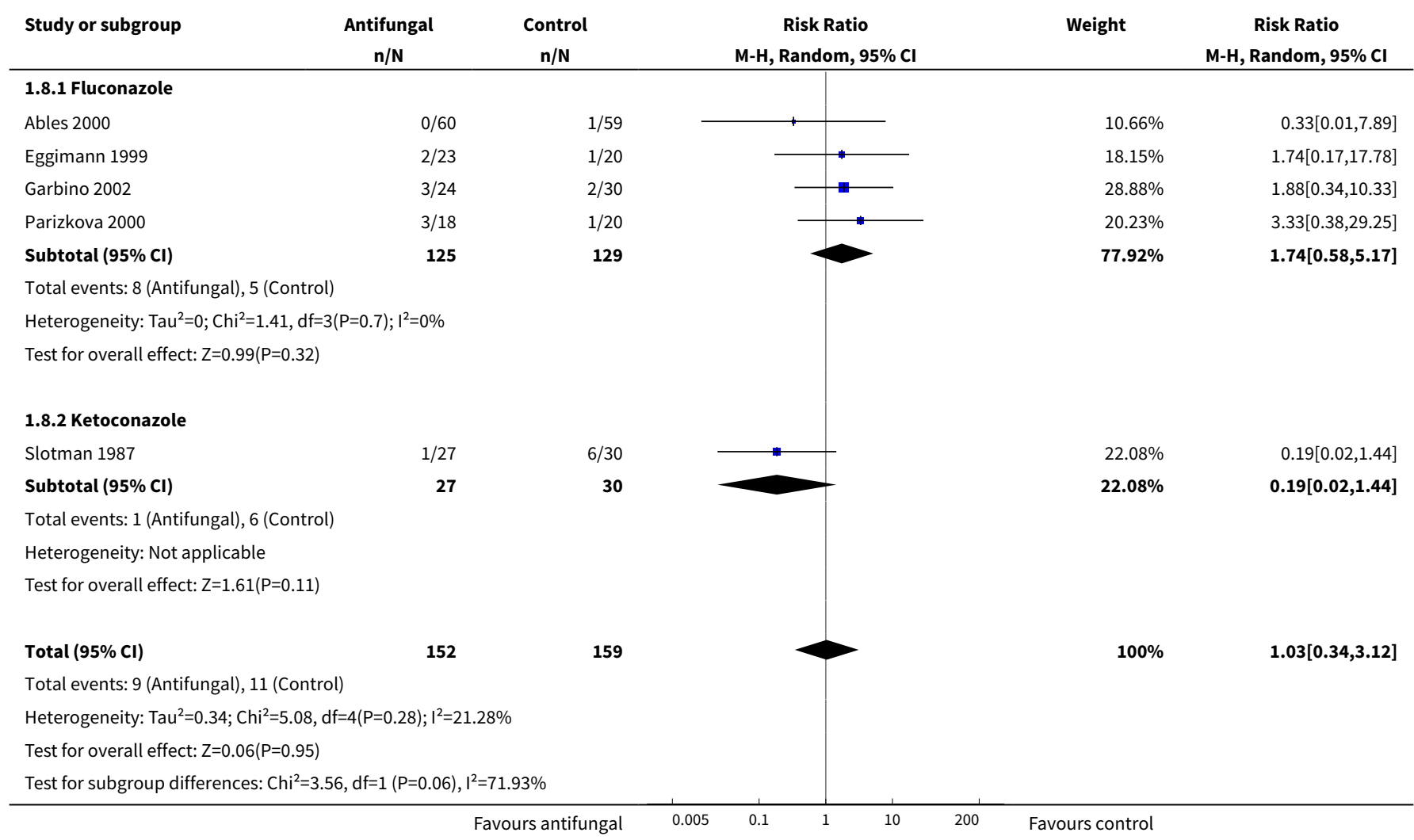

Analysis 1.9. Comparison 1 Primary analysis: untargeted antifungal treatment with any antifungal drug (systemic or nonabsorbable) compared to placebo/no antifungal/any other antifungal drug, Outcome 9 Adverse events requiring cessation.

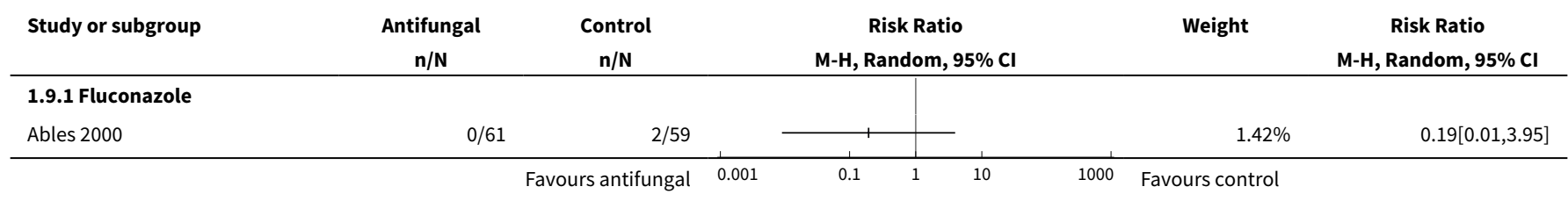




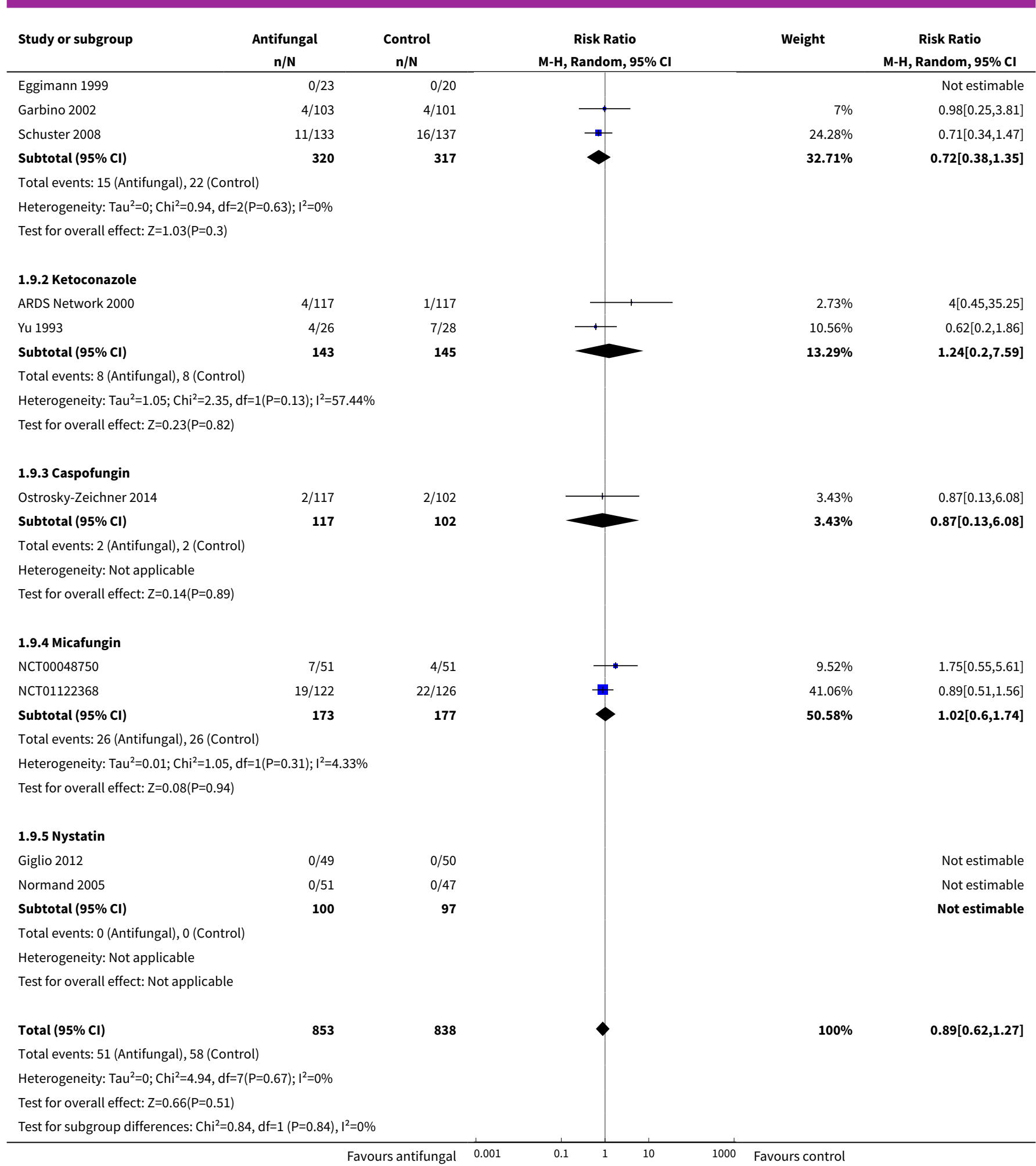




\section{Comparison 2. Subgroup analysis}

\begin{tabular}{|c|c|c|c|c|}
\hline Outcome or subgroup title & $\begin{array}{l}\text { No. of } \\
\text { studies }\end{array}$ & $\begin{array}{l}\text { No. of } \\
\text { partici- } \\
\text { pants }\end{array}$ & Statistical method & Effect size \\
\hline 1 Mortality. Types of participants & 17 & 2038 & Risk Ratio (M-H, Random, 95\% Cl) & $0.92[0.76,1.11]$ \\
\hline 1.1 Post-surgical patients $\geq 75 \%$ & 7 & 811 & Risk Ratio (M-H, Random, 95\% Cl) & $0.81[0.60,1.08]$ \\
\hline 1.2 Post-surgical patients $<75 \%$ & 10 & 1227 & Risk Ratio (M-H, Random, 95\% Cl) & $1.00[0.78,1.28]$ \\
\hline 2 Mortality. Fluconazole dose & 9 & 1130 & Risk Ratio (M-H, Random, 95\% Cl) & $0.86[0.62,1.18]$ \\
\hline 2.1 Fluconazole dose $\geq 400 \mathrm{mg} / \mathrm{die}$ & 6 & 813 & Risk Ratio (M-H, Random, 95\% Cl) & $0.95[0.68,1.33]$ \\
\hline 2.2 Fluconazole dose $<400 \mathrm{mg} / \mathrm{die}$ & 3 & 317 & Risk Ratio (M-H, Random, 95\% Cl) & $0.82[0.33,2.03]$ \\
\hline $\begin{array}{l}3 \text { Mortality. Systemic or non-absorbable } \\
\text { antifungal drug }\end{array}$ & 19 & 2374 & Risk Ratio (M-H, Random, 95\% Cl) & $0.93[0.79,1.09]$ \\
\hline 3.1 Systemic & 16 & 2118 & Risk Ratio (M-H, Random, 95\% Cl) & $0.91[0.76,1.11]$ \\
\hline 3.2 Non-absorbable & 3 & 256 & Risk Ratio (M-H, Random, 95\% Cl) & $0.94[0.62,1.41]$ \\
\hline 4 Mortality. Drug class & 16 & 2123 & Risk Ratio (M-H, Random, 95\% Cl) & $0.91[0.76,1.10]$ \\
\hline 4.1 Azoles & 12 & 1494 & Risk Ratio (M-H, Random, 95\% Cl) & $0.84[0.67,1.07]$ \\
\hline 4.2 Echinocandins & 4 & 629 & Risk Ratio (M-H, Random, 95\% Cl) & $1.12[0.82,1.54]$ \\
\hline 5 Mortality. Type of intervention & 18 & 2348 & Risk Ratio (M-H, Random, 95\% Cl) & $0.93[0.79,1.09]$ \\
\hline 5.1 Prophylaxis & 12 & 1609 & Risk Ratio (M-H, Random, 95\% Cl) & $0.92[0.78,1.09]$ \\
\hline 5.2 Empiric treatment & 6 & 739 & Risk Ratio (M-H, Random, 95\% Cl) & $0.90[0.57,1.44]$ \\
\hline 6 Mortality. Type of control group & 19 & 2374 & Risk Ratio (M-H, Random, 95\% Cl) & $0.93[0.79,1.09]$ \\
\hline 6.1 Placebo & 15 & 2105 & Risk Ratio (M-H, Random, 95\% Cl) & $0.93[0.78,1.11]$ \\
\hline 6.2 No intervention & 4 & 269 & Risk Ratio (M-H, Random, 95\% Cl) & $0.95[0.52,1.74]$ \\
\hline 7 Proven IFI. Type of participants & 15 & 1877 & Risk Ratio (M-H, Random, 95\% Cl) & $0.59[0.40,0.89]$ \\
\hline 7.1 Post-surgical patients $\geq 75 \%$ & 6 & 754 & Risk Ratio (M-H, Random, 95\% Cl) & $0.57[0.33,0.99]$ \\
\hline 7.2 Post-surgical patients $<75 \%$ & 9 & 1123 & Risk Ratio (M-H, Random, 95\% Cl) & $0.57[0.29,1.15]$ \\
\hline 8 Proven IFI. Fluconazole dose & 10 & 1173 & Risk Ratio (M-H, Random, 95\% Cl) & $0.45[0.30,0.68]$ \\
\hline 8.1 Fluconazole dose $\geq 400 \mathrm{mg} / \mathrm{die}$ & 6 & 813 & Risk Ratio (M-H, Random, 95\% Cl) & $0.51[0.32,0.79]$ \\
\hline 8.2 Fluconazole dose $<400 \mathrm{mg} / \mathrm{die}$ & 4 & 360 & Risk Ratio (M-H, Random, 95\% Cl) & $0.29[0.12,0.72]$ \\
\hline $\begin{array}{l}9 \text { Proven IFI. Systemic or non-ab- } \\
\text { sorbable antifungal drug }\end{array}$ & 17 & 2024 & Risk Ratio (M-H, Random, 95\% Cl) & $0.57[0.39,0.83]$ \\
\hline
\end{tabular}




\begin{tabular}{|c|c|c|c|c|}
\hline Outcome or subgroup title & $\begin{array}{l}\text { No. of } \\
\text { studies }\end{array}$ & $\begin{array}{l}\text { No. of } \\
\text { partici- } \\
\text { pants }\end{array}$ & Statistical method & Effect size \\
\hline 9.1 Systemic & 14 & 1776 & Risk Ratio (M-H, Random, 95\% Cl) & $0.52[0.37,0.73]$ \\
\hline 9.2 Non-absorbable & 3 & 248 & Risk Ratio (M-H, Random, 95\% Cl) & $1.24[0.64,2.39]$ \\
\hline 10 Proven IFI. Drug class & 14 & 1776 & Risk Ratio (M-H, Random, 95\% Cl) & $0.52[0.37,0.73]$ \\
\hline 10.1 Azoles & 11 & 1244 & Risk Ratio (M-H, Random, 95\% Cl) & $0.44[0.30,0.66]$ \\
\hline 10.2 Echinocandins & 3 & 532 & Risk Ratio (M-H, Random, 95\% Cl) & $0.42[0.07,2.46]$ \\
\hline 11 Proven IFI. Type of intervention & 16 & 1998 & Risk Ratio (M-H, Random, 95\% Cl) & $0.57[0.39,0.83]$ \\
\hline 11.1 Prophylaxis & 12 & 1385 & Risk Ratio (M-H, Random, 95\% Cl) & $0.39[0.26,0.60]$ \\
\hline 11.2 Empiric treatment & 4 & 613 & Risk Ratio (M-H, Random, 95\% Cl) & $1.03[0.67,1.60]$ \\
\hline 12 Proven IFI. Type of control group & 17 & 2024 & Risk Ratio (M-H, Random, 95\% Cl) & $0.57[0.39,0.83]$ \\
\hline 12.1 Placebo & 12 & 1718 & Risk Ratio (M-H, Random, 95\% Cl) & $0.59[0.39,0.87]$ \\
\hline 12.2 No intervention & 5 & 306 & Risk Ratio (M-H, Random, 95\% Cl) & $0.30[0.07,1.28]$ \\
\hline
\end{tabular}

Analysis 2.1. Comparison 2 Subgroup analysis, Outcome 1 Mortality. Types of participants.

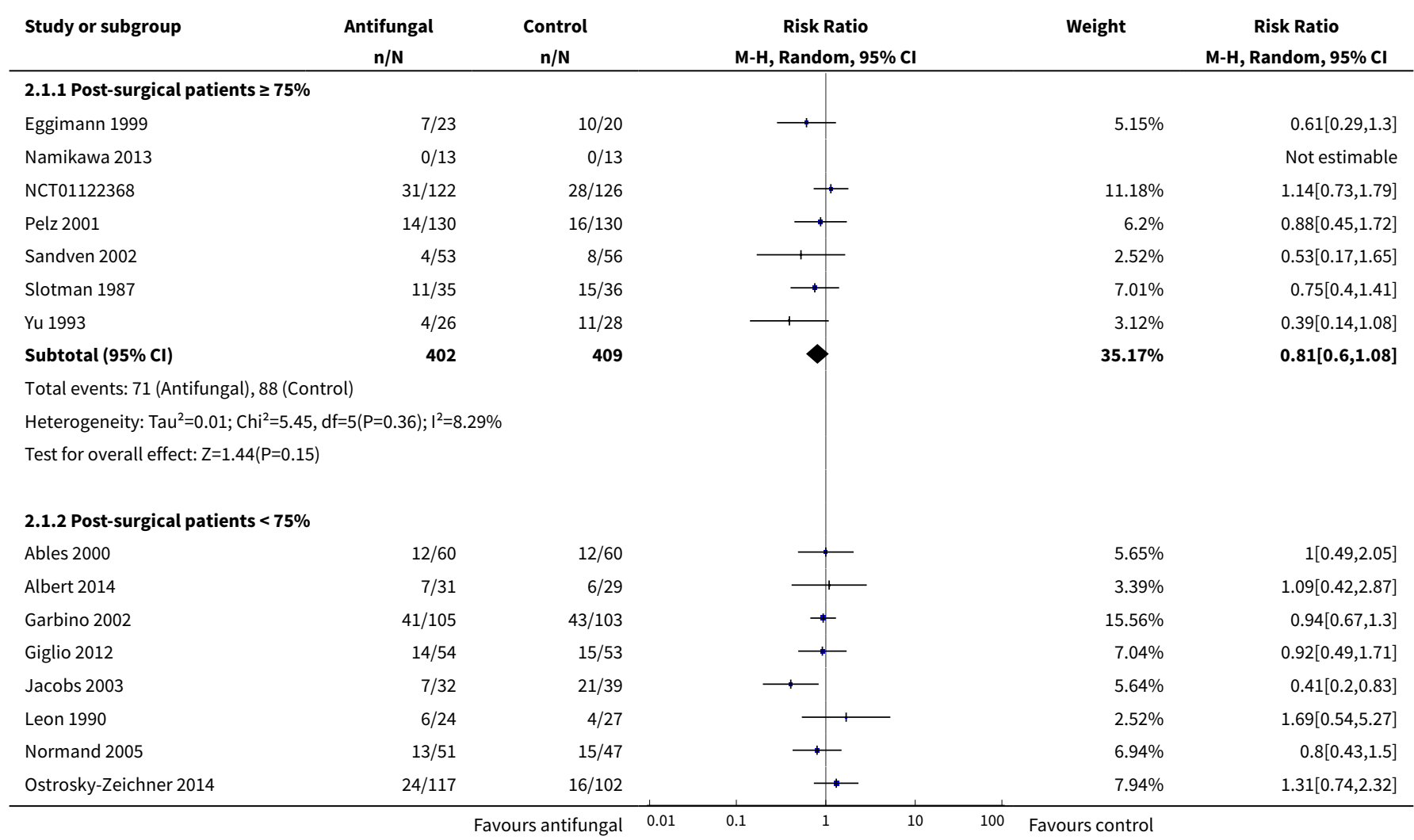




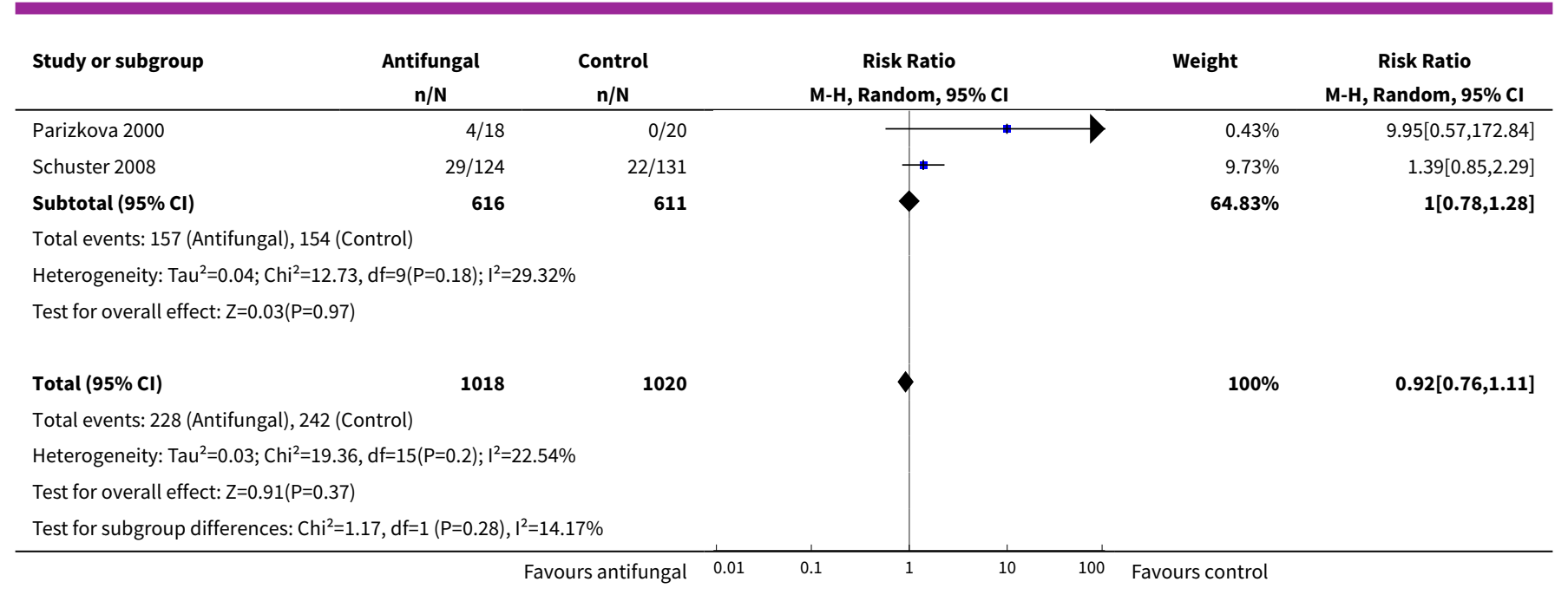

Analysis 2.2. Comparison 2 Subgroup analysis, Outcome 2 Mortality. Fluconazole dose.

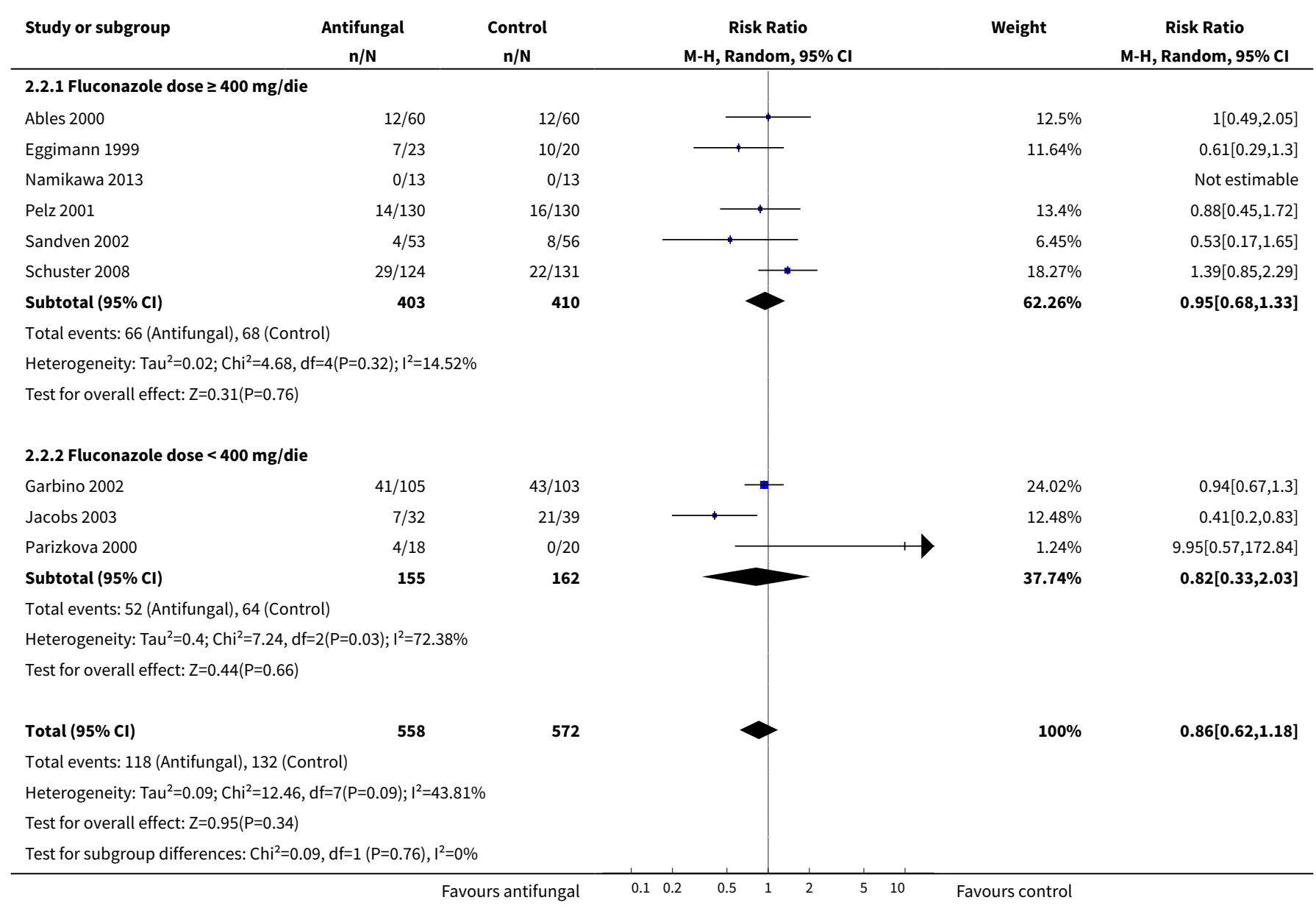


Analysis 2.3. Comparison 2 Subgroup analysis, Outcome 3 Mortality. Systemic or non-absorbable antifungal drug.

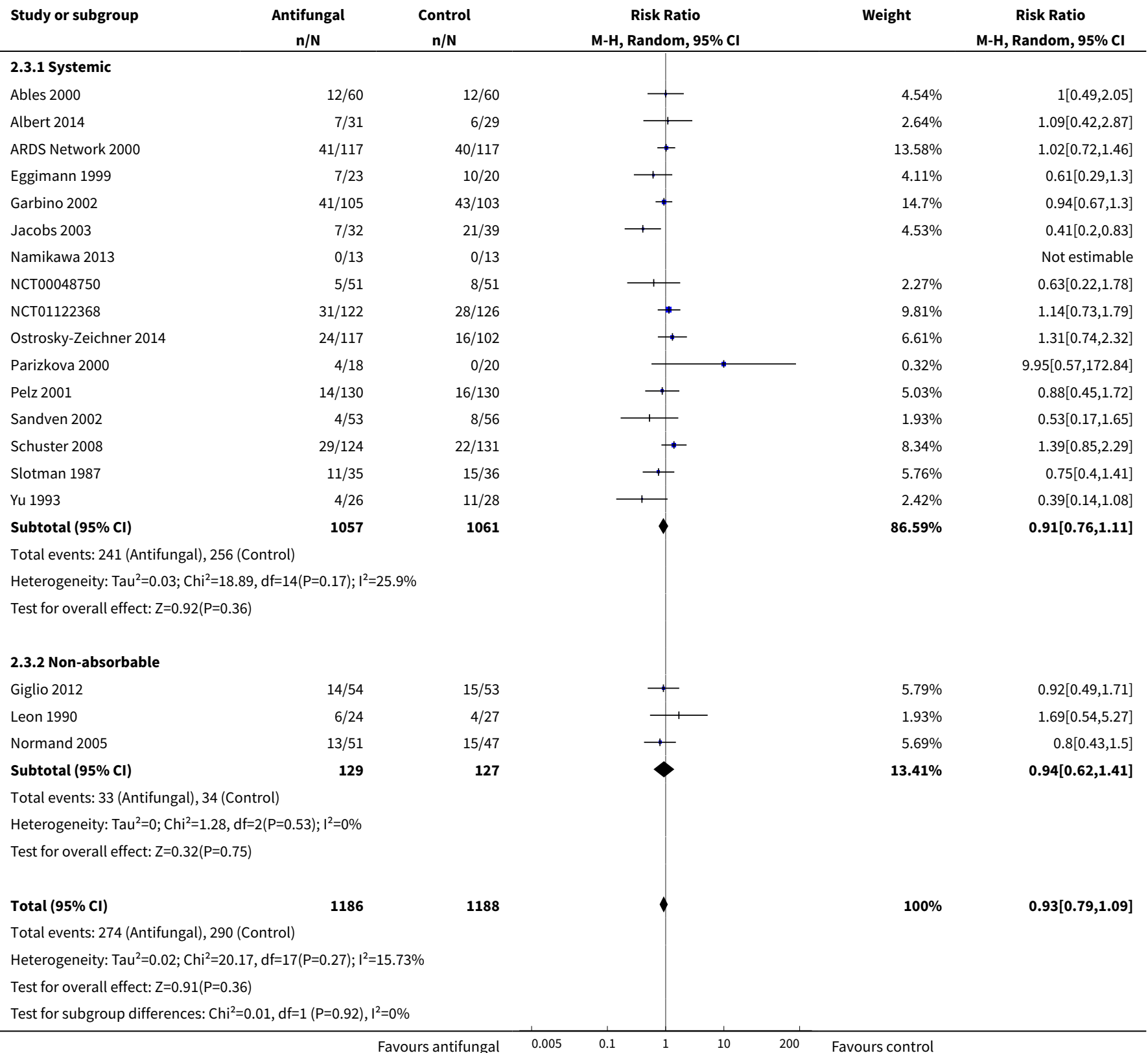

Analysis 2.4. Comparison 2 Subgroup analysis, Outcome 4 Mortality. Drug class.

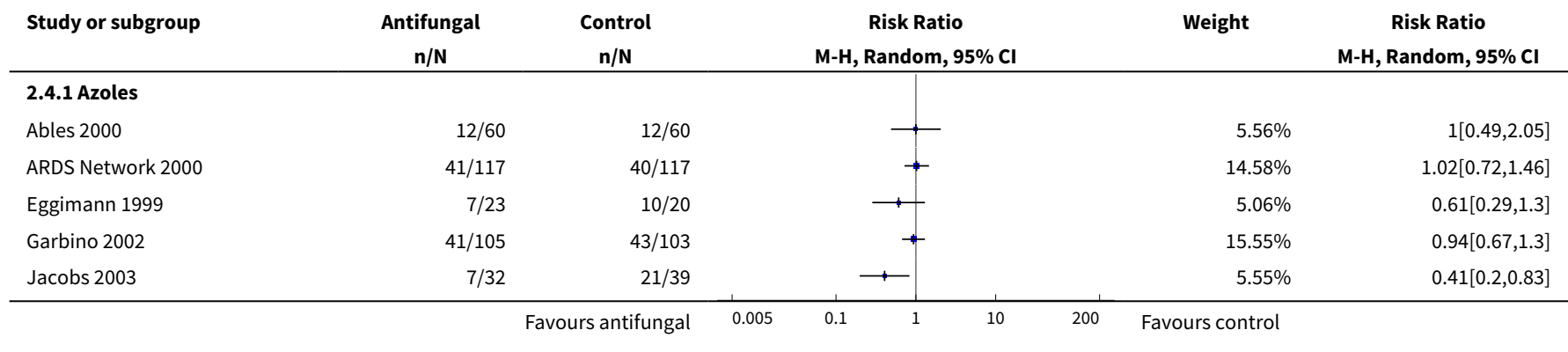




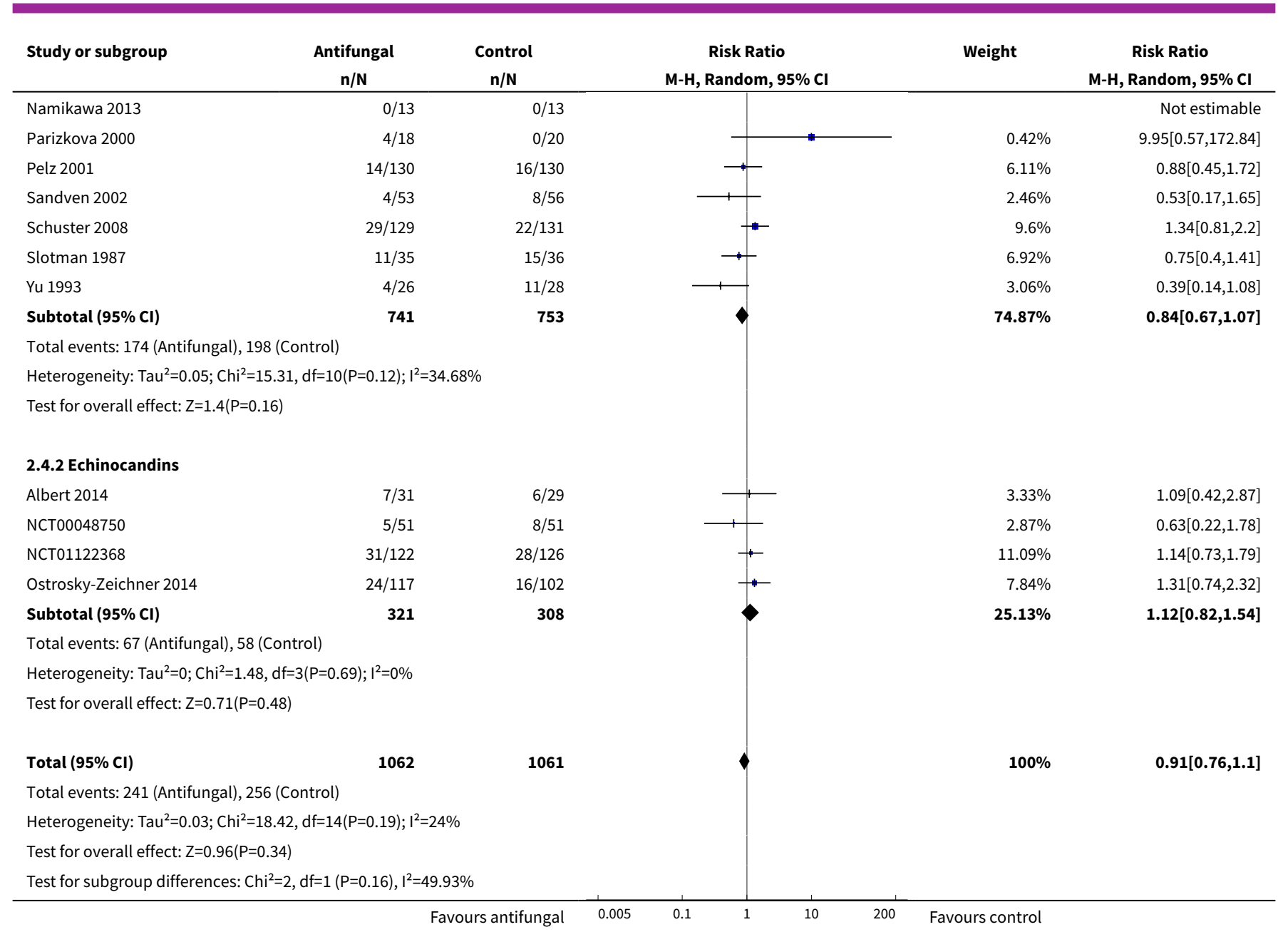

Analysis 2.5. Comparison 2 Subgroup analysis, Outcome 5 Mortality. Type of intervention.

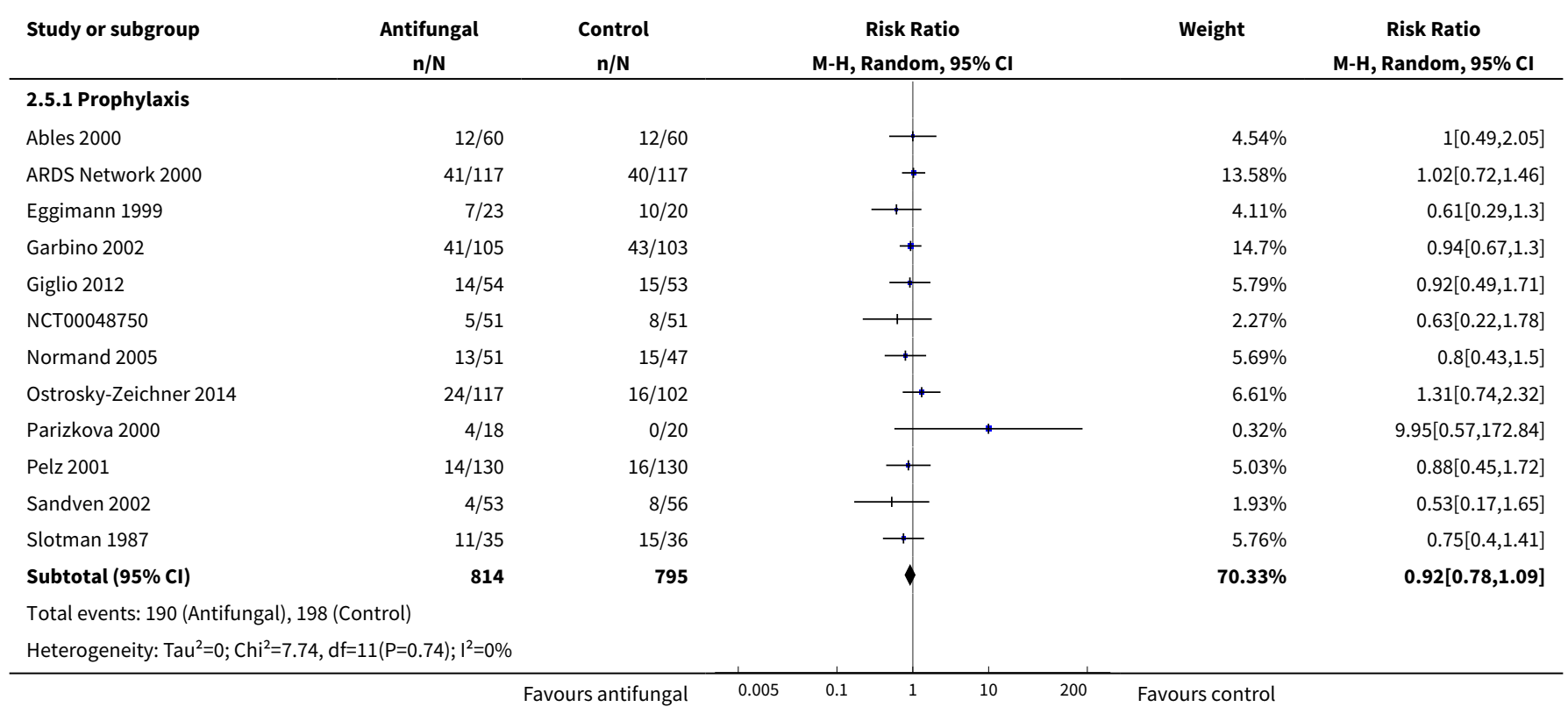




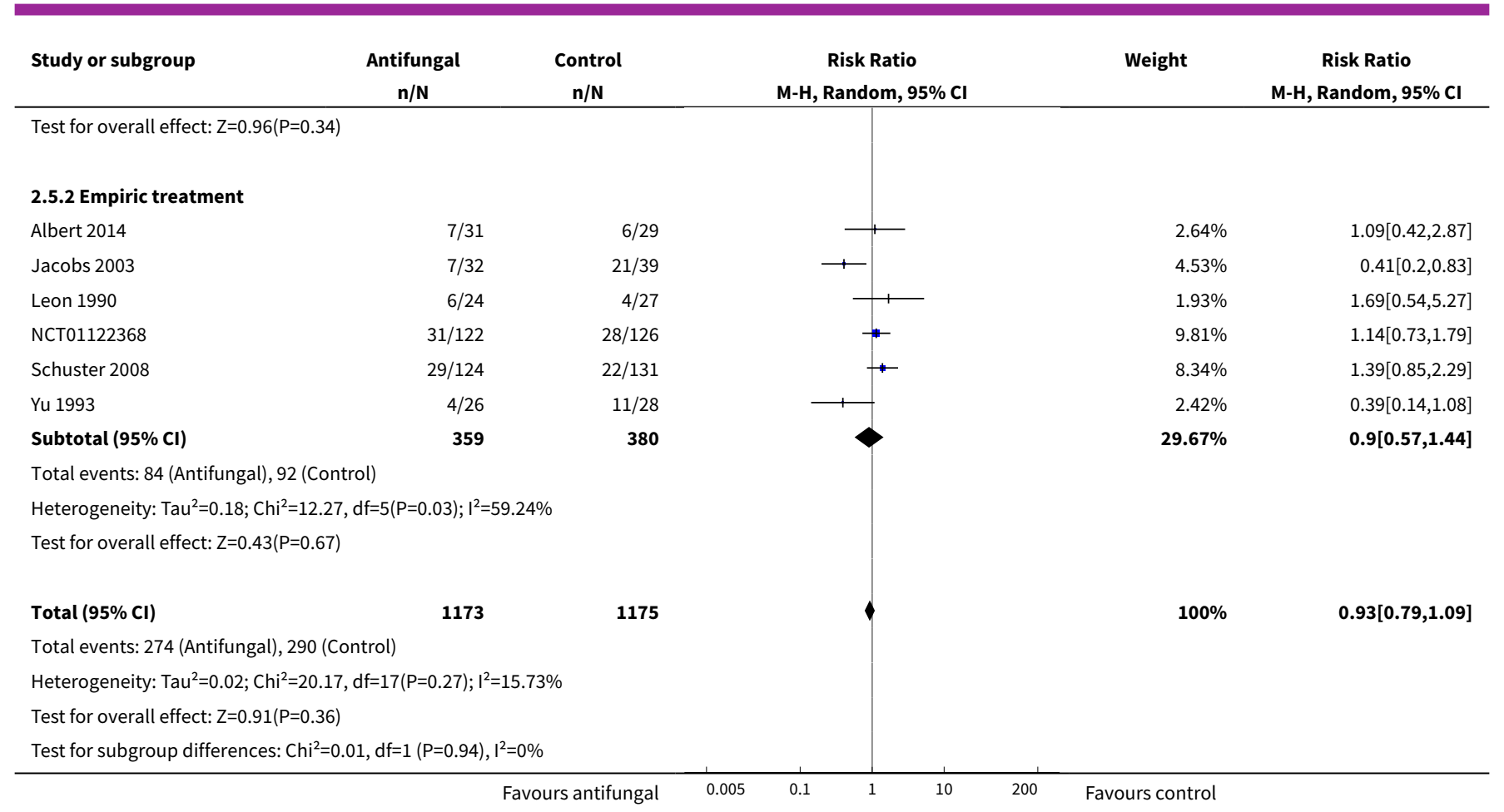

Analysis 2.6. Comparison 2 Subgroup analysis, Outcome 6 Mortality. Type of control group.

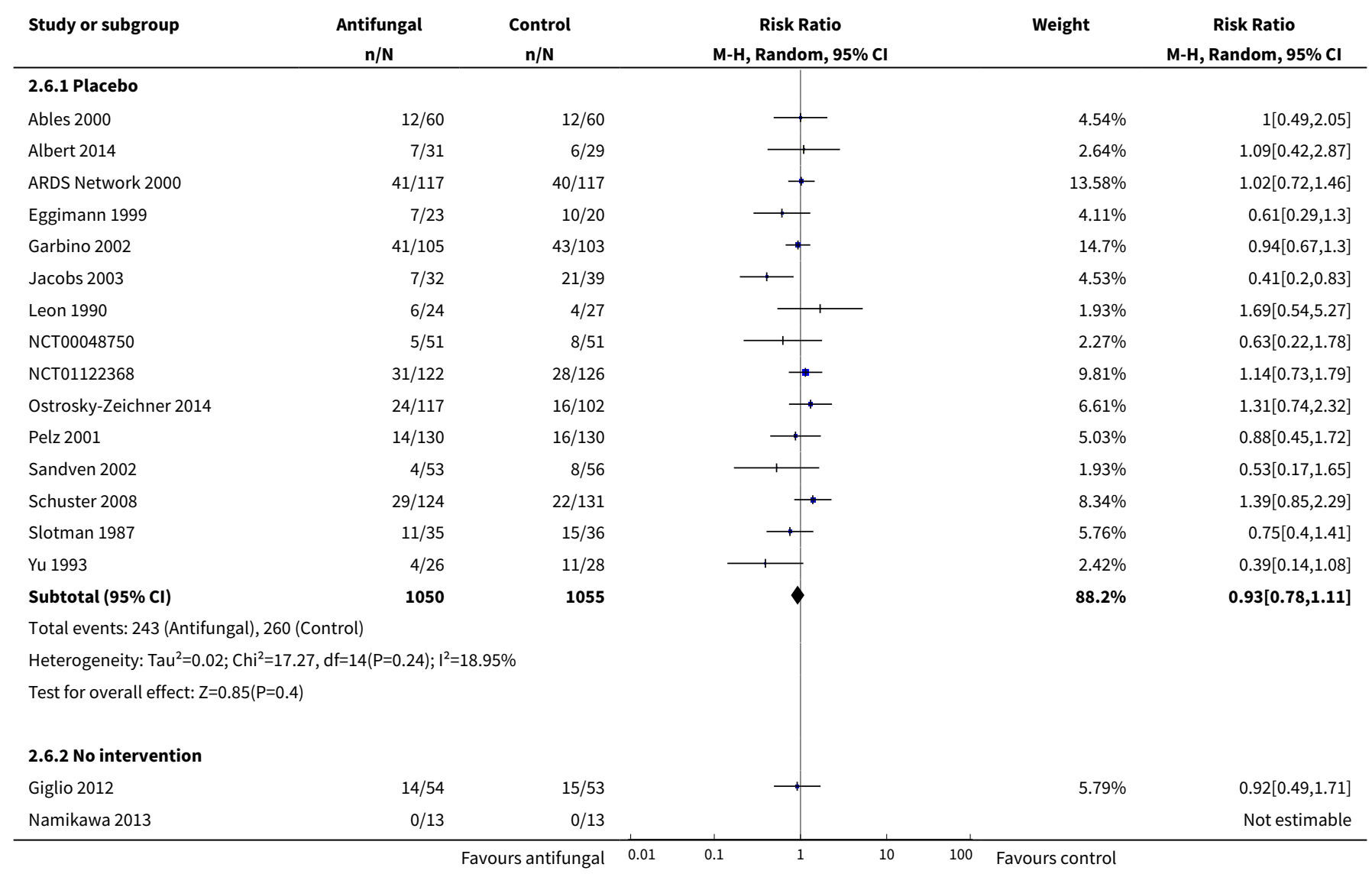




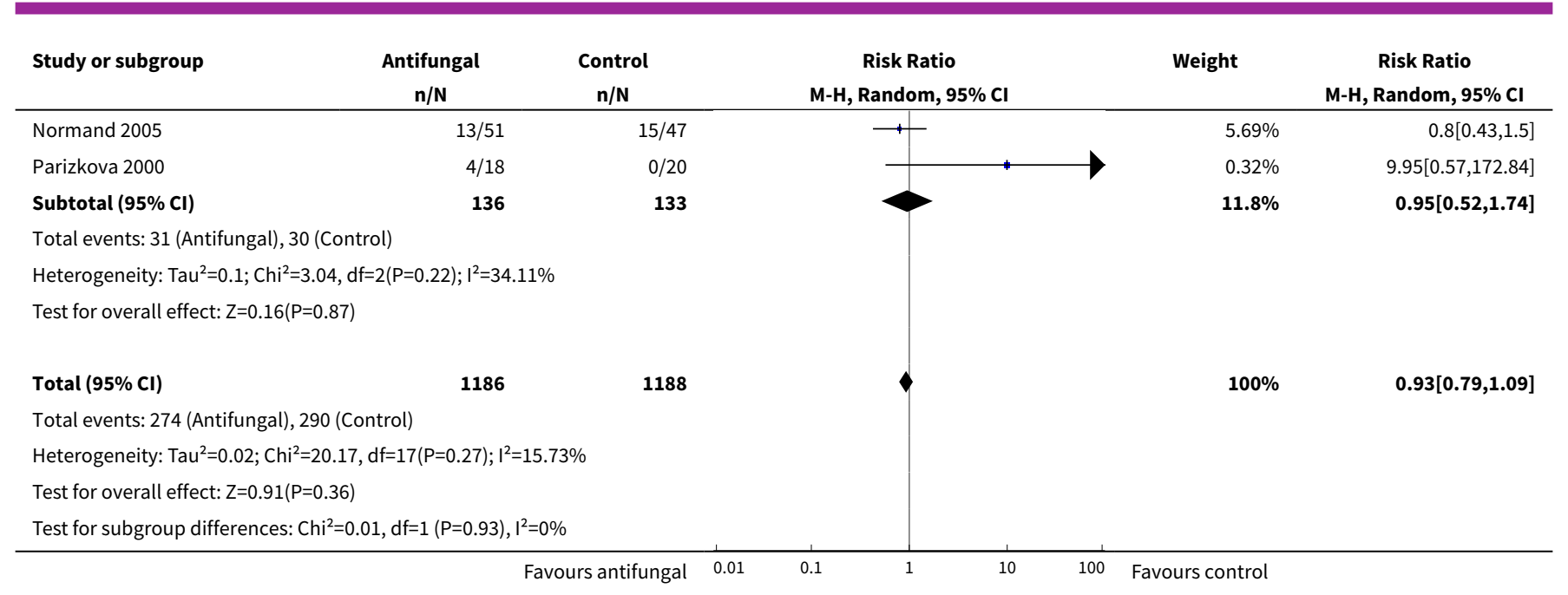

Analysis 2.7. Comparison 2 Subgroup analysis, Outcome 7 Proven IFI. Type of participants.

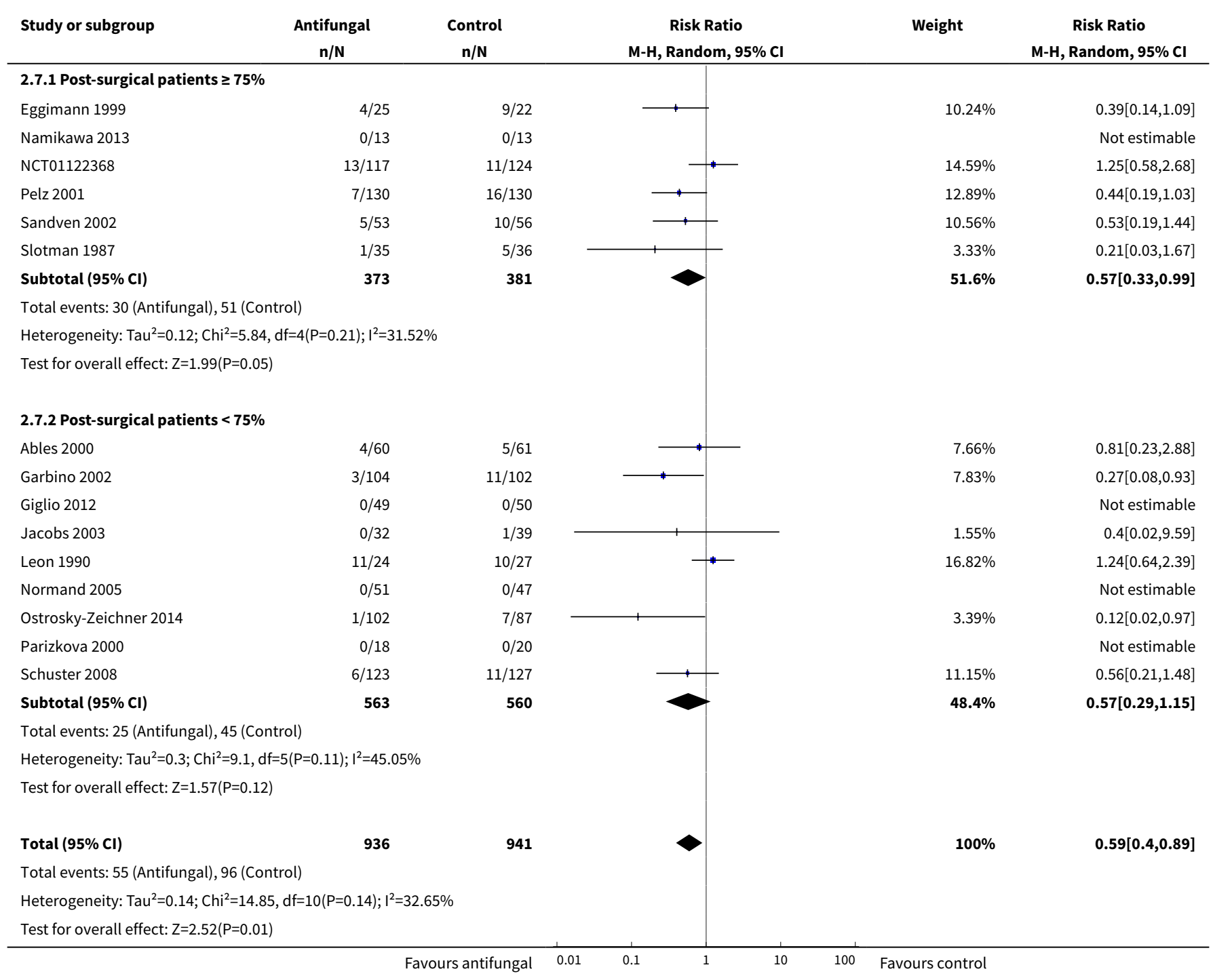




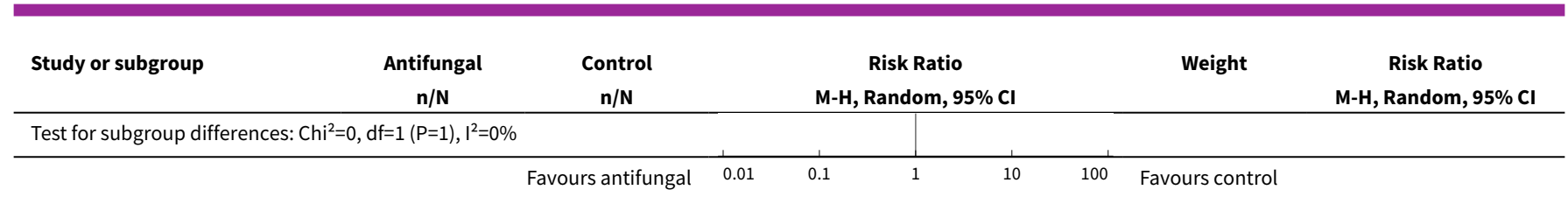

Analysis 2.8. Comparison 2 Subgroup analysis, Outcome 8 Proven IFI. Fluconazole dose.

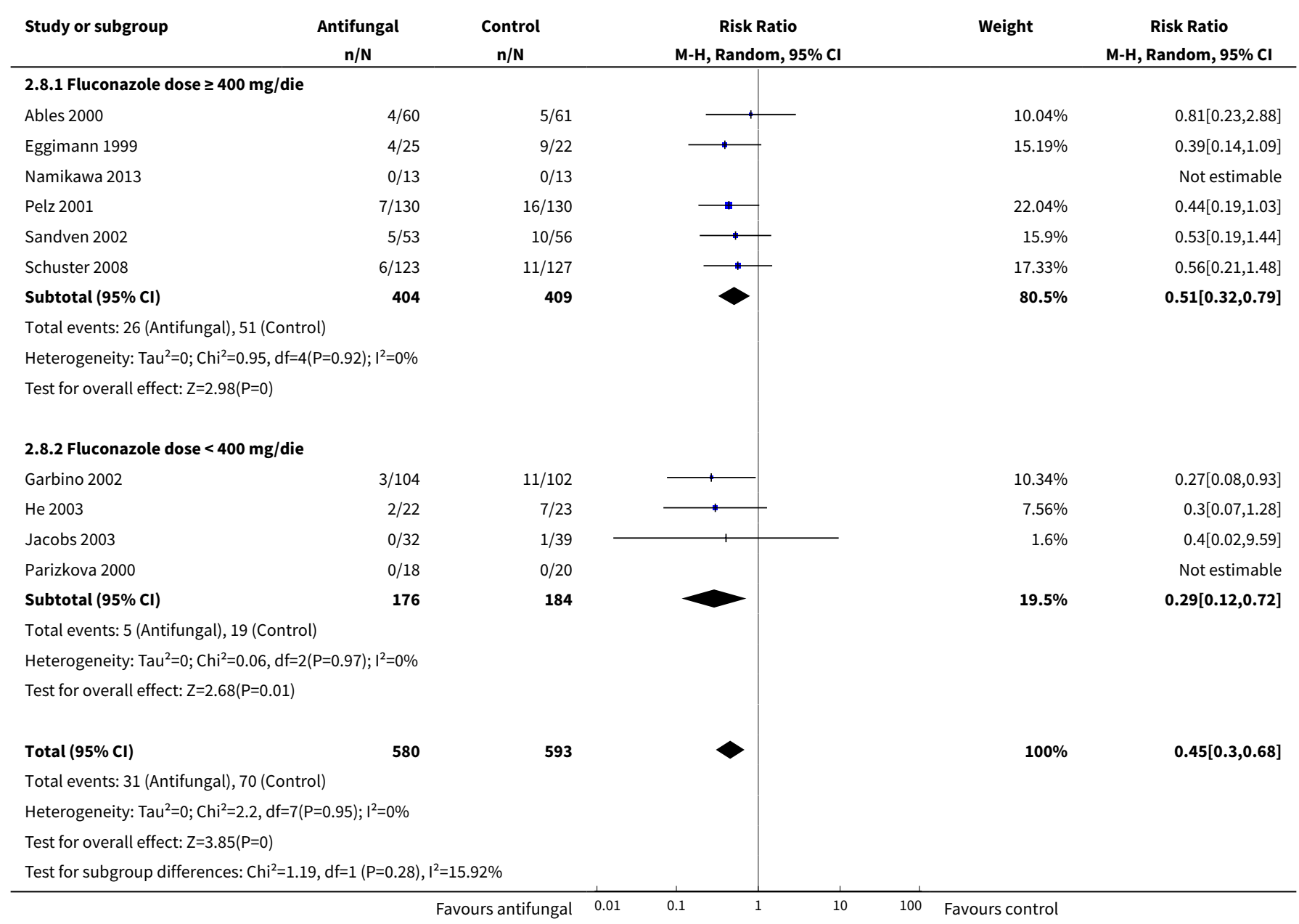

Analysis 2.9. Comparison 2 Subgroup analysis, Outcome 9 Proven IFI. Systemic or non-absorbable antifungal drug.

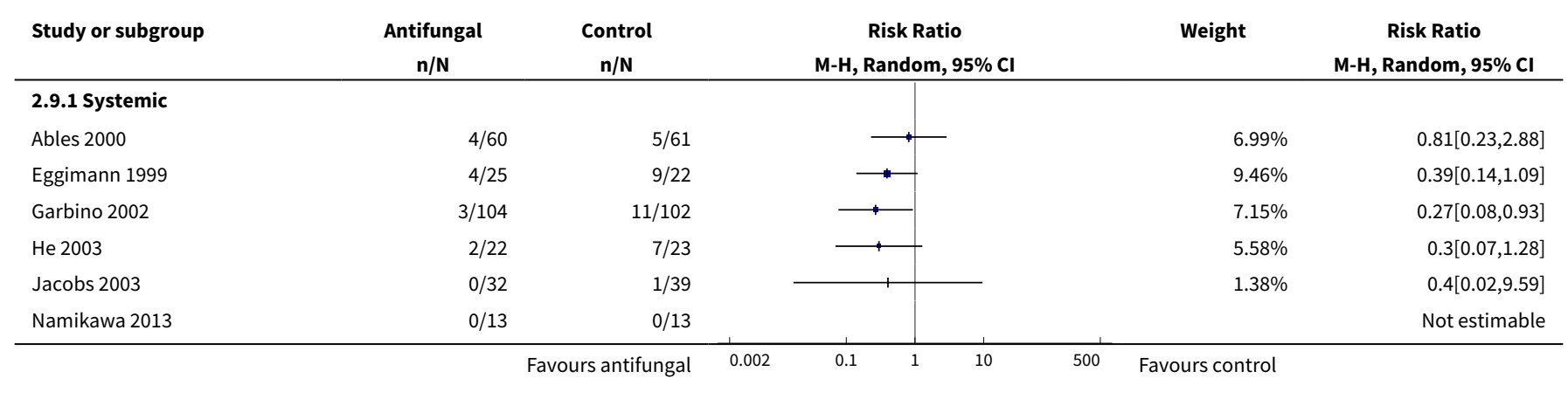




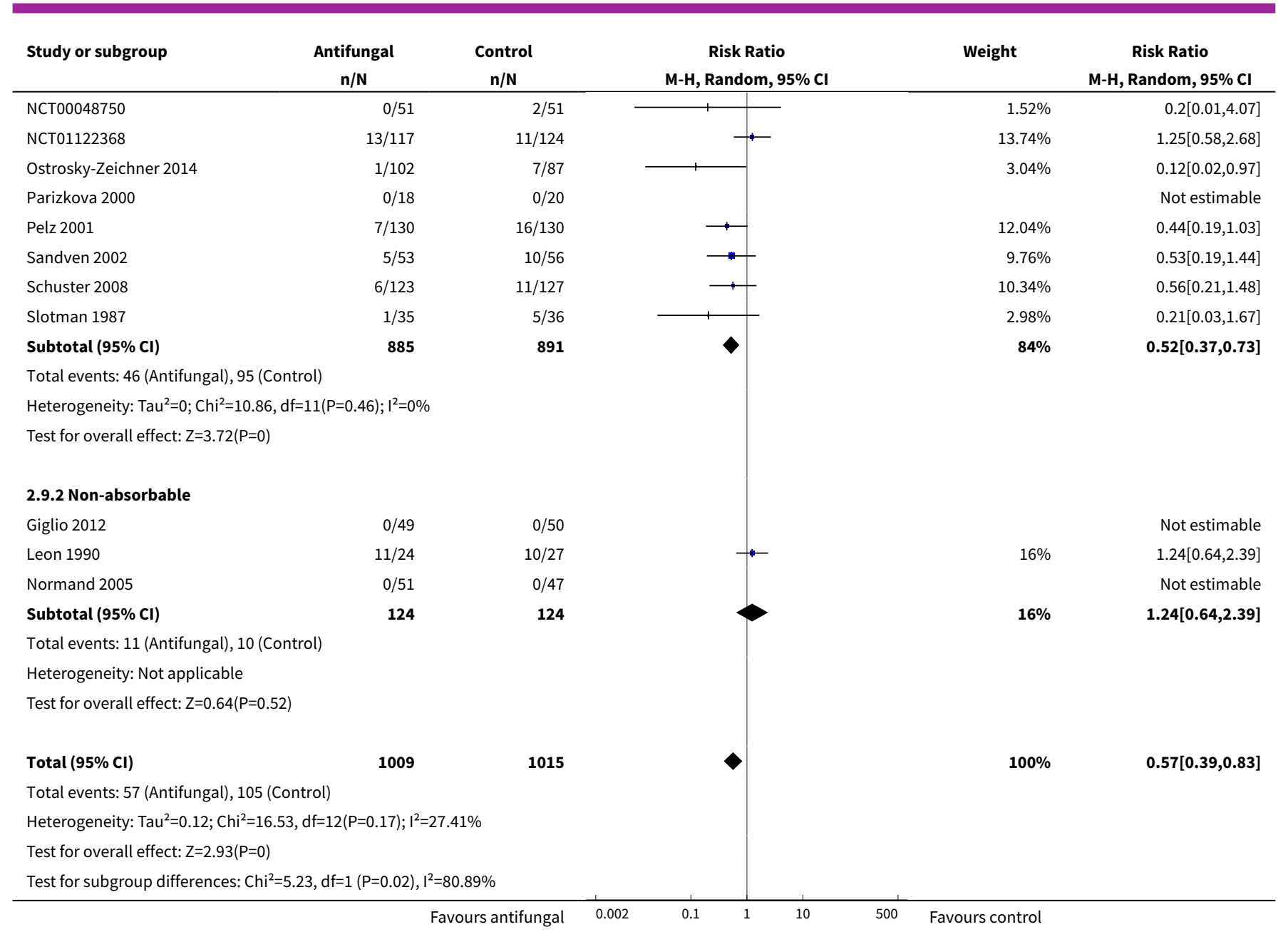

Analysis 2.10. Comparison 2 Subgroup analysis, Outcome 10 Proven IFI. Drug class.

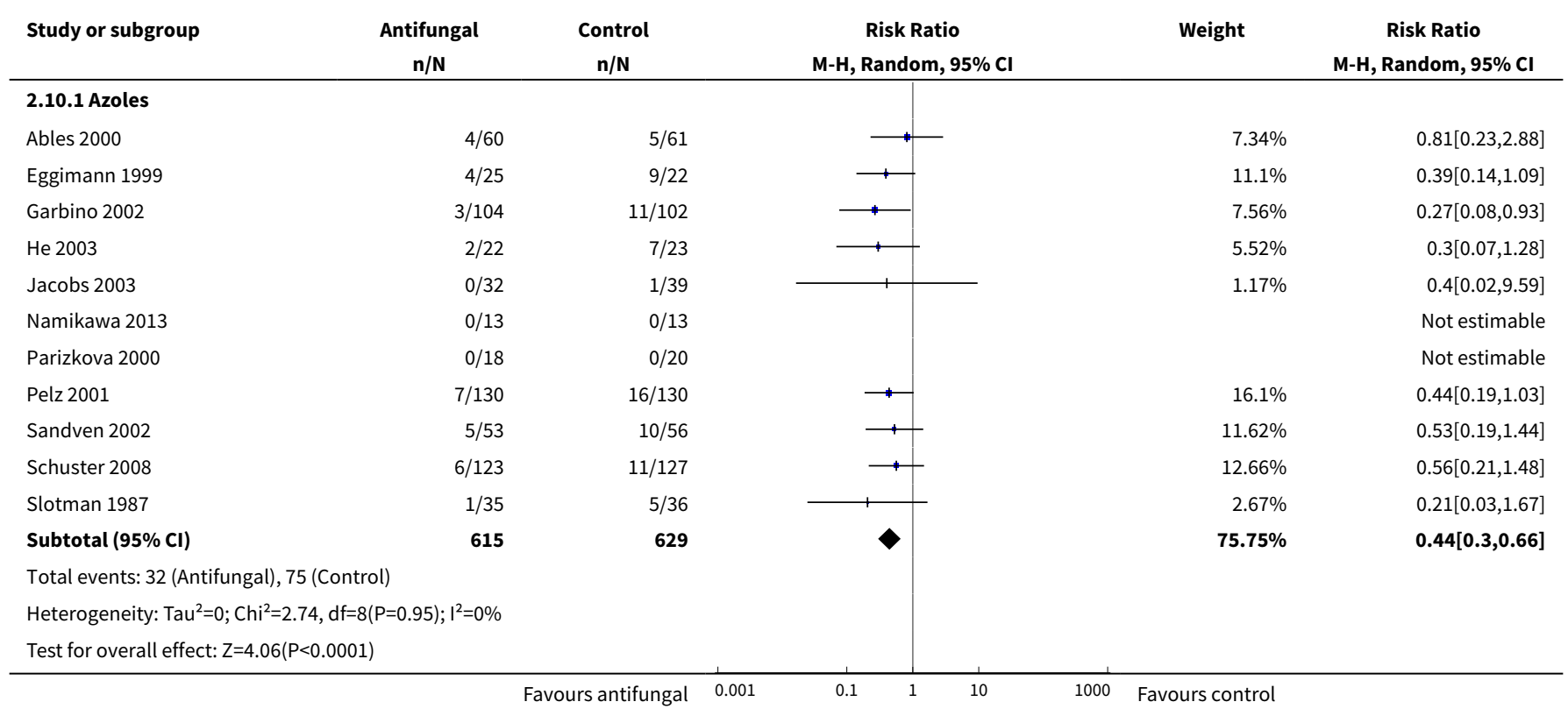




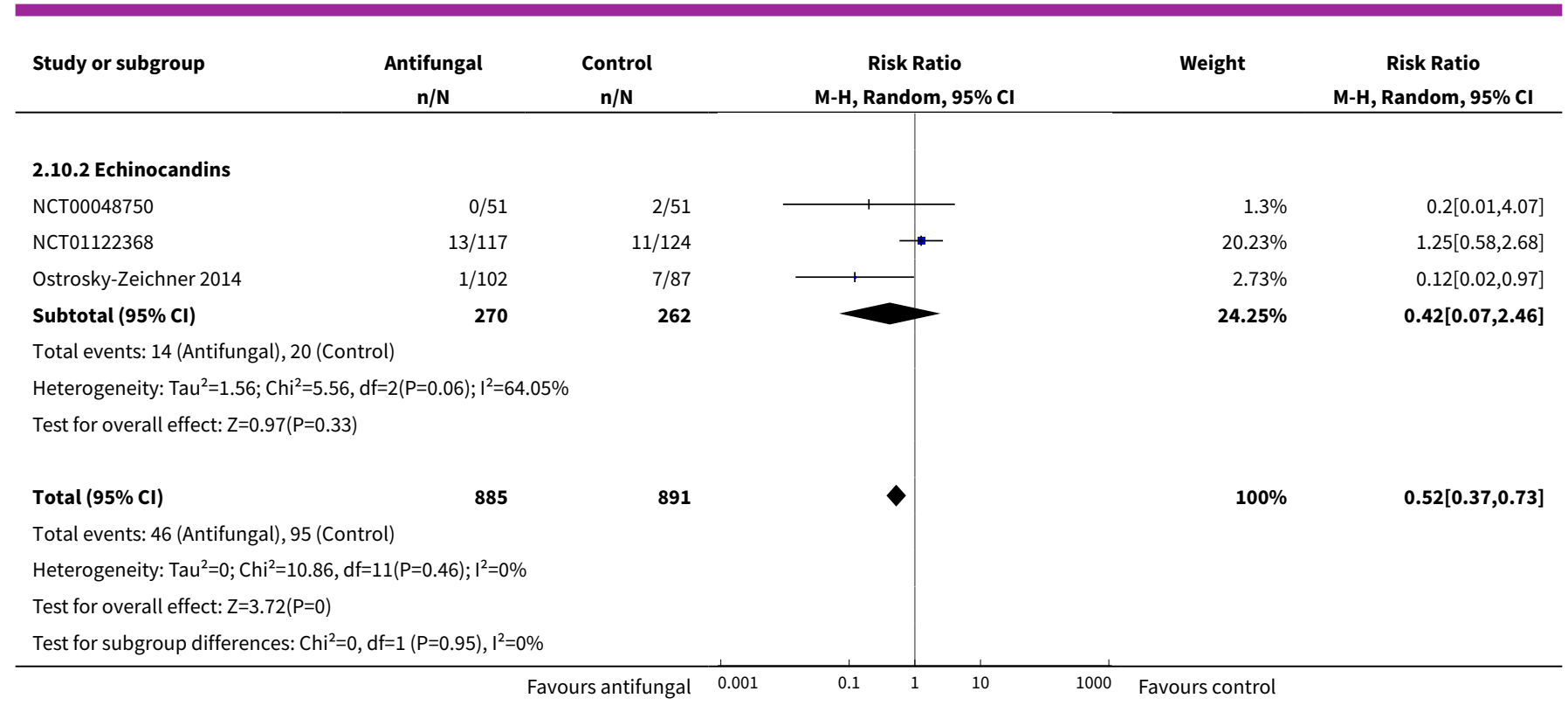

Analysis 2.11. Comparison 2 Subgroup analysis, Outcome 11 Proven IFI. Type of intervention.

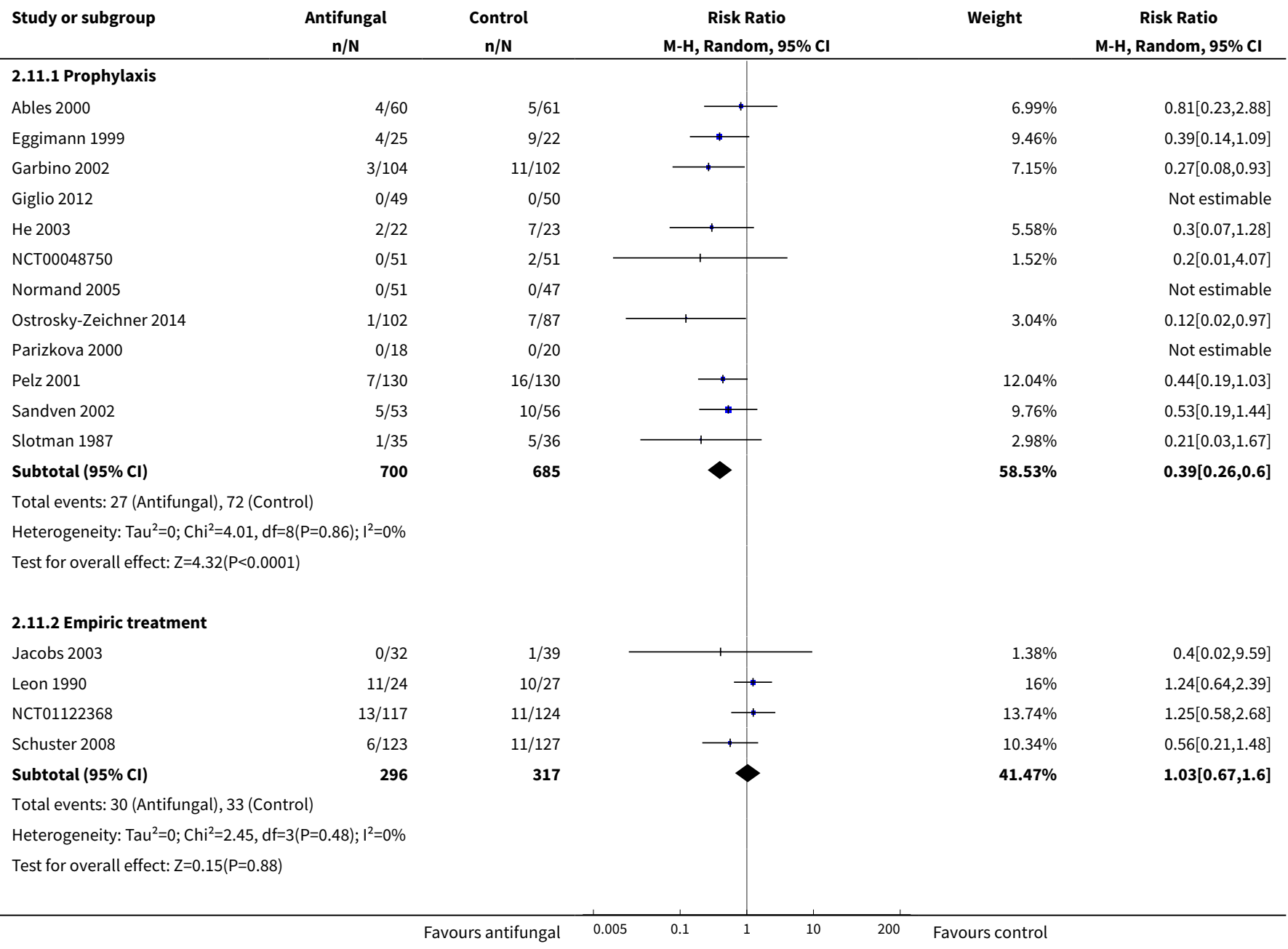




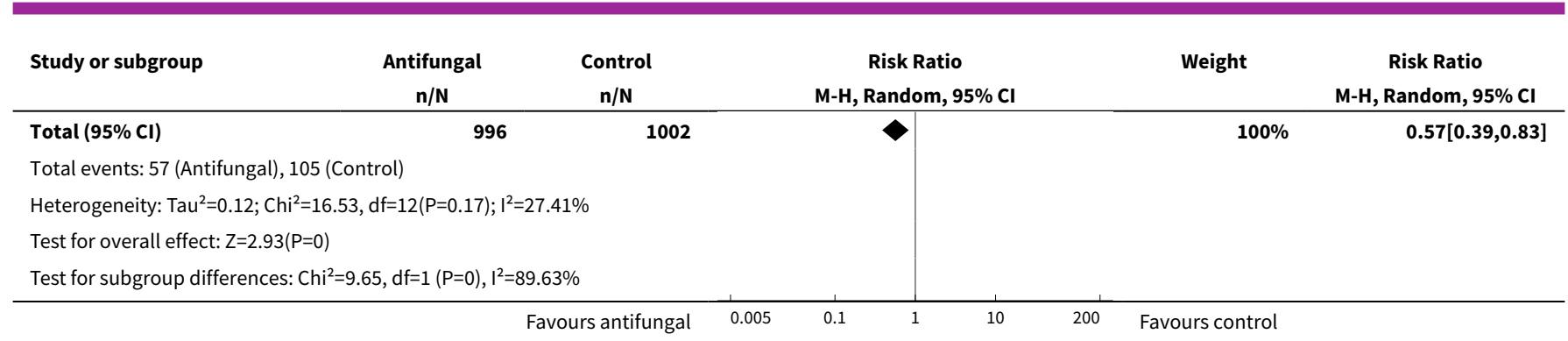

Analysis 2.12. Comparison 2 Subgroup analysis, Outcome 12 Proven IFI. Type of control group.

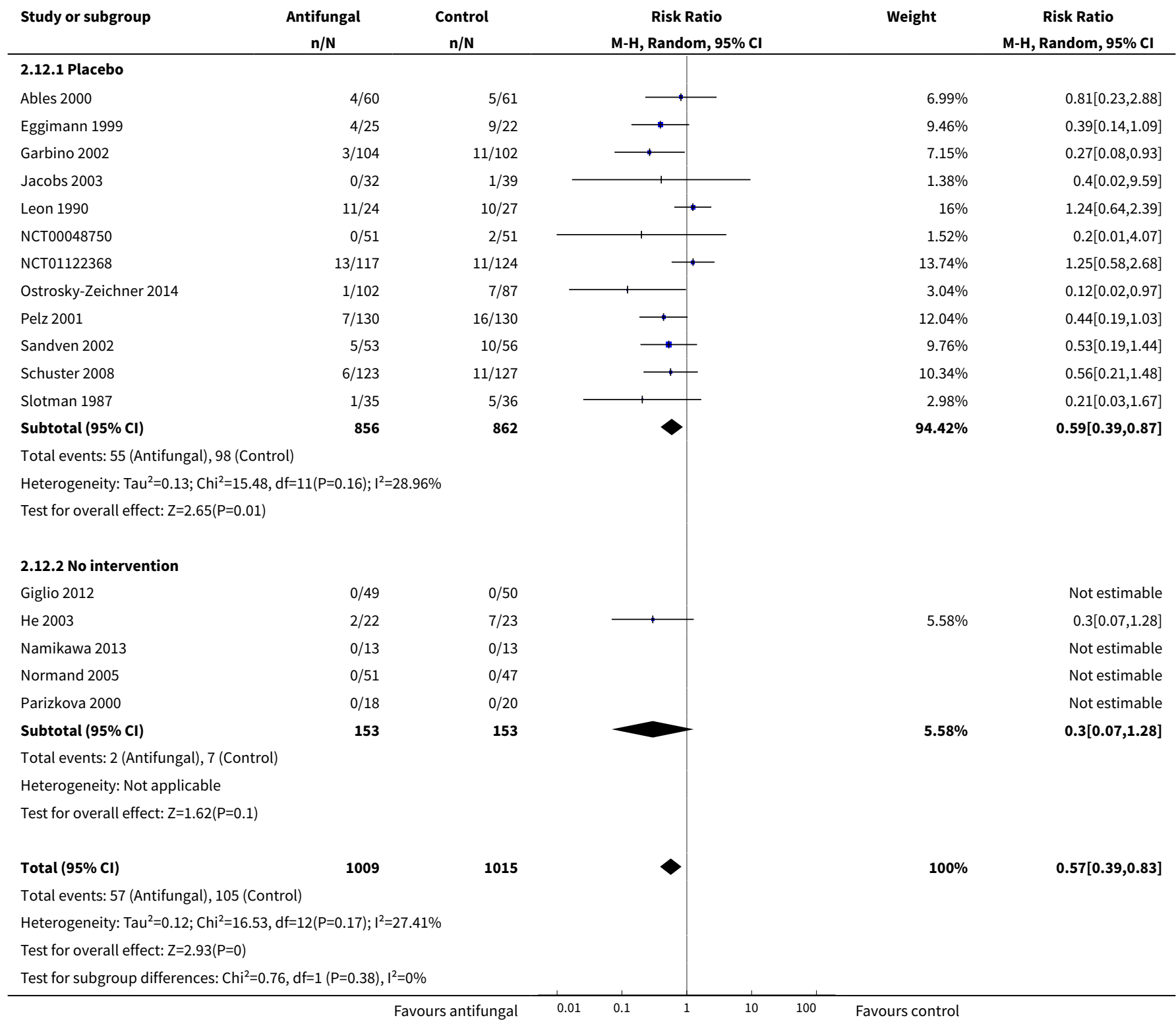




\section{Comparison 3. Sensitivity analysis}

\begin{tabular}{lllll}
\hline Outcome or subgroup title & $\begin{array}{l}\text { No. of } \\
\text { studies }\end{array}$ & $\begin{array}{l}\text { No. of } \\
\text { partici- } \\
\text { pants }\end{array}$ & Statistical method & Effect size \\
\hline $\begin{array}{l}1 \text { Mortality. Fixed-effect model meta-analy- } \\
\text { sis }\end{array}$ & 19 & 2374 & Risk Ratio (M-H, Fixed, 95\% Cl) & $0.95[0.82,1.09]$ \\
\hline $\begin{array}{l}2 \text { Mortality. Risk of bias for key domains: all } \\
\text { studies }\end{array}$ & 20 & 2666 & Risk Ratio (M-H, Random, 95\% Cl) & 0.93 [0.80, 1.08] \\
\hline $\begin{array}{l}3 \text { Mortality. Studies without any high risk of } \\
\text { bias. }\end{array}$ & 17 & 2174 & Risk Ratio (M-H, Random, 95\% Cl) & $0.94[0.79,1.12]$ \\
\hline $\begin{array}{l}4 \text { Proven IFl. Fixed-effect model meta-analy- } \\
\text { sis }\end{array}$ & 17 & 2024 & Risk Ratio (M-H, Fixed, 95\% Cl) & $0.56[0.42,0.75]$ \\
\hline $\begin{array}{l}5 \text { Proven IFl. Risk of bias for key domains: all } \\
\text { studies }\end{array}$ & 19 & 2366 & Risk Ratio (M-H, Random, 95\% Cl) & $0.55[0.38,0.81]$ \\
\hline $\begin{array}{l}6 \text { Proven IFl. Studies without any high risk of } \\
\text { bias }\end{array}$ & 14 & 1753 & Risk Ratio (M-H, Random, 95\% Cl) & $0.59[0.40,0.88]$ \\
\hline
\end{tabular}

Analysis 3.1. Comparison 3 Sensitivity analysis, Outcome 1 Mortality. Fixed-effect model meta-analysis.

\begin{tabular}{|c|c|c|c|c|c|}
\hline Study or subgroup & $\begin{array}{c}\text { Antifungal } \\
\mathrm{n} / \mathrm{N}\end{array}$ & $\begin{array}{c}\text { Control } \\
n / N\end{array}$ & $\begin{array}{c}\text { Risk Ratio } \\
\text { M-H, Fixed, 95\% Cl }\end{array}$ & Weight & $\begin{array}{c}\text { Risk Ratio } \\
\text { M-H, Fixed, 95\% Cl }\end{array}$ \\
\hline Ables 2000 & $12 / 60$ & $12 / 60$ & 1 & $4.15 \%$ & $1[0.49,2.05]$ \\
\hline Albert 2014 & $7 / 31$ & $6 / 29$ & 1 & $2.14 \%$ & $1.09[0.42,2.87]$ \\
\hline ARDS Network 2000 & $41 / 117$ & $40 / 117$ & $\rightarrow$ & $13.82 \%$ & $1.02[0.72,1.46]$ \\
\hline Eggimann 1999 & $7 / 23$ & $10 / 20$ & 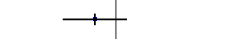 & $3.7 \%$ & $0.61[0.29,1.3]$ \\
\hline Garbino 2002 & $41 / 105$ & $43 / 103$ & + & $15 \%$ & $0.94[0.67,1.3]$ \\
\hline Jacobs 2003 & $7 / 32$ & $21 / 39$ & $\longrightarrow$ & $6.54 \%$ & $0.41[0.2,0.83]$ \\
\hline Leon 1990 & $6 / 24$ & $4 / 27$ & 1 & $1.3 \%$ & $1.69[0.54,5.27]$ \\
\hline Namikawa 2013 & $0 / 13$ & $0 / 13$ & & & Not estimable \\
\hline NCT00048750 & $5 / 51$ & $8 / 51$ & & $2.76 \%$ & $0.63[0.22,1.78]$ \\
\hline NCT01122368 & $31 / 122$ & $28 / 126$ & 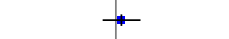 & $9.52 \%$ & $1.14[0.73,1.79]$ \\
\hline Normand 2005 & $13 / 51$ & $15 / 47$ & $\rightarrow$ & $5.39 \%$ & $0.8[0.43,1.5]$ \\
\hline Parizkova 2000 & $4 / 18$ & $0 / 20$ & & $0.16 \%$ & $9.95[0.57,172.84]$ \\
\hline Pelz 2001 & $14 / 130$ & $16 / 130$ & $\longrightarrow$ & $5.53 \%$ & $0.88[0.45,1.72]$ \\
\hline Sandven 2002 & $4 / 53$ & $8 / 56$ & $1+$ & $2.69 \%$ & $0.53[0.17,1.65]$ \\
\hline Schuster 2008 & $29 / 124$ & $22 / 131$ & $\rightarrow$ & $7.39 \%$ & $1.39[0.85,2.29]$ \\
\hline Slotman 1987 & $11 / 35$ & $15 / 36$ & 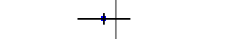 & $5.11 \%$ & $0.75[0.4,1.41]$ \\
\hline Yu 1993 & $4 / 26$ & $11 / 28$ & $\longrightarrow$ & $3.66 \%$ & $0.39[0.14,1.08]$ \\
\hline Total $(95 \% \mathrm{Cl})$ & 1186 & 1188 & 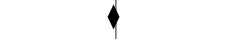 & $100 \%$ & $0.95[0.82,1.09]$ \\
\hline \multicolumn{6}{|c|}{ Total events: 274 (Antifungal), 290 (Control) } \\
\hline \multicolumn{6}{|c|}{ Heterogeneity: Tau $^{2}=0 ; \mathrm{Chi}^{2}=20.17, \mathrm{df}=17(\mathrm{P}=0.27) ; \mathrm{I}^{2}=15.73 \%$} \\
\hline \multicolumn{6}{|c|}{ Test for overall effect: $\mathrm{Z}=0.76(\mathrm{P}=0.45)$} \\
\hline
\end{tabular}


Analysis 3.2. Comparison 3 Sensitivity analysis, Outcome 2 Mortality. Risk of bias for key domains: all studies.

\begin{tabular}{|c|c|c|c|c|c|}
\hline Study or subgroup & $\begin{array}{c}\text { Antifungal } \\
\mathrm{n} / \mathrm{N}\end{array}$ & $\begin{array}{l}\text { Control } \\
\mathrm{n} / \mathrm{N}\end{array}$ & $\begin{array}{c}\text { Risk Ratio } \\
\text { M-H, Random, } 95 \% \mathrm{Cl}\end{array}$ & Weight & $\begin{array}{c}\text { Risk Ratio } \\
\text { M-H, Random, } 95 \% \mathrm{Cl}\end{array}$ \\
\hline Ables 2000 & $12 / 60$ & $12 / 60$ & 千 & $4.15 \%$ & $1[0.49,2.05]$ \\
\hline Albert 2014 & $7 / 31$ & $6 / 29$ & 1 & $2.37 \%$ & $1.09[0.42,2.87]$ \\
\hline ARDS Network 2000 & $41 / 117$ & $40 / 117$ & + & $13.59 \%$ & $1.02[0.72,1.46]$ \\
\hline Eggimann 1999 & $7 / 23$ & $10 / 20$ & -1 & $3.74 \%$ & $0.61[0.29,1.3]$ \\
\hline Garbino 2002 & $41 / 105$ & $43 / 103$ & + & $14.9 \%$ & $0.94[0.67,1.3]$ \\
\hline Giglio 2012 & $14 / 54$ & $15 / 53$ & + & $5.35 \%$ & $0.92[0.49,1.71]$ \\
\hline Jacobs 2003 & $7 / 32$ & $21 / 39$ & 一 & $4.14 \%$ & $0.41[0.2,0.83]$ \\
\hline Leon 1990 & $6 / 24$ & $4 / 27$ & 1 & $1.72 \%$ & $1.69[0.54,5.27]$ \\
\hline Namikawa 2013 & $0 / 13$ & $0 / 13$ & & & Not estimable \\
\hline NCT00048750 & $5 / 51$ & $8 / 51$ & - & $2.03 \%$ & $0.63[0.22,1.78]$ \\
\hline NCT01122368 & $31 / 122$ & $28 / 126$ & 4 & $9.44 \%$ & $1.14[0.73,1.79]$ \\
\hline Normand 2005 & $13 / 51$ & $15 / 47$ & $\rightarrow$ & $5.26 \%$ & $0.8[0.43,1.5]$ \\
\hline Ostrosky-Zeichner 2014 & $24 / 117$ & $16 / 102$ & + & $6.16 \%$ & $1.31[0.74,2.32]$ \\
\hline Parizkova 2000 & $4 / 18$ & $0 / 20$ & * & $0.28 \%$ & $9.95[0.57,172.84]$ \\
\hline Pelz 2001 & $14 / 130$ & $16 / 130$ & $一$ & $4.62 \%$ & $0.88[0.45,1.72]$ \\
\hline Sandven 2002 & $4 / 53$ & $8 / 56$ & - & $1.72 \%$ & $0.53[0.17,1.65]$ \\
\hline Savino 1994 & $30 / 220$ & $11 / 72$ & - & $5.12 \%$ & $0.89[0.47,1.69]$ \\
\hline Schuster 2008 & $29 / 124$ & $22 / 131$ & $\leftarrow$ & $7.91 \%$ & $1.39[0.85,2.29]$ \\
\hline Slotman 1987 & $11 / 35$ & $15 / 36$ & $\rightarrow$ & $5.33 \%$ & $0.75[0.4,1.41]$ \\
\hline Yu 1993 & $4 / 26$ & $11 / 28$ & 1 & $2.16 \%$ & $0.39[0.14,1.08]$ \\
\hline Total $(95 \% \mathrm{Cl})$ & 1406 & 1260 & 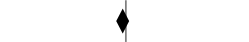 & $100 \%$ & $0.93[0.8,1.08]$ \\
\hline \multicolumn{6}{|c|}{ Total events: 304 (Antifungal), 301 (Control) } \\
\hline \multicolumn{6}{|c|}{ Heterogeneity: $\operatorname{Tau}^{2}=0.01 ; \mathrm{Chi}^{2}=20.2, \mathrm{df}=18(\mathrm{P}=0.32) ; I^{2}=10.87 \%$} \\
\hline \multicolumn{6}{|c|}{ Test for overall effect: $Z=0.95(P=0.34)$} \\
\hline
\end{tabular}

Analysis 3.3. Comparison 3 Sensitivity analysis, Outcome 3 Mortality. Studies without any high risk of bias..

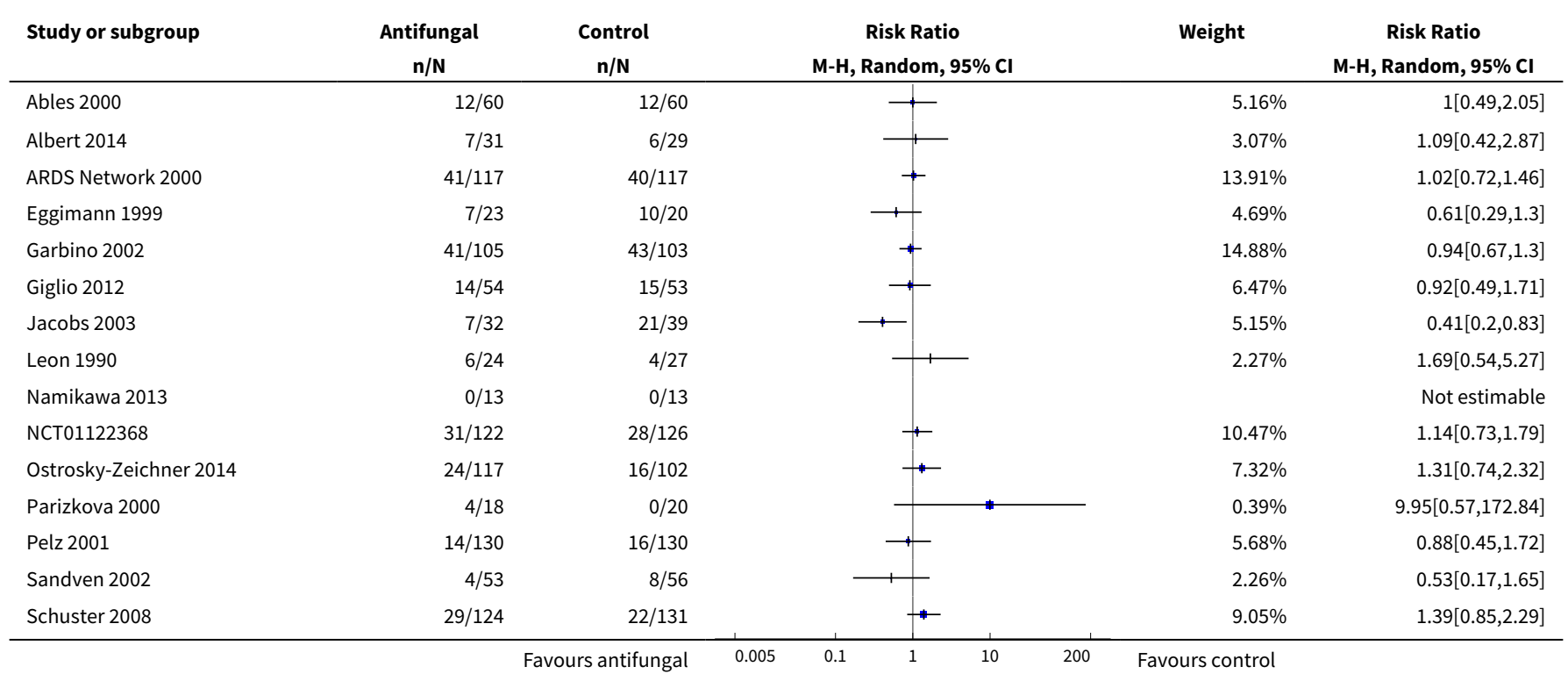




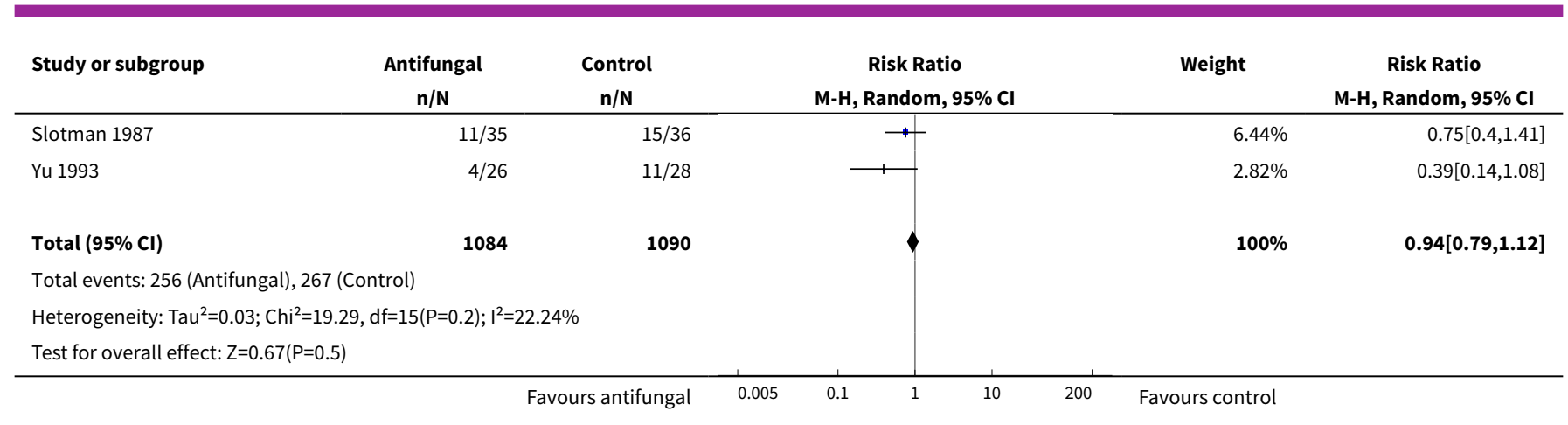

Analysis 3.4. Comparison 3 Sensitivity analysis, Outcome 4 Proven IFI. Fixed-effect model meta-analysis.

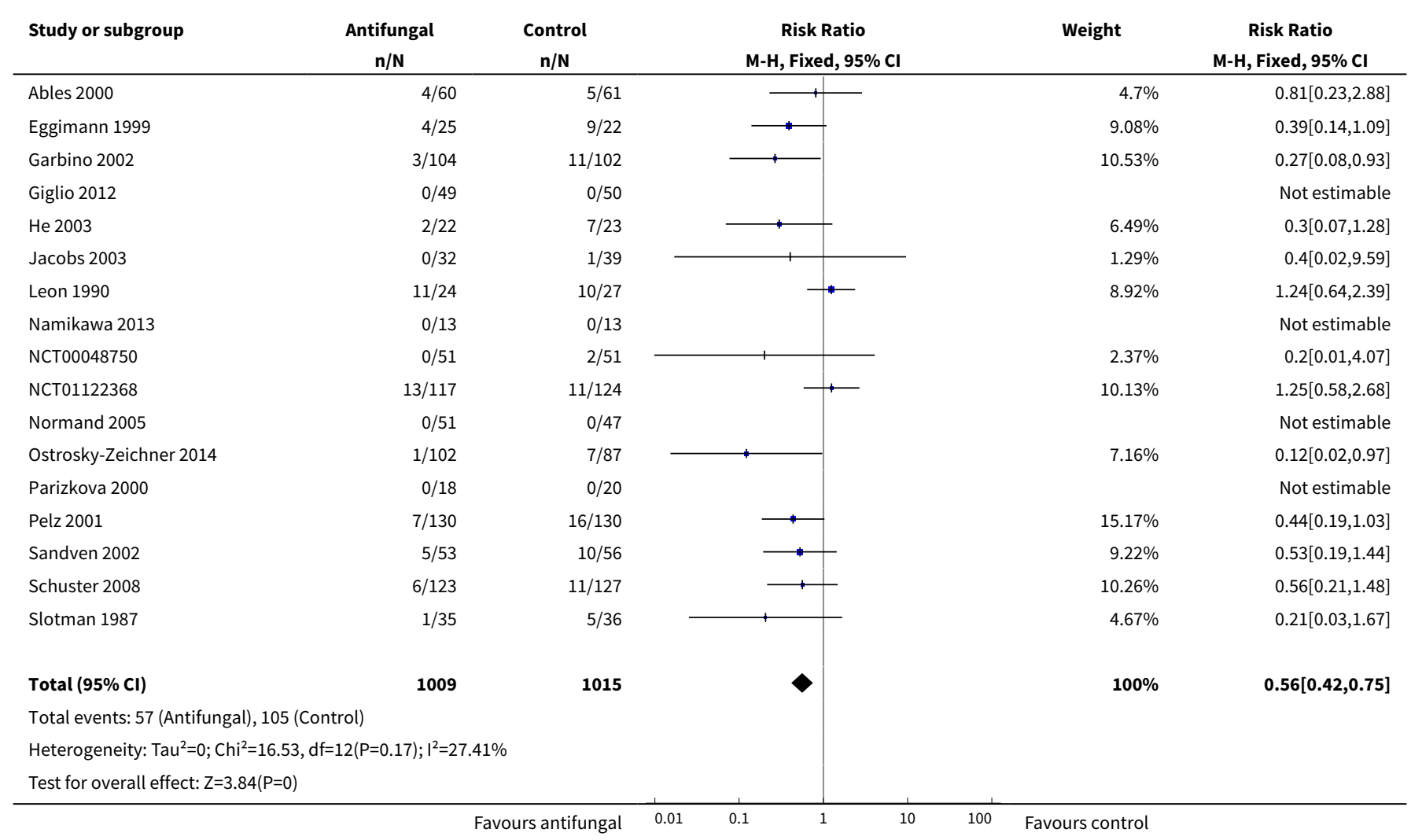

Analysis 3.5. Comparison 3 Sensitivity analysis, Outcome 5 Proven IFI. Risk of bias for key domains: all studies.

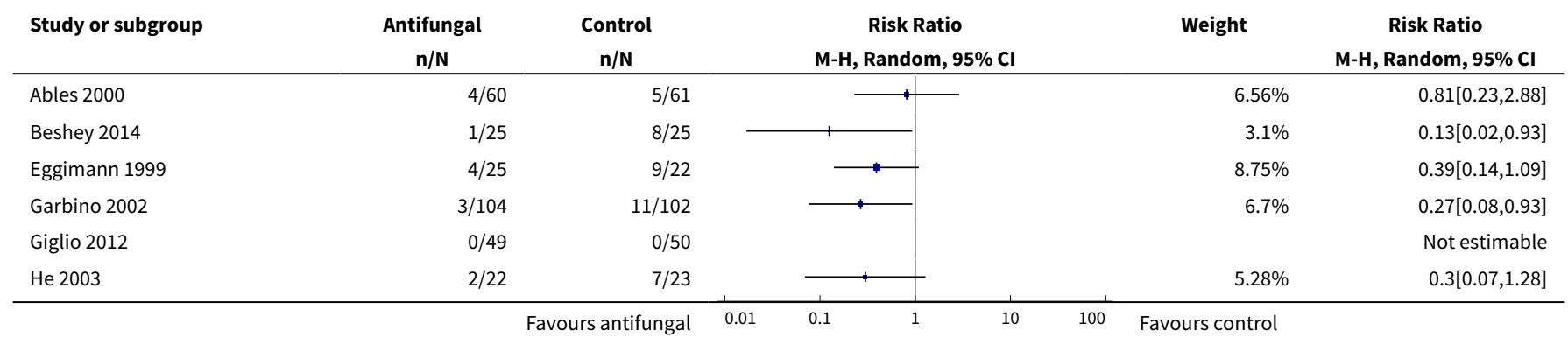




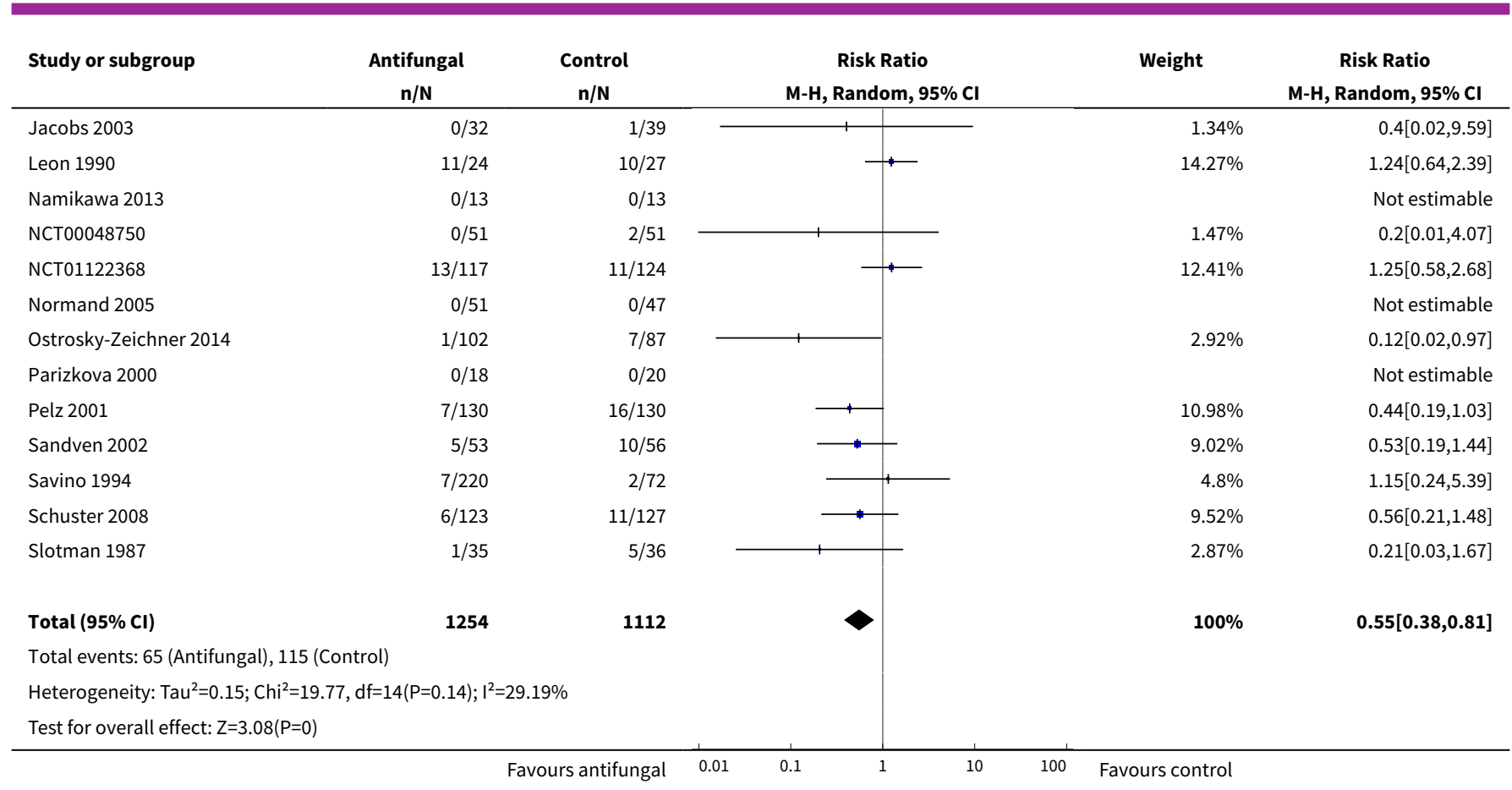

Analysis 3.6. Comparison 3 Sensitivity analysis, Outcome 6 Proven IFI. Studies without any high risk of bias.

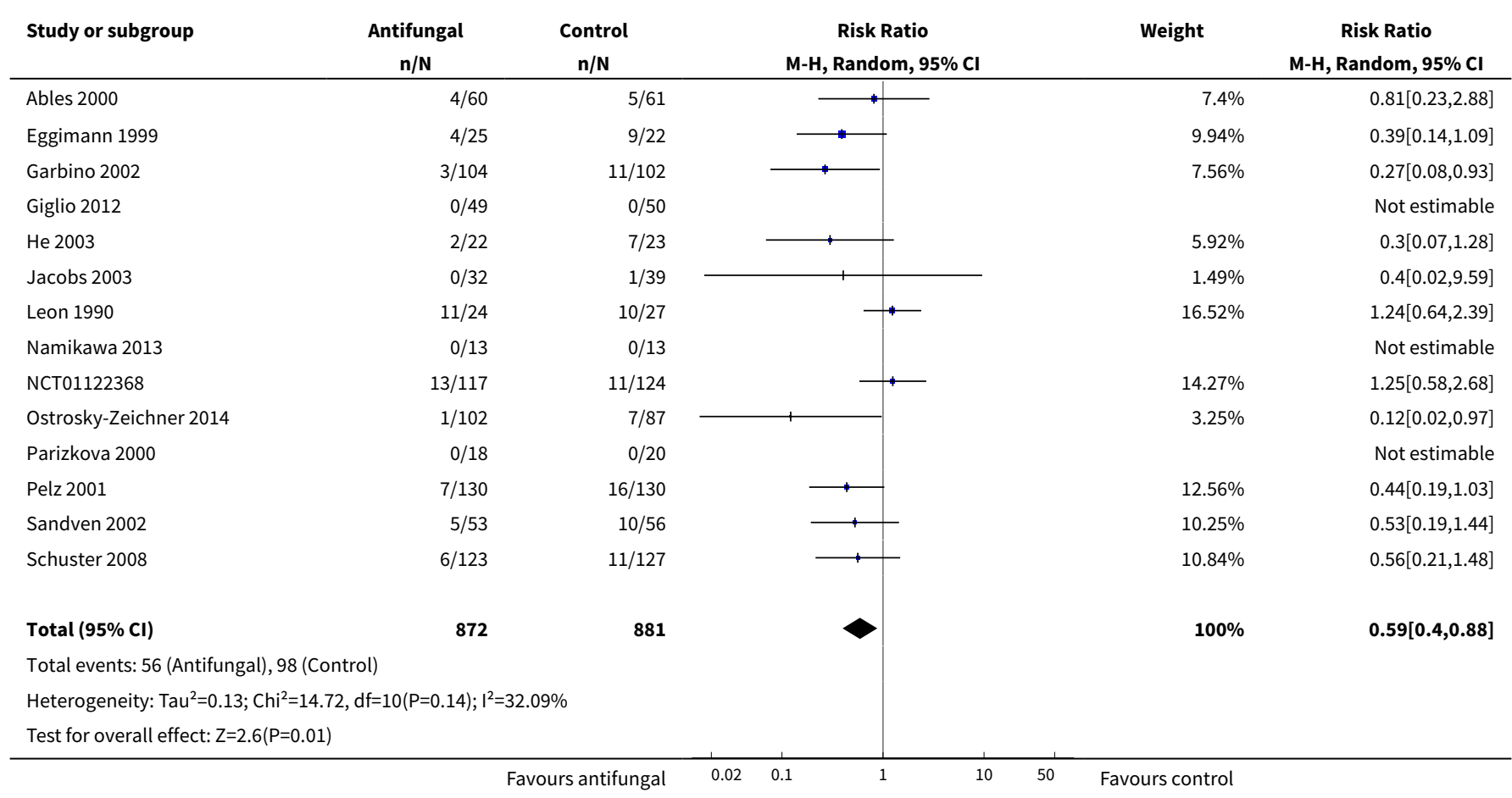

\section{ADDITIONAL TABLES}


Table 1. Other sensitivity analyses

\begin{tabular}{|c|c|c|c|c|}
\hline Outcome. Name of sensitivity analysis & Studies & $\begin{array}{l}\text { Partici- } \\
\text { pants }\end{array}$ & Statistical methods & Effect Estimate \\
\hline $\begin{array}{l}\text { Mortality. Random sequence generation: low } \\
\text { risk of bias }\end{array}$ & 6 & 807 & Risk Ratio (M-H, Random, 95\% Cl) & $1.06[0.83,1.35]$ \\
\hline $\begin{array}{l}\text { Mortality. Random Sequence Generation: un- } \\
\text { clear/high risk of bias }\end{array}$ & 15 & 1909 & Risk Ratio (M-H, Random, 95\% Cl) & $0.87[0.71,1.06]$ \\
\hline $\begin{array}{l}\text { Mortality. Allocation concealment: low risk of } \\
\text { bias }\end{array}$ & 9 & 1313 & Risk Ratio (M-H, Random, 95\% Cl) & $0.88[0.70,1.12]$ \\
\hline $\begin{array}{l}\text { Mortality. Allocation concealment: un- } \\
\text { clear/high risk of bias }\end{array}$ & 12 & 1403 & Risk Ratio (M-H, Random, 95\% Cl) & $0.97,[0.78-1.20]$ \\
\hline $\begin{array}{l}\text { Mortality. Blinding of outcome assessment: } \\
\text { low risk of bias }\end{array}$ & 12 & 1943 & Risk Ratio (M-H, Random, 95\% Cl) & $0.99[0.85,1.16]$ \\
\hline $\begin{array}{l}\text { Mortality. Blinding of outcome assessment: un- } \\
\text { clear/high risk of bias }\end{array}$ & 9 & 773 & Risk Ratio (M-H, Random, 95\% Cl) & $0.78[0.51,1.19]$ \\
\hline $\begin{array}{l}\text { Mortality. Incomplete data outcome: low risk } \\
\text { of bias }\end{array}$ & 18 & 2309 & Risk Ratio (M-H, Random, 95\% Cl) & $0.92[0.78 .1 .08]$ \\
\hline $\begin{array}{l}\text { Mortality. Incomplete data outcome: un- } \\
\text { clear/high risk of bias }\end{array}$ & 2 & 357 & Risk Ratio (M-H, Random, 95\% Cl) & $0.93[0.48,1.82]$ \\
\hline $\begin{array}{l}\text { Proven IFI. Random sequence generation: low } \\
\text { risk of bias }\end{array}$ & 4 & 508 & Risk Ratio (M-H, Random, 95\% Cl) & $0.79[0.43,1.45]$ \\
\hline $\begin{array}{l}\text { Proven IFI. Random Sequence Generation: un- } \\
\text { clear/high risk of bias }\end{array}$ & 14 & 1566 & Risk Ratio (M-H, Random, 95\% Cl) & $0.44[0.28,0.70]$ \\
\hline $\begin{array}{l}\text { Proven IFI. Allocation concealment: low risk of } \\
\text { bias }\end{array}$ & 8 & 1068 & Risk Ratio (M-H, Random, 95\% Cl) & $0.44[0.28,0.68]$ \\
\hline $\begin{array}{l}\text { Proven IFI. Allocation concealment: un- } \\
\text { clear/high risk of bias }\end{array}$ & 11 & 1298 & Risk Ratio (M-H, Random, 95\% Cl) & $0.59[0.32,1.11]$ \\
\hline $\begin{array}{l}\text { Proven IFI. Blinding of outcome assessment: } \\
\text { low risk of bias }\end{array}$ & 9 & 1395 & Risk Ratio (M-H, Random, 95\% Cl) & $0.55[0.35,0.87]$ \\
\hline $\begin{array}{l}\text { Proven IFI. Blinding of outcome assessment: } \\
\text { unclear/high risk of bias }\end{array}$ & 10 & 920 & Risk Ratio (M-H, Random, 95\% Cl) & $0.41[0.22,0.74]$ \\
\hline $\begin{array}{l}\text { Proven IFI. Incomplete data outcome: low risk } \\
\text { of bias }\end{array}$ & 16 & 1966 & Risk Ratio (M-H, Random, 95\% Cl) & $0.53[0.35,0.79$ \\
\hline $\begin{array}{l}\text { Proven IFI. Incomplete data outcome: un- } \\
\text { clear/high risk of bias }\end{array}$ & 4 & 445 & Risk Ratio (M-H, Random, 95\% Cl) & $0.52[0.21,1.28]$ \\
\hline
\end{tabular}

$\mathrm{Cl}=$ confidence interval

$\mathrm{IFI}=$ invasive fungal infection

$\mathrm{M}-\mathrm{H}=$ Mantel-Haenszel 
APPENDICES

\section{Appendix 1. Search strategies for electronic databases}

\begin{tabular}{ll}
\hline Database & Search strategy \\
\hline Cochrane Central Register of & $\# 1$ MeSH descriptor: [Antifungal Agents] explode all trees \\
Controlled Trials & $\# 2$ MeSH descriptor: [Mycoses] explode all trees \\
& $\# 3$ (micafungin or anidulafungin or fung* or fluconazole or diflucan or itraconazole or sporanox or \\
& ketoconazole or nizoral or voriconazole or amphotericin or ambisome or amphotec or abelcet or \\
& flucytosine or nystatin or miconazole or echinocandin $\$$ or caspofungin) \\
& $\# 4$ MeSH descriptor: [Critical Care] explode all trees \\
& $\# 5$ intensive care or critical* or surg* \\
& $\# 6$ or $\# 2$ or \#3 \\
& $\# 74$ or $\# 5$ \\
& $\# 8$ and $\# 7$
\end{tabular}

MEDLINE (OVID)

1. exp Antifungal Agents/ or exp Mycoses/ or (micafungin or anidulafungin or fung* or fluconazole or diflucan or itraconazole or sporanox or ketoconazole or nizoral or voriconazole or amphotericin or ambisome or amphotec or abelcet or flucytosine or nystatin or miconazole or echinocandin* or caspofungin or (select ${ }^{\star}$ adj3 decontam $\left.{ }^{\star}\right)$ ).mp.

2. exp Intensive Care Units/ or (intensive care or critical ${ }^{\star}$ or surg $^{\star}$ ).mp.

3. ((randomized controlled trial or controlled clinical trial).pt. or randomized.ab. or placebo.ab. or clinical trials as topic.sh. or randomly.ab. or trial.ti.) not (animals not (humans and animals)).sh.

\section{1 and 2 and 3}

EMBASE (OVID)

1. antifungal agent/ or mycosis/ or (micafungin or anidulafungin or fung* or fluconazole or diflucan or itraconazole or sporanox or ketoconazole or nizoral or voriconazole or amphotericin or ambisome or amphotec or abelcet or flucytosine or nystatin or miconazole or echinocandin ${ }^{\star}$ or caspofungin or (select* adj3 decontam*)).ti,ab.

2. intensive care unit/ or (intensive care or critical ${ }^{\star}$ or surg*).ti,ab.

3. (placebo.sh. or controlled study.ab. or random ${ }^{\star}$. ti,ab. or trial ${ }^{\star}$.ti,ab. or ((singl ${ }^{\star}$ or doubl ${ }^{\star}$ or trebl* or tripl ${ }^{\star}$ ) adj3 (blind* or mask $\left.{ }^{\star}\right)$ ).ti,ab.) not (animals not (humans and animals)).sh.

4. 1 and 2 and 3

\section{Appendix 2. Data Extraction Form}

\section{Source}

Study ID

Citation

\section{Eligibility}

Confirm eligibility for review

\section{Reason for exclusion}


(Continued)

\section{Methods}

\section{Study design}

Study duration

\section{No of centres involved in the study}

Sequence generation

\section{Allocation concealment}

Randomization method

\section{Blinding}

Calculated sample - size

\section{Participants}

\section{Number}

Setting

Age

Gender

Comorbidities

Disease severity score (e.g. APACHE II, SOFA)

Proportion of post-surgical patients

Proportion of patients with baseline colonization

Proportion of patients with immunosuppression

Inclusion criteria

Exclusion criteria

\section{Interventions}

Number of arms

Intervention type (among prophylaxis, pre-emptive and empiric)

$$
\text { Drug }
$$

Dose

Method of administration

Duration of administration 
(Continued)

\section{Outcomes}

Definitions

Primary outcomes

Secondary outcomes

\section{Results}

Number of patients allocated to each intervention group

No of patients who received each treatment

No who did not receive intended treatment and why

No included in the final analysis

No of lost patients and why

\section{Analysis}

Method

\section{Conclusions}

\section{Corresponding author and contact}

\section{Study period}

\section{Declaration of interest among the primary researchers}

\section{Funding sources}

\section{Note}

\section{FEE D B A C K}

\section{Why was a study excluded}

\section{Summary}

\section{Feedback 1}

Why was the De Jonge 2003 study excluded? The text says the intervention was not eligible but it included topical / non-absorbable amphotericin B (in combination with other interventions, as per "types of study" described in the methods section).

Surely many of the Selective Digestive Decontamination (SDD) trials (D'Amico 2009) would be potentially eligible for inclusion as they contain antifungal prophylactic treatment in critically ill patients?

\section{Feedback 2 (response to reply one)}

The authors clarification in the Types of interventions "The study groups were required to differ only for the antifungal regimen under investigation; other co-interventions and aspects of care, including the routine use of other antimicrobial agents, were required to be the same to avoid potentially confounded comparisons." clarifies why SDD trial were not included. 
However, I would suggest that this contradicts the wording of the Types of studies included "We considered all randomized controlled trials (RCTS) that evaluated the effect of any antifungal agent (either systemic or nonabsorbable; alone or in combination with other interventions) given as untargeted treatment in non-neutropenic critically ill adults and children." This suggests that other co-interventions (i.e. SDD trials) would be eligible, hence the confusion. Maybe this wording could be altered to improve clarity?

\section{Reply}

\section{Response to feedback one}

Thank you for your query. We included randomized controlled trials (RCTs) which compared the use of any antifungal drugs either absorbable or non absorbable to no antifungal, placebo or any other antifungal drug. Moreover, we specified in the methods section (Types of interventions): "The study groups were required to differ only for the antifungal regimen under investigation; other co-interventions and aspects of care, including the routine use of other antimicrobial agents, were required to be the same to avoid potentially confounded comparisons.". We excluded De Jonge 2003 because the two groups (SDD versus control or standard of care) differed not only for the antifungal drugs administered.

We considered for inclusion RCTs investigating SDD if the intervention arm and the control arm differed only for the administration of antifungal drugs. Notably, we included Beshey 2014 in the qualitative analysis for this reason. We excluded trials investigating SDD regimens, even if including antifungal drugs, if co-interventions were different between study groups as in De Jonge 2003

\section{Response to feedback two}

Thank you for your feedback on this review. We have been in correspondence with the review author who has agreed to make the following recommended change and this will appear shortly along with your feedback.

'Types of studies' now reads: "We considered all randomized controlled trials (RCTs) that evaluated the effect of any antifungal agent given as untargeted treatment in non-neutropenic critically ill adults and children."

We removed the section previously in parenthesis (either systemic or nonabsorbable; alone or in combination with other interventions). The

explanation in parenthesis was unnecessary because the full clarification is in 'Types of interventions'. I hope this addresses your feedback.

\section{Contributors}

\section{Author of feedback one and two}

Anthony Gordon, Reader, Critical Care Medicine, Imperial College London, UK

I certify that I have no affiliations with or involvement in any organization or entity with a financial interest in the subject matter of my feedback.

\section{Author of reply to feedback one}

Andrea Cortegiani, Department of Biopathology and Medical Biotechnologies (DIBIMED), Section of Anaesthesia, Analgesia, Intensive Care and Emergency, University Hospital P. Giaccone, University of Palermo, Via del Vespro 129, Palermo, Italy

\section{Author of reply to feedback two}

Bronagh Blackwood, Feedback Editor, Cochrane Anaesthesia Anaesthesia, Critical and Emergency Medicine Group, Belfast, Northern Ireland, UK

\section{WHAT'S NEW}

\begin{tabular}{lll}
\hline Date & Event & Description \\
\hline 13 December 2018 & Amended & Editorial team changed to Cochrane Emergency and Critical Care \\
\hline
\end{tabular}

\section{HISTORY}

Protocol first published: Issue 3, 2004

Review first published: Issue 1, 2006 


\begin{tabular}{lll}
\hline Date & Event & Description \\
\hline 17 February 2017 & Amended & Summary of review published in JAMA (see Cortegiani 2017) \\
\hline 11 April 2016 & Feedback has been incorporated & $\begin{array}{l}\text { We amended the wording in the Types of studies section follow- } \\
\text { ing Feedback }\end{array}$ \\
\hline
\end{tabular}

15 January $2016 \quad$ New search has been performed

This is an update of a previous Cochrane systematic review with the same title (Playford 2006a). The search was rerun and covers the period of the original review to February 2015 with the addition of new search terms in the search strategy.

We included 10 new studies (Albert 2014; Beshey 2014; Giglio 2012; Leon 1990; Namikawa 2013; NCT00048750; NCT01122368; Normand 2005; Ostrosky-Zeichner 2014; Schuster 2008) with a total of 1155 additional participants. We excluded 18 new studies (Aerdts 1991; Azoulay 2011; Blair 1991; Daeem 2012; De Jonge 2003; Hanson 2011; Latif 2012; Milanov 2010; Milanov 2013; NCT00095316; NCT00099775; NCT00163111; NCT00689338; NCT01045798; NCT01524081; Restrepo 2010; Sorkine 1996; Wang 2009). In addition, we identified two new ongoing studies (LassFlörl 2013; Timsit 2012) and four studies awaiting classification (Chen 2013; Havlicek 2008; Milesi 2002; Whitby 2005)

15 January $2016 \quad$ New citation required and conclusions have changed
Seven new authors (AC, VR, AM, MA, ARN, SMR, AG) conducted the update of the review.

Our conclusions differed from those of the original review (Playford 2006a).

This updated version includes an extensive revision and update to the text and layout of the review, a 'Risk of bias' assessment according to the last updates of the Cochrane's tool for assessing risk of bias (including the identification of three key domains for risk of bias assessment), the inclusion of a 'Summary of findings' table and incorporates GRADE.

We adopted the term 'untargeted antifungal treatment' instead of 'antifungal prophylaxis' (used in the original review) to include the following antifungal treatment strategies: prophylaxis, preemptive and empiric treatment.

We modified the definition for the outcomes of invasive fungal infection and fungal colonization.

We considered untargeted nonabsorbable antifungal an eligible option for the intervention of our interest, so we changed the name of the comparison to: untargeted treatment with any antifungal drug (systemic or nonabsorbable) compared to placebo/no antifungal/any other antifungal.

We performed additional sensitivity analyses: risk of bias for key domains (all studies versus unclear/high risk), incomplete data outcome (low risk versus unclear/high risk of bias).

We did not perform the subgroup analysis entitled: "Definition of invasive fungal infection conforms to that used in this review" included in the previous version of this review (Playford 2006a). We modified the definition of invasive fungal infection and colonization according to recent evidence leading to discrepancies with definitions provided by most of the studies. 


\begin{tabular}{lll}
\hline Date Event $\quad$ Description & E
\end{tabular}

We decided to classify the intervention of the included studies in three classes (prophylaxis, pre-emptive treatment, empiric treatment) according to the current classification of antifungal treatment of the European Society of Clinical Microbiology and Infectious Diseases (Cornely 2012).

8 November $2005 \quad \begin{aligned} & \text { New citation required and conclusions } \\ & \text { have changed }\end{aligned}$

\section{CONTRIBUTIONS OFAUTHORS}

This is an updated version of a Cochrane review which was originally done by Elliott Geoffrey Playford, Angela C Webster, Tania C Sorrell and Jonathan C Craig (Playford 2006a).

For this updated version, authors' contributions were as follows.

Andrea Cortegiani (AC) and Vincenzo Russotto (VR) conceived this updated version, screened and selected studies, extracted data, assessed risk of bias, contacted study authors, pharmaceutical companies and experts in the field for additional data, performed statistical analysis, interpreted results and wrote the review.

Alessandra Maggiore (AM), screened and selected studies, extracted data, helped assess risk of bias and write the review.

Alessandro R Naro (ARN) and Massimo Attanasio (MA) helped perform statistical analysis and checked data analysis.

Santi Maurizio Raineri (SMR) and Antonino Giarratano (AG) provided perspectives on background and method and helped interpret study results.

All review authors approved the final version of this review. AC served as the guarantor of this review.

\section{DECLARATIONSOF INTEREST}

Andrea Cortegiani: none known

Vincenzo Russotto: none known

Alessandra Maggiore: none known

Alessandro R Naro: none known

Massimo Attanasio: none known

Antonino Giarratano: received grants, fees for educational presentation and advisory board membership, without any relationship to the submitted work, from Pfizer, Merck and Gilead. His institution received a grant from Gilead, Pfizer and Merck Sharp without any relationship to the submitted work.

\section{DIFFERENCES BETWEEN PROTOCOL AND REVIEW}

We made the following changes to the published protocol of the review (Playford 2004b).

- Authors of this updated review were different from those who conceived the protocol and conducted the original systematic review and meta-analysis.

- The term " untargeted antifungal treatment" was adopted instead of antifungal prophylaxis and it included the following antifungal treatment strategies: prophylaxis, pre-emptive and empiric treatment.

\section{NOTES}

Feedback incorporated - April 2016 (see Feedback).

Please note: the previous authors originally published: "Antifungal agents for preventing fungal infections in non-neutropenic critically ill patients and solid organ transplant recipients" with the Cochrane Gynaecological Cancer Group. The authors then split the title and published a further protocol: "Antifungal agents for preventing fungal infections in solid organ transplant recipients" with the Cochrane 
Renal Group. The Cochrane Gynaecological Cancer Group has kindly agreed to the author splitting the original published protocol again and registering it with the Anaesthesia Group as: "Antifungal agents for preventing fungal infections in non-neutropenic critically ill patients" (Playford 2004b).

\section{INDEX TERMS}

\section{Medical Subject Headings (MeSH)}

Amphotericin B [therapeutic use]; Antifungal Agents [ ${ }^{*}$ therapeutic use]; Critical Illness [ ${ }^{*}$ mortality]; Fluconazole [therapeutic use]; Immunocompromised Host; Mycoses [mortality] [* prevention \& control]; Randomized Controlled Trials as Topic

\section{MeSH check words}

Adult; Humans 